\title{
Probabilistic Assessments of Soil Liquefaction Hazard
}

\author{
by \\ Tareq Salloum, M.A.Sc., Carleton University
}

\author{
A thesis submitted to \\ the Faculty of Graduate Studies and Research \\ in partial fulfillment of \\ the requirements for the degree of
}

\section{Doctor of Philosophy}

Department of Civil and Environmental Engineering

\author{
The Doctor of Philosophy Program \\ in Civil and Environmental Engineering \\ is a joint program with the University of Ottawa, \\ administered by the Ottawa-Carleton Institute for Civil Engineering \\ Carleton University \\ Ottawa, Ontario \\ May 2008 \\ C2008, Tareq Salloum
}




$\begin{array}{ll}\begin{array}{l}\text { Library and } \\ \text { Archives Canada }\end{array} & \begin{array}{l}\text { Bibliothèque et } \\ \text { Archives Canada }\end{array} \\ \begin{array}{l}\text { Published Heritage } \\ \text { Branch }\end{array} & \begin{array}{l}\text { Direction du } \\ \text { Patrimoine de l'édition }\end{array} \\ \begin{array}{l}\text { 395 Wellington Street } \\ \text { Ottawa ON K1A 0N4 } \\ \text { Canada }\end{array} & \begin{array}{l}\text { 395, rue Wellington } \\ \text { Ottawa ON K1A 0N4 } \\ \text { Canada }\end{array}\end{array}$

Your file Votre référence ISBN: 978-0-494-40535-2

Our file Notre référence

ISBN: 978-0-494-40535-2

NOTICE:

The author has granted a nonexclusive license allowing Library and Archives Canada to reproduce, publish, archive, preserve, conserve, communicate to the public by telecommunication or on the Internet, loan, distribute and sell theses worldwide, for commercial or noncommercial purposes, in microform, paper, electronic and/or any other formats.

The author retains copyright ownership and moral rights in this thesis. Neither the thesis nor substantial extracts from it may be printed or otherwise reproduced without the author's permission.
AVIS:

L'auteur a accordé une licence non exclusive permettant à la Bibliothèque et Archives Canada de reproduire, publier, archiver, sauvegarder, conserver, transmettre au public par télécommunication ou par l'Internet, prêter, distribuer et vendre des thèses partout dans le monde, à des fins commerciales ou autres, sur support microforme, papier, électronique et/ou autres formats.

L'auteur conserve la propriété du droit d'auteur et des droits moraux qui protège cette thèse. $\mathrm{Ni}$ la thèse ni des extraits substantiels de celle-ci ne doivent être imprimés ou autrement reproduits sans son autorisation.
In compliance with the Canadian Privacy Act some supporting forms may have been removed from this thesis.

While these forms may be included in the document page count, their removal does not represent any loss of content from the thesis.
Conformément à la loi canadienne sur la protection de la vie privée, quelques formulaires secondaires ont été enlevés de cette thèse.

Bien que ces formulaires aient inclus dans la pagination, il n'y aura aucun contenu manquant.

\section{Canada}




\section{ABSTRACT}

The seismic loading and design provisions of the 2005 edition of the National Building Code of Canada have undergone various amendments for implementation in structural and geotechnical designs. As the changes and requirements introduced have been the direct outcome of the recent advances in structural engineering and seismology, structural designers have accepted the new changes with minimal implications to their designs. However, serious implications to geotechnical designs (liquefaction in particular) have made the new changes impractical and in many cases cause confusion. The ground motion in the seismic provisions of building codes is often used inconsistently with the Seed-Idriss approach for liquefaction design. The inconsistency arises from combining the probabilistic ground motion and the deterministic curves compiled by Seed and Idriss in their approach. This inconsistency is particularly acute in the NBCC 2005. A simple and practical method, which harmonizes the Seed-Idriss approach with the NBCC 2005 requirements, is proposed. The proposed method stems from resolving the inconsistency noted above in using the Seed-Idriss approach for estimating future liquefaction failures.

A probabilistic approach for evaluating soil liquefaction failure is also developed. The probability of liquefaction in this approach considers both the statistical distributions of soil and seismic parameters as well as the spatial and temporal distributions of seismic parameters. The probability of liquefaction considering the statistical distributions of soil and seismic parameters was evaluated via a reliability-based model that incorporates a seismic energy approach for evaluating soil liquefaction. The probability of the seismic parameter occurrences was estimated based on the spatial distribution of source-to-site 
distance and the temporal distribution of earthquake occurrences. Evaluating the performances of past liquefaction case histories using this approach may provide some baselines for choosing adequate hazard levels for future liquefaction designs.

A logistic regression model has been developed in a systematic approach utilizing soil and seismic parameters for evaluating liquefaction probability. Incorporation and representation of seismic and soil parameters in the model have been justified based on diagnostic techniques that are commonly used in logistic models. Other diagnostic techniques were also used to check the adequacy and the validity of the developed logistic model. 


\section{ACKNOWLEDGMENT}

I would like to extend my sincere thanks and gratitude to my research advisor Prof. K. T. Law for his continuous support at all levels. Surely, it was a rewarding and rich experience to work under his supervision.

I would also like to thank all my teachers at Carleton University for sharing their knowledge, particularly Prof. Sivathayalan, whose course, Geotechnical Earthquake Engineering, certainly inspired me into such discipline. Thank you also for the great effort you have put together with Prof. Law to make the geotechnical discipline at Carleton University stand out.

To my friends and colleagues at Carleton University and University of Ottawa, the merry time we spent together made this journey a whole lot better and will make it one of my favorite memorable journey. Thank you for being there.

To my brother and sister, thank you for all the time you spent teaching me in elementary school, I have come to know now that it was not such an easy task. But I hope I would always make you proud as I am always proud of you.

To my parents, your guidance has always enlightened me to a better life. Thank you for your unconditional love and support.

To my beloved wife whose love, patience and understanding are always behind me. I would not have done it without you. Thank you also for taking care of all the babysitting.

To my little daughter, sorry your dad has not spent with you as much time as he would love to, but I promise from now on, we will be having lots of fun together. 


\section{TABLE OF CONTENTS}

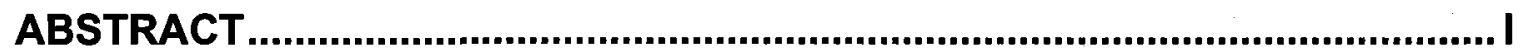

ACKNOWLEDGMENT ............................................................................... III

TABLE OF CONTENTS ................................................................................. IV

TABLE OF FIGURES......................................................................................

LIST OF TABLES ..............................................................................XII

CHAPTER 1 ............................................................................................. 1

INTRODUCTION ..................................................................................... 1

$1.1 \quad$ Research Statement.........................................................................................................................................1

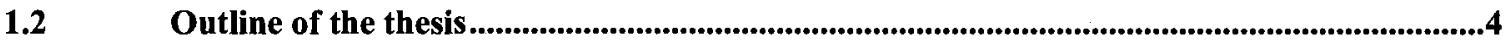

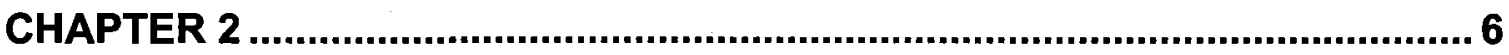

FUNDAMENTALS OF SOIL LIQUEFACTION............................................ 6

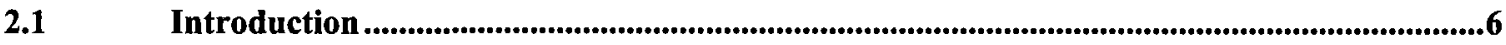

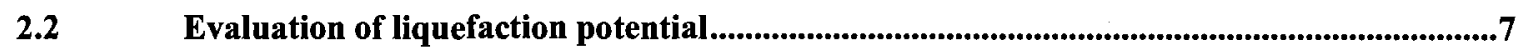

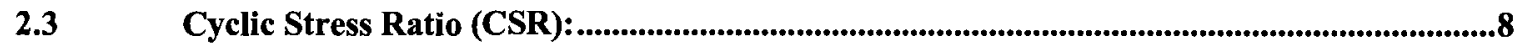




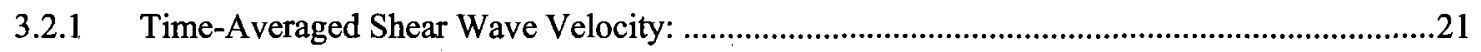

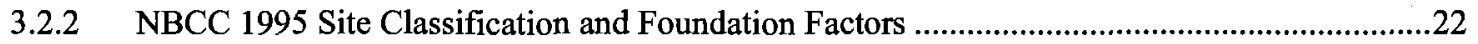

3.2.3 NBCC 2005 Site Classification and Foundation Factors ....................................................25

Return period (Hazard Level) ...................................................................................................33

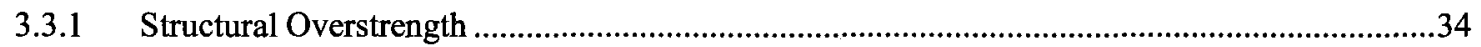

3.3.2 Seismic Hazard Dissimilarities between the East and the West.................................................34

Implications of the NBCC 2005 Changes and New Requirements ........................................38

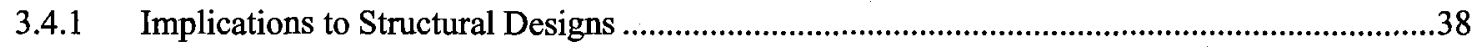

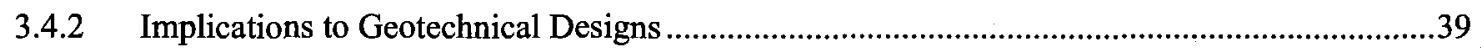

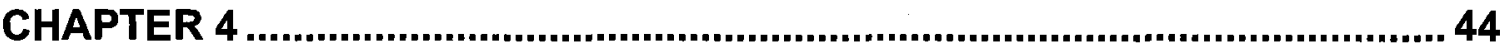

\section{HARMONIZING SEED-IDRISS APPROACH FOR LIQUEFACTION DESIGNS}

WITH THE NBCC 2005 REQUIREMENTS ............................................... 44

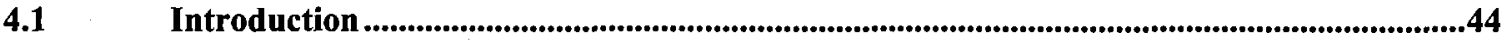

Inconsistency between $P G A$ and Seed-Idriss curves...............................................................45 
4.4 Application of the Proposed Method on Selected Canadian Cities.

4.5 Comparison with the NEHRP Approach (the American Approach)

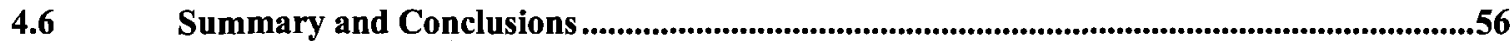

4.7 Comparison with other proposed Methods: ....................................................................................57

4.7.1 Proposed methods by Finn and Wightman (2006): ................................................................57

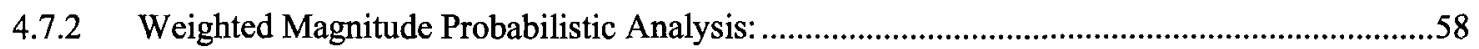

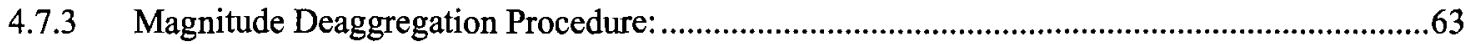

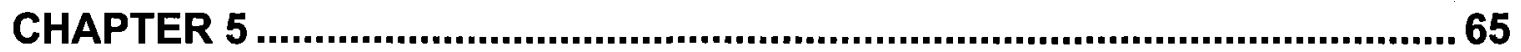

\section{A FULLY PROBABILISTIC APPROACH FOR EVALUATION OF SOIL

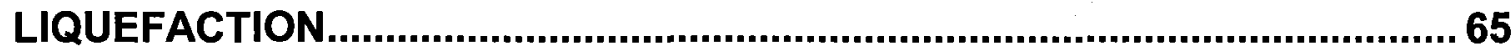

Introduction ........................................................................................................................................65

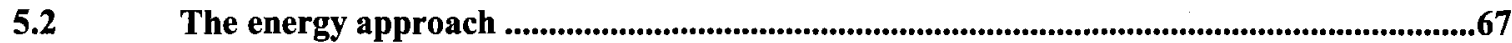

5.2.1 The Energy Approach by Law et al. 1990 ................................................................................68

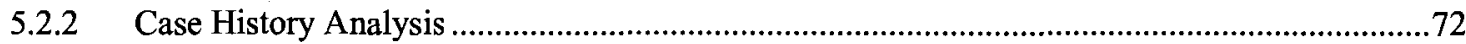

$5.3 \quad$ Probability/Reliability Analysis .................................................................................................75

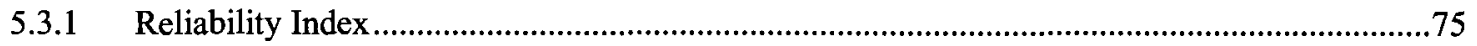

5.3.2 Development of limit state and performance functions..........................................................

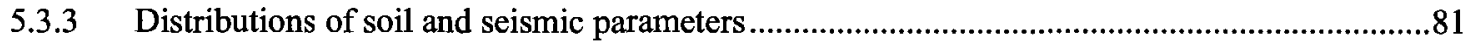

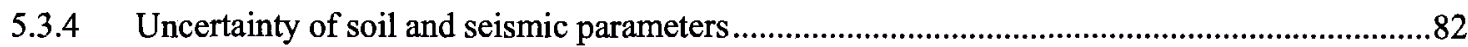

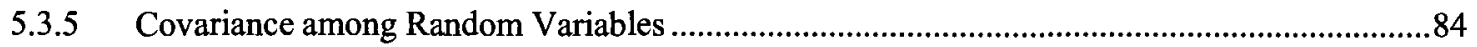

5.3.6 Calculating the reliability indices and probability of liquefaction ............................................85 
$5.4 \quad$ Spatial and Temporal Distributions of Seismic Parameters.................................................93

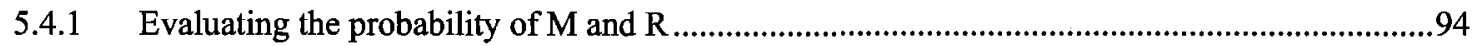

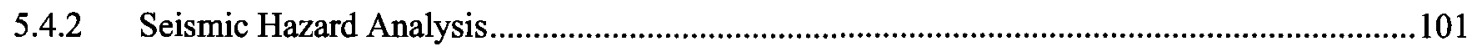

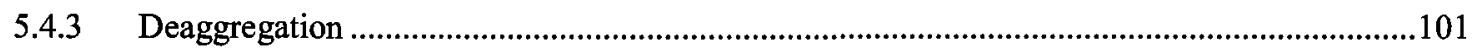

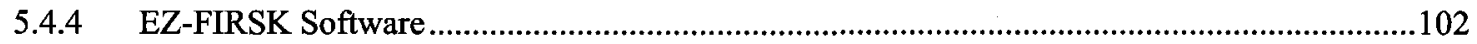

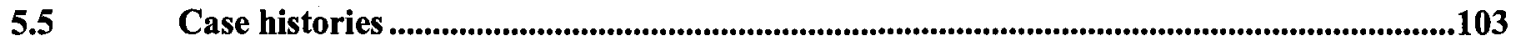

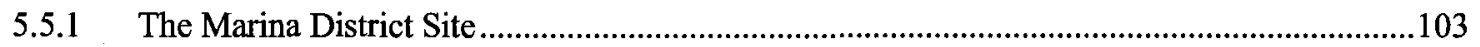

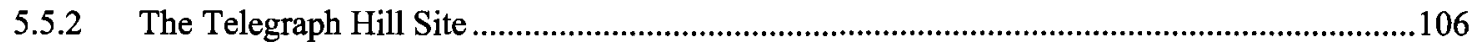

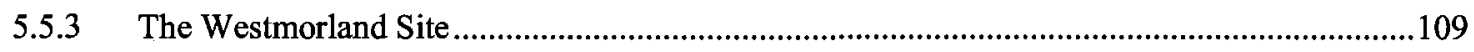

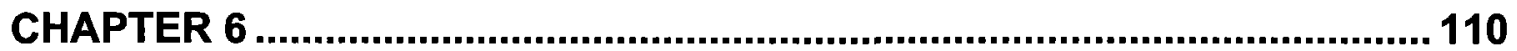

\section{DEVELOPMENT OF A LOGISTIC REGRESSION MODEL FOR EVALUATING}

PROBABILITY OF LIQUEFACTION FAILURE ...........................................110

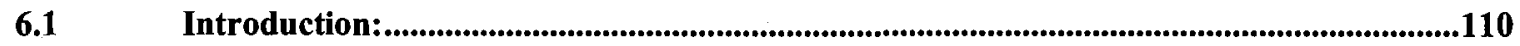

6.2 Constructing the Logistic regression Model: ...............................................................................111

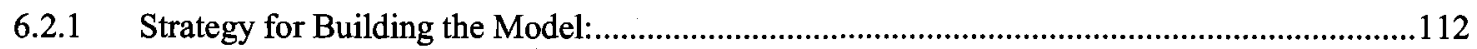

$6.3 \quad$ Model Checking (Diagnostics): ...................................................................................123

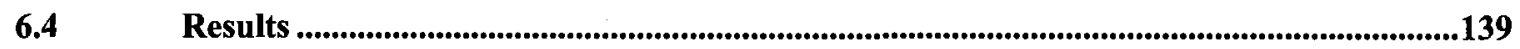

6.5 Comparison between the Logistic regression model and the reliability-based model......140

6.6 AN Alternative Model: A model containing the seismic energy and the standard penetration resistance 
7.1 Summary contributions

REFERENCES

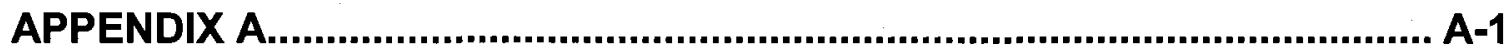

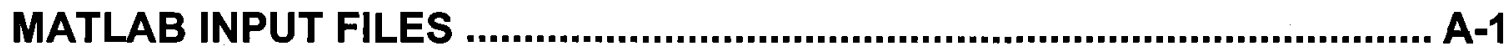

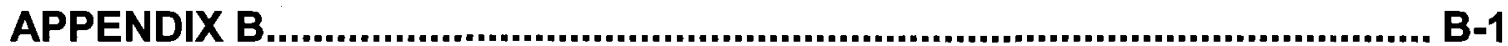

CASE HISTORIES OF LIQUEFACTION/NON-LIQUEFACTION RECORDS.. B-1

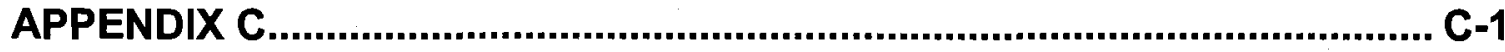

RELIABILITY INDICES AND PROBABILITY OF LIQUEFACTION DATA ..... C-1

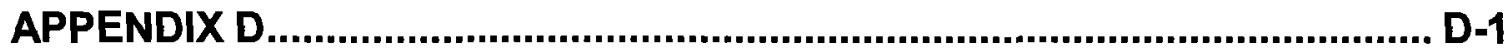

LOGISTIC REGRESSION ANALYSIS ........................................................ D-1

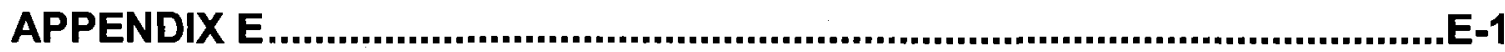

CONTOURS OF LIQUEFACTION PROBABILITY ...........................................1 


\section{TABLE OF FIGURES}

Figure 2-1: Procedure for determining maximum shear stress, $\left(\tau_{\max }\right)_{\mathrm{r}}$, and the stress reduction coefficient, rd (after Seed and Idriss, 1982)

Figure 2-2: Depth reduction factor $r_{d}$ versus depth below level or gently sloping ground surface ......10

Figure 2-3: Relationship between the cyclic resistance ratio and $\left(N_{1}\right)_{60}$ for $M_{w}=7.5$ earthquakes $\ldots . . . .18$

Figure 3-1: Shear modulus/damping ratio versus shear strain relationship.....................................24

Figure 3-2: Amplification of ground motions at the Treasure Island site (after Jarpe et al. 1989)......25

Figure 3-3: Mean Shear-Wave Velocity to $30 \mathrm{~m}, \mathrm{v}(\mathrm{m} / \mathrm{s})($ after Borcherdt 1994) .................................26

Figure 3-4: Two-factor approach to local site response (NEHRP 1994)........................................27

Figure 3-5: Seismic Hazard Curves for Several Canadian Cities ...................................................36

Figure 3-6: Comparison of CSR in two editions of NBCC in selected Canadian cities........................42

Figure 3-7: Comparison of CSR in two editions of NBCC in selected Canadian cities.........................43

Figure 4-1: Contours of Liquefaction Probability (after Cetin 2002)..............................................49

Figure 4-2: Probability of liquefaction curves and Seed-Idriss deterministic bounds (after Cetin 2000)

Figure 4-3: Comparison of PGA values required to cause liquefaction for NBCC editions and the proposed procedure for Site Class $\mathbf{E}$

Figure 4-4: Comparison of PGA values required to cause liquefaction for NBCC editions and the proposed procedure for Site Class D.

Figure 4-5: Comparison between NEHRP and the proposed approach for Site Class E.

Figure 4-6: Comparison between NEHRP and the proposed approach for Site Class D .55

Figure 4-7: Cumulative Contribution of Magnitude at Various Levels of Acceleration at Site in

Southern California (after Idriss 1985).

Figure 4-8: Cumulative Contribution of Magnitude at Various Levels of Acceleration at Site in

Southern California in which Magnitude Contributions are Weighted with Respect to $\mathbf{m = 7 . 5}$

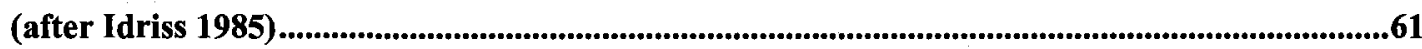

Figure 4-9: M-R Deaggregation Matrix for PGA in Vancouver (Finn and Wightman 2006) 64 
Figure 5-1: Flowchart of the Proposed Methodology

Figure 5-2: Liquefied and Non-liquefied sites alongside with the Corrected SPT and the Seismic

Energy arriving at the each site 74

Figure 5-3: Probability densities of typical capacity and demand ...............................................78

Figure 5-4: Probability density function of the margin of safety M.......................................................78

Figure 5-5: Illustration shows the development of the limit state function ..........................................80

Figure 5-6: Histogram and Possible Fits for Performance Function G(X) .......................................86

Figure 5-7: Probability of Liquefaction plotted against Reliability Index ............................................87

Figure 5-8: Distributions and the overlapping of the reliability indices of liquefied/non-liquefied cases

Figure 5-9: Probability of Liquefaction plotted against Factor of Safety .89

Figure 5-10: Probability of Liquefaction plotted against the Factor of Safety 90

Figure 5-11: Probability of Liquefaction plotted against the Factor of Safety .91

Figure 5-12: Variations of source-to-site distance for different source zone geometries (Kramer 1999)

Figure 5-13: Gutenberg-Richter recurrence law, showing meaning of $a$ and $b$ parameters (Kramer 1999)

Figure 5-14: Seismic Activity Matrix for the Marina District site 104

Figure 6-1: Constructed variable plot for $\mathbf{N}$ in a linear logistic regression model fitted to the compiled data.

Figure 6-2: Constructed variable plot for $\mathbf{N}$ in a linear logistic regression model fitted to the compiled data after smoothing them out

Figure 6-3: Constructed variable residuals of the earthquake magnitude $M$.

Figure 6-4: Constructed variable residuals of $M$ after transformation 128

Figure 6-5: Constructed variable plot for the explanatory variable $\mathbf{R}$ .131

Figure 6-6: Constructed variable plot for the transformed $R$.

Figure 6-7: Constructed variable plot for the effective overburden stress. .135

Figure 6-8: Constructed variable plot for the transformed $\sigma_{0}$, 135 
Figure 6-9: Added variable plot for the inclusion of the total stress $\sigma$

Figure 6-10: Half-normal plot of the standardized deviance residuals after fitting a logistic regression

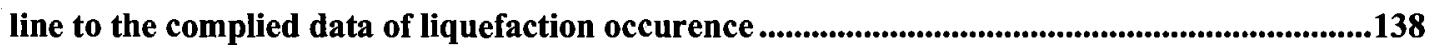

Figure 6-11: The constructed variable plot for the seismic energy ..................................................145

Figure 6-12: Half-normal probability plot with simulated envelope for the simple model.................147

Figure 6-13: Probability contours derived from the simple model ......................................................148

Figure 6-14: Comparison between the deterministic and probabilistic (0.5) models ..........................149

Figure 6-15: Probability contours imposed on the original data......................................................150 


\section{LIST OF TABLES}

Table 2-1: Recommended SPT procedure for use in liquefaction correlations (after Seed et al. 1984)

Table 2-2: Summary for the correction factors for SPT measurements (after 1997 NCEER

Workshop)

Table 3-1: NBCC 1995 Site Classification and Foundation Factors

Table 3-2: Exponent values at different ground motion levels obtained using the general equations in conjunction with results from laboratory and numerical site response analyses (modified from Bocherdt 1994)

Table 3-3: Values of $F_{a}$ as a function of site conditions and shaking intensity $A_{a}$ (NEHRP 1994) .......29

Table 3-4: Values of $F_{v}$ as a function of site conditions and shaking intensity $A_{v}($ NEHRP 1994) ........30

Table 3-5: NBCC 2005 Site Classification ..................................................................................................................31

Table 3-6: NBCC 2005 Foundation Factors for Short Period ....................................................................32

Table 3-7: NBCC 2005 Foundation Factors for Long Period.......................................................................32

Table 3-8: Comparison of Peak Ground Acceleration ........................................................................................37

Table 3-9: Spectral Acceleration, Foundation Factors for Site Class E and D, Maximum magnitude used in practice, Modal Magnitude for Canadian Cities Based on Deaggregating the Seismic Hazard Peak Ground Acceleration for 2\%/50 Year and the Corresponding Magnitude Scaling

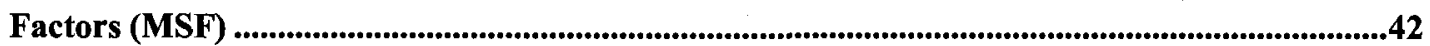

Table 4-1: NEHRP and the proposed PGA reduction ratios and their corresponding $a_{\max }$ values......56

Table 4-2: Magnitude Scaling Factors (Yould et al., 2001)................................................................................60

Table 4-3: Proposed Magnitude-Acceleration Pairs by Finn and Wightman (2006) .............................63

Table 4-4: Comparison of Finn \& Wightman PGA with the Author's ........................................................63

Table 5-1: Summaries the random variables and there statistical distribution parameters ..................84

Table 5-2: Effects of $10 \%$ increase on probability of liquefaction at various levels of random variables 
Table 5-3: Soil and seismic parameters and the probability of liquefaction failure for several sites at

the Marina District .104

Table 5-4: Soil and seismic parameters measured at the borings of the Telegraph Hill site. .107

Table 5-5: Seismic parameters, probability inferred from the statistical distribution of soil and seismic parameters, the probability inferred from the spatial and temporal distribution of soil and seismic parameters, the total probability of liquefaction, the return period and the reliability index associated with the probability of liquefaction

Table 5-6: Soil and seismic parameters and the probability of liquefaction failure for several sites at

Westmorland. 109

Table 6-1: Estimated Coefficients for the Logistic Regression Model Using the Standard Penetration Resistance $\mathbf{N}$ 114

Table 6-2: Correlation Matrix for the Coefficients .115

Table 6-3: Estimated Coefficients for the Logistic Regression Model Using the Standard Penetration Resistance $\mathbf{N}$ and the Earthquake Magnitude $M$ as Explanatory Variables 117

Table 6-4: Correlation Matrix for the Coefficients .117

Table 6-5: Estimated Coefficients for the Logistic Regression Model Using the Standard Penetration Resistance N, the Earthquake Magnitude M, and the Hypocenter Distance as Explanatory Variables. 119

Table 6-6: Correlation Matrix for the Coefficients

Table 6-7: : Estimated Coefficients for the Logistic Regression Model Using the Standard

Penetration Resistance N, the Earthquake Magnitude M, the Hypocenter Distance, and the

effective overburden stress as Explanatory Variables. .121

Table 6-8: Correlation Matrix for the Coefficients 122

Table 6-9: Summary Statistics of Four Nested Models. 122

Table 6-10: Estimated Coefficients for the Logistic Regression Model Using the Standard Penetration Resistance N, the Earthquake Magnitude as $\mathbf{M}^{-2}$, the Hypocenter Distance, and the effective overburden stress as Explanatory Variables.

Table 6-11: Correlation Matrix for the Coefficients 130 
Table 6-12: Estimated Coefficients for the Logistic Regression Model Using the Standard Penetration Resistance $\mathbf{N}$, the Earthquake Magnitude as $\mathbf{M}^{-2}$, the Hypocenter Distance as $\ln (\mathrm{R})$, and the effective overburden stress as Explanatory Variables.

Table 6-13: Correlation Matrix for the Coefficients

Table 6-14: Comparison of Probabilities obtained from Logistic Model and Reliability Model .140

Table 6-15: Estimated Coefficients for the Logistic Regression Model Using the Standard Penetration Resistance $\mathbf{N}$ and the Seismic Energy $\mathbf{S}$

Table 6-16: Correlation Matrix for the Coefficients .144

Table 6-17: Estimated Coefficients for the Logistic Regression Model Using the Standard Penetration

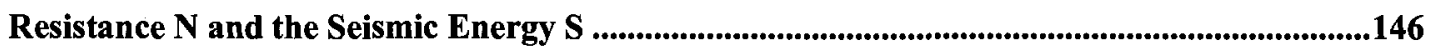

Table 6-18: Correlation Matrix for the Coefficients 146 


\section{Chapter 1}

\section{INTRODUCTION}

\subsection{RESEARCH STATEMENT}

Earthquake-induced liquefaction hazard has been one of the major topics of concern geotechnical engineers due to the fact that liquefaction has been one of the most contributing factors to the damage of civil engineering structures during earthquakes. Several methods are devoted to evaluate liquefaction occurrences which could be divided into two main categories: stress methods and energy methods. These two methods can be implemented in a deterministic or probabilistic framework. The deterministic approaches give a yes/no answer to whether liquefaction will occur or not, whereas, the probabilistic approaches evaluate the liquefaction in terms of probability of occurrence. The major merit of the probabilistic approaches is that the uncertainty associated with soil parameters is quantified.

The stress method developed by Seed et al. (1971) is the most commonly used method in liquefaction design and evaluation. It uses the peak ground acceleration (PGA) (suggested by the National Building Code of Canada (NBCC)) along with a representative earthquake magnitude to calculate the seismic stress that causes soil to 
liquefy. The PGA proposed by the code is a key factor in Seed's approach. It usually corresponds to a probability of occurrence (return period).

The NBCC 2005 has introduced new changes and requirements, chief among them is adopting a new return period ( $2 \% / 50$ years instead of $10 \% / 50$ years) which constitutes the basis for structural and geotechnical seismic designs. As the new return period suggested by the NBCC 2005 was the direct outcome of the recent advances in structural engineering and seismology, implications of the new changes were minimal on the structural designs. However, implications on geotechnical designs were much more pronounced and have raised several concerns among the geotechnical community in Canada. Adopting the new return period for liquefaction design has either invalidated Seed's approach for liquefaction designs or produced conservative results (see Task Force Report 2007). Therefore, of paramount importance to the current practice is to provide realistic hazard levels that can be used for liquefaction designs. This research proposes a method for the selection of a return period (or ground acceleration) for liquefaction design.

The second part of this study is the development of a fully probabilistic approach for evaluating soil liquefaction probability. The probability of soil liquefaction in this approach considers both the statistical distributions of soil and seismic parameters as well as the spatial and temporal distributions of the seismic parameters. The probability of liquefaction considering only the statistical distribution of soil and seismic parameters is based on an energy approach for evaluating liquefaction failure. This energy approach 
comprises four parameters: the earthquake magnitude, the hypocentral distance of earthquake, the standard penetration resistance of soil, and the effective overburden stress. Each of these parameters is modeled as a random variable characterized by a certain statistical distribution. The probability of the seismic parameter occurrences were estimated based on the spatial distribution of source-to-site distance and the temporal distribution of earthquake occurrences.

The third part of this research focuses on the systematic development of a logistic regression model for evaluating liquefaction probability. The development of the logistic model is based on a binary regression analysis of 363 case histories of liquefaction/nonliquefaction data. The model utilizes seismic parameters, namely, earthquake magnitude and hypocenter distance, and soil parameters, namely, standard penetration resistance and effective overburden stress, for evaluating the probability of soil liquefaction. Incorporation and representation of seismic and soil parameters in the logistic model have been justified based on selected diagnostic techniques that are commonly used in conjunction with logistic models. Other diagnostic techniques were also used to check the adequacy and the validity of the developed logistic model. Interpretation of the developed logistic model is also presented to help understand the physical meaning of all the included parameters and their coefficients. The motivation behind the development of the logistic model is twofold. First, it is of vital importance to validate the results obtained from the reliability-based analysis. Second, it is also desirable to derive a closed-form equation to infer the probability of soil liquefaction failure based directly on soil and seismic parameters. 
Liquefaction probability curves based on varying seismic and soil parameters have been developed based on the proposed model. For practical purposes, the developed model is also implemented to establish the relationship between the factor of safety against liquefaction and the probability of liquefaction.

\subsection{OUTLINE OF THE THESIS}

The second chapter of this thesis outlines the fundamentals of soil liquefaction phenomena. Discussion of the new changes and requirements that are of relevance to liquefaction designs are presented in Chapter 3 with some background about the evolution of the NBCC 2005 proposed return period. Implications of the NBCC 2005 amendments on liquefaction designs in selected Canadian cities are also presented in Chapter 3.

Chapter 4 introduces the proposed method of harmonizing the Seed and Idriss approach with the new NBCC 2005 requirements. It also compares the proposed method with other approaches for softening the impact of the NBCC 2005 requirements on liquefaction design.

Chapter 5 introduces the fully probabilistic model for evaluating soil liquefaction probability. It starts off with explaining the general methodology and then discusses each individual element of the methodology in more detail. Illustrative examples of the methodology are presented in the same chapter as well. 
Chapter 6 deals with the development of a logistic regression model for evaluation liquefaction probability. Finally, a summary and contributions of the research is given in Chapter 7. 


\section{Chapter 2}

\section{FUNDAMENTALS OF SOIL LIQUEFACTION}

\subsection{INTRODUCTION}

Soil liquefaction is a complicated phenomenon that can manifest itself in several different ways in the field. When high porewater pressures are generated in a substantially thick soil layer that is relatively near the ground surface, the upward flowing porewater may carry sand particles up to the ground surface where they are deposited in a generally conical pile called a sand boil. While sand boils represent the most common evidence of subsurface soil liquefaction, they are not damaging from an engineering point of view. Liquefaction can, however, produce significant soil deformations, both horizontal and vertical, that can cause significant damage to a variety of structures.

Soil liquefaction has attracted considerable attention from geotechnical engineering researchers over the past 40 years. Liquefaction research has been undertaken from several different perspectives, which has led to some ambiguity and inconsistency in the terminology used to describe various liquefaction-related phenomena. For example, liquefaction was viewed by one group of researchers to correspond to the condition at which the effective stress reaches (momentarily) a value of zero, while another group considered liquefaction to have occurred when the soil deforms to large strains under constant shearing resistance. The first phenomenon is now referred to as cyclic mobility 
and the second as flow liquefaction. In the field, significant lateral deformations can be caused by either of these phenomena. The deformations produced by flow liquefaction are usually referred to as flow slides, and those produced by cyclic mobility as lateral spreads, but it is frequently impossible to distinguish between the two in the field. Further complicating the matter is the fact that some flow slides begin as lateral spreads, so that the final deformations reflect both phenomena.

\subsection{EVALUATION OF LIQUEFACTION POTENTIAL}

Several methods have evolved to evaluate liquefaction occurrences which could be divided into three main categories: stress, strain and energy methods. These three methods can be implemented in a deterministic or probabilistic approach. The deterministic approaches give a yes/no answer to whether liquefaction will occur or not, whereas, the probabilistic approaches evaluate liquefaction in terms of probability of occurrence. The major advantage of the probabilistic approaches is that the uncertainties associated with soil parameters are quantified.

Stress methods have been developed by many researchers Seed and Idriss (1971), Robertson and Wride (1998), and Robertson and Campanella (1985). However, the method by Seed and Idriss (1971) is the most documented and commonly used method in liquefaction design and evaluation. Therefore, this method will be described in more detail as it will be the basis for addressing the implications of the changes proposed by the NBCC 2005 on liquefaction design. 
Seed and Idriss method for liquefaction design is based on the evaluation of the cyclic stress ratio $(C S R)$ and then selecting an appropriate standard penetration resistance $S P T-N$ that the soil must have to resist liquefaction failure.

\subsection{CYCLIC STRESS RATIO (CSR):}

Shear stresses developed at soil depth $h$ at time $t$ due to vertical propagation of shear waves can be calculated as (assuming the soil mass above the depth $h$ to be rigid):

$$
\tau(t)_{\text {rigid }}=\frac{\gamma \cdot h}{g} \cdot a(t)
$$

Eq. 2-1

where $a(t)$ is the ground surface acceleration at time $t, \gamma$. is the unit weight of the soil, and $g$ is the gravitational acceleration.

Given the fact that the actual shear stresses induced in the soil due to a particular earthquake (ground surface acceleration) would be less that those developed in a rigid body for the same earthquake (predicted by the above equation) a stress reduction factor $r_{d}$ needs to be incorporated in the above equation. Figure 2-1 illustrates a simplified procedure proposed by Seed and Idriss (1982) for the determination of the maximum shear stress. It is indicated that the depth reduction factor decreases with depth.

$$
\tau(t)_{\text {deformable }}=\frac{\gamma \cdot h}{g} \cdot a(t) \cdot r_{d}
$$

Eq. 2-2 
A range of values for the depth reduction factor $r_{d}$ versus depth below ground surface is shown in Figure 2-2. As shown in Figure 2-2 Idriss (1999) indicates that the values of $r_{d}$ depend on the magnitude of the earthquake. However, in practice, the $r_{d}$ values are usually obtained from the curve labeled "Average values by Seed and Idriss (1971)" shown in Figure 2-2. 

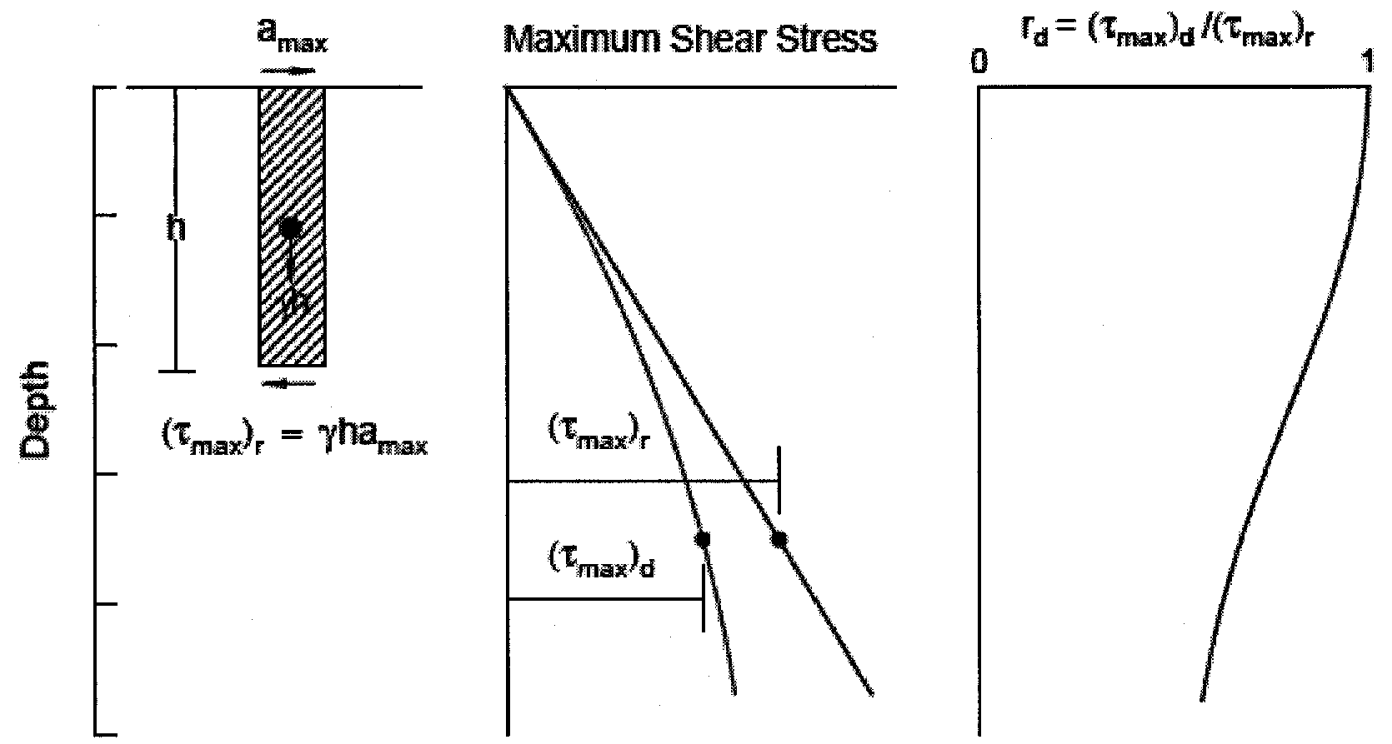

Figure 2-1: Procedure for determining maximum shear stress, $\left(\tau_{\max }\right)_{\mathrm{r}}$, and the stress reduction coefficient, rd (after Seed and Idriss, 1982)

\section{Stress Reduction Coefficient, $r_{d}$}

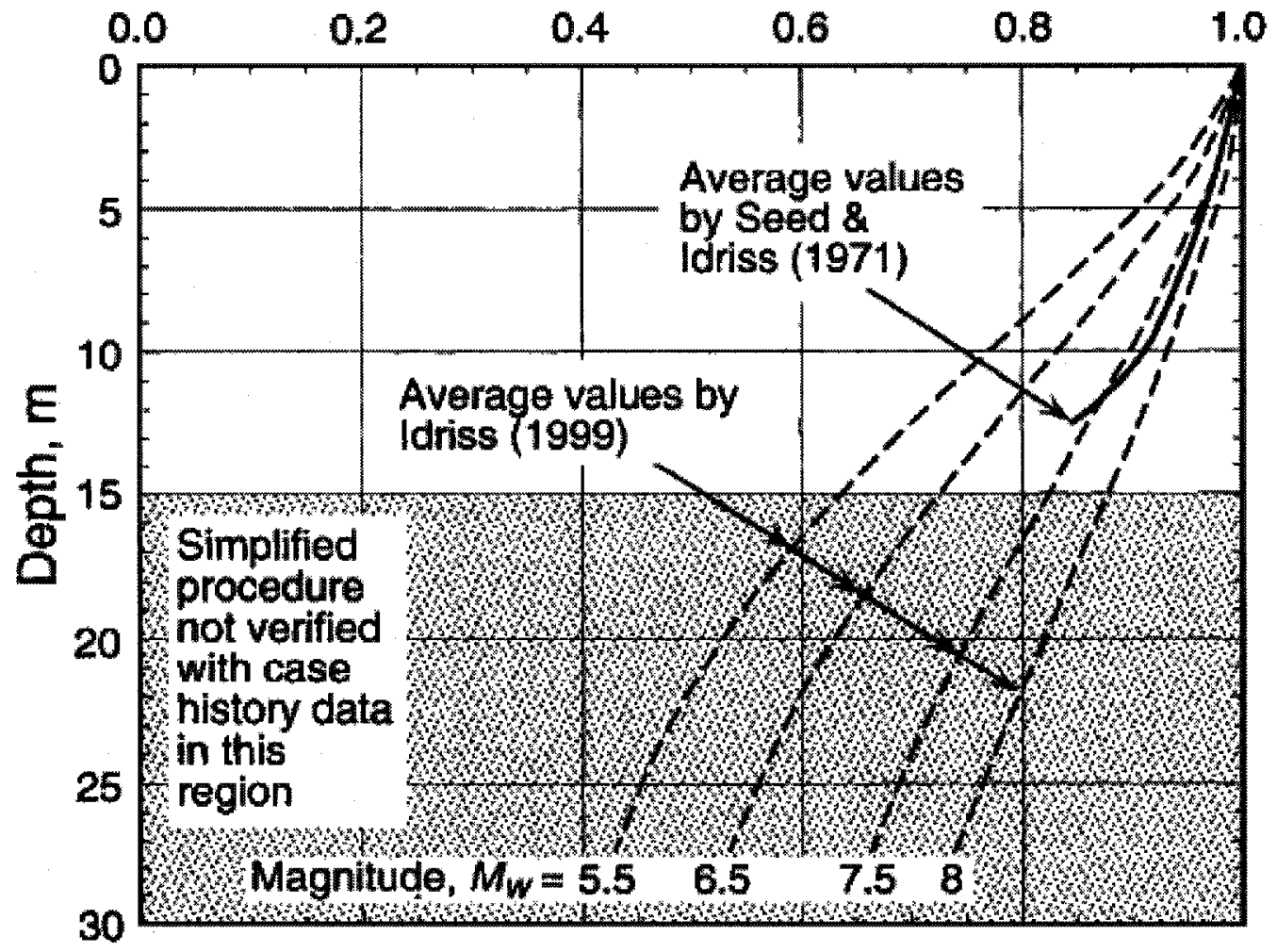

Figure 2-2: Depth reduction factor $r_{d}$ versus depth below level or gently sloping ground surface (after Andrus and Stokoe 2000) 
A weighted averaging scheme is required to convert irregular forms of seismic shear stress time histories to a simpler equivalent series of uniform stress cycles. Based on laboratory test data, it has been found that a reasonable amplitude to select for the "average" or equivalent uniform stress, $\tau_{\mathrm{av}}$ (or $\tau_{\mathrm{cyc}}$ ) is about $65 \%$ of the maximum shear stress, $\tau_{\max }$, a value arrived at by comparing rates of porewater pressure generation caused by transient earthquake shear stress histories with rates caused by uniform harmonic shear stress histories (Seed et al. 1975). The average (or equivalent) cyclic shear stress is given as:

$$
\tau_{a v} \approx 0.65 \cdot \frac{\gamma \cdot h}{g} \cdot a_{\max } \cdot r_{d}
$$

where $a_{\max }$ is the maximum ground surface acceleration.

The cyclic stress ratio, CSR, as proposed by Seed and Idriss (1971), is defined as the average cyclic shear stress, $\tau_{a v}$, developed on a horizontal surface of soil layers due to vertically propagating shear waves normalized by the initial vertical effective stress, $\sigma_{v}^{\prime}$, to incorporate the increase in shear strength due to an increase in effective stress.

$$
C S R=\frac{\tau_{a v}}{\sigma_{v}^{\prime}}=0.65 \cdot \frac{a_{\max }}{g} \cdot \frac{\sigma_{v}}{\sigma_{v}^{\prime}} \cdot r_{d}
$$

Eq. 2-4

To incorporate the effects of magnitude (ground motion duration or number of cycles) of the earthquake shaking, a magnitude scaling factor was added to the above equation as: 


$$
C S R=\frac{\tau_{a v}}{\sigma_{v}^{\prime}}=0.65 \cdot \frac{a_{\max }}{g} \cdot \frac{\sigma_{v}}{\sigma_{v}^{\prime}} \cdot \frac{r_{d}}{M S F}
$$

The magnitude scaling factor is a function of the earthquake magnitude and is expressed as Seed and Idriss (1971):

$$
M S F=\frac{10^{2.24}}{M^{2.56}}
$$

Eq. 2-6

There exists other formulas for evaluating magnitude scaling factors, however, the above equation is recommended by Idriss (as reported by Youd et al. (2001)) and considered to be the lower bound to all factors recommended by NCEER (1997). In addition the above equation is recommended for use for magnitudes greater than 7.5.

It should be noted that two pieces of ground motion information - $a_{\max }$ and earthquake magnitude - are required for the estimation of the cyclic stress ratio.

The above equation is used in conjunction with Seed and Idriss liquefaction curves for the selection of an appropriate SPT-N value that should be used in designs against liquefaction.

\subsection{STANDARD PENETRATION TEST:}

The standard penetration test (SPT) is one of the oldest methods of in-situ testing of soils. In performing the SPT, a standard sampling tube $(5 \mathrm{~cm}$ outer diameter and $3.5 \mathrm{~cm}$ inner 
diameter) is driven $45 \mathrm{~cm}$ into the ground by means of a $63.5 \mathrm{~kg}$ hammer falling at a free height of $76 \mathrm{~cm}$. To eliminate seating errors, the numbers of blows required to drive the sampling tube the last $30 \mathrm{~cm}$ into the ground constitute the $\mathrm{N}$ value, also commonly known as the "blow count". The N value obtained by the SPT gives an indication of the soil stiffness and it can be empirically correlated with many soil characteristics such as unconfined compression strength $\left(q_{u}\right)$, relative density $\left(D_{r}\right)$ and the angle of friction $(\phi)$, see Das (1998).

The measured SPT resistance needs to be corrected to account for overburden stress. The normalized SPT blowcounts $\left(\mathrm{N}_{1}\right.$-values) corresponds to the SPT resistance (N values) corrected to values that would have been measured at a vertical effective stress equal to 1 atmosphere pressure as (Liao and Whitman 1986):

$$
N_{1}=N \cdot C_{N}
$$

Eq. $2-7$

where $C_{N}$ is an effective overburden-based correction factor.

The actual energy delivered to the drill rods in performing the SPT may vary between 40 to $90 \%$ of the theoretical free-fall energy intended to be delivered by the falling hammer. The main reason for this variation is the use of different methods for raising and dropping the hammer. The mean energy ratio delivered by a safety hammer with a rope and pulley hammer release mechanism is $\sim 60 \%$. Similarly, the energy ratio delivered by a donut hammer with a rope and pulley mechanism is estimated as $45 \%$. 
The length of the drill rod and the diameter of the borehole also affect the SPT data. When the length of the drill rod is less than about $3 \mathrm{~m}$, there is a reflection of energy in the rod which reduces the energy available for driving the sampling tube into the ground (Seed at al., 1984). The loss of driving energy in short lengths of rod can affect the SPT blow-count by $25 \%$. Similarly, if a borehole diameter larger than the standard borehole diameter of 65 to $115 \mathrm{~mm}$ is drilled then the SPT measurements can be off as much as 15 $\%$.

The type of tube used for soil sampling differs from one region to another, which can affect the SPT blow-counts by $20 \%$. The ASTM sampler, commonly used in the U.S.A., has a $3.5 \mathrm{~cm}$ inner diameter shoe and a barrel, that can be fitted with liners to provide a constant inner diameter of $3.5 \mathrm{~cm}$. However, the barrel is often used without liners in which case the inner diameter is $3.8 \mathrm{~cm}$. If the liner provisioned samplers are used without liners in place, the SPT measurements can be reduced by as much as $20 \%$ due to higher frictional resistance inside the sampler. Contrary to the practice in the U.S.A, in Japan the standard sampler does not have provisions for liners and it has a constant barrel diameter of $3.5 \mathrm{~cm}\left(1 \frac{3}{8} \mathrm{in}\right)$.

The standard SPT procedure for use in liquefaction correlations was recommended by Seed at al. (1984) and is shown in Table 2-1. However, the SPT has been performed differently in different parts of the world which has resulted in modification of the procedure recommended by Seed et al. (1984). Corrections for all the deviations in the 
SPT procedures from the standard procedure have been put forward by the NCEER (1997) as follows:

$$
N_{1,60}=N \cdot C_{N} \cdot C_{E} \cdot C_{B} \cdot C_{R} \cdot C_{S}
$$

Eq. 2-8

where $\mathrm{N}$ is the in-situ measured SPT blowcounts obtained by driving a standard sampling tube $(5 \mathrm{~cm}$ outer diameter and $3.5 \mathrm{~cm}$ inner diameter) $30 \mathrm{~cm}$ into the ground. The definitions and the suggested values for correction terms are summarized in Table 2-2.

Table 2-1: Recommended SPT procedure for use in liquefaction correlations (after Seed et al. 1984)

\begin{tabular}{|c|c|}
\hline Borehole & $\begin{array}{l}10 \text { to } 12 \mathrm{~cm} \text { diameter rotary borehole with } \\
\text { bentonite drilling mud for borehole stability }\end{array}$ \\
\hline Drill Bit & $\begin{array}{l}\text { Upward deflection of drilling mud (tricone of } \\
\text { baffled drag bit) }\end{array}$ \\
\hline Sampler & $\begin{array}{c}\text { Outer Diameter }=5 \mathrm{~cm} \\
\text { Inner Diameter }=3.5 \mathrm{~cm}-\text { Constant (i.e. no room } \\
\text { for liners in barrel) }\end{array}$ \\
\hline Drill Rods & $\begin{array}{l}\text { A or AW for depths less than } 15 \mathrm{~m} \\
\mathrm{~N} \text { or NW for greater depths }\end{array}$ \\
\hline Energy Delivered to Sampler & $284 \mathrm{~N}-\mathrm{m} .(60 \%$ of theoretical maximum) \\
\hline Blowcount Rate & 30 to 40 blows per minute \\
\hline Penetration Resistance Count & $\begin{array}{l}\text { Measure over range of } 15-20 \mathrm{~cm} \text { of penetration } \\
\text { into the ground }\end{array}$ \\
\hline
\end{tabular}


Table 2-2: Summary for the correction factors for SPT measurements (after 1997 NCEER Workshop)

\begin{tabular}{|c|c|c|c|}
\hline Factor & Term & $\begin{array}{c}\text { Equipment } \\
\text { Variable }\end{array}$ & Correction \\
\hline $\begin{array}{c}\text { Overburden } \\
\text { Pressure }\end{array}$ & $C_{N}$ & - & $\begin{array}{c}\left(\mathrm{P}_{\mathrm{a}} / \sigma_{\mathrm{v}}^{\prime}\right)^{0.5} \\
\mathrm{C}_{\mathrm{N}} \leq 2\end{array}$ \\
\hline Energy Ratio & $C_{E}$ & $\begin{array}{l}\text { Safety Hammer } \\
\text { Donut Hammer }\end{array}$ & $\begin{array}{l}0.60-1.17 \\
0.45-1.00\end{array}$ \\
\hline $\begin{array}{l}\text { Borehole } \\
\text { Diameter }\end{array}$ & $C_{B}$ & $\begin{array}{l}65-115 \mathrm{~mm} \\
150 \mathrm{~mm} \\
200 \mathrm{~mm}\end{array}$ & $\begin{array}{l}1.00 \\
1.05 \\
1.15\end{array}$ \\
\hline Rod Length & $C_{R}$ & $\begin{array}{c}3-4 \mathrm{~m} \\
4-6 \mathrm{~m} \\
6-10 \mathrm{~m} \\
10-30 \mathrm{~m} \\
>30 \mathrm{~m}\end{array}$ & $\begin{array}{c}0.75 \\
0.85 \\
0.95 \\
1.0 \\
\\
<1.0\end{array}$ \\
\hline Sampling Method & $C_{S}$ & $\begin{array}{c}\text { Standard Sampler } \\
\text { Sampler without } \\
\text { liners }\end{array}$ & $\begin{array}{c}1.0 \\
1.15-1.30\end{array}$ \\
\hline
\end{tabular}




\subsection{SEED'S LIQUEFACTION CURVES:}

Seed et al. (1975) compiled 127 case history data points of field performance of sands and silty sands for sites with and without liquefaction failure during earthquakes of magnitude 7.5. A good empirical correlation between the minimum cyclic stress ratio that caused liquefaction and the soil penetration resistance $\left(\mathrm{N}_{1}\right)_{60}$ was established, see Figure 2-3. The curves shown in Figure 2-3 are known as the Seed and Idriss liquefaction curves and are intended for use as a deterministic procedure for liquefaction evaluation and design and have no formal probabilistic basis. The deterministic curves have been widely accepted and used in practice. 


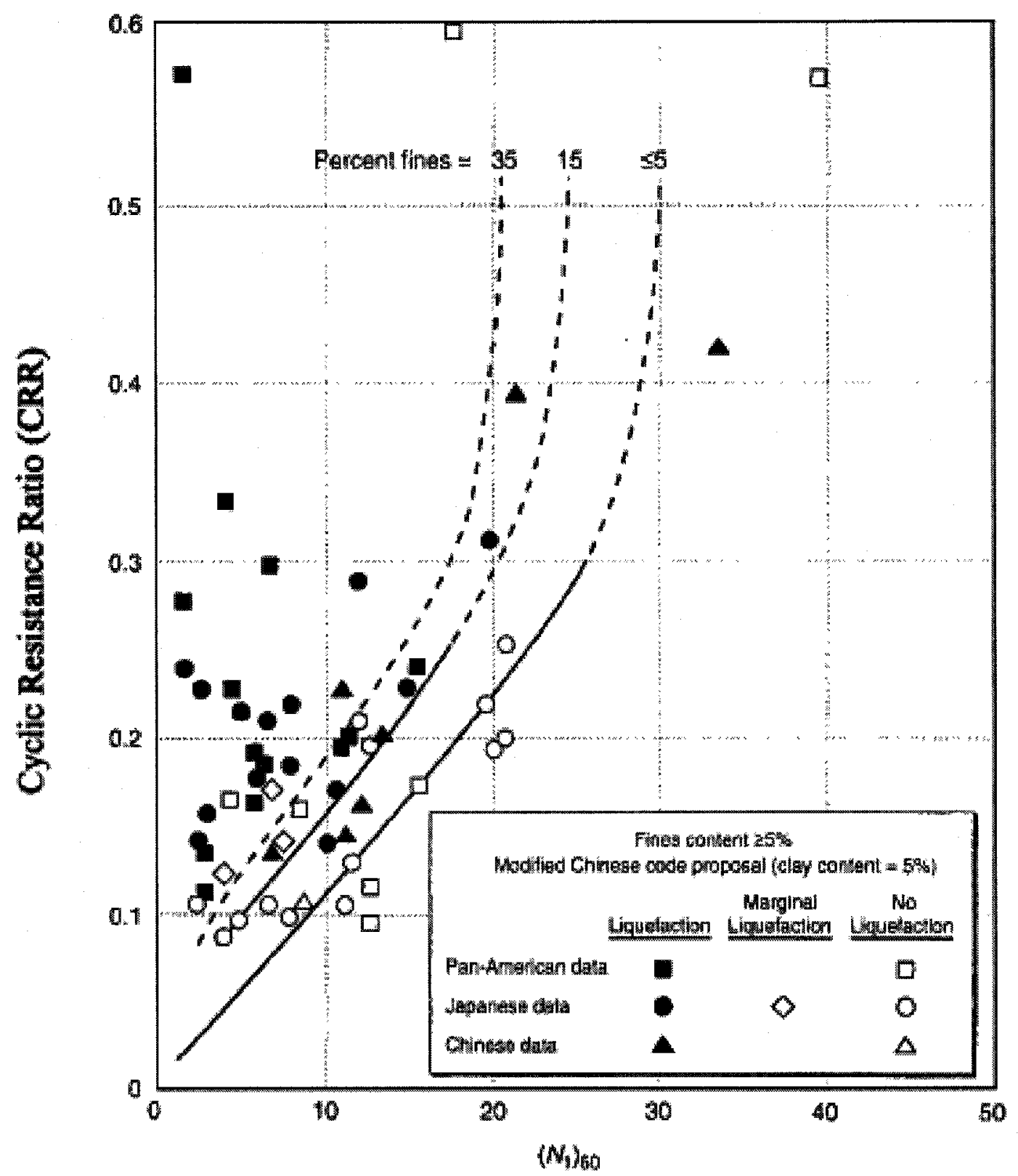

Figure 2-3: Relationship between the cyclic resistance ratio and $\left(N_{1}\right)_{60}$ for $M_{w}=7.5$ earthquakes (After Seed et al. 1975) 


\section{Chapter 3}

\section{NBCC 2005 CHANGES \& IMPLICATIONS}

\subsection{INTRODUCTION}

Several amendments have been introduced to the seismic loading and design provisions of the National Building Code of Canada NBCC 2005. These amendments are due to recent advances in both structural engineering and seismology. This chapter discusses the changes that are of direct relevance to liquefaction design, which are, site classification and their corresponding foundation factors and the return period. It also discusses the implications of the new changes proposed in the NBCC 2005.

\subsection{SITE CLASSIFICATION AND FOUNDATION FACTORS}

Effects of local soil conditions on earthquake-induced ground motions are usually expressed through foundation factors. Foundation factors (also called amplification factors) are defined as the ratio of an observed intensity measure (e.g., peak ground acceleration or spectral acceleration) to a reference value of that intensity measure for a particular site condition (e.g. hard rock or very dense soil), see Stewart et al. (2001). 
Many evidences of damage patterns gathered after major earthquakes such as the 1985 Michoacan and the 1989 Loma Prieta earthquakes suggest that an earthquake ground motion may be amplified multiple times as it propagates through a soft soil layer. In the Michoacan earthquake for instance, peak accelerations of incoming motions in rock were generally less than $0.04 \mathrm{~g}$ and had predominant periods of around $2 \mathrm{~s}$. Many clay sites in the dried lakebed on which the original city was founded had site periods also around $2 \mathrm{~s}$ and were excited into resonant response by the incoming motions. As a result the bedrock outcrop motions were amplified about 5 times. The amplified motions had devastating effects on structures with periods close to site period (Housner 1989, cited by Finn and Wightman 2003).

Amplification factors can be estimated by using either observational or theoretical approaches. Observational approaches compare motions for various site conditions with motions for a reference site condition (usually rock), and the amplification factors derived using such approaches inherently contain all the site effects (ground response, basin, topographic) that exist in the data set. Theoretical analyses can be useful to extend amplification factor models to conditions poorly represented in empirical data sets, but may be limited in their ability to accurately capture the complex physics of true site response (Stewart et al. 2001).

The amplification of incoming outcrop motion is generally governed by four parameters: the thickness of the soil layer, the characteristic shear wave velocity of the soil layer, the impedance ratio of the soil layer to the rock, and the damping ratio of the soil (Okamoto 
1973). The impedance ratio is defined as $\left(\rho_{\text {soil }} \cdot V_{\text {soil }} / \rho_{\text {rock }} \cdot V_{\text {rock }}\right)$, where $\rho$ is density and $V$ is shear wave velocity.

Four schemes can be utilized for site classifications for the purpose of estimating amplification effects: surface geology, averaged shear wave velocity in the upper $30 \mathrm{~m}$ $\left(\mathrm{V}_{\mathrm{s}-30}\right)$, geotechnical data, and basin geometric parameters including depth to basement rock and distance to basin edge (Stewart et al. 2001).

The averaged shear wave velocity is the most widely used in current practice, therefore, it will be discussed in more detail.

\subsubsection{Time-Averaged Shear Wave Velocity:}

It is known from the theory of wave propagation that the amplitude of the ground motion is dependent on the density and the characteristic shear wave velocity of near-surface materials. As density may have little variation with depth, the shear wave velocity would be the logical choice for representing site conditions. Two methods have been proposed for representing depth dependent velocity profiles with a single representative value. The first method takes velocity over the depth range corresponding to one-quarter wavelength of the period of interest (Joyner et al. 1981) which produces frequency-dependent values.

A practical problem with the quarter wavelength $V_{s}$ parameter is that the associated depths are often deeper than those that can be economically reached with boreholes. Therefore, the second method proposes the $V_{s-30}$ parameter to overcome this difficulty 
and has found widespread use in practice. Parameter $V_{s-30}$ is defined as the ratio of $30 \mathrm{~m}$ to the time for vertically propagating shear waves to travel from the $30 \mathrm{~m}$ depth to the surface and is given as:

$$
V_{S-30}=\frac{30}{\sum_{i=1}^{N} \frac{h_{i}}{V_{i}}}
$$

where $h_{i}$ and $V_{i}$ denote the thickness and shear wave velocity of the $i^{\text {th }}$ layer existing in the top 30 meters of materials.

\subsubsection{NBCC 1995 Site Classification and Foundation Factors}

A scheme based on geotechnical data was utilized in the NBCC 1995 to classify a wide variety of possible soil conditions into four site categories and the foundation factor is taken as a function of soil condition and its thickness. The foundation factors presented in the NBCC 1995 are based on the work of Seed et al. (1976). Table 3-1 shows the four site categories and their corresponding foundation factors which vary from 1.0 to 2.0. The last foundation factor $(\mathrm{F}=2)$ in Table 3-1 is not based on research, it was added as a result of the observation of large amplifications of incoming earthquake motions in the clay deposits of Mexico City during the 19 September 1985 earthquake in Mexico (Finn and Wightman 2003). 
Table 3-1: NBCC 1995 Site Classification and Foundation Factors

\begin{tabular}{|c|c|c|}
\hline Category & $\begin{array}{l}\text { Type and depth of soil measured from the foundation or pile cap } \\
\text { level }\end{array}$ & $\mathbf{F}$ \\
\hline 1 & $\begin{array}{l}\text { Rock, dense and very dense coarse-grained soils, very stiff and hard fine- } \\
\text { grained soils, compact coarse-grained soils and firm and stiff fine-grained } \\
\text { soils from } 0 \text { to } 15 \mathrm{~m} \text { deep }\end{array}$ & 1 \\
\hline 2 & $\begin{array}{l}\text { Compact coarse-grained soils, firm and stiff fine-grained soils with a depth } \\
\text { greater than } 15 \mathrm{~m} \text {, very loose and loose coarse-grained soils and very soft } \\
\text { and soft fine-grained soils from } 0 \text { to } 15 \mathrm{~m} \text { deep }\end{array}$ & 1.3 \\
\hline 3 & Very loose and loose coarse-grained soils with depth greater than $15 \mathrm{~m}$ & 1.5 \\
\hline 4 & Very soft and soft fine-grained soils with depth greater than $15 \mathrm{~m}$ & 2 \\
\hline
\end{tabular}

The approach used in the NBCC 1995 for developing the foundation factors had two flaws. First, there exists some ambiguity pertaining to which category a soil should be classified and second, it does not take into consideration the nonlinear behavior of soils. As discussed earlier, the amount of soil amplification depends on the characteristic shear wave velocity of the soil layer, which in turn will cause the amplification factor to be dependent on the shear modulus of the soil layer. Since soil exhibits nonlinear behavior, the increased strain will reduce the shear modulus of the soil (Fig. 3-1), and at the same time increase the damping ratio resulting in reduced amplification due to high intensity of shaking.

The Loma Prieta earthquake and its major aftershocks provided a clear example of this phenomenon. Jarpe et al. (1989) compared the spectral ratios of the Treasure Island (TRI) site, which is underlain by saturated sand or fill, and those of the Yerba Buena Island (YBI) rock site. The spectral ratios were computed for the first five seconds (before any liquefaction took place) of the main shock of the Loma Prieta earthquake, which 
represented the strong ground motion, and seven of its subsequent aftershocks that represent weak ground motion. Figure 3-2 shows the spectral ratios (amplification ratios) for the main earthquake shock (solid line) and the aftershocks, represented by the $95 \%$ confidence region (shaded area). It is readily seen from the figure that the amplification ratios, between 1 and $4 \mathrm{~Hz}$, for the main shock of the Loma Prieta earthquake are significantly less than those of the aftershocks, suggesting that soils under the TRI responded nonlinearly to the main shock (strong ground motion).

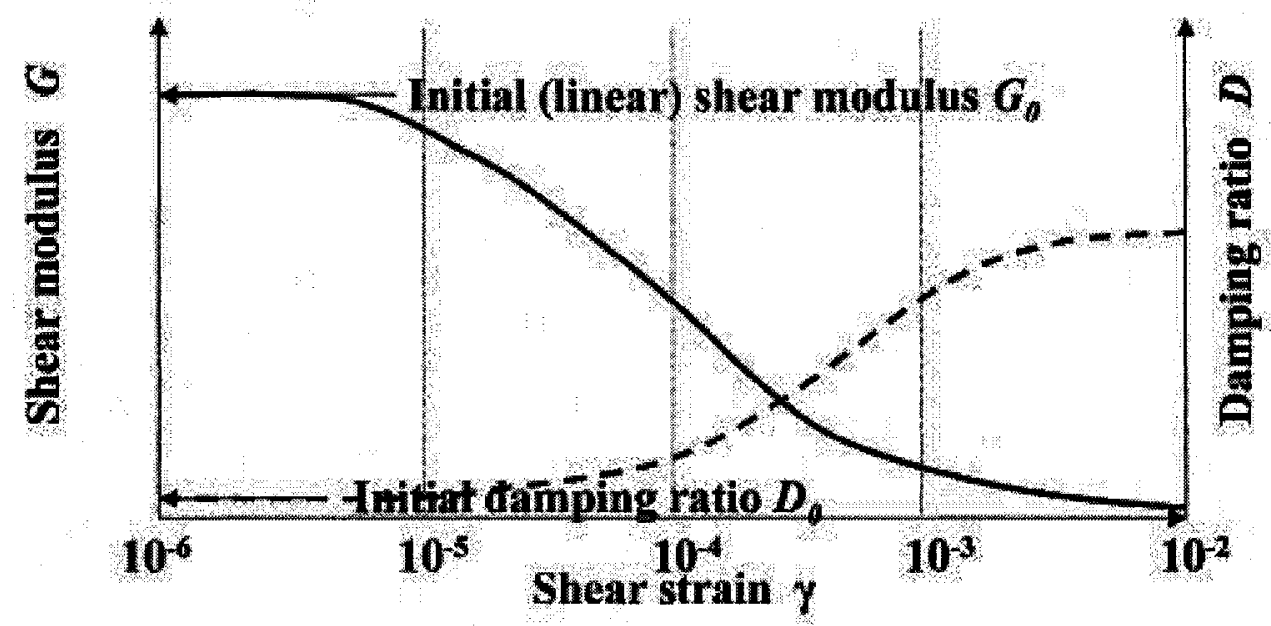

Figure 3-1: Shear modulus/damping ratio versus shear strain relationship 


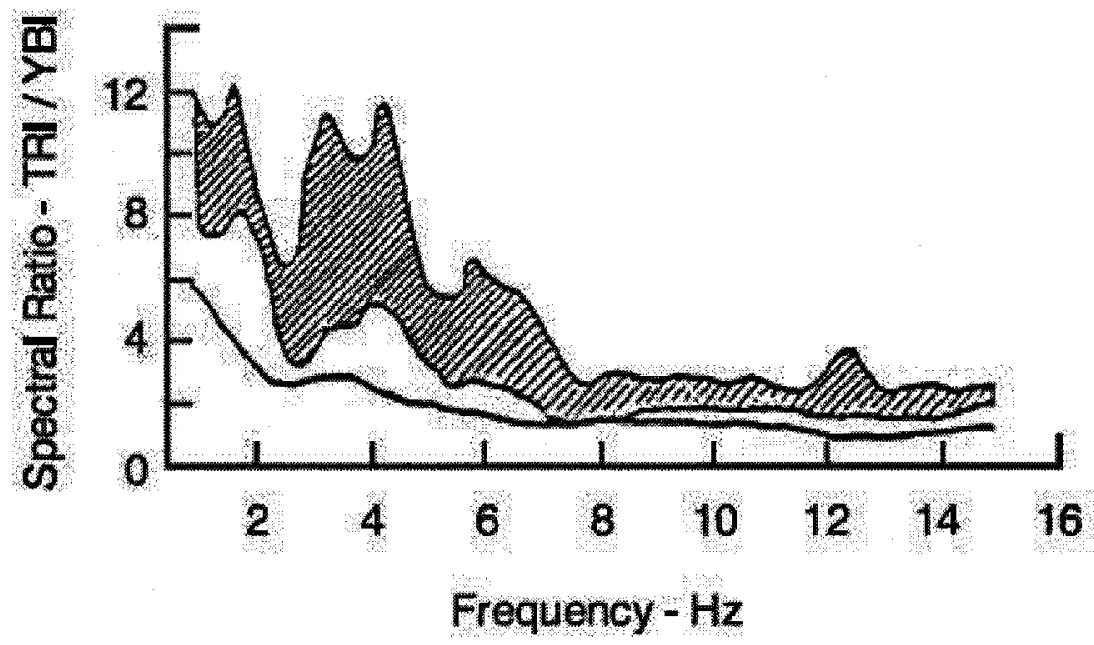

Figure 3-2: Amplification of ground motions at the Treasure Island site (after Jarpe et al. 1989)

\subsubsection{NBCC 2005 Site Classification and Foundation Factors}

The NBCC 2005 adopts the NEHRP (National Earthquake Hazard Reduction Program) approach for the development of foundation factors. Site classification is quantitatively determined through either the strength characteristics of soils, i.e., standard penetration resistance $N_{60}$ and undrained shear strength $S_{u}$, or parameters known to characterize the response of near-surface deposits, i.e., mean shear wave velocity $V_{s}$, which can be inferred or measured directly. This approach simplifies soil classification and reduces ambiguity in the classification process.

The foundation factors presented in NEHRP, and accordingly in NBCC 2005, were essentially based on studies by Borcherdt (1994) and Borcherdt (2002) where extensive sets of in-situ measurements were obtained from the 1989 Loma Prieta earthquake. The measurements were obtained from 35 free-field sites located on a variety of geologic deposits ranging from very soft clays to hard rock. The mean shear wave velocity was 
used to classify the sites where the data was obtained. Then the average amplification ratios, with respect to Firm to Hard rock, inferred from strong-motion recordings of the Loma Prieta earthquake were used to provide regression curves for the average spectral amplification as a function of mean shear wave velocity for the short-, intermediate-, long and mid-period bands, see Figure 3-3.

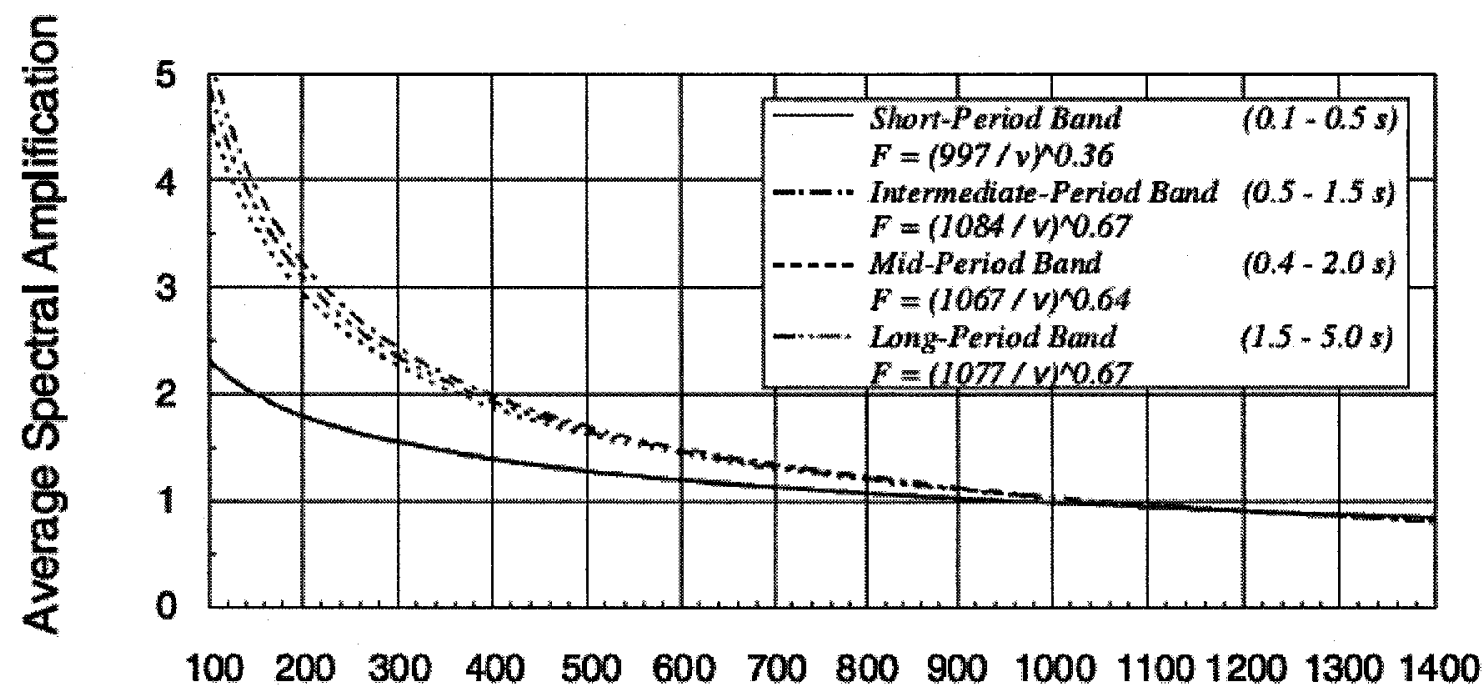

Figure 3-3: Mean Shear-Wave Velocity to $30 \mathrm{~m}, \mathrm{v}(\mathrm{m} / \mathrm{s})$ (after Borcherdt 1994)

Two important conclusions were inferred from the above figure. First, spectral amplification ratios increase with decreasing shear wave velocity, this result is in conformity with theoretical studies (Okamoto 1973). Second, it is readily observed that the increase in amplification factor with decreasing shear wave velocity is less pronounced for the short-period motion as opposed to the intermediate-, mid-, and long period motion. This observation implies that two factors suffice to characterize the site response: one for the short-period component of motion and another for other period 
bands. This important result is consistent with the two-factor approach to response spectrum construction summarized in Figure 3-4 (NEHRP 1994).

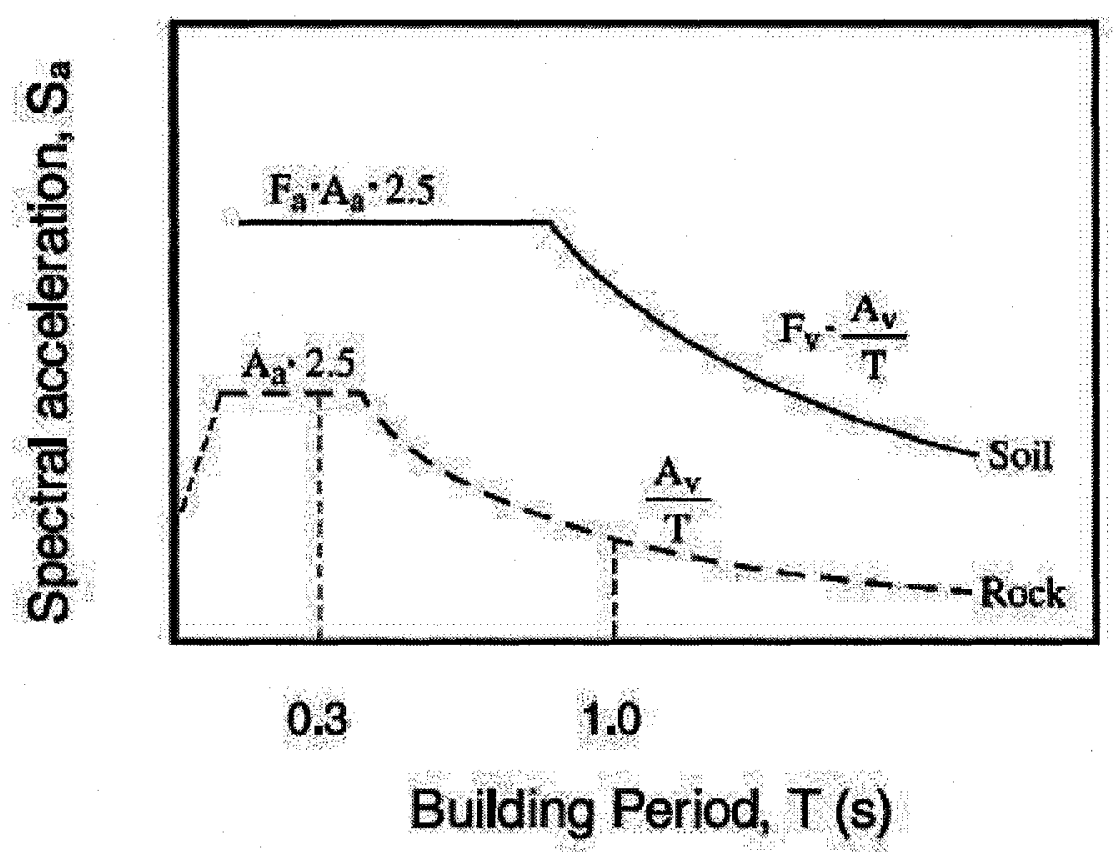

Figure 3-4: Two-factor approach to local site response (NEHRP 1994)

The regression curves presented in Figure 3-3 can be expressed as:

$$
\begin{aligned}
& F_{a}=\left(\frac{1050}{\overline{V_{30}}}\right)^{0.35} \\
& F_{v}=\left(\frac{1050}{\overline{V_{30}}}\right)^{0.65}
\end{aligned}
$$

Eq. 3-3

where $F_{a}$ and $F_{v}$ are the foundation factors for short- and long-period motion respectively, $\overline{V_{30}}$ is the shear wave velocity of the soil layer in $\mathrm{m} / \mathrm{s}$. 
A general form of the above equations can also be expressed as:

$$
\begin{aligned}
& F_{a}=\left(\frac{V_{r e f}}{\overline{V_{30}}}\right)^{m_{a}} \\
& F_{v}=\left(\frac{V_{r e f}}{\overline{V_{30}}}\right)^{m_{v}}
\end{aligned}
$$

where $V_{r e f}$ is the shear wave velocity for a reference site and $m_{a}$ and $m_{v}$ are exponents based on regression analysis and dependent on ground motion intensities.

The general equations developed by Borcherdt (1994) were primarily based on ground motions of around $0.1 \mathrm{~g}$ or less as stronger ground motions records were not available. However, these equations were also used to predict foundation factors for stronger ground motions by utilizing the results of site response analyses of stronger ground motion intensities $(>0.1 \mathrm{~g})$ obtained through laboratory and numerical modeling by other researchers such as Seed et al. (1992) and Dobry et al. (1992). Thus, estimating the foundation factors for ground motions stronger than $0.1 \mathrm{~g}$ boils down to estimating the exponents $m_{a}$ and $m_{v}$ for the above equations that would give the best fit to the laboratory and numerical data. Table 3-2 summarizes the exponent values for different ground motion intensities that were obtained using the general equations in conjunction with results from laboratory and numerical site response analyses. 
Tables 3-3 and 3-4 show the NEHRP foundation factors as a function of site conditions and shaking intensities. It should be noted that Site Class $B$ is taken as a reference site for the estimation of the foundation factors, i.e., $V_{\text {ref }}=1050 \mathrm{~m} / \mathrm{s}$.

Table 3-2: Exponent values at different ground motion levels obtained using the general equations in conjunction with results from laboratory and numerical site response analyses (modified from Bocherdt 1994)

\begin{tabular}{|c|c|c|}
\hline Input Ground Motion (g) & $m_{a}$ & $m_{v}$ \\
\hline 0.1 & 0.35 & 0.65 \\
\hline $\mathbf{0 . 2}$ & 0.25 & 0.60 \\
\hline $\mathbf{0 . 3}$ & 0.10 & 0.53 \\
\hline $\mathbf{0 . 4}$ & -0.05 & 0.45 \\
\hline
\end{tabular}

Table 3-3: Values of $F_{a}$ as a function of site conditions and shaking intensity $A_{a}$ (NEHRP 1994)

\begin{tabular}{|c|c|c|c|c|c|}
\hline \multirow[b]{2}{*}{ Site Class } & \multicolumn{5}{|c|}{$A_{a}$} \\
\hline & $0.1 \mathrm{~g}$ & $0.2 \mathrm{~g}$ & $0.3 \mathrm{~g}$ & $0.4 \mathrm{~g}$ & $0.5 \mathrm{~g}$ \\
\hline $\mathbf{A}$ & 0.8 & 0.8 & 0.8 & 0.8 & 0.8 \\
\hline B & 1.0 & 1.0 & 1.0 & 1.0 & 1.0 \\
\hline $\mathrm{C}$ & 1.2 & 1.2 & 1.1 & 1.0 & 1.0 \\
\hline $\mathbf{D}$ & 1.6 & 1.4 & 1.2 & 1.1 & 1.0 \\
\hline $\mathbf{E}$ & 2.5 & 1.7 & 1.2 & 0.9 & a \\
\hline $\mathbf{F}$ & _a & _a & _a & _a & _a \\
\hline
\end{tabular}

${ }^{\mathrm{a}}$ Site-specific geotechnical investigations and dynamic site response analyses should be performed. 
Table 3-4: Values of $F_{v}$ as a function of site conditions and shaking intensity $A_{v}$ (NEHRP 1994)

\begin{tabular}{|c|c|c|c|c|c|}
\hline \multirow[b]{2}{*}{ Site Class } & \multicolumn{5}{|c|}{$A_{v}$} \\
\hline & $0.1 \mathrm{~g}$ & $0.2 \mathrm{~g}$ & $0.3 \mathrm{~g}$ & $0.4 \mathrm{~g}$ & $0.5 \mathrm{~g}$ \\
\hline $\mathbf{A}$ & 0.8 & 0.8 & 0.8 & 0.8 & 0.8 \\
\hline B & 1.0 & 1.0 & 1.0 & 1.0 & 1.0 \\
\hline $\mathbf{C}$ & 1.7 & 1.6 & 1.5 & 1.4 & 1.3 \\
\hline D & 2.4 & 2.0 & 1.8 & 1.6 & 1.5 \\
\hline $\mathbf{E}$ & 3.5 & 3.2 & 2.8 & 2.4 & $\mathbf{a}$ \\
\hline $\mathbf{F}$ & - & _a & - a & _a & _a \\
\hline
\end{tabular}

${ }^{2}$ Site-specific geotechnical investigations and dynamic site response analyses should be performed.

The NBCC 2005 adopts the NEHRP foundation factors and site classifications systems with two minor changes. The site reference is taken as Site Class $C$ (i.e., $V_{r e f}=540 \mathrm{~m} / \mathrm{s}$ ) to reflect the common conditions of Canadian soils and the intensity of shaking is presented in terms of spectral acceleration instead of the peak ground acceleration used by NEHRP. It should be noted that peak ground (rock) acceleration of $0.1 \mathrm{~g}$ corresponds approximately to a response spectral acceleration on rock at 0.2 -second period $\left(S_{0.2}\right)$ equal to $0.25 \mathrm{~g}$ and to a response spectral acceleration on rock at 1.0 -second period $\left(S_{1.0}\right)$ equal to 0.1g (NEHRP 2003).

Table 3-5 shows the NBCC 2005 site classification and Tables 3-6 and 3-7 show the NBCC 2005 foundation factors, where the intensity of the shaking is defined by the short-period $(T=0.2 \mathrm{~s})$ and the long-period $(T=1.0 \mathrm{~s})$ spectral accelerations $S_{0.2}$ and $S_{1.0}$ respectively. 
Table 3-5: NBCC 2005 Site Classification

\begin{tabular}{|c|c|c|c|c|}
\hline \multirow[b]{2}{*}{$\begin{array}{l}\text { Site } \\
\text { Class }\end{array}$} & \multirow[b]{2}{*}{$\begin{array}{l}\text { Soil Profile } \\
\text { Name }\end{array}$} & \multicolumn{3}{|c|}{ Average Properties in Top $30 \mathrm{~m}$} \\
\hline & & $\begin{array}{c}\text { Soil Shear Wave } \\
\text { Average } \\
\text { velocity, } V_{\mathbf{s}}(\mathrm{m} / \mathrm{s})\end{array}$ & $\begin{array}{c}\text { Standard } \\
\text { Penetration } \\
\text { Resistance, } \mathbf{N}_{60}\end{array}$ & $\begin{array}{c}\text { Soil Undrained } \\
\text { Shear Strength, } \\
\mathbf{S}_{\mathbf{u}}\end{array}$ \\
\hline $\mathbf{A}$ & Hard Rock & $V_{s}>1500$ & Not applicable & Not applicable \\
\hline B & Rock & $760<V_{s} \leq 1500$ & Not applicable & Not applicable \\
\hline $\mathbf{C}$ & $\begin{array}{l}\text { Very Dense } \\
\text { Soil and } \\
\text { Soft Rock }\end{array}$ & $360<V_{s}<760$ & $\mathrm{~N}_{60}>\mathbf{5 0}$ & $S_{u}>150 \mathrm{kPa}$ \\
\hline D & Stiff Soil & $180<V_{s}<360$ & $15 \leq \mathbf{N}_{60} \leq 50$ & $\begin{array}{c}50<S_{\mathbf{u}} \leq 100 \\
\mathbf{k P a}\end{array}$ \\
\hline $\mathbf{E}$ & Soft Soil & $V_{\mathrm{s}}<\mathbf{1 8 0}$ & $\mathbf{N}_{60}<15$ & $\mathrm{~S}_{\mathbf{u}}<50 \mathrm{kPa}$ \\
\hline $\mathbf{E}$ & & \multicolumn{3}{|c|}{$\begin{array}{l}\text { - Any profile with more than } 3 \mathrm{~m} \text { of soil with the following } \\
\text { characteristics: } \\
\text { - Plastic Index PI }>20 \\
\text { - Moisture Content } w \geq 40 \% \text {, and } \\
\text { - Undrained shear strength } \mathrm{S}_{\mathrm{u}}<25 \mathrm{kPa}\end{array}$} \\
\hline $\mathbf{F}$ & Others & \multicolumn{3}{|c|}{ Site specific evaluation required } \\
\hline
\end{tabular}


Table 3-6: NBCC 2005 Foundation Factors for Short Period

\begin{tabular}{|c|c|c|c|c|c|}
\hline \multirow{2}{*}{$\begin{array}{c}\text { Site } \\
\text { Class }\end{array}$} & \multicolumn{5}{|c|}{ Values of $\mathrm{F}_{\mathrm{a}}$} \\
\cline { 2 - 6 } & $\mathrm{Sa}(0.2)$ & $\mathrm{Sa}(0.2)$ & $\mathrm{Sa}(0.2)$ \\
$=0.25$ & $\mathrm{Sa}(0.2)$ & $\mathrm{Sa}(0.2)$ \\
$=0.75$ & 1.00 & $\geq 1.25$ \\
\hline A & 0.7 & 0.7 & 0.8 & 0.8 & 0.8 \\
\hline B & 0.8 & 0.8 & 0.9 & 1.0 & 1.0 \\
\hline C & 1.0 & 1.0 & 1.0 & 1.0 & 1.0 \\
\hline D & 1.3 & 1.2 & 1.1 & 1.1 & 1.0 \\
\hline E & 2.1 & 1.4 & 1.1 & 0.9 & 0.9 \\
\hline F & $(1)$ & $(1)$ & $(1)$ & $(1)$ & $(1)$ \\
\hline
\end{tabular}

Table 3-7: NBCC 2005 Foundation Factors for Long Period

\begin{tabular}{|c|c|c|c|c|c|}
\hline \multirow{2}{*}{$\begin{array}{l}\text { Site } \\
\text { Class }\end{array}$} & \multicolumn{5}{|c|}{ Values of $F_{v}$} \\
\hline & $\begin{array}{l}\mathrm{Sa}(0.2) \\
\leq 0.25\end{array}$ & $\begin{array}{l}\mathrm{Sa}(0.2) \\
=0.50\end{array}$ & $\begin{array}{l}\mathrm{Sa}(0.2) \\
=0.75\end{array}$ & $\begin{array}{l}\mathrm{Sa}(0.2) \\
=1.00\end{array}$ & $\begin{array}{l}\mathrm{Sa}(0.2) \\
\geq 1.25\end{array}$ \\
\hline $\mathbf{A}$ & 0.5 & 0.5 & 0.5 & 0.6 & 0.6 \\
\hline B & 0.6 & 0.7 & 0.7 & 0.8 & 0.8 \\
\hline $\mathbf{C}$ & 1.0 & 1.0 & 1.0 & 1.0 & 1.0 \\
\hline D & 1.4 & 1.3 & 1.2 & 1.1 & 1.1 \\
\hline $\mathbf{E}$ & 2.1 & 2.0 & 1.9 & 1.7 & 1.7 \\
\hline $\mathbf{F}$ & (1) & (1) & (1) & (1) & (1) \\
\hline
\end{tabular}

(1) To determine $F_{a}$ and $F_{v}$ for Site Class $F$, site specific geotechnical investigations and dynamic site response analysis should be performed. 


\subsection{RETURN PERIOD (HAZARD LEVEL)}

The seismic loading and design provision of the NBCC 2005 has introduced a lower hazard level, $2 \%$ in 50 years instead of $10 \%$ in 50 years, to be used for structure and geotechnical designs (Adams et al. 2004, 2003 and 2000).

Lowering the hazard level has been the most controversial change for the geotechnical community in Canada as it has caused many implications to geotechnical design in Canada. While many papers commenting on the NBCC 2005 within the structural discipline have touched on the rationale behind this change as to achieve a uniform reliability across Canada, none of these papers have explicitly explained the rationale behind adopting the new return period in structural seismic designs. As a result, a great deal of ambiguity exists around the idea behind going to the 2475 year seismic event rather than 475 year seismic event. Concerns within the geotechnical community were also raised questioning the applicability of the 2475 year return period adopted by the "structural people" to geotechnical problems.

To properly address those concerns as well as fully understand the logic associated with introducing a 2475 years return period, the overstrength concept and the seismic hazard dissimilarities between Eastern and Western North America should be addressed. 


\subsubsection{Structural Overstrength}

Many sources contribute to the safety of a building during its design process. For example, load factors greater than unity are applied to the loads (other than seismic loads) and reduction factors are applied to material strengths. Other sources contributing to building safety may come during its construction process. As a result, the expected structural resistance is always greater than the factored (reduced) resistance.

When considering all sources contributing to building safety, it has been found that buildings are reliably in the order of 1.3-1.7 times stronger than their factored (reduced) resistance used in structural design (DeVall 2006). A similar overstrength factor of 1.5 was reached by Kennedy et al. (1994), Cornell (1994), and Ellingwood (1994) who evaluated structural design margins (overstrength) and reached similar conclusions. The overstrength varies depending on materials, type of structure, detailing requirements, etc. However, the 1.5 overstrength factor is currently implemented in the design process (see Section 2.3.2).

\subsubsection{Seismic Hazard Dissimilarities between the East and the West}

Eastern North America (ENA) and Western North America (WNA) have different seismic hazard characteristics, the West being more active than the East in terms of seismicity. This difference has led to a more rigorous seismic design process (detailing) in the West than the East. 
As discussed in the previous section, structures will have a reliable overstrength of about 1.5 before exhausting their capacity and reaching collapse or the verge of collapse. Therefore, if the overstrength factor is considered in the well established design process in the West, the return period of the earthquake that would deplete the overstrength is about 2475 years. However, if the same overstrength factor is considered in ENA, the corresponding return period would be of about 1500 years. As such, the level of protection against collapse in ENA is different (i.e. less) from that in WNA (Whitman 1990).

To gain a better insight into the issue at hand, the peak ground acceleration (PGA) for 12 Canadian cities normalized at 2 percent probability of exceedance in 50 years versus the annual frequency of exceedance is shown in Figure 3-5. In the Western cities such as, Vancouver and Victoria, the ratio between the PGA for the 2 and the 10 percent probabilities of exceedance in 50 years is about 1.5 whereas, in the Eastern cities such as St. John and Quebec, the ratio varies from 2.0 to 5.0. In other words, if a structure in Vancouver was designed to resist a 475 year earthquake and the 2475 year return period earthquake were to occur, the structure would likely resist the earthquake due to the inherent " 1.5 overstrength" in the system. However, if the same scenario is applied to the Eastern cities in Canada, chances are low that structures would resist the 2475 year earthquake as there would not be sufficient overstrength to accommodate the excess forces induced by such an earthquake. 


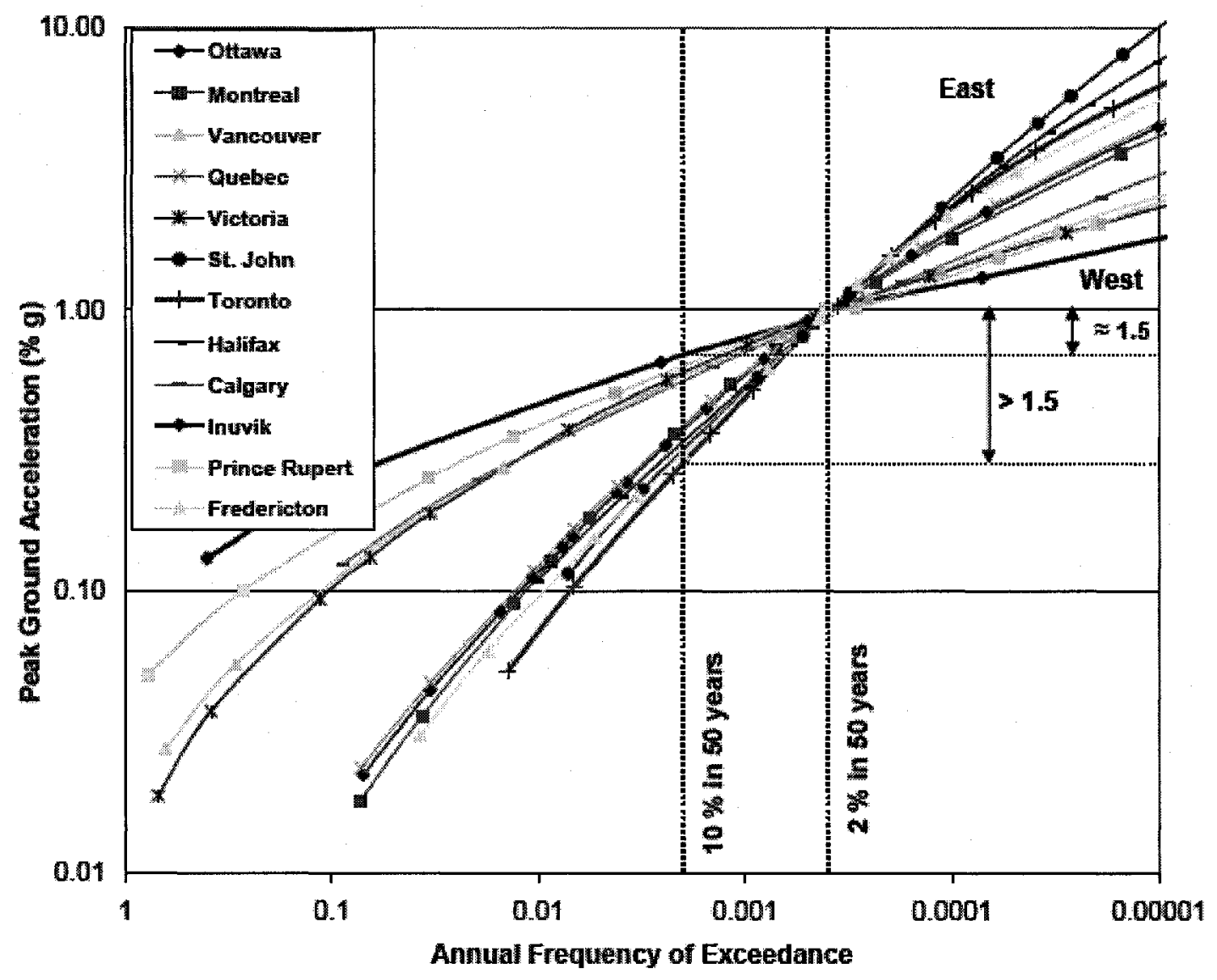

Figure 3-5: Seismic Hazard Curves for Several Canadian Cities

The objective was therefore to unify the safety margin against collapse nationwide. To achieve this objective, seismic design was anchored to the well established process in the West by considering the 2475 year earthquake as the basis for design. However, as the design forces corresponding to that earthquake would be much higher than those corresponding to 475 year earthquake (particularly in the East), the overstrength concept is now incorporated into the design process to mitigate the "would be" drastic increases in seismic design forces. By doing so, two implicit performance objectives are achieved (DeVall 2006): 
- the essential service objective where a structure designed in accordance with this current code, would resist all minor earthquakes (those correspond to less than 2475 year seismic event) without damage, and

- the basic objective where the same structure would survive a very rare earthquake that corresponds to 2475 year return period at near collapse state.

As a result of lowering the hazard level, the resulting ground accelerations have increased considerably across Canada especially in the low seismicity areas, see Table 3-8.

Table 3-8: Comparison of Peak Ground Acceleration

\begin{tabular}{|c|c|c|}
\hline \multirow{2}{*}{ City } & \multicolumn{2}{|c|}{ Peak Ground Acceleration 9\% } \\
\cline { 2 - 3 } & NBCC 1995 & NBCC 2005 \\
\hline Vancouver & 22 & 48 \\
\hline Calgary & 1.9 & 8.8 \\
\hline Toronto & 5.6 & 20 \\
\hline Ottawa & 20 & 42 \\
\hline Montreal & 18 & 43 \\
\hline Quebec City & 19 & 37 \\
\hline Fredericton & 9.6 & 27 \\
\hline Halifax & 5.6 & 12 \\
\hline St. John's & 5.4 & 9 \\
\hline
\end{tabular}




\subsection{IMPLICATIONS OF THE NBCC 2005 CHANGES AND NEW REQUIREMENTS}

The new changes and requirements introduced to the seismic provisions of the NBCC 2005 have many implications to structural and geotechnical design. While implications to structural design have been thoroughly discussed by many researchers (Heidebrecht 2003, Saatcioglu and Humar 2003, Humar and Mahgoub 2003, and Mitchell et al. 2003), implications to geotechnical design have not yet been thoroughly addressed.

\subsubsection{Implications to Structural Designs}

The increased level of ground motion resulted from lowering the hazard level, from $10 \%$ in 50 years to $2 \%$ in 50 years, did not lead to a proportional increase in the seismic design forces from the NBCC 1995 (Heidebrecht 2003). As discussed earlier, structural engineers have mitigated the increased level of seismic design forces by considering the overstrength factor in the design process and, by doing so, buildings will have achieved two implicit performance objectives (2.3.2).

A common question arises among engineers whether buildings designed in accordance with the NBCC 1995 are no longer safe according to the new requirements of the NBCC 2005. The answer is no. They are safe. However, the performance objective was only to resist earthquakes corresponding to 475 years return period without any damage. 


\subsubsection{Implications to Geotechnical Designs}

Conventional geotechnical engineering designs for liquefaction or earth pressure due to an earthquake and for slope stability during an earthquake involve terms that are directly proportional to the $P G A$. Hence, application of the $2 \%$ in 50 years values from the 2005 Code to current practice might be expected to lead to conservative designs (i.e. safer).

\subsubsection{Implications of NBCC 2005 to Soil Liquefaction Designs}

Comprehending the implications of the NBCC 2005 requirements on liquefaction designs is best achieved through the comparison of the liquefaction designs for selected Canadian cities obtained in accordance with both editions (1995 and 2005) of the NBCC. As stated earlier in this chapter, liquefaction designs will be based on Seed and Idriss approach as it is the most used approach in practice.

\subsubsection{Implications of NBCC 2005 to Cyclic Stress Ratio (CSR):}

There are two terms in the Seed and Idriss equation, which are influenced by the changes introduced in the NBCC 2005: the maximum design acceleration at the ground surface $\left(a_{\max }\right)$ obtained by multiplying the mapped $P G A$ with the short period foundation factor $\left(F_{a}\right)$, and the magnitude scaling factor $(M S F)$. The mapped $P G A$ corresponding to the new hazard level ranges from 1-4.6 times those in the NBCC 1995, and therefore, resulting in doubling and in some cases quadrupling the $a_{\max }$ values, particularly in low seismicity areas such as Toronto. The high values of $a_{\max }$ in the Seed and Idriss equation may be reduced by the magnitude scaling factor. However, the net effect is still an 
increased level of CSR in most Canadian cities. The increased level of the CSR either conflicts with the Seed and Idriss approach as the Seed and Idriss liquefaction curves were developed with seismic data lacking in values where $C S R>0.25$ (Cetin 2000), or leads to conservative liquefaction designs.

When designing against liquefaction, a representative earthquake magnitude needs to be selected so that the duration of the earthquake (or the number of cyclic shear stress induced by the earthquake) is taken into consideration. In current practice, a representative earthquake magnitude is selected as the maximum earthquake experienced or the maximum predicted earthquake in the governing seismic source zone (Table 3-9). However, for liquefaction designs, using a single earthquake magnitude in conjunction with the probabilistically-obtained $P G A$ is not entirely rational (Idriss 1985). Typically, the $P G A$ is obtained through a probabilistic seismic hazard evaluation, where different earthquake magnitudes contribute differently to the $P G A$. Therefore, a rational selection of a representative magnitude would be based on its contribution to the $P G A$. The modal earthquake, defined as the earthquake that contributes the most to $P G A$ and the most probable earthquake to occur in a return period of interest (2475 years), may be a reasonable representative earthquake magnitude for use in liquefaction designs and evaluations.

The modal earthquake is usually obtained through deaggregation of seismic hazard at a return period of interest. Table 3-9 (columns 7 \& 8) shows the modal earthquake magnitudes, associated with a return period of 2475 years, for various Canadian cities 
(obtained using the EZ-FRISK software) and the corresponding magnitude scaling factors. It should be noted that the EZ-FRISK does not account for the epistemic uncertainty in its analysis and therefore, the results obtained using the EZ-FRISK software may slightly differ from those reported by Geological Survey of Canada (GSC) where the GSCFRISK software was used to handle the epistemic uncertainty. Therefore, the modal earthquakes obtained using the EZ-FRISK were adjusted to reflect those reported by GSC (Halchuk et al. 2007).

Figures 3-6 and 3-7 compare the CSR values in both editions of NBCC for selected Canadian cities. It can be readily seen from both figures that there is an increase in the $C S R$ values computed using Seed and Idriss method. This increase is more pronounced in low seismicity areas such as Toronto, Halifax, St. John's, Fredericton, and Calgary.

The Standard Penetration Resistance, $\left(N_{I}\right)_{60}$, calculated based on the $C S R$ values shown in Figures 3-6 and 3-7 will always be in the range of 25-30. These results indicate that there is an obvious conservatism as past experience and observations have shown that sandy sites with $\left(N_{1}\right)_{60}=25-30$ seldom liquefy as there are almost no liquefaction records of soils having $\left(N_{1}\right)_{60} \geq 28$. It can also be seen from the Seed-Idriss liquefaction curves (Figure 2-3) that the liquefaction curves become parallel to the CSR axis starting at $\left(N_{1}\right)_{60}$ values of 20 and 28 (depending on fines content), suggesting that there is a low chance that the soil will liquefy beyond these $\left(N_{1}\right)_{60}$ values. 
Table 3-9: Spectral Acceleration, Foundation Factors for Site Class E and D, Maximum magnitude used in practice, Modal Magnitude for Canadian Cities Based on Deaggregating the Seismic Hazard Peak Ground Acceleration for 2\%/50 Year and the Corresponding Magnitude Scaling Factors (MSF)

\begin{tabular}{|c|c|c|c|c|c|c|c|}
\hline \multirow[b]{2}{*}{ City } & \multirow[b]{2}{*}{$\beta_{a}(0.2)$} & \multicolumn{2}{|c|}{ Foundation Factor } & \multirow[b]{2}{*}{$M_{\mathbf{x} 1995}$} & \multirow[b]{2}{*}{ MSF $_{1995}$} & \multirow[b]{2}{*}{ Modal M } & \multirow[b]{2}{*}{ MSF $_{2005}$} \\
\hline & & $\begin{array}{c}\text { Site Class } \\
\text { E }\end{array}$ & $\begin{array}{c}\text { Site Class } \\
\text { D }\end{array}$ & & & & \\
\hline Inuvik & 0.12 & 2.10 & 1.30 & 6.0 & 1.77 & 6.95 & 1.21 \\
\hline Prince Rupert & 0.38 & 1.74 & 1.25 & 7.5 & 1.00 & 8.05 & 0.83 \\
\hline Victoria & 1.20 & 0.90 & 1.10 & 7.5 & 1.00 & 8.98 & 0.64 \\
\hline Vancouver & 0.96 & 0.93 & 1.10 & 7.3 & 1.07 & 7.05 & 1.17 \\
\hline Calgary & 0.15 & 2.10 & 1.30 & 5.5 & 2.21 & 5.05 & 2.75 \\
\hline Toronto & 0.28 & 2.02 & 1.29 & 6.0 & 1.77 & 5.90 & 1.85 \\
\hline Ottawa & 0.67 & 1.20 & 1.13 & 6.9 & 1.24 & 5.90 & 1.85 \\
\hline Montreal & 0.69 & 1.17 & 1.12 & 6.5 & 1.44 & 5.90 & 1.85 \\
\hline Quebec City & 0.59 & 1.29 & 1.16 & 6.0 & 1.77 & 5.90 & 1.85 \\
\hline Fredericton & 0.39 & 1.71 & 1.24 & 6.0 & 1.77 & 5.90 & 1.85 \\
\hline Halifax & 0.23 & 2.10 & 1.30 & 6.0 & 1.77 & 5.90 & 1.85 \\
\hline St. John's & 0.18 & 2.10 & 1.30 & 6.0 & 1.77 & 5.90 & 1.85 \\
\hline
\end{tabular}

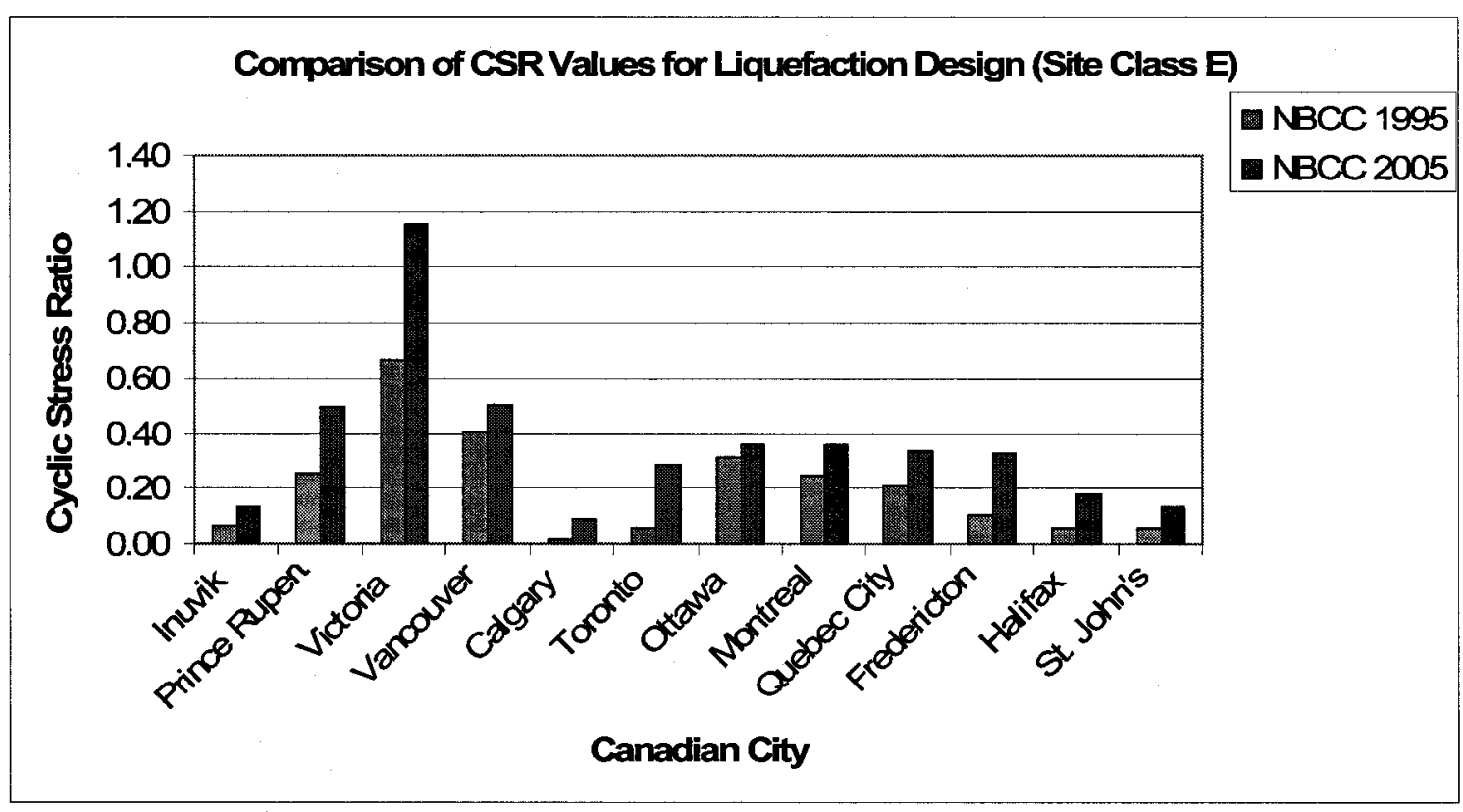

Figure 3-6: Comparison of CSR in two editions of NBCC in selected Canadian cities 


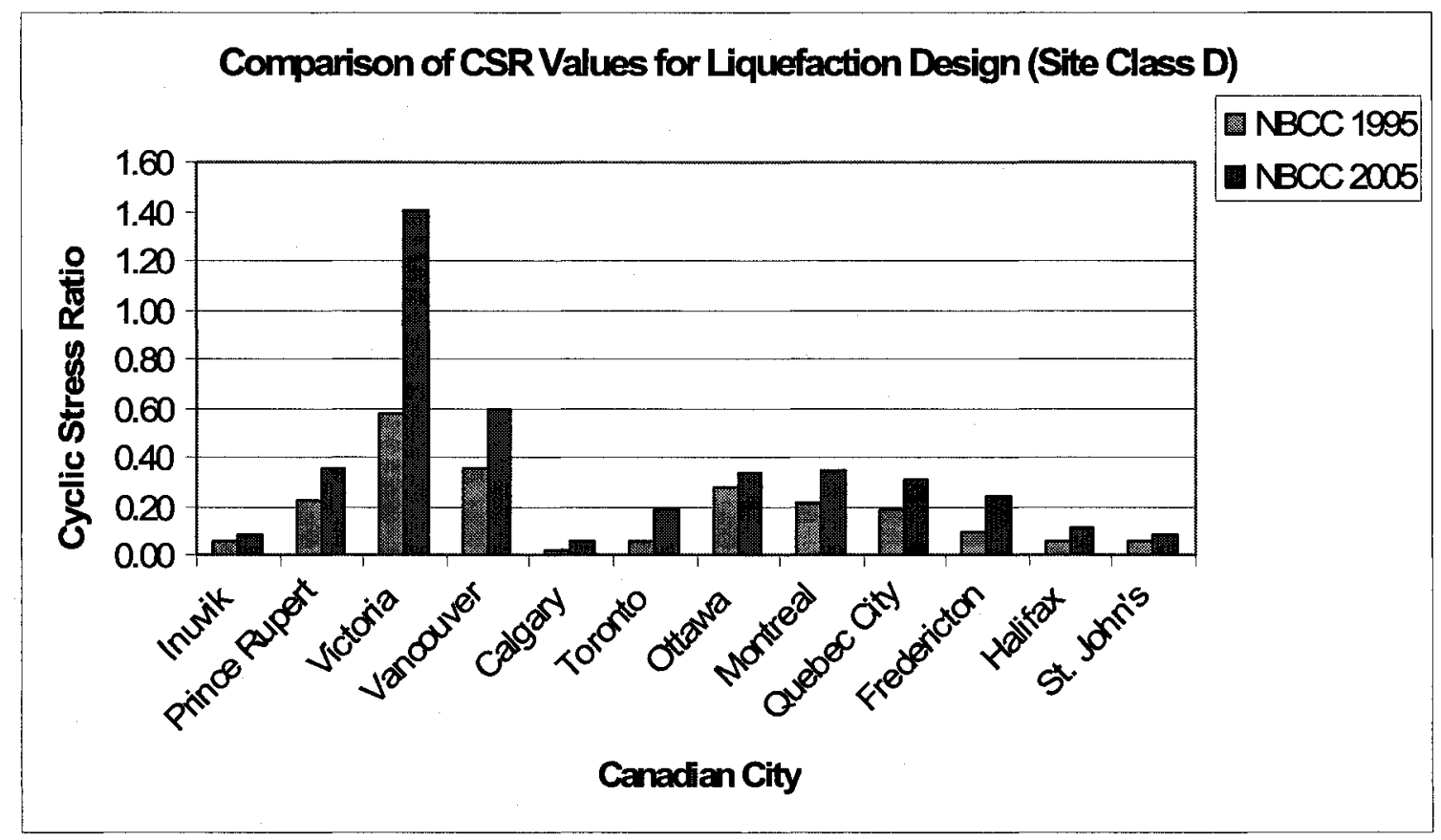

Figure 3-7: Comparison of CSR in two editions of NBCC in selected Canadian cities

The conservative results are due to an inconsistency arising from combining the probabilistically-obtained $P G A$ and the deterministic Seed and Idriss curves. This will be further discussed in the next chapter. 


\title{
Chapter 4
}

\section{HARMONIZING SEED-IDRISS APPROACH FOR}

LIQUEFACTION DESIGNS WITH THE NBCC 2005

\author{
REQUIREMENTS
}

\subsection{INTRODUCTION}

The ground motion in the seismic provisions of building codes is often used inconsistently with the Seed-Idriss approach for liquefaction design. The inconsistency arises from combining the probabilistic ground motion and the deterministic curves compiled by Seed and Idriss in their approach. This inconsistency is particularly acute in the NBCC 2005 (as discussed in the previous chapter). A simple and practical method, which harmonizes the Seed-Idriss approach with the NBCC 2005 requirements, is proposed here. The solution stems from resolving the inconsistency in using the Seed and Idriss approach for estimating future liquefaction failure. Application of the proposed method for various Canadian cities reveals that the new method results in uniform liquefaction performance across Canada. A comparison between the proposed method and the NEHRP approach suggests that the latter tends to underestimate liquefaction performance in some cities and hence, does not meet the desired return period recommended by the NBCC 2005. 


\subsection{INCONSISTENCY BETWEEN PGA AND SEED-IDRISS}

\section{CURVES}

The mapped peak ground acceleration ( $P G A)$ is usually evaluated probabilistically. Conventionally, the $P G A$ is computed corresponding to a particular probability of exceedance in a given time period.

The NBCC 2005 evaluated ground motion parameters (including $P G A$ ) for Canadian cities based on the $2 \%$ probability of exceedance in 50 years $(0.000404$ per annum or 2475-year return period). The ground motion parameters corresponding to this hazard level are to be used in structural and geotechnical designs across Canada.

However, using the NBCC 2005 probabilistically-based PGA (associated with 2475 years return period) with the Seed-Idriss deterministically-based liquefaction curves leads to conservative liquefaction designs as the resulting liquefaction return period will be much longer than 2475 years as explained in the following.

Although the Seed-Idriss liquefaction curves are perceived by geotechnical engineers as deterministic, they suffer from a great deal of uncertainties as they were developed based on a limited number of seismic events and they have not included the increasing body of field case history data from seismic events that have occurred since 1984 (Cetin 2000). They are also lacking in data from cases with high peak ground shaking levels $(C S R>$ 0.25 ), an increasingly common design range in regions of high seismicity. Other sources 
of uncertainties in the Seed and Idriss approach stem from the estimation of the depth reduction and the magnitude scaling factors, both being essential parameters in the Seed and Idriss approach.

Therefore, the return period of liquefaction occurrence obtained from the Seed and Idriss approach will be different from that (2475 years) of the $P G A$ used as the input for the approach. Let $P_{P G A}$ be the probability of occurrence of the seismic event $\left(P_{P G A}=\right.$ 0.0004040, which is the probability of $P G A$ based on NBCC 2005). Let $P_{\text {Seed }}$ be the probability that quantifies the uncertainty associated with the Seed-Idriss curve. Then the total probability of liquefaction will be the product of $P_{P G A}$ and $P_{\text {Seed. }}$ As $P_{\text {Seed }}$ is less than 1, it will always reduce the total probability of liquefaction failure and therefore, lengthen the liquefaction return period.

Just to illustrate the idea, let us assume that $P_{\text {Seed }}=0.5$, meaning that there is a fifty percent chance that liquefaction will occur based on the Seed-Idriss approach, then the total probability of liquefaction would be:

$$
P_{L i q}=P_{P G A} \times P_{\text {Seed }}=0.0004040 \times 0.5=0.0002020
$$

The liquefaction return period corresponding to that probability level will be 4950 years ( $1 \%$ in 50 years) which is twice the proposed return period in comparison to the NBCC 2005. 
Therefore, in keeping with the NBCC 2005 requirement on hazard level, one has to design for a liquefaction event with a return period of 2475 years. That is, one has to select a 1237-year $P G A$ for the above case to give a liquefaction return period of 2475 years (Salloum and Law 2006 and Law and Salloum 2006).

The assumption of $P_{\text {Seed }}=0.5$ is merely an example. In fact, as $P_{\text {seed }}$ is less than 1.0, the liquefaction return period is always longer than the $P G A$ return period. In the following, a method is proposed to meet the hazard level recommended by the NBCC 2005 by incorporating the probabilistic nature of both the Seed-Idriss curve and the $P G A$.

\subsection{PROPOSED METHOD}

Resolving the inconsistency should stem from quantifying all sources of uncertainties involved in the Seed-Idriss approach so that the Seed-Idriss liquefaction curves can be viewed within a probabilistic point of view rather than deterministic. Therefore, the liquefaction design boils down to combining the probabilistically-evaluated PGA (and in turn $C S R$ ) with the probabilistically-presented Seed-Idriss liquefaction curves. As a result, no inconsistency arises.

Fortunately, many researchers such as Liao et al. (1988), and Toprak et al. (1999), have recognized the uncertainties associated with the Seed-Idriss approach and tried to develop similar approaches in probabilistic forms. The most comprehensive study was done by Cetin (2000) and Cetin et al. (2002), where all field case histories employed in the 
previous studies were used in addition to other data sets in the development of a stochastic model. Moreover, the model has been developed within a Bayesian framework, which was the fundamental reason behind choosing Cetin's model over others. In the course of developing the model, all relevant uncertainties have been addressed, which include (a) measurement/estimation errors, (b) model imperfection, (c) statistical uncertainty, and (d) those arising from inherent variables. Contours for the probability of liquefaction values $P_{L}=5,20,50,80$, and $95 \%$ are presented in Figure 4-1. The equation used to draw the contours is:

$C R R\left(N_{1,60}, M_{W}, \sigma_{v}^{\prime}, F C, P_{L}\right)=\exp \left[\frac{\left(N_{1,60} \cdot(1+0.004 \cdot F C)-29.53 \cdot \ln \left(M_{W}\right)-3.70 \cdot \ln \left(\frac{\sigma_{v}^{*}}{P_{a}}\right)+0.05 \cdot F C+16.85+2.70 \cdot \Phi^{-1}\left(P_{L}\right)\right)}{13.32}\right]$

Eq. 4-2

where:

$N_{1,60}$ : the normalized standard penetration resistance

$F C$ : fines content

$M_{W}$ : earthquake magnitude

$\sigma_{v}^{\prime}:$ effective overburden stress

$P_{a}$ : atmospheric pressure

$\Phi^{-1}:$ inverse of the standard cumulative normal distribution

It should be emphasized that the study by Cetin (2000) and Cetin et al. (2002) was not done for the very problem the author is presenting in this research. However, the results from their studies can be used in the present study. 


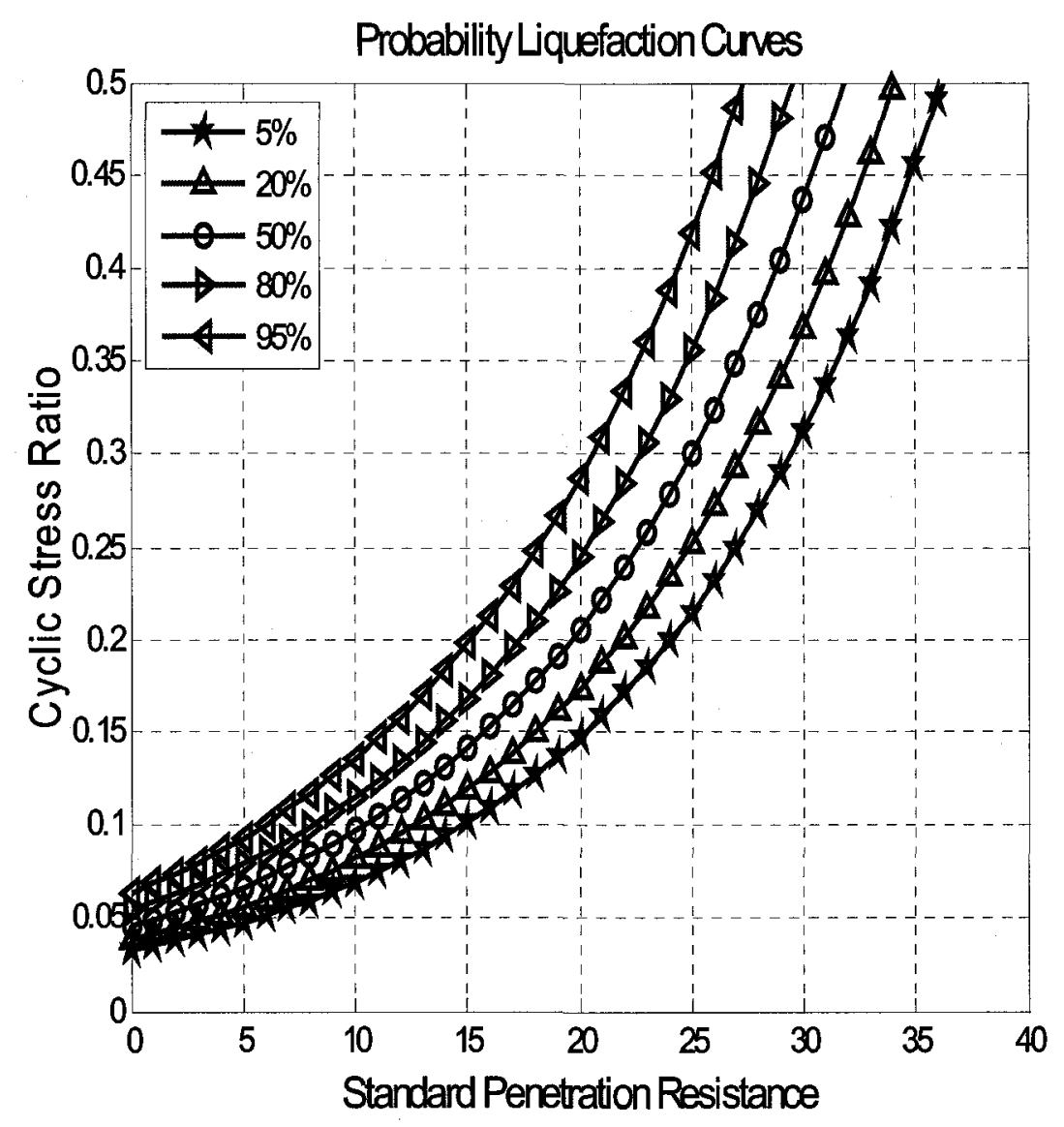

Figure 4-1: Contours of Liquefaction Probability (after Cetin 2002)

The uncertainty (probability) associated with the Seed and Idriss curves can be estimated with the aid of the liquefaction probability contours superimposed on the Seed-Idriss liquefaction curves (Figure 4-2). 


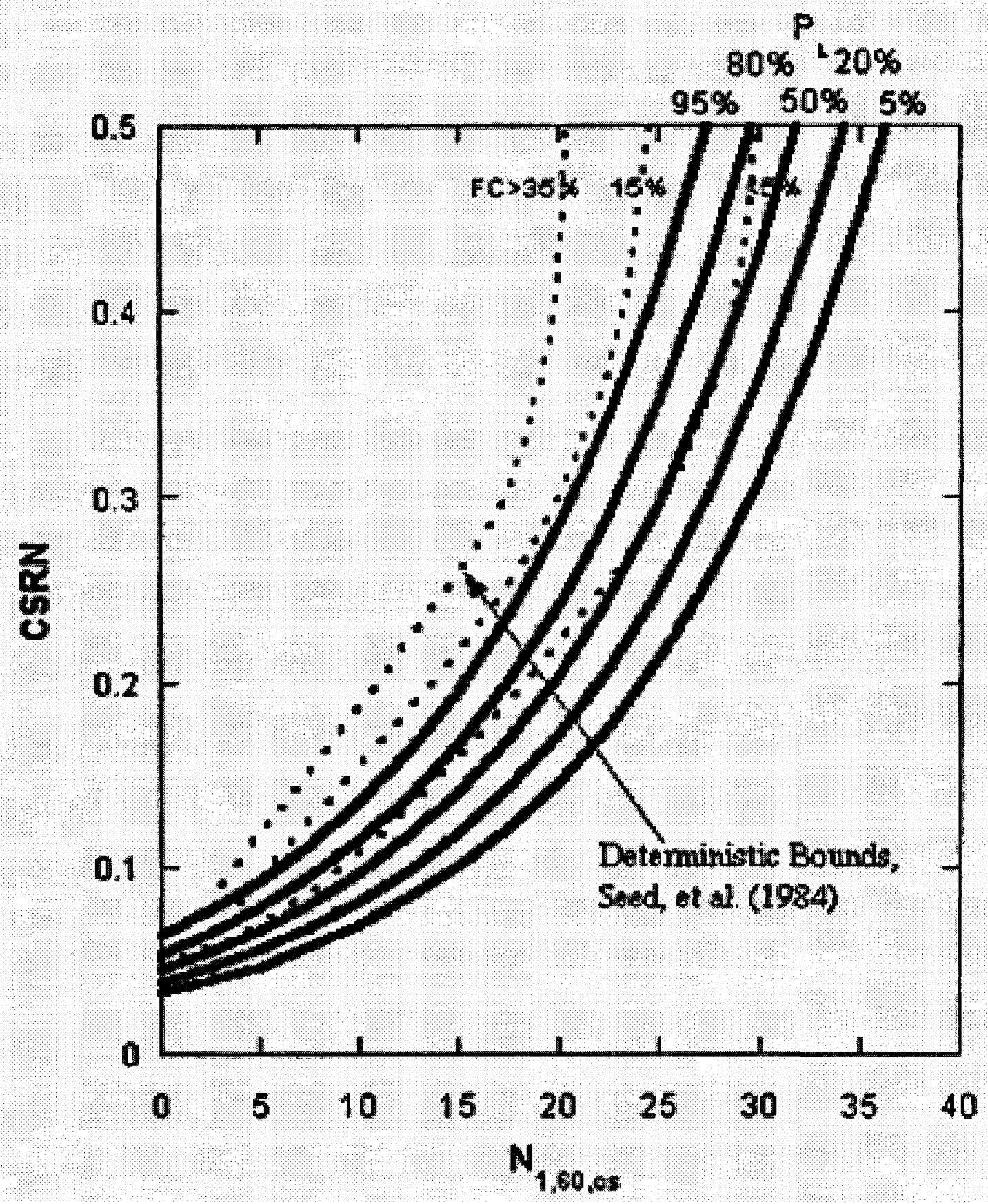

Figure 4-2: Probability of liquefaction curves and Seed-Idriss deterministic bounds (after Cetin 2000) 
In order to meet the NBCC 2005 seismic requirements, the probabilistically-determined ground motion and the probabilistically-represented Seed-Idriss curves can be combined and the solution is obtained with an iterative procedure as described in the following:

1. Start off with a $P G A$ that corresponds to 2475 -year return period, i.e., $P_{P G A}=$ 0.000404 .

2. Calculate the corresponding CSR using the Seed-Idriss equation.

3. With the aid of Figure 4-2, determine the probabilistic value, $P_{\text {Seed }}$, associated with the Seed-Idriss curve.

4. Calculate the liquefaction performance (return period) $T_{L i q}$, where: $T_{L i q}=\frac{1}{P_{P G A} \times P_{\text {Seed }}}$.

5. If $T_{L i q}$ computed in Step 4 is outside the range of $2475 \pm 100$ years, redo steps 2 to 4 using a new $P G A$ where $P_{P G A}=\frac{1}{P_{\text {Seed }}} \times 0.000404$, and $P_{\text {Seed }}$ is the probability value of the Seed-Idriss curve in the last iteration.

6. If $T_{L i q}$ computed in Step 4 lies within $2475 \pm 100$ years, the set of values computed in the last iteration ( $T_{L i q}, C S R, P_{P G A}$, and $\left.P_{S e e d}\right)$ are considered the solution that satisfies the NBCC 2005 seismic requirements.

It must be emphasized that the frequency of exceedance of the PGA is different from the frequency of occurrence of PGA. However, the difference of the two values tends to be negligible as the frequency of exceedance gets smaller. In addition, when carrying out the iterative procedure, the modal magnitude corresponding to a different hazard level may 
change when moving up and down on the hazard curve. However, it was observed that this change was small enough to be neglected.

\subsection{APPLICATION OF THE PROPOSED METHOD ON SELECTED CANADIAN CITIES}

The above procedure is carried out for selected Canadian cities for Site Classes $E$ and $D$. Shown in Figures 4-5 and 4-6 are the required $P G A$ values to cause liquefaction evaluated from this procedure compared with those computed as per NBCC 1995 and NBCC 2005. The comparison shows that there is a reduction in CSR based on the procedure proposed here while reaching the desired liquefaction performance of 2475year return period. 


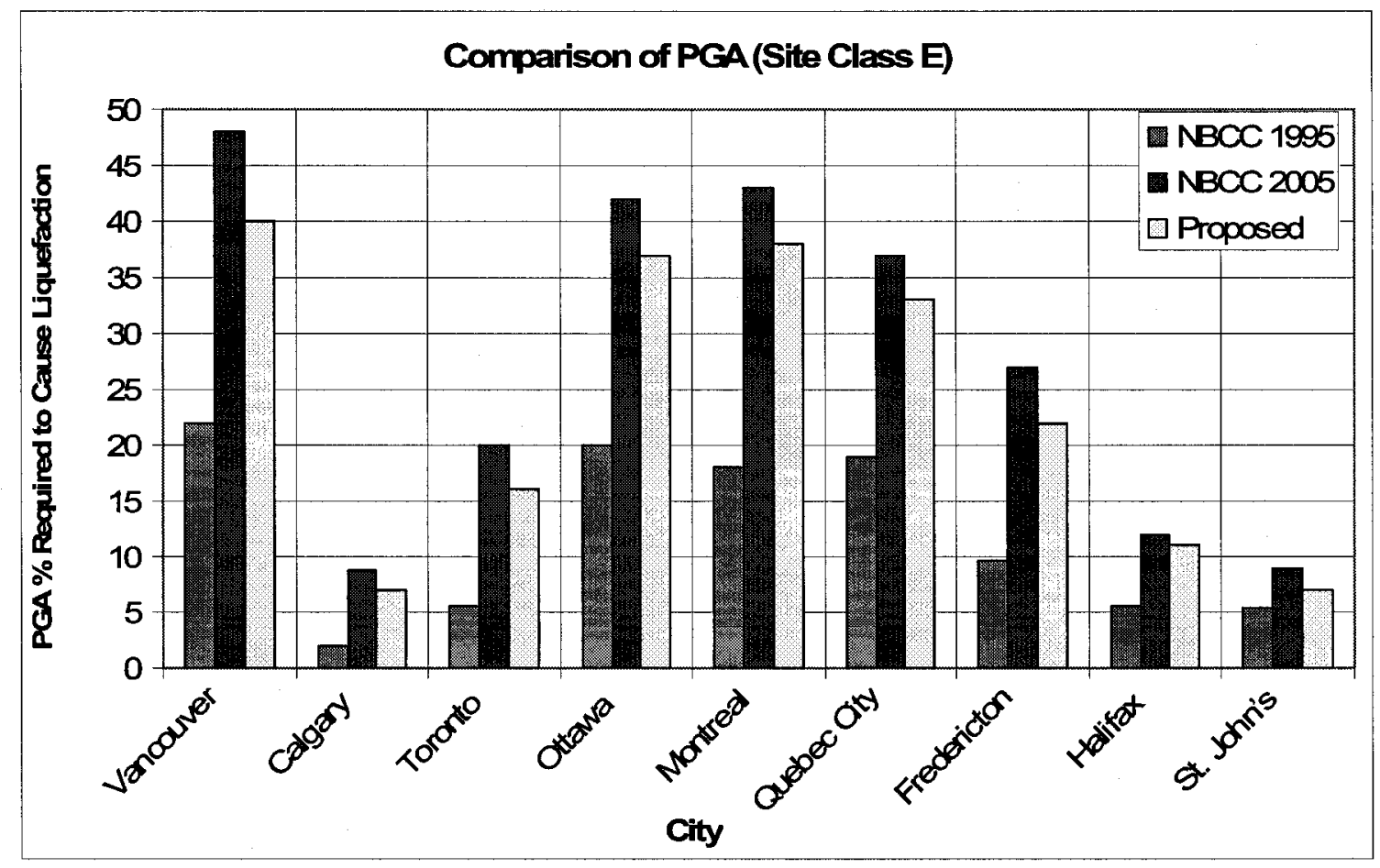

Figure 4-3: Comparison of PGA values required to cause liquefaction for NBCC editions and the proposed procedure for Site Class $\mathbf{E}$

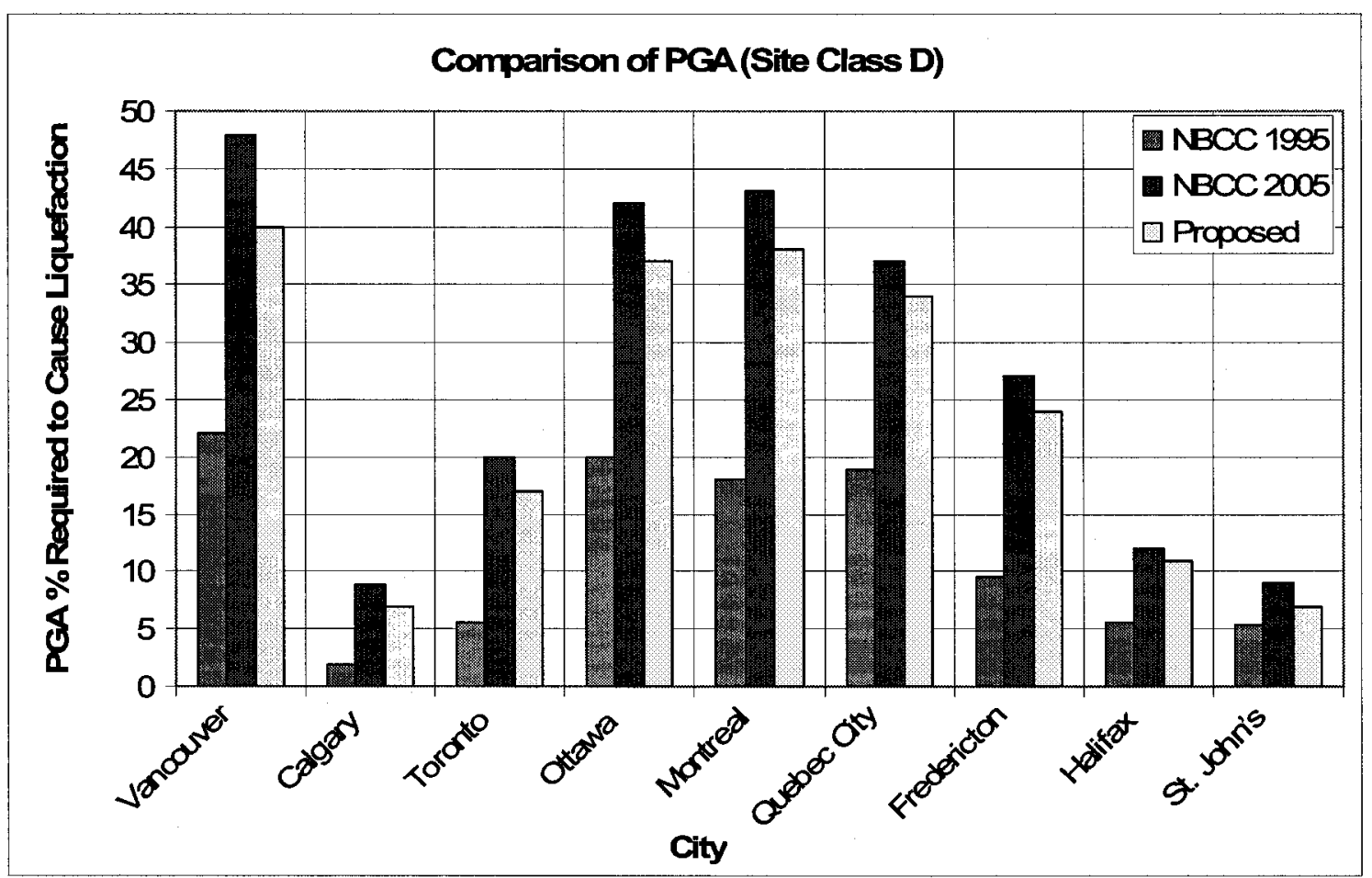

Figure 4-4: Comparison of PGA values required to cause liquefaction for NBCC editions and the proposed procedure for Site Class D 


\subsection{COMPARISON WITH THE NEHRP APPROACH (THE}

\section{AMERICAN APPROACH)}

The National Earthquake Hazard Reduction Program (NEHRP 1997 Edition) recommended that the design earthquake ground motion should be obtained using a reduction ratio $\left(\rho_{\mathrm{NEHRP}}\right)$ of $2 / 3(1 / 1.5)$ applied to the maximum considered earthquake ground motion. However, no compelling argument or explanation was given on why that value was chosen. It is most likely that the level was chosen based on accumulated experience. The NEHRP foundation factors are interpolated for the selected Canadian cities and summarized in Table 4-1 alongside with the NBCC 2005 foundation factors. As well the NEHRP and the proposed PGA reduction ratios ( $\rho_{\text {NEHRP }}$ and $\left.\rho_{\text {Proposed }}\right)$ and the corresponding $a_{\max }$ are shown in the same table, where $\rho_{\text {Proposed, }}$ is the ratio of the $P G A$ that gives a liquefaction return period of 2475 year to the 2475 -year PGA. Figures $4-5$ and 4-6 compare the $P G A$ values required to cause liquefaction in Site Classes $E$ and $D$ based on the proposed procedure and the NEHRP procedure. It can be seen that both approaches are in relatively good agreement for Toronto, Ottawa, and Montreal. However, the NEHRP approach generally underestimates the liquefaction performance. Using a similar procedure to the one proposed above, one can readily show that the NEHRP approach does not yield the desired performance recommended by the NBCC 2005 of 2475 years. 


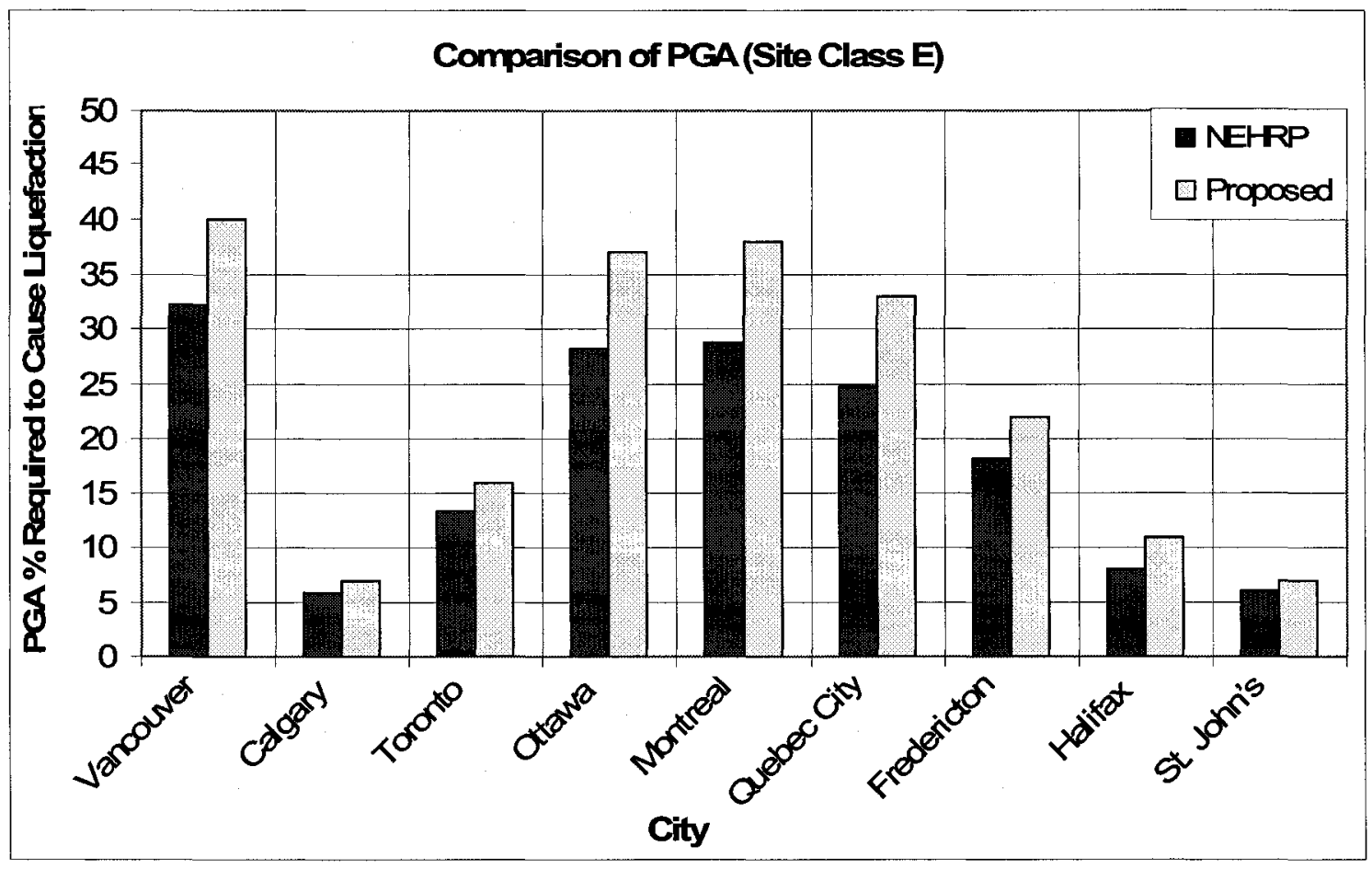

Figure 4-5: Comparison between NEHRP and the proposed approach for Site Class E

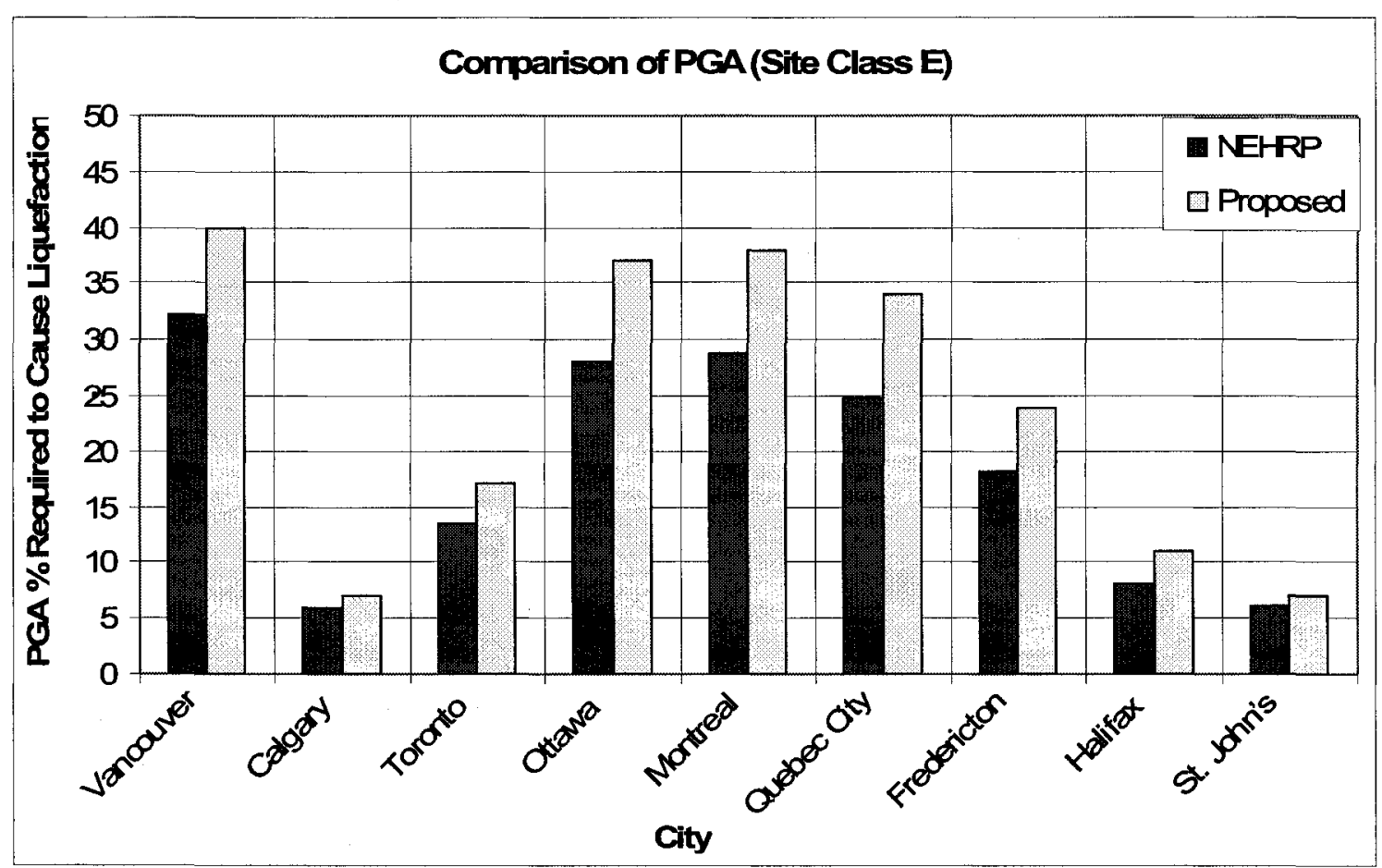

Figure 4-6: Comparison between NEHRP and the proposed approach for Site Class D 
Table 4-1: NEHRP and the proposed PGA reduction ratios and their corresponding $a_{\max }$ values

\begin{tabular}{|c|c|c|c|c|}
\hline \multirow{2}{*}{ City } & \multirow{2}{*}{ PGA\% } & \multirow{2}{*}{$\rho_{\text {NEHRP }}$} & \multicolumn{2}{|c|}{$\rho_{\text {Proposed }}$} \\
\cline { 4 - 5 } & & & $E$ & D \\
\hline Vancouver & 48 & 0.67 & 0.83 & 0.83 \\
\hline Calgary & 8.8 & 0.67 & 0.80 & 0.80 \\
\hline Toronto & 20 & 0.67 & 0.80 & 0.85 \\
\hline Ottawa & 42 & 0.67 & 0.88 & 0.88 \\
\hline Montreal & 43 & 0.67 & 0.88 & 0.88 \\
\hline Quebec City & 37 & 0.67 & 0.89 & 0.92 \\
\hline Fredericton & 27 & 0.67 & 0.81 & 0.89 \\
\hline Halifax & 12 & 0.67 & 0.92 & 0.92 \\
\hline St. John's & 9 & 0.67 & 0.78 & 0.78 \\
\hline
\end{tabular}

\subsection{SUMMARY AND CONCLUSIONS}

Conventionally, the ground motion in the seismic provisions of building codes is often used inconsistently with the Seed-Idriss approach for liquefaction designs. The inconsistency arises from combining the probabilistically-evaluated ground motion and the deterministically-based liquefaction curves compiled by Seed and Idriss in their approach. This inconsistency is particularly acute in the NBCC 2005 and has caused conservative liquefaction designs especially in low seismicity areas such as Toronto. A proposed method has been introduced, which takes advantage of the work done by Cetin 
(2000) and Cetin et al. (2002), to resolve the inconsistency by quantifying all sources of uncertainties inherent in the Seed-Idriss approach. The proposed procedure meets the liquefaction performance of 2475 years and results in eliminating unnecessary conservatism in the design process. Illustration of the proposed procedure has been carried out for selected Canadian cities and a comparison with the NEHRP approach suggests that NEHRP approach does not yield the desired performance recommended by the NBCC 2005. The new $P G A$ reduction ratios, $\rho_{\text {Proposed, }}$ can be used for design against liquefaction across Canadian cities to meet the uniform hazard level required by the NBCC 2005.

\subsection{COMPARISON WITH OTHER PROPOSED METHODS:}

Other researchers have proposed different methods to reduce the conservatism caused by the new seismic requirements introduced in the NBCC 2005. The following sections review these methods and a comparison with the author's method is made.

\subsubsection{Proposed methods by Finn and Wightman (2006):}

Two methods for resolving the conservatism in liquefaction designs due to the new return period ( 2475 years) suggested by the NBCC 2005 were proposed by Finn and Wightman (2006). The first method is based on a probabilistic hazard analysis using weighted magnitudes, which was first introduced by Idriss (1985), and the second method is a weighted magnitude procedure based on a magnitude deaggreagation, which was 
developed by Kramer and Mayfield (2005 and 2006), for the hazard level in NBCC 2005. The key point of the two methods is to find a compatible pair of earthquake magnitudes and accelerations as inputs in the Seed-Idriss equation for liquefaction designs and evaluations. Using the two proposed methods, factors of safety against liquefaction were calculated as a function of standard penetration number $\left(\mathrm{N}_{1}\right)_{60}$ for four Canadian cities that have different seismic environments, Vancouver, Toronto, Ottawa, and Montreal. Both methods yield comparable results for the calculated factors of safety and they logically solve the notion of the lost "representative" magnitude that should be used with the probabilistically-obtained peak ground acceleration as input for Seed's equation.

A brief explanation of the two methods is presented in the following sections.

\subsubsection{Weighted Magnitude Probabilistic Analysis:}

It was demonstrated by Idriss (1985) that the contributions of smaller magnitude earthquakes decrease as the acceleration level increases regardless of the recurrence model being used. Shown in Figure 4-7 is a plot of the cumulative contribution of magnitude at three acceleration levels for a site in Southern California. At a low acceleration level $(0.1 \mathrm{~g})$, about 80 percent is contributed by $m \leq 6.5$ earthquakes. At a high acceleration level $(0.5 \mathrm{~g})$, about 25 percent is contributed by $m \leq 6.5$. 


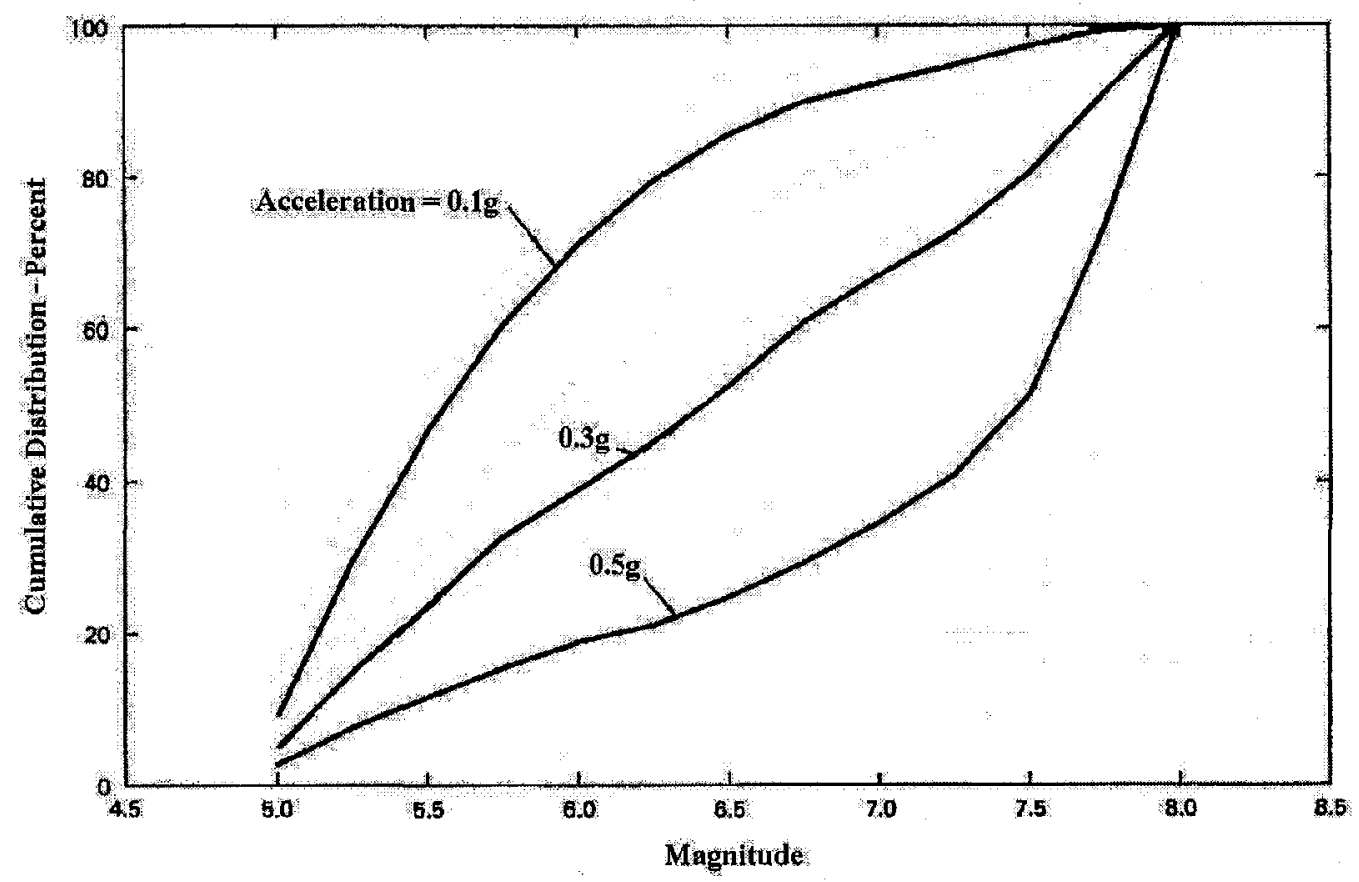

Figure 4-7: Cumulative Contribution of Magnitude at Various Levels of Acceleration at Site in Southern California (after Idriss 1985)

In a typical seismic hazard evaluation, equal weights are assigned to all earthquake magnitudes. However, as illustrated in Figure 4-7 above that different magnitudes contribute differently at various levels of ground shaking. Different magnitudes can produce identical levels of shaking, but the smaller the magnitude the shorter is the duration. Duration has a significant influence on the potential for soil failure due to earthquake loading conditions. Therefore, it is important that the difference in duration for various earthquake magnitudes be accounted for when the results are to be used for evaluating the potential for soil failure (liquefaction). A simple and direct way to achieve that is to use a weighting scheme that implicitly incorporates the duration of various magnitude earthquakes. 
Magnitude scaling factors (MSF) are developed by correlating between the number of cycles to cause liquefaction in sands and silty sands and the estimated average number of cycles associated with various magnitude earthquakes. The cyclic stress ratio required to cause liquefaction is based on (a) calculating the number of equivalent stress cycles from recorded accelerograms using 0.65 times the $P G A$ to represent an equivalent uniform stress, and (b) normalizing the cyclic test results with respect to 15 cycles, which is considered representative of magnitude 7.5. Various MSF have been developed over the last four decades. Table 4-2 shows the MSF(s) that have been used recommended by Idriss (as reported by Youd et al. (2001)) which were used by Finn and Wightman (2006) in their analysis.

Table 4-2: Magnitude Scaling Factors (Yould et al., 2001)

\begin{tabular}{|c|c|c|c|c|c|c|}
\hline $\mathbf{M}$ & 5.5 & 6.0 & 6.5 & 7.0 & 7.5 & 8.0 \\
\hline MSF & 2.2 & 1.76 & 1.44 & 1.19 & 1.0 & 0.84 \\
\hline
\end{tabular}

The tabulated values presented above are based on the following equation (Youd et al. 2001):

$$
M S F_{M}=\frac{10^{2.24}}{M^{2.56}}
$$

The above tabulation indicates, for example, that the stress level from a magnitude 6 earthquake must be about 76 percent higher than that from a magnitude of 7.5 earthquake 
in order to induce the same damage. Since stress is directly proportional to acceleration, the same ratio can be applied to peak acceleration (Idriss 1985). Therefore, the inverse of this ratio is representative of the weight of peak accelerations due to a magnitude 6 earthquake relative to peak accelerations due to a magnitude 7.5 earthquake. That is, the weight of $m=6$ is $1 / 1.76=0.568$ relative to $m=7.5$. Similarly, the weight of $m=8.5$ is $1 / 0.84=1.19$ relative to $m=7.5$.

The cumulative contributions of various magnitudes at acceleration levels of $0.1 \mathrm{~g}, 0.3 \mathrm{~g}$, and $0.5 \mathrm{~g}$ at the same site (see above) incorporating Equation 4-3 is shown in Figure 4-8.

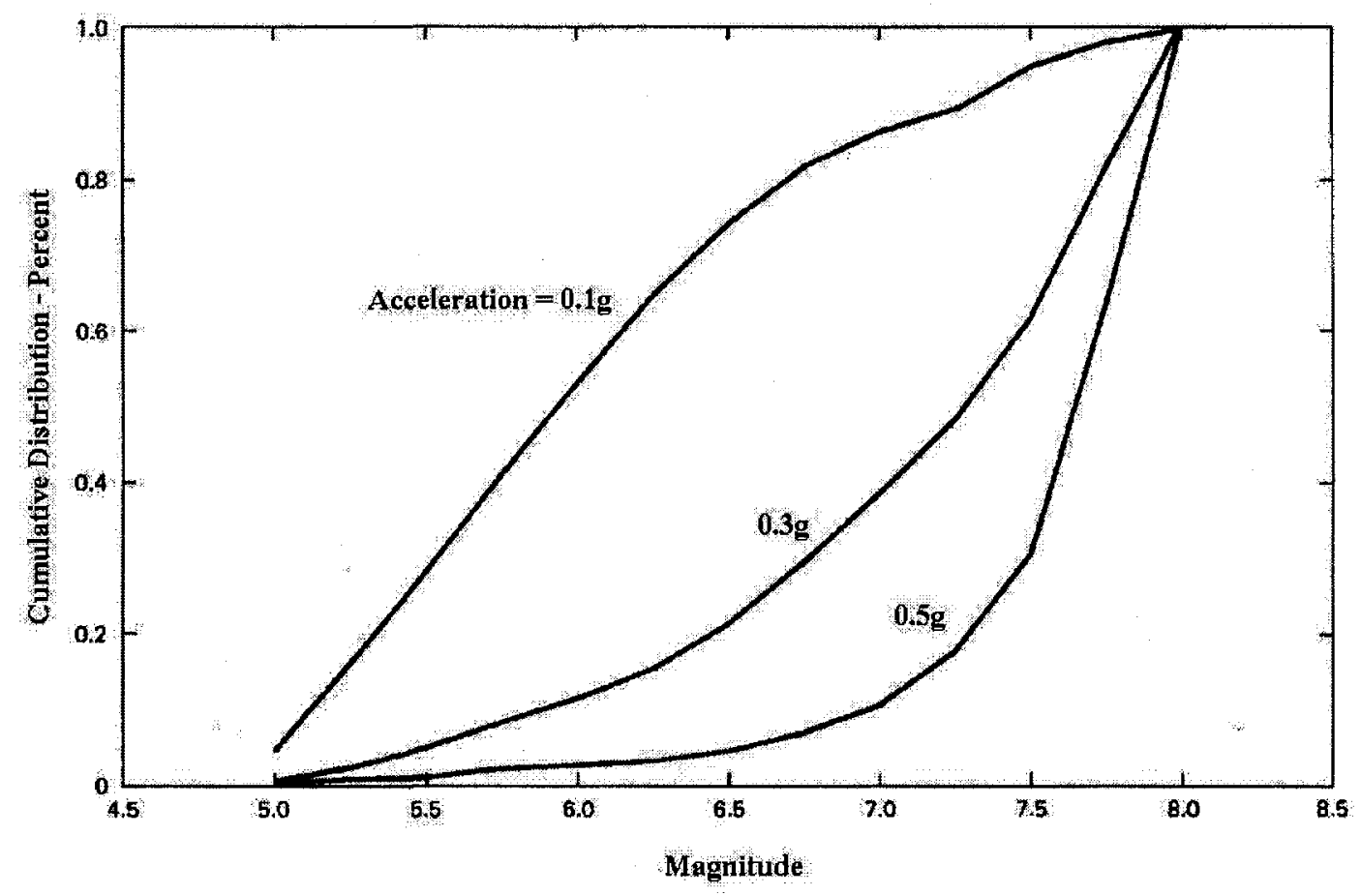

Figure 4-8: Cumulative Contribution of Magnitude at Various Levels of Acceleration at Site in Southern California in which Magnitude Contributions are Weighted with Respect to $m=7.5$ (after Idriss 1985) 
Comparing Figures 4-7 and 4-8 reveals that the contributions of small magnitudes are significantly reduced when the weighting scheme is used, especially at the higher acceleration levels.

Liquefaction hazard curves can then be obtained in a similar way to that of seismic hazard curves with minor modification. The recurrence relationship used in the seismic hazard analysis is multiplied by the inverse of the magnitude scaling factor equation, all the other steps in the probabilistic hazard evaluation remain the same.

Finn and Wightman (2006) conducted the weighted magnitude probabilistic analysis and produced the seismic hazard curves, weighted for an earthquake magnitude of 7.5 , for selected Canadian cities. From the obtained seismic hazard curves, a peak ground acceleration corresponding to the return period recommended by the NBCC 2005 was selected for the purpose for evaluating liquefaction potential. As noted above that the earthquake magnitude used with the selected acceleration is 7.5. The weighted probabilistic analysis can also be done for other normalizing magnitude, however, the appropriate magnitude weighting factor should be applied again when calculating liquefaction resistance using Seed-Idriss curves. Table 4-3 lists the magnitudeacceleration pairs proposed by Finn and Wightman (2006).

Table 4-4 compares the results of Finn and Wightman with the proposed method. It should be noted that the PGA values of the proposed method should first be divided by the magnitude scaling factor so that both accelerations are based on the 7.5 magnitude. 
Table 4-3: Proposed Magnitude-Acceleration Pairs by Finn and Wightman (2006)

\begin{tabular}{|c|c|c|}
\hline \multirow{2}{*}{ City } & \multicolumn{2}{|c|}{$\begin{array}{c}\text { Magnitude-Acceleration } \\
\text { Pair }\end{array}$} \\
\cline { 2 - 3 } & $\mathrm{M}_{\mathrm{w}}$ & PGA \\
\hline Vancouver & 7.5 & $0.32 \mathrm{~g}$ \\
\hline Toronto & 7.5 & $0.10 \mathrm{~g}$ \\
\hline Ottawa & 7.5 & $0.25 \mathrm{~g}$ \\
\hline Montreal & 7.5 & $0.26 \mathrm{~g}$ \\
\hline
\end{tabular}

Table 4-4: Comparison of Finn \& Wightman PGA with the Author's

\begin{tabular}{|c|c|c|}
\hline \multirow{2}{*}{ City } & \multicolumn{2}{|c|}{ Peak Ground Acceleration (g\%) } \\
\cline { 2 - 3 } & Finn \& Wightman (2006) & Proposed \\
\hline Vancouver & 32 & 34 \\
\hline Toronto & 10 & 9 \\
\hline Ottawa & 25 & 20 \\
\hline Montreal & 26 & 21 \\
\hline
\end{tabular}

\subsubsection{Magnitude Deaggregation Procedure:}

In this method the PGA deaggregation matrix is obtained at the return period recommended by the NBCC 2005. The deaggregation matrix is a 3-D bar plot where it gives the contributions to hazard in terms of earthquake magnitude and distance. It can also be viewed as a 2-D plot shown in Figure 4-9. For instance, the total contribution per magnitude bin is obtained by summing the distance contributions, and the total contribution per distance bin is obtained by summing the magnitude contributions (Kramer and Mayfield, 2005 and 2006). 


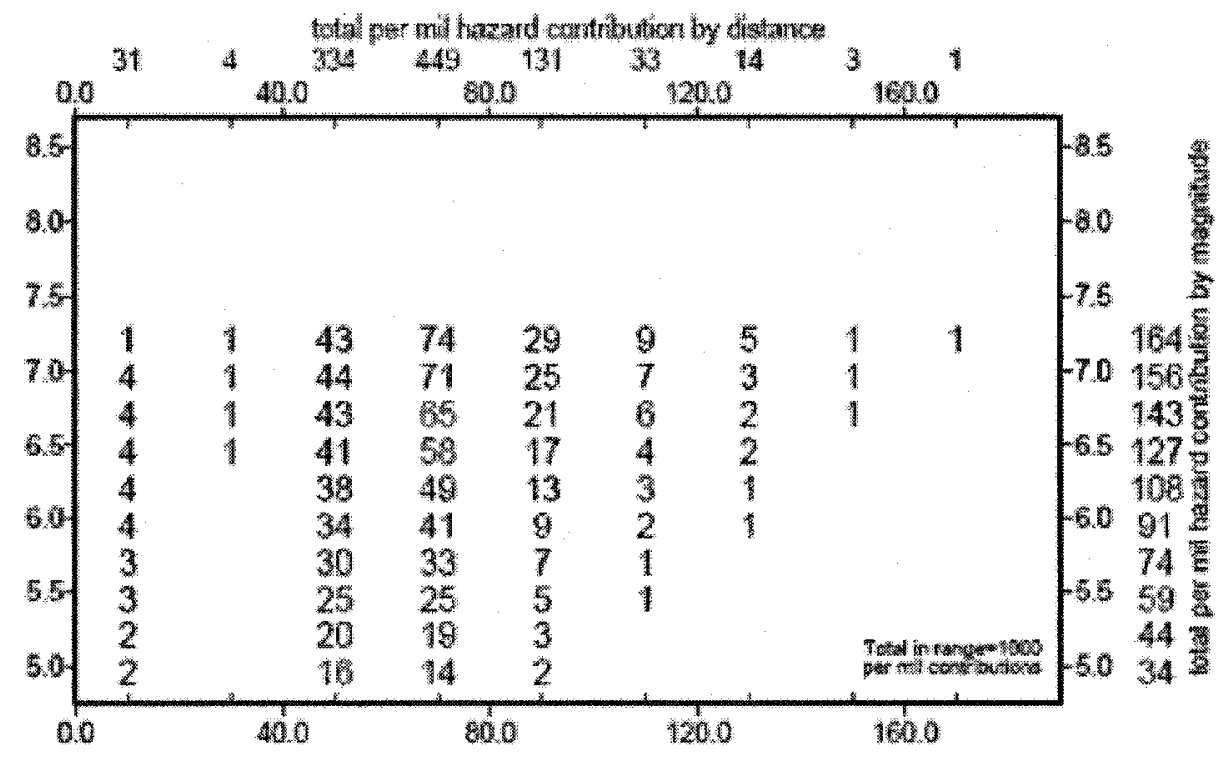

Figure 4-9: M-R Deaggregation Matrix for PGA in Vancouver (Finn and Wightman 2006)

Factor of safety against liquefaction is calculated at the acceleration level recommended by the code (at $2 \% / 50$ yrs) for each binned magnitude and then multiplied by the contribution of the magnitude to the total hazard. Then, by summing all the factors of safety, the global factor of safety is obtained. 


\section{Chapter 5}

\section{A FULLY PROBABILISTIC APPROACH FOR}

EVALUATION OF SOIL LIQUEFACTION

\subsection{INTRODUCTION}

A fully probabilistic approach for evaluating soil liquefaction is presented in this chapter. Unlike other probabilistic studies of soil liquefaction such as Liao et al. (1988), Moss (2003), and Juang et al. (2001), the probability of soil liquefaction in this study considers both the statistical distributions of soil and seismic parameters as well as the spatial and temporal distributions of the seismic parameters. The probability of liquefaction considering the statistical distributions of soil and seismic parameters was evaluated via a reliability-based model that incorporates the seismic energy approach developed by Law et al. (1990) for evaluating soil liquefaction. This energy approach comprises four parameters: the earthquake magnitude, the hypocentral distance of earthquake, the standard penetration resistance of soil, and the effective overburden stress. Each of these parameters is modeled as a random variable characterized by a certain statistical distribution. The probability of the seismic parameters occurrences were estimated based on the spatial distribution of source-to-site distance and the temporal distribution of earthquakes occurrences. Figure $5-1$ is a flowchart of the general methodology used to arrive at the probability of liquefaction failure. 


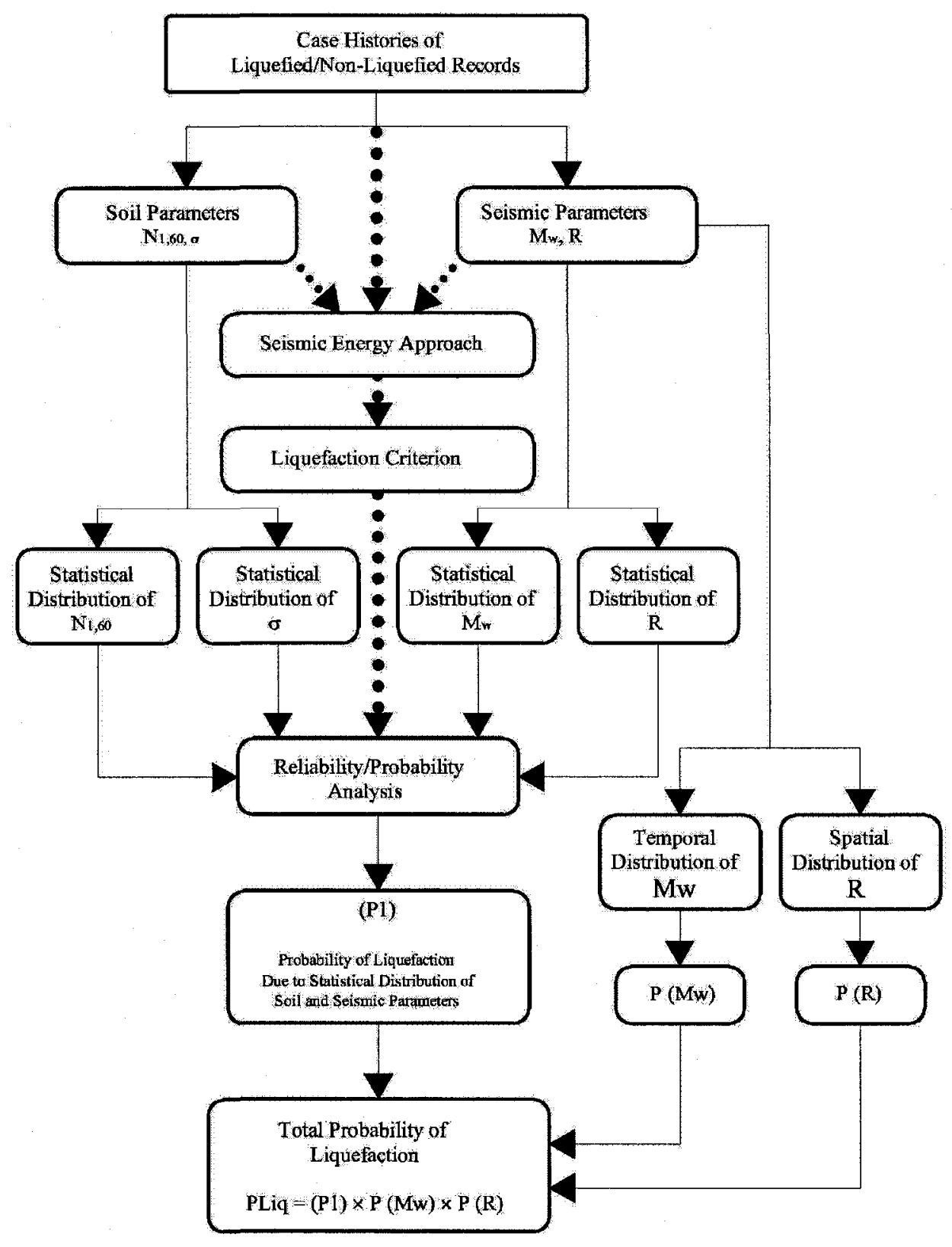

Figure 5-1: Flowchart of the Proposed Methodology 


\subsection{THE ENERGY APPROACH}

The energy method is based on the dissipated seismic energy. During an earthquake, a large amount of energy is released and propagates from the source of the earthquake in several forms of seismic waves such as body waves, shear waves and surface waves. Part of this seismic energy will be dissipated in remote soil deposits causing the pore water pressure to rise. Liquefaction is triggered once the excess pore water pressure reaches a level equal the initial effective confining stress.

The use of dissipated energy as a measure of liquefaction resistance offers a number of advantages. Dissipated energy is related to both cyclic stresses and cyclic strain. It can be related to inherently stochastic earthquake ground motions in a way that methods based on peak ground motion parameters alone cannot. It is a scalar quantity and can be related to fundamental earthquake parameters (Kramer 1996). Moreover, the amount of dissipated energy per unit volume for liquefaction is independent of loading form (Davis and Berrill 1982).

The following section explains the energy-based method used in this research. It is chosen because of its simplicity among other existing energy methods such as Davis and Berrill 1982 and Trifunace 1995. 


\subsubsection{The Energy Approach by Law et al. 1990}

Law et al. (1990) have shown that a unique relation exists between the dissipated energy during cyclic loading and the excess pore pressure that eventually leads to liquefaction failure. This unique relation has been combined with an energy attenuation equation to develop a criterion for defining the liquefaction potential of a site.

Mathematically, this can be expressed as:

$$
\frac{\Delta u}{\sigma_{0}^{\prime}}=\alpha W_{N}^{\beta}
$$

Eq. 5-1

where $\sigma_{o}^{\prime}=$ initial effective confining stress

$W_{N}=$ dissipated energy per unit volume expressed in a dimensionless form $\Delta u=$ excess pore water pressure $\alpha$ and $\beta$ are experimentally determined constants

The total seismic energy released during an earthquake is often expressed as (Gutenberg and Richter 1956):

$$
\log E=11.8+M_{S}
$$

Eq. 5-2

where $E$ is expressed in ergs and $M_{s}$ is the surface wave magnitude. This relationship is also applicable to moment magnitude as well (Kanamori 1977 and Hanks and Kanamori 1979): 


$$
\log E=1.5 M_{W}+11.7
$$

Eq. 5-3

where $E$ is expressed in ergs, or

$$
\log E=1.5 M_{W}+4.7
$$

Eq. 5-4

where $E$ is expressed in joules.

Due to dispersion, attenuation and geometric damping, only a fraction of that energy will be arriving at a remote site from the earthquake. Studies by Murphy and O'Brien (1977), Hasegawa et al. (1981), and Nuttli (1979) have shown that the energy arriving at a site is inversely proportional to a power of the distance, $R$, between the source and the site and is expressed as:

$$
E(R)=\theta \frac{E}{R^{B}}
$$

where $\theta$ is assumed to be a constant used to represent the correlation and $B$ is an attenuation coefficient dependent on the properties of the rock through which the seismic waves travel.

Estimation of the attenuation coefficient $(B)$ is done by plotting, on a logarithmic scale, the square of the peak ground velocity (PGV) for a given region against the distance, for various magnitudes of earthquake, the average slope of the curves will then be equal to the value of $B$ for that region. This approach stems from the theory that the energy is directly proportional to the square of the velocity. The value of $B$ varies from 2.5 to 5.0. Atkinson and Boore (1995) have shown that for Eastern North America the value of $B$ is about 2 which is equal to the $B$ value for California based on studies by Atkinson and 
Silva (2000). For the Canadian West coast the attenuation is high with $B=4.3$, whereas, for Eastern Canada $B=3.2$ (Law et al. 1990).

In developing the energy method for general use, Lock (2001) has shown that the value of $B$ can be chosen as equal to 2. Therefore, a general form for the seismic energy arriving at a site can be written as:

$$
E(R)=\theta_{1} \frac{E}{R^{2}}
$$

Eq. 5-6

Substituting Eq. 5-4 into the above equation yields:

$$
E(R)=\theta_{1} \frac{\left(10^{1.5 M_{w}+4.7}\right)}{R^{2}}
$$

or

$$
E(R)=\theta_{2} \frac{\left(10^{1.5 M_{w}}\right)}{R^{2}}
$$

where $\theta_{2}$ is once again, a constant used to represent the correlation.

A normalized seismic energy concept is introduced by dividing the seismic energy by the vertical effective in-situ stress to describe the energy arriving at a site in a dimensionless quantity at the point where liquefaction potential is assessed. This results in dimensionless $E(R)$ :

$$
E(R)=\theta_{3} \frac{\left(10^{1.5 M_{w}}\right)}{\sigma_{v}^{\prime} R^{2}}
$$


where $R$ is measured in $\mathrm{km}$ and $\theta_{3}$ has a dimension of $\mathrm{m}^{-1}$ (Lock 2001).

With the constant $\theta_{3}=1$, based on regression analysis from earthquakes in the West coast of U.S.A., Japan, China and Chile, Law et al. (1990), the seismic energy arriving at a site $R$ away from the source of an earthquake is given as:

$$
S=\frac{\left(10^{1.5 M_{w}}\right)}{\sigma_{v}^{\prime} R^{2}}
$$

The seismic energy dissipated in the soil deposit $W_{R}$ is a function of the seismic energy arriving at a site and the characteristics of the soil deposits and can now be expressed as (Law et al. 1990):

$$
\mathrm{W}_{\mathrm{R}}=\mathrm{F}\left(\mathrm{S},\left(\mathrm{N}_{1}\right)_{60} \mathrm{cs}\right)
$$

Eq. 5-11

where $\left(N_{l}\right)_{60 \_c s}$ is the normalized and corrected standard penetration resistance. It is used here to represent soil characteristics.

Now substituting the above equation into Eq. 5-1 yields:

$$
\frac{\Delta \mathrm{u}}{\sigma_{\mathrm{ov}}^{\prime}}=\alpha\left[\mathrm{F}\left(\mathrm{M}, \mathrm{R},\left(\mathrm{N}_{1}\right)_{60} \mathrm{cs}\right)\right]^{\beta}
$$

Eq. 5-12 
Liquefaction failure is defined here as the condition when the excess pore pressure is equal to the initial effective confining stress, i.e., when $\Delta u / \sigma_{0 v}^{\prime}=1$. Expressed in energy terms, the condition of liquefaction failure is therefore, given by:

$$
\left.\alpha\left[\mathrm{F}\left(\mathrm{M}, \mathrm{R},\left(\mathrm{N}_{1}\right)_{60 \_c s}\right)\right]\right]^{\beta} \geq 1.0
$$

Eq. 5-13

The left hand side of the above equation can be split into two functions, one representing the aspect of seismic energy and the other representing the soil characteristics. The functions are the seismic energy function $S$ and the liquefaction resistance function, $\eta\left(\left(N_{1}\right)_{60 \_c s}\right)$. Then the liquefaction criterion can now be written as:

$$
\frac{\mathrm{S}(\mathrm{M}, \mathrm{R})}{\eta\left(\left(\mathrm{N}_{1}\right)_{60} \mathrm{cs}\right)} \geq 1.0
$$

The $\eta$ function, representing soil characteristics, will be evaluated in the following section based on regression analysis of previous liquefaction data as we shall see.

\subsubsection{Case History Analysis}

A total of 363 independent liquefied and non-liquefied cases have been systematically compiled and listed in Appendix B. Among them, there are 160 liquefied cases and 203 non-liquefied cases. These cases are from 30 different earthquakes in more than 10 countries around the world. 
The period of time covering these liquefied and non-liquefied events is from 1891 to 1999. For each site the following information was gathered: earthquake magnitude $M_{w}$, hypocentral distance or closest distance to the fault of the site $R$, depth of soil studied $D$, depth of ground water table $D_{w}$, standard penetration resistance $N$, fines content $(F C)$ and identification of liquefaction occurrence. The $N$ value was corrected for resistance, fines content and the over burden effective pressure so that $\left(N_{1}\right)_{60}$ cs could be obtained.

For every case, the seismic energy was calculated using Eq. 5-10, then a plot of the seismic energy $S$ vs. $\left(N_{1}\right)_{60 \_c s}$ was made based on all the compiled data (Fig. 5-2) . Each solid circle represents a case of liquefaction failure, while each circle represents a nonliquefied site. A straight line is drawn to define the boundary separating the liquefied and non-liquefied sites. This line, therefore, mathematically corresponds to the equation for the condition of liquefaction and can be written as:

$$
S=3.49\left(N_{1,60}\right)_{c s}^{7.8 *} * 10^{-4}
$$

It should be noted that a seismic energy threshold can also be established below which liquefaction will not occur.

It should also be noted that the Cone Penetration Test (CPT) is more common nowadays than the SPT especially for seismic designs. However, there exist several relationships that correlate the SPT and the CPT values (Robertson and Wride 1997). 


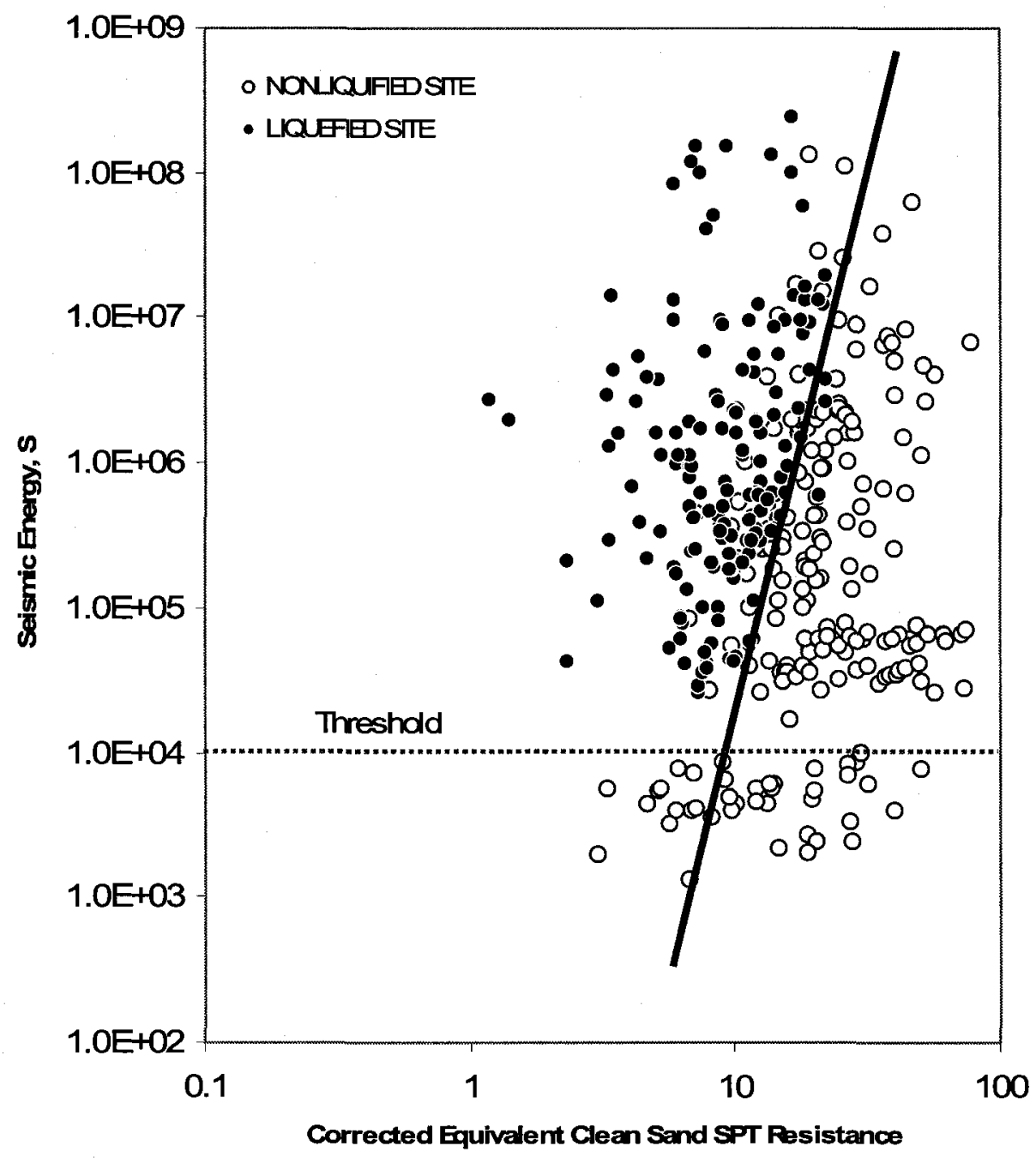

Figure 5-2: Liquefied and Non-liquefied sites alongside with the Corrected SPT and the Seismic Energy arriving at the each site 


\subsection{PROBABILITY/RELIABILITY ANALYSIS}

The reliability analysis can now be conducted as the liquefaction criterion has been defined. Carrying out the probability/reliability analysis comprises the following steps: development of the limit state and performance functions, assigning proper statistical distributions to the random variables that constitute the performance function, examining the correlation among the random variables, and finally calculating the reliability index and the corresponding probability of failure (liquefaction). The following sections will examine the aforementioned steps in more detail after a brief definition of the reliability index.

\subsubsection{Reliability Index}

The margin of safety, $M$, or the factor of safety, FS, are usually the conventional choices when assessing the risk of failure in civil engineering. Both measures are defined in terms of a system capacity, $C$, and demand, $D$. The margin of safety is expressed as:

$$
M=C-D
$$

Eq. 5-16

and the factor of safety is expressed as:

$$
F S=\frac{C}{D}
$$

Eq. 5-17 
However, as the capacity and demand are usually uncertain quantities, so these variables have mean or expected values, variances, and covariances and some other statistical descriptions.

From the elementary definitions of mean and variance, it follows that regardless of the probability distributions of $C$ and $D$ the mean value of the margin of safety $(M)$ is (Harr 1987):

$$
\mu_{M}=\mu_{C}-\mu_{D}
$$

Eq. 5-18

and the variance of $M$ is:

$$
\sigma_{M}^{2}=\sigma_{C}^{2}+\sigma_{D}^{2}-2 \rho_{C D} \sigma_{C} \sigma_{D}
$$

Eq. $5-19$

where $\rho_{C D}$ is the coefficient of correlation between $C$ and $D$.

The reliability index, $\beta$, is then defined as:

$$
\beta=\frac{\mu_{M}}{\sigma_{M}}=\frac{\mu_{C}-\mu_{D}}{\sqrt{\sigma_{C}^{2}+\sigma_{D}^{2}-2 \rho_{C D} \sigma_{C} \sigma_{D}}}
$$

which expresses the distance of the mean margin of safety from its critical value $(M=0)$ in units of standard deviation. If the load and resistance are uncorrelated, the correlation coefficient is zero, and: 


$$
\beta=\frac{\mu_{M}}{\sigma_{M}}=\frac{\mu_{C}-\mu_{D}}{\sqrt{\sigma_{C}^{2}+\sigma_{D}^{2}}}
$$

When the reliability index, $\beta$, is expressed in terms of factor of safety, $F S$, the above equation becomes (Baecher and Christian 2003):

$$
\beta=\frac{E[F S]-1}{\sigma_{F S}}
$$

Calculations of the reliability index are more difficult when it is expressed in terms of the factor of safety because $F S$ is the ratio of two uncertain quantities while $M$ is their difference.

Figure 5-3 shows plots of typical probability distributions of $C$ and $D$. Figure 5-4 shows the resulting probability distribution of $M$. The probability of failure is the probability that $M$ is less than 0.0 , which is the shaded area in the figure. 


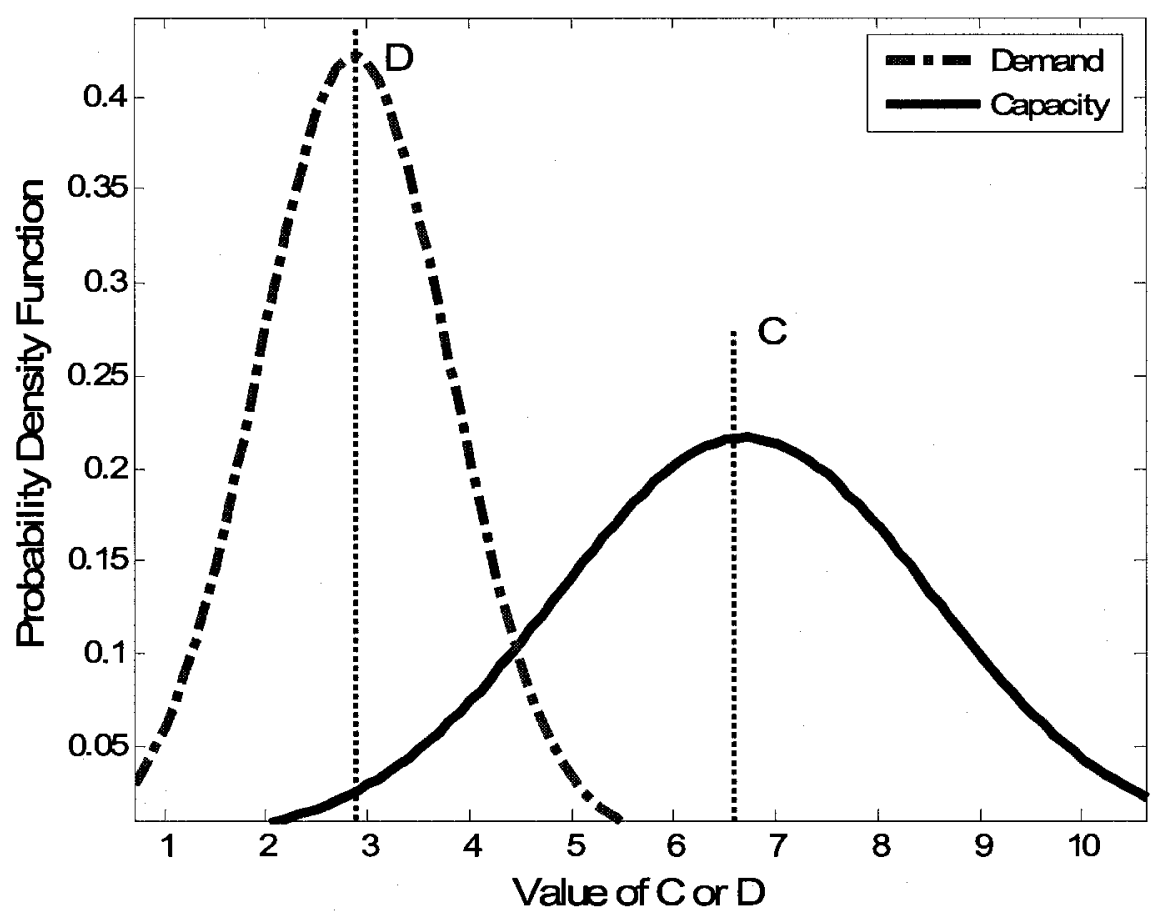

Figure 5-3: Probability densities of typical capacity and demand

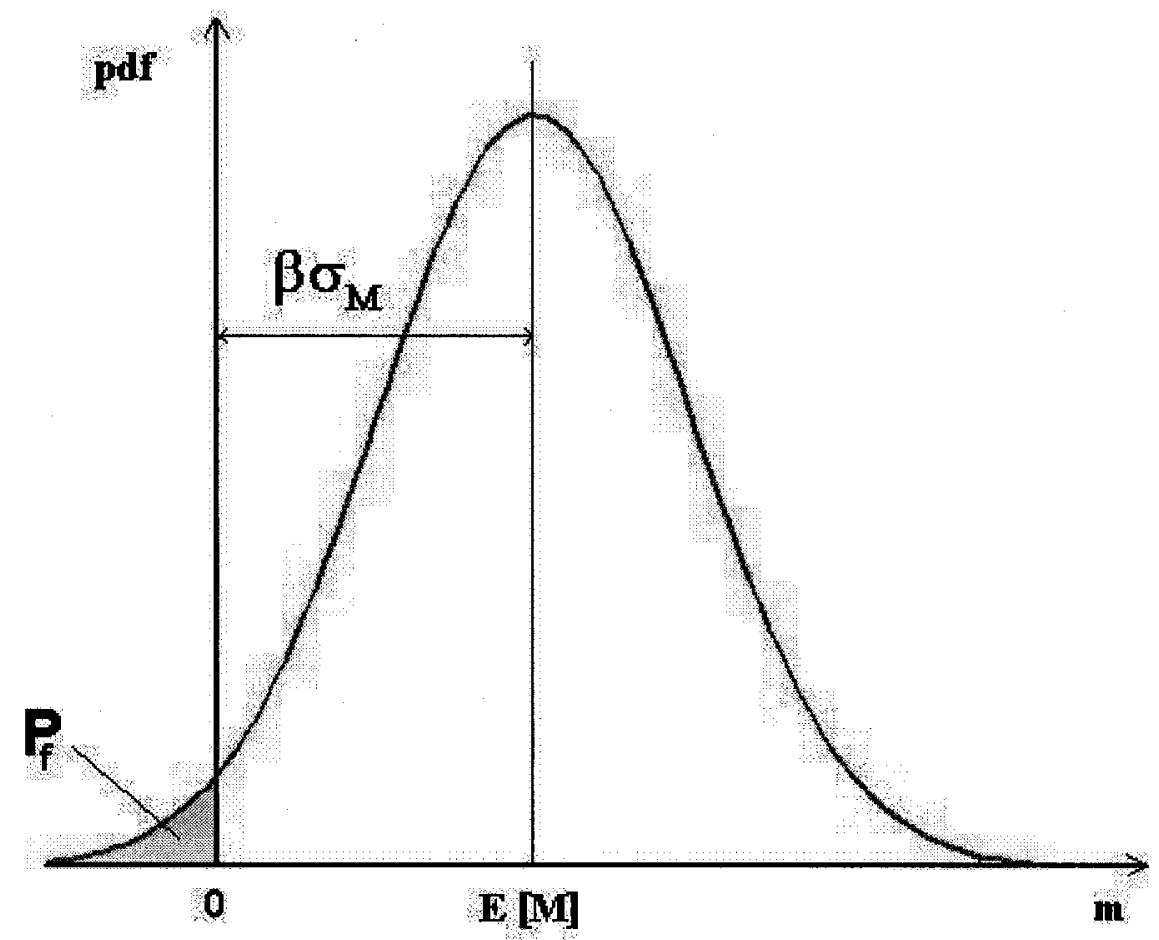

Figure 5-4: Probability density function of the margin of safety $M$ (The shaded area is the probability of failure) 


\subsubsection{Development of limit state and performance functions}

The limit state function is the surface that separates the safe region (non-liquefaction) from the failure region (liquefaction). For the calculation of the reliability of a system, that state must be defined in terms of capacity $C$ and demand $D$. These quantities are, in general, functions of several random variables $\left\{X_{D}\right\}$ and $\left\{X_{C}\right\}$ associated with $D$ and $C$ respectively. The limit state is then described in terms of a performance function, $G(X)=$ $f($ Capacity, Demand).

The limit state function is defined as follows:

Consider a site $A$ as shown in Figure 5-5. We can define the margin of safety against liquefaction for that site as:

$$
M=N_{\text {Capacity }}-N_{\text {Demand }}
$$

Eq. 5-23

where

$N_{\text {Capacity }}$ is the corrected standard penetration resistance at the site, and

$N_{\text {Demand }}$ is the minimum required standard penetration resistance that the soil deposit at the site must have in order not to liquefy. 


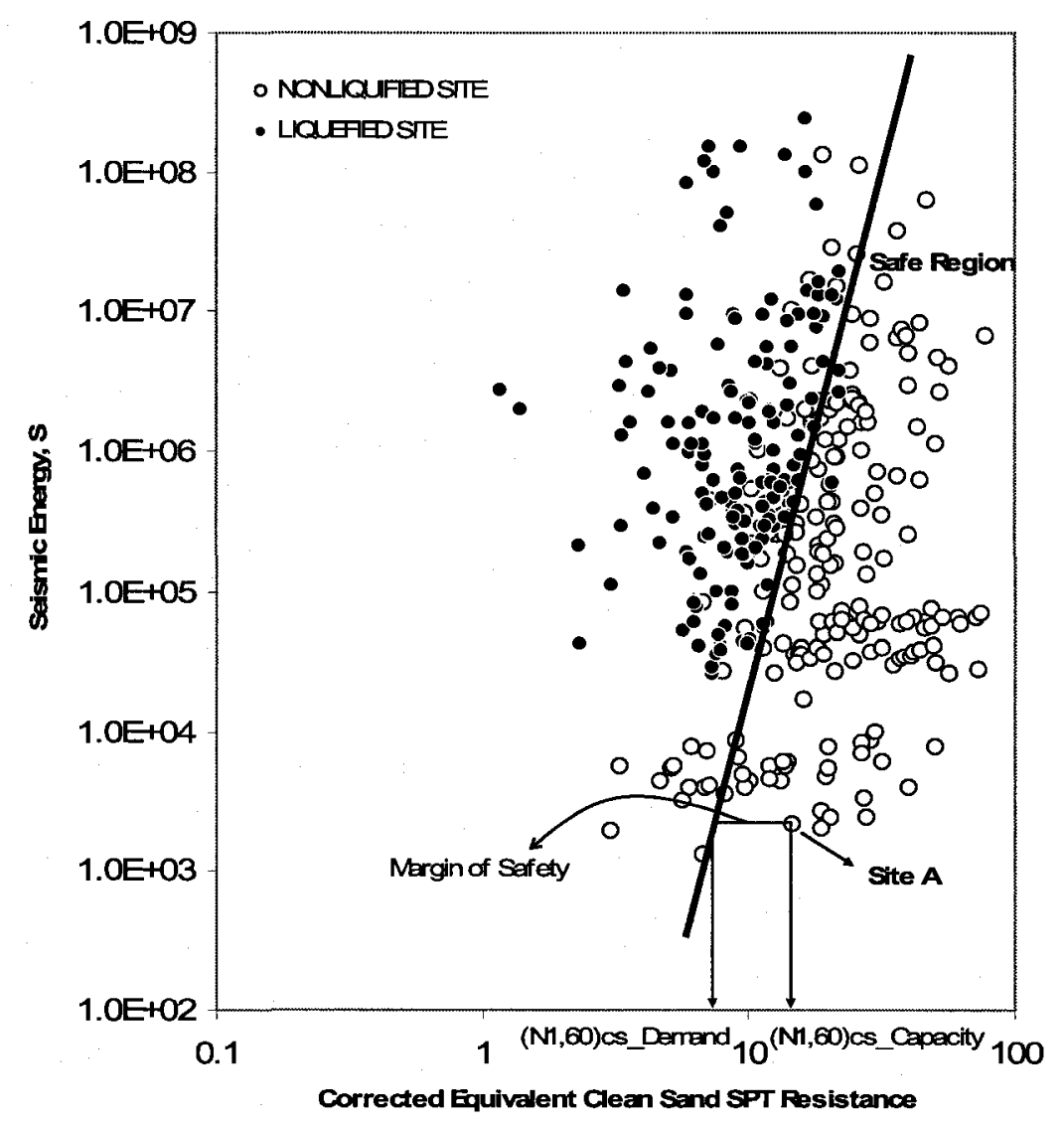

Figure 5-5: Illustration shows the development of the limit state function

The $N_{\text {Demand }}$ is calculated based on the seismic energy dissipated at the site, Eq. 5-15. Thus:

$$
N_{\text {Demand }}=\left(\frac{S}{3.49 \times 10^{-4}}\right)^{\frac{1}{7.8}}
$$

Substituting Eq. 5-10 into Eq. 5-24 yields: 


$$
N_{\text {Demand }}=\left(\frac{10^{1.5 \cdot M_{w}}}{3.49 \times 10^{-4} \times \sigma_{v}^{\prime} \times R^{2}}\right)^{\frac{1}{7.8}}
$$

Therefore, the performance function can be written as:

$$
G(X)=M=N_{\text {Capcity }}-N_{\text {Demand }}
$$

Substituting Eq. 5-25 into Eq. 5-26 we get:

$$
G(X)=N_{\text {Capacity }}-\left(\frac{10^{1.5 \cdot M_{w}}}{3.49 \times 10^{-4} \times \sigma_{v}^{\prime} \times R^{2}}\right)^{\frac{1}{7.8}}
$$

The above equation is called the performance function.

\subsubsection{Distributions of soil and seismic parameters}

The second step in performing the reliability analysis is assigning proper distributions to the random variables that comprise the performance function. Justified by the central limit theorem, which states that variables composed of the sum of independent perturbations necessarily tend toward normal distributions as the number of perturbations becomes large, many researchers (Juang et al. 1999, Juang et al. 2000, and Juang et al. 2001) have adopted the Normal distribution to be representative of the measurements employed in their analyses, such as the cone penetration resistance (CPT), the overburden stress, the effective overburden stress, the earthquake magnitude and the 
surface peak ground acceleration. In addition, Baecher and Christian (2003) reported that many measures of soil strength can be modeled by the Normal distributions.

In this study, the Normal distribution has been assigned to all the random variables employed in the performance function. It is possible, though, to determine the best distributions that would model our variables using several goodness of fit tests such as the Kolmogorov-Smirnov goodness-of-fit. However, as the number of the compiled data points is limited, the distribution that might pass the Kolmogorov-Smirnov goodness-offit might not represent the distributions of the variables in reality.

\subsubsection{Uncertainty of soil and seismic parameters}

An additional statistic must be assigned to each of the random variables to fully characterize in the performance function. The coefficient of variation (c.o.v), which is defined as the ratio of the standard deviation to the mean, is a conventional measure for describing parameter uncertainty (variability).

The coefficients of variation used in this study were based on statistical studies done to quantify the uncertainties associated with different types of measurements of soil and seismic parameters. Hilldale (1971), Harr (1987) and later Phoon and Kulhawy (1996 and 1999) analyzed the probable measurement error in different types of in-situ measurements including the SPT and reported a coefficient of variation for the SPT due to various measurement errors (equipment, procedure, random noise) of between 15 $45 \%$, see also Jones et al. (2002). The coefficient of variation for the effective overburden 
stress was also reported to fall within the range of $10-20 \%$. The uncertainty in the effective overburden stress stems from the uncertainty in the soil unit weight and variability in ground water level. In geotechnical literature (e.g. Juang et al. 1999), the coefficient of variation for the effective overburden stress has been taken to be constant at $15 \%$ which is consistent with the values reported by Phoon and Trautmann (1996).

Uncertainty in the moment magnitude $\left(M_{w}\right)$ of a seismic event derives essentially from the non-unique inversions of seismograms recorded at various stations, and decreases with increasing magnitude due to less uncertain estimation of seismological parameters for large earthquakes (Uzielli 2004). A constant coefficient of variation of $5 \%$ has been used in past studies (e.g. Chen \& Juang 2000) which were based on studies by Espinosa (1982) and Comartin et al. (1995). In this study, a proposed approximation by Moss (2003) of the variance of the earthquake magnitude is adopted as:

$$
\sigma_{M_{w}}^{2} \cong 0.5-0.45 \log M_{w}
$$

Kramer (1999) also reported the standard deviation errors associated with several empirical relationships between the moment magnitude, surface rupture length, rupture area and the maximum surface displacement. The reported $\left(\sigma_{M_{w}}\right)$ values were between 23 to $40 \%$, which is consistent with the above equation.

The coefficient of variation for the hypocenter distance is set as high as $50 \%$ (Dewey 1979 and Adams (2007-Personal communication)). Table 5-1 summarizes the 
coefficients of variation of the random variables and their assigned statistical distributions.

Table 5-1: Summaries the random variables and there statistical distribution parameters

\begin{tabular}{|c|c|c|}
\hline Variable & Distribution Type & $\begin{array}{c}\text { Coefficient of Variation } \\
\text { C.O.V }\end{array}$ \\
\hline $\mathbf{M}$ & Normal & Based on Eq. 5-28 \\
\hline $\mathbf{R}$ & Normal & 0.5 \\
\hline $\boldsymbol{\sigma}$ & Normal & 0.15 \\
\hline $\mathbf{N}$ & Normal & 0.3 \\
\hline
\end{tabular}

\subsubsection{Covariance among Random Variables}

When dealing with more than one variable, uncertainties in one may be associated with uncertainties in the other. In other words, some of the uncertainties may not be independent. Dependencies among events or among the uncertainties in estimates can be critical to obtaining proper numerical results in reliability analysis (Baecher and Christian 2003). The most common measure of dependence among uncertain quantities is the correlation coefficient. This measures the degree to which one uncertain quantity varies linearly with another uncertain quantity. In this study, the correlation coefficients among the random variables were set to zero as there are no dependency among them. It should be noted that the correlation between the standard penetration resistance and the effective overburden stress has been already accounted for when calculating the corrected standard resistance. 


\subsubsection{Calculating the reliability indices and probability of liquefaction}

The reported values, in each case, of the four random variables are taken as the mean values, while the c.o.v values are used along with the assumption of normal distributions. There exist many methods to calculate the reliability index such as the First Order Second Moment Methods (FOSM), the Second Order Reliability Methods (SORM) and the Monte Carlo Simulation. Several textbooks also provide in detail of the above methods (e.g., Baecher and Christian (2003) and Fishman 1995).

As the performance function is highly nonlinear, the Monte Carlo simulation is deemed appropriate for the calculation of the reliability index (Ditlevsen and Madsen 2005). The Monte Carlo simulation method was fully programmed in MATLAB to calculate the reliability index and the corresponding probability of liquefaction failure, see Appendix A.

The relationship between the reliability index, $\beta$, and the probability of failure is not unique. It depends on the distribution of the performance function, $G(X)$. Figure 5-6 shows a histogram of $G(X)$ along with two possible probability distribution fits, the Logistic and the Normal distributions. There is a negligible difference between the two distributions as shown in Figure 5-6, therefore, the Normal distribution is adopted to infer the probability of liquefaction failure as it will be more conservative. 


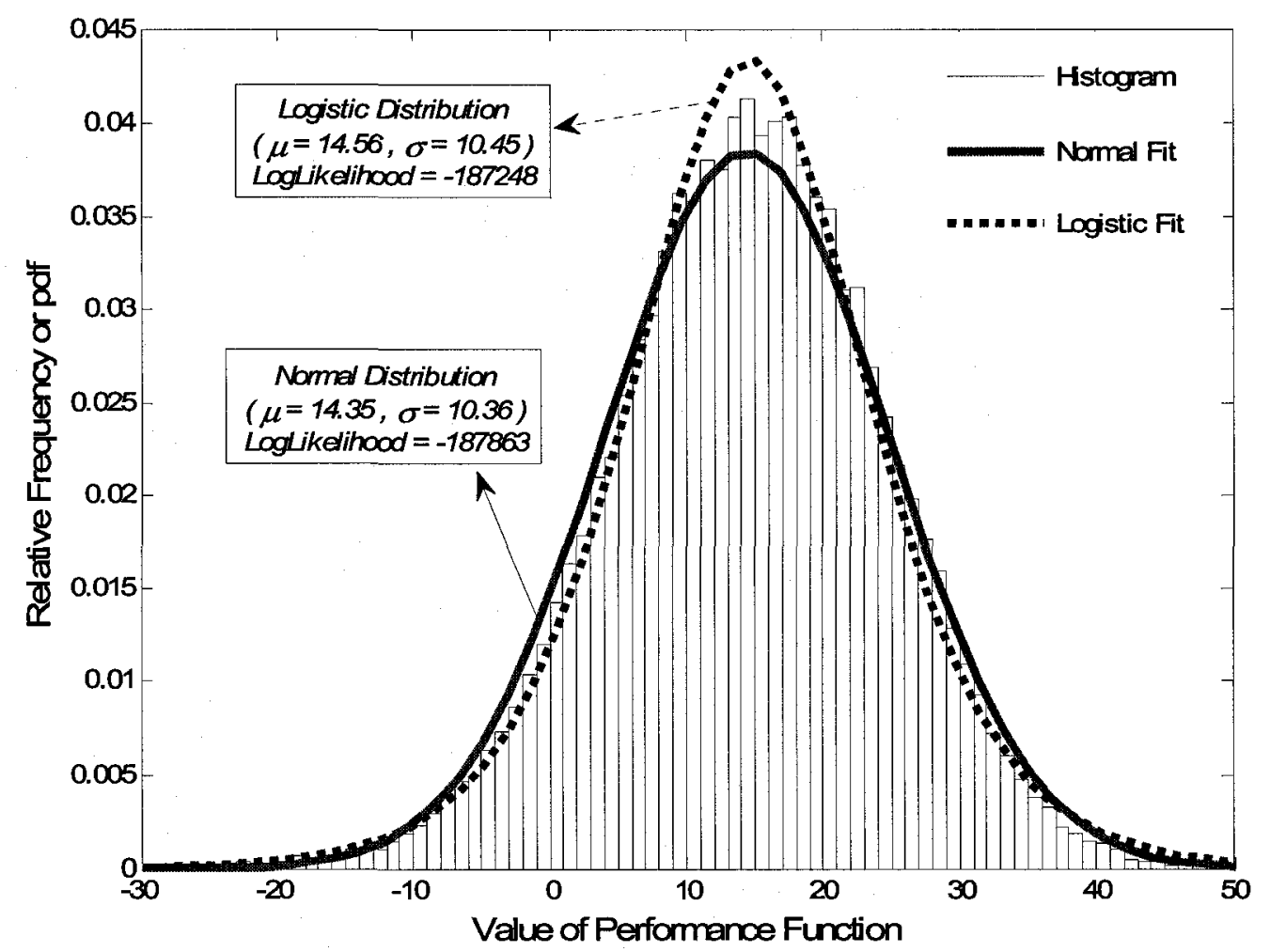

Figure 5-6: Histogram and Possible Fits for Performance Function G(X)

The probability of liquefaction failure is then obtained as (Christian 2004):

$$
P_{L i q}=\Phi(-\beta)
$$

Eq. 5-29

where $\Phi$ is the cumulative standard normal distribution.

Figure 5-7 plots the reliability index versus the probability of liquefaction failure for all the compiled case histories. It can be readily seen that the probability of liquefaction decreases as the reliability index increases. Also seen in the figure is that at a reliability index of zero there is a $50 \%$ chance of liquefaction failure. 


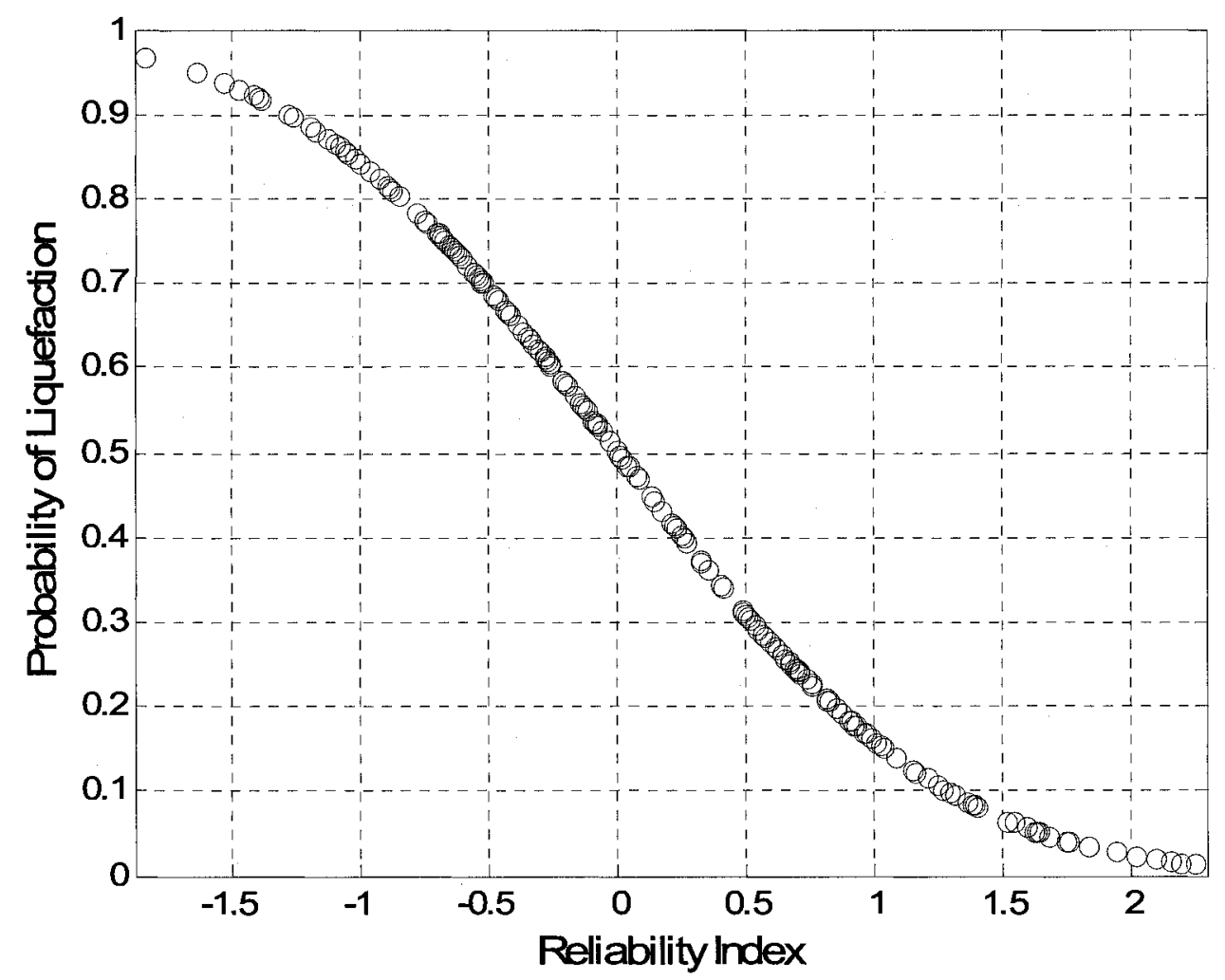

Figure 5-7: Probability of Liquefaction plotted against Reliability Index

The calculated $\beta$ values are grouped according to whether or not liquefaction actually occurred at the site. Figure 5-8 shows the results of these calculations for all cases. As expected, there is some overlap between the liquefied cases and the non-liquefied cases. This overlap is partially due to the ambiguity inherent in the deterministic model adopted in this study. 


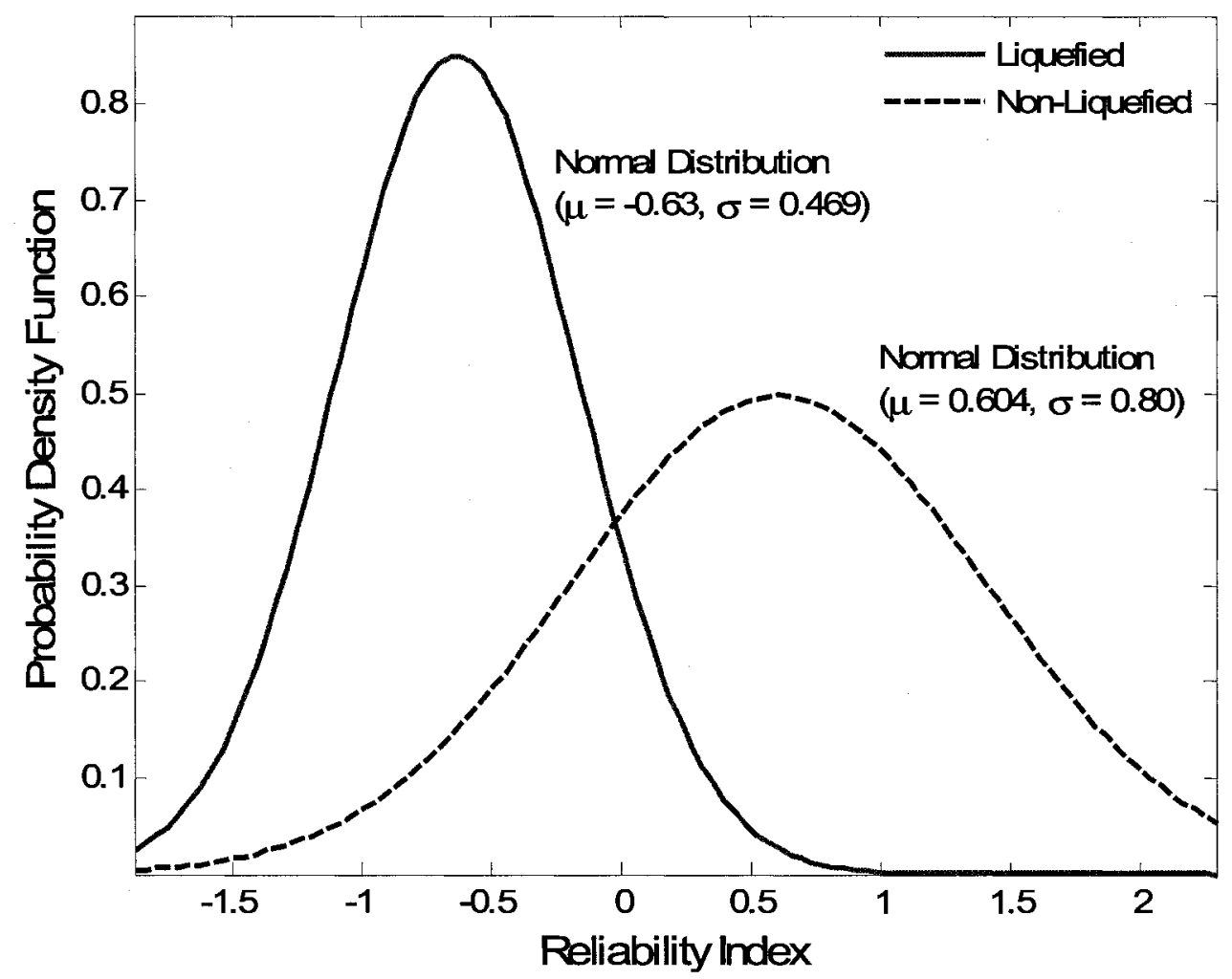

Figure 5-8: Distributions and the overlapping of the reliability indices of liquefied/non-liquefied cases

It is also desirable, for practical reasons, to plot the probability of liquefaction in terms of the factor of safety against liquefaction as shown in Figure 5-9. An equation that maps the relationship between the factor of safety and the probability of liquefaction can be expressed as:

$$
P_{L i q}=\frac{1}{1+0.76 \cdot F S^{3.69}}
$$


Thus, for a soil with site conditions similar to those of the cases in the database, the probability of liquefaction failure in future seismic events may be inferred from the equation based on the calculated factor of safety.

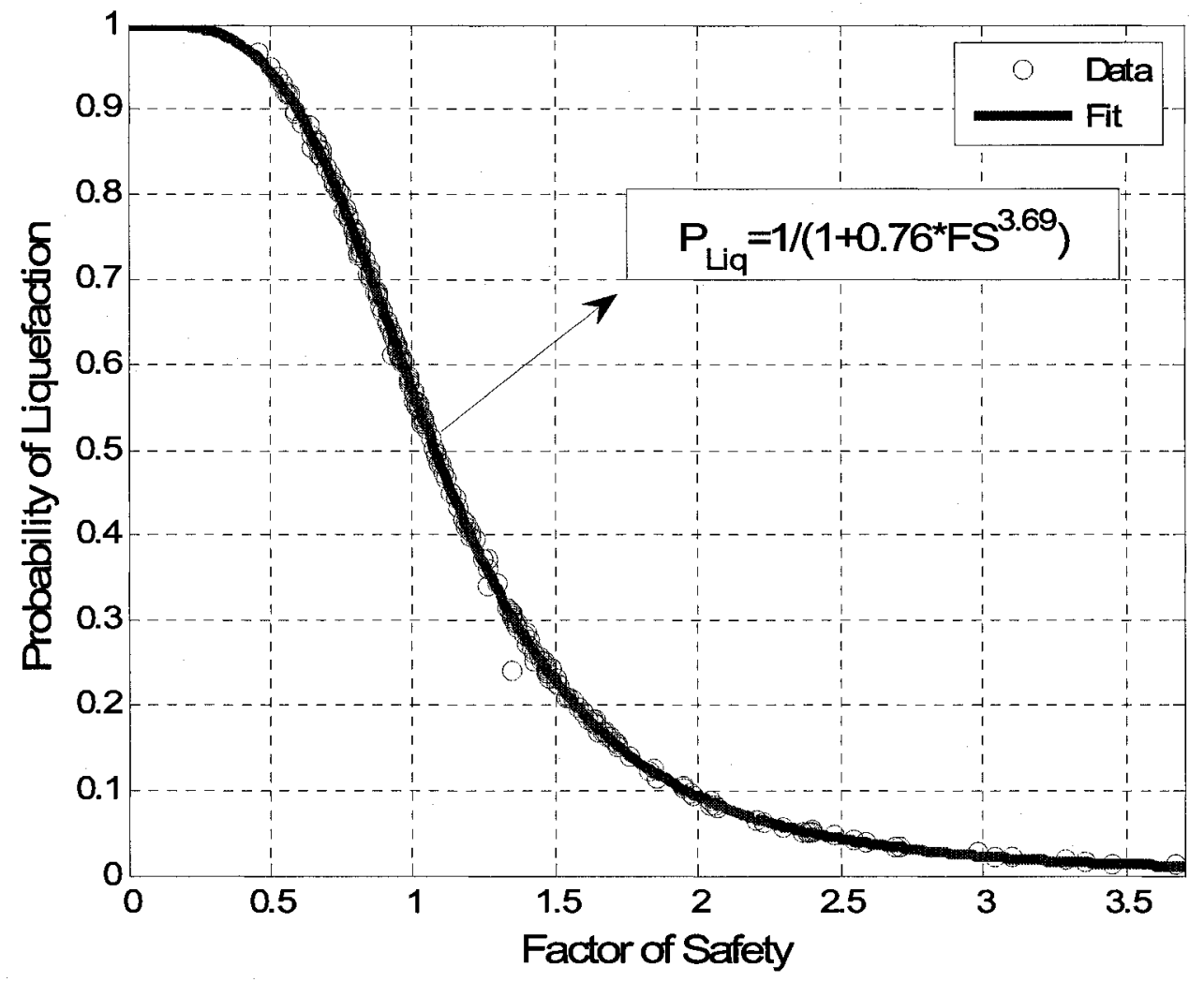

Figure 5-9: Probability of Liquefaction plotted against Factor of Safety

Juang et al. (2000) have also developed a similar equation using a different data set and they employed a different deterministic approach based on the CPT liquefaction analysis and arrived at a similar equation:

$$
P_{L i q}=\frac{1}{1+F S^{4.65}}
$$


If we try to apply the same form of the above equation, using only one coefficient, the resulting equation will be such as:

$$
P_{L i q}=\frac{1}{1+F S^{3.55}}
$$

The above equation is shown in Figure 5-10.

It can be seen from Figure 5-11 that the three curves (equations) are similar.

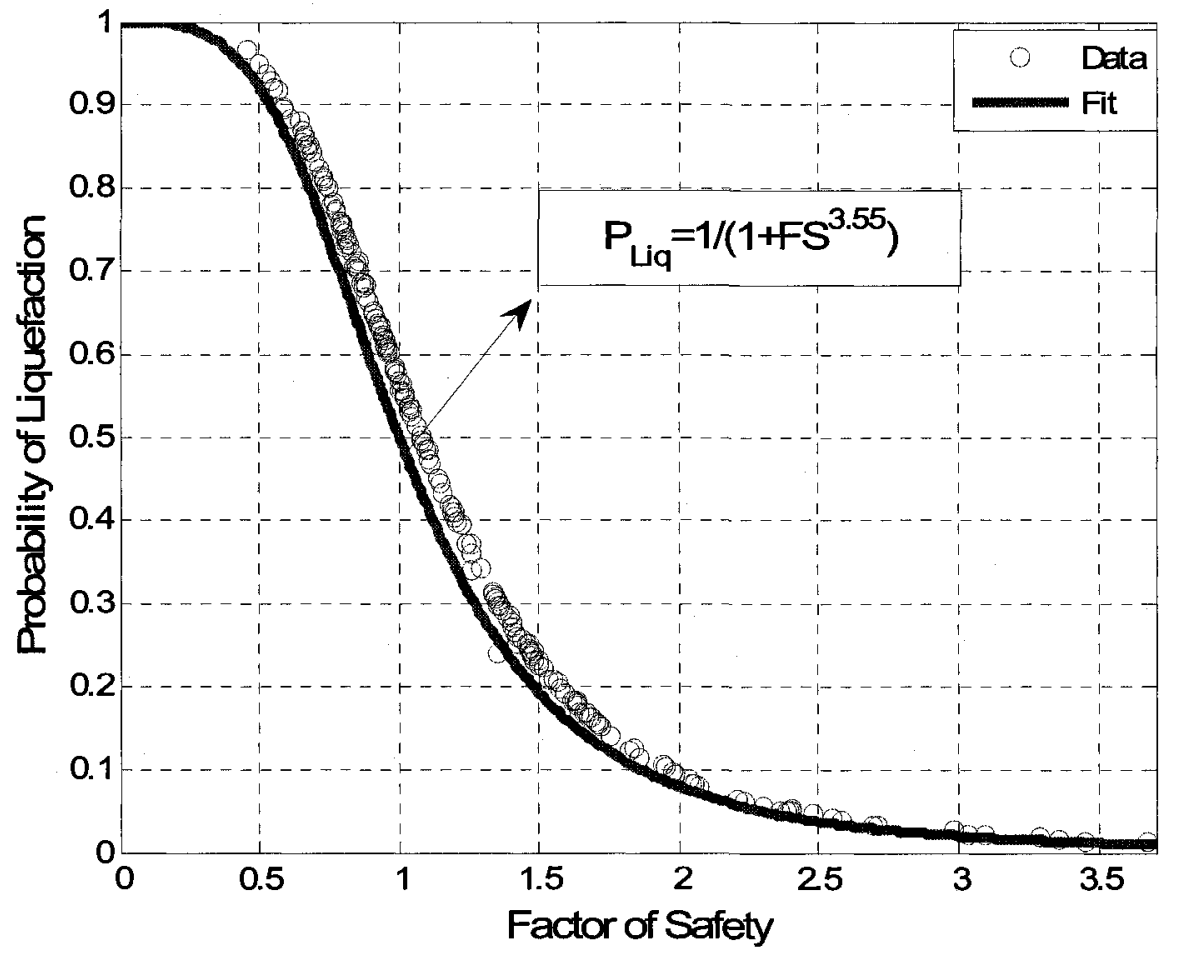

Figure 5-10: Probability of Liquefaction plotted against the Factor of Safety 


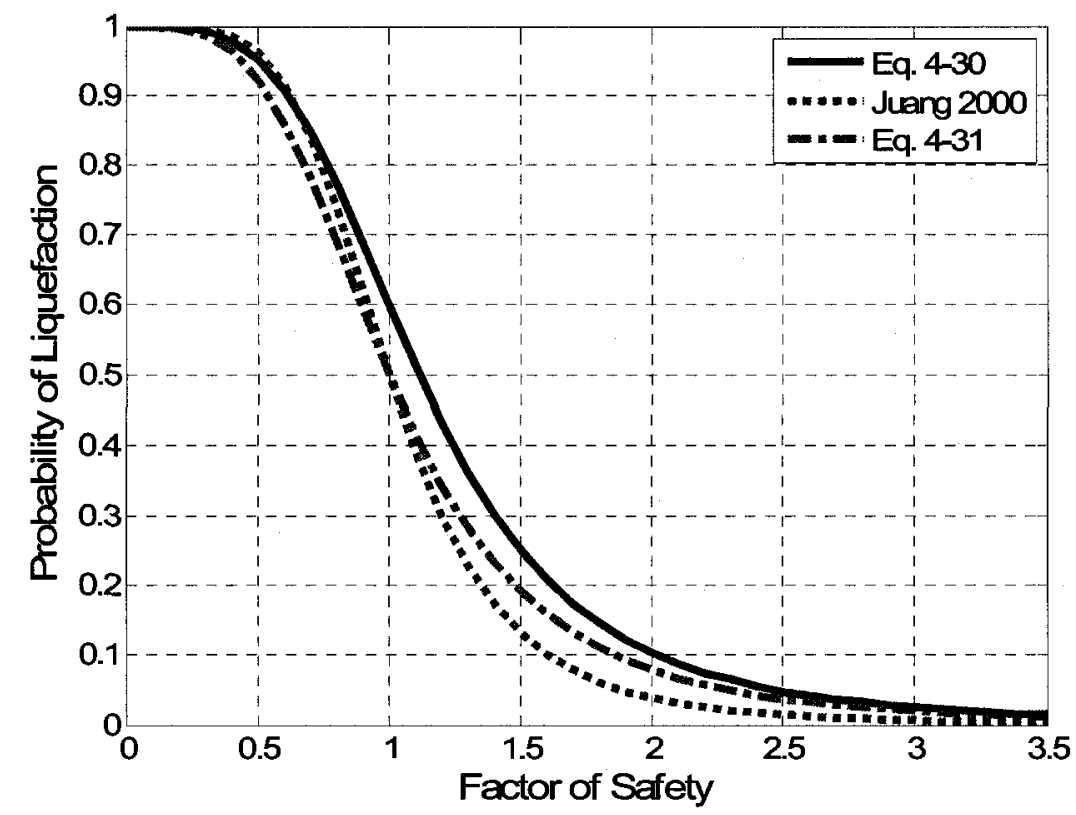

Figure 5-11: Probability of Liquefaction plotted against the Factor of Safety

\subsubsection{Sensitivity Analysis}

The effect of each random variable in the performance function has been investigated to verify the extent to which the probability of liquefaction might change due to a certain increase in the random variable. To do that, a $10 \%$ increase in the value of the variable is given, at different levels, to each variable at a time while the other variables hold constant to their values. As the performance function is nonlinear in terms of the random variables, it can be seen from Table 5-2 below that the effect of increase of each random variable on the probability of liquefaction changes at different "levels" of the random variables. It is also seen from the table that the effective overburden stress has little effect on the probability of liquefaction failure, a $3 \%$ decrease in the probability of liquefaction was observed due to a $10 \%$ increase in the effective overburden stress at various levels of the random variables. The same type of effect was observed for the hypocenter distance, 
a decrease of probability of liquefaction between $4-7 \%$ was observed due to a $10 \%$ increase at various levels of the random variables. The constant change of the probability of liquefaction failure due to a constant increase in the effective overburden stress and hypocenter distance suggests that the probability of liquefaction is somehow linear in terms of these variables. The variables that seem to have the most effect on the probability of liquefaction are the earthquake magnitude and the standard penetration resistance. A $10 \%$ increase in the earthquake magnitude may lead to an increase of probability of liquefaction between $24-48 \%$. Similarly, a $10 \%$ increase in the standard penetration resistance may lead to $16-27 \%$ reduction in the probability of liquefaction. The varying change in the probability of liquefaction due to constant changes in the values of earthquake magnitude and standard penetration resistance suggests that the probability of liquefaction is linear in terms of these variables.

Table 5-2: Effects of $10 \%$ increase on probability of liquefaction at various levels of random variables

\begin{tabular}{|c|c|c|c|c|c|c|}
\hline Variable & Value & dP/dVar & Value & dP/dVar & Value & dP/dVar \\
\hline $\mathbf{M}$ & 6 & $+24 \%$ & 6.5 & $+32 \%$ & 8 & $+48 \%$ \\
\hline $\mathbf{R}$ & 25 & $-4 \%$ & 38 & $-4 \%$ & 100 & $-7 \%$ \\
\hline$\sigma$ & 50 & $-2 \%$ & 75 & $-2 \%$ & 150 & $-3 \%$ \\
\hline $\mathbf{N}$ & 10 & $-16 \%$ & 12 & $-19 \%$ & 20 & $-24 \%$ \\
\hline
\end{tabular}


Continue the above table

\begin{tabular}{|c|c|c|c|c|}
\hline Variable & Value & dP/dVar & Value & dP/dVar \\
\hline M & 7 & $+41 \%$ & 7.5 & $+45 \%$ \\
\hline $\mathbf{R}$ & 50 & $-6 \%$ & 75 & $-5 \%$ \\
\hline$\sigma$ & 100 & $-3 \%$ & 125 & $-3 \%$ \\
\hline $\mathbf{N}$ & 15 & $-27 \%$ & 17 & $-27 \%$ \\
\hline
\end{tabular}

\subsection{SPATIAL AND TEMPORAL DISTRIBUTIONS OF SEISMIC}

\section{PARAMETERS}

The probability of soil liquefaction calculated above was based only on the statistical distributions of soil and seismic parameters and it only accounted for the uncertainty inherent in the measurements of soil and seismic parameters as well as the deterministic model implemented in the analysis. It does not consider, however, the probabilistic nature of the seismic parameter occurrences, the temporal distribution of the earthquake magnitude and the spatial distribution of the hypocenter distance.

Therefore, to evaluate the total probability of liquefaction, one must consider two probabilities, the probability stemming from the uncertainties of soil and seismic parameter measurements and the deterministic model used to evaluate liquefaction potential, and the probability stemming from the probabilistic occurrences of seismic parameters. Mathematically, assuming that the two events are independent, the total probability of liquefaction failure can be expressed as follows: 


$$
P_{\text {Liq }}=P_{1} \times P(M) \times P(R)
$$

where:

$P_{L i q}$ is the total probability of liquefaction

$P_{1}$ is the probability of liquefaction considering the uncertainties inherent in soil and seismic parameters as well as the deterministic liquefaction model

$P(M) \times P(R)$ is the probability of an earthquake of magnitude $M$ occurring at a distance $R$

\subsubsection{Evaluating the probability of $M$ and $R$}

To account for the temporal and spatial distributions of the seismic parameters, an evaluation of the probability $P(M) \times P(R)$ is warranted.

To evaluate the probability of an earthquake of magnitude $M$ occurring at a distance $R$, the seismicity around the site of interest must be defined and characterized properly. That includes the definition of the seismic sources surrounding the site, the seismicity rates and recurrence relationships associated with every seismic source as well as the spatial distributions of source-to-site distances for the site under investigation. The following section briefly explains the above steps. 


\subsubsection{Spatial Uncertainty}

Depending on the geometries of seismic sources and the purposes of a seismic hazard analysis, earthquake sources can be characterized as point sources, two-dimensional areal sources, or three-dimensional volumetric sources. It is usually assumed that earthquakes within the seismic source are uniformly distributed which implies that earthquakes are considered equally likely to occur anywhere within the seismic source. A uniform distribution within the source zone does not necessarily mean a uniform distribution of source to site distance (Kramer 1999). The uncertainty in source-to-site distance is described by a probability density function. Shown in Figure 5-12 are three types of earthquake sources and the source-to-site variations associated with each type.

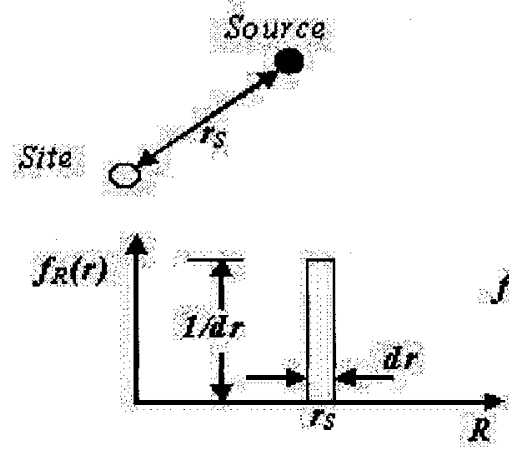

(a)
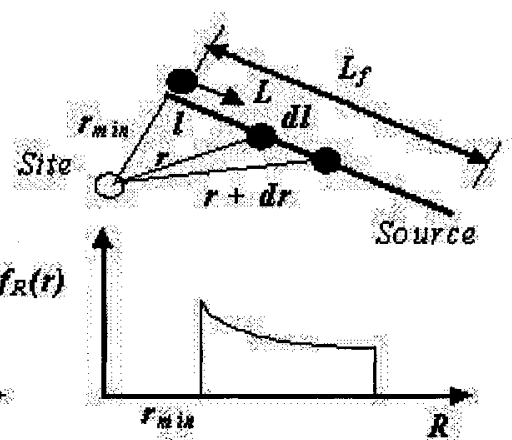

(b)

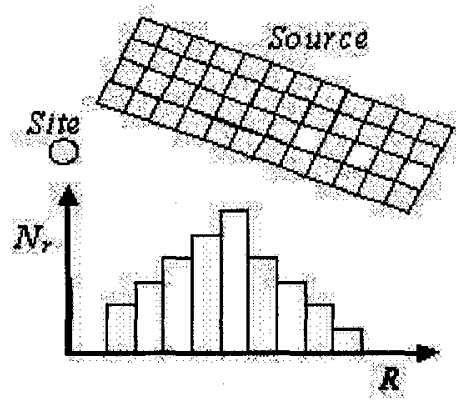

(c)

Figure 5-12: Variations of source-to-site distance for different source zone geometries (Kramer 1999)

\subsubsection{Recurrence Relationship}

A recurrence relationship for a seismic source is obtained in the following manner. First, the number of earthquakes that exceed different magnitudes during a time period is obtained. Second, the number of exceedances of different magnitudes is divided by the length of the time period to define a mean annual rate of exceedance, $\lambda_{m}$, of an 
earthquake of magnitude $m$. Third, the logarithm of the mean annual rate of exceedance is plotted against earthquake magnitude and a linear line is regressed through the plotted points to obtained the $a$ and $b$ parameters of the recurrence relationship:

$$
\log \lambda_{m}=a-b \cdot m
$$

Eq. 5-34

where $\lambda_{m}$ is the mean annual rate of exceedance of magnitude $m, 10^{a}$ is the mean yearly number of earthquakes of magnitude greater than or equal to zero, and $b$ describes the relative likelihood of large and small earthquakes. It should be noted that the above relationship was developed by the Gutenberg-Richter (1944) and it is illustrated schematically in Figure 5-13. As the $b$ value increases, the number of larger magnitude earthquakes decreases compared to those of smaller magnitudes. 


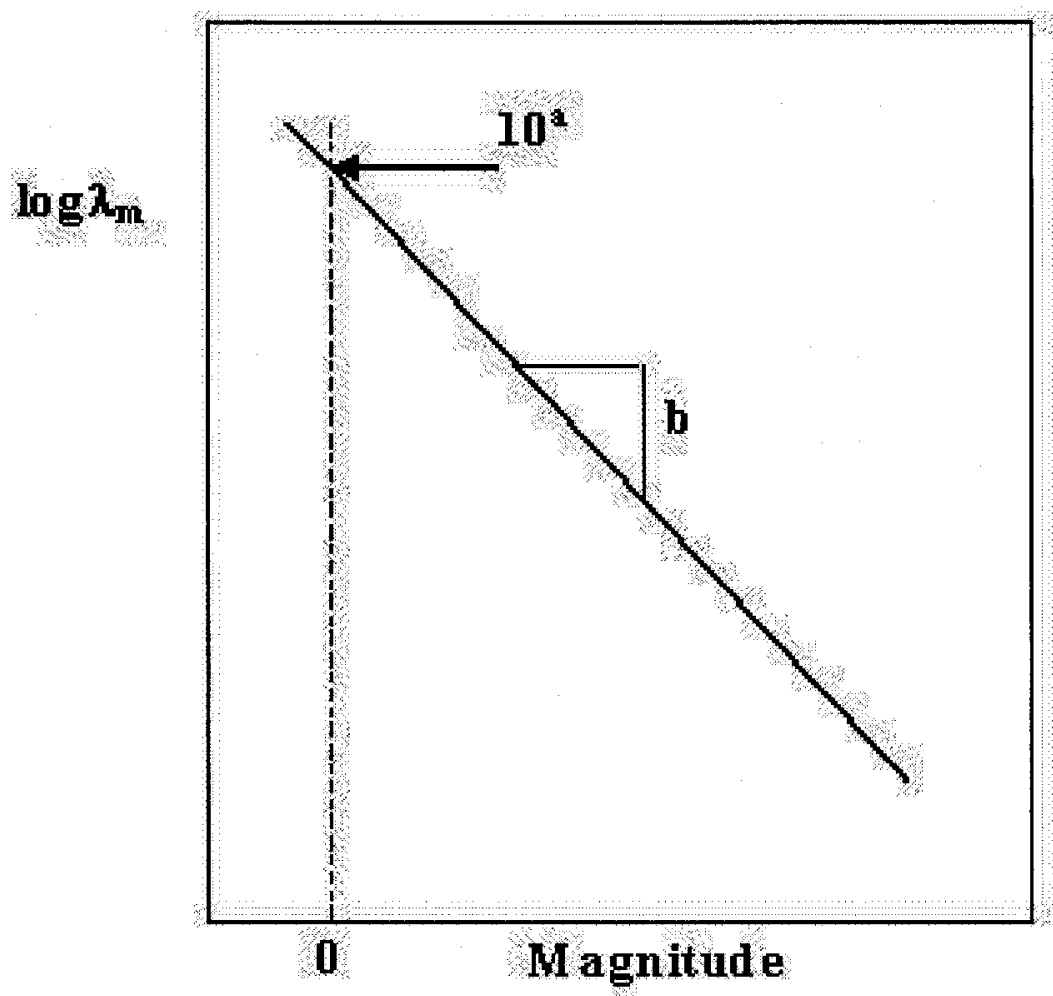

Figure 5-13: Gutenberg-Richter recurrence law, showing meaning of $a$ and $b$ parameters (Kramer 1999)

The Gutenberg-Richter law may also be expressed as:

$$
\lambda_{m}=10^{a-b \cdot m}=\exp (\alpha-\beta \cdot m)
$$

Eq. 5-35

where $\alpha=2.303 a$ and $\beta=2.303 b$. The above equation implies that earthquake magnitudes are exponentially distributed.

If earthquakes smaller than a lower threshold magnitude $m_{o}$ are eliminated and some maximum magnitude $m_{\max }$ that could be associated with the seismic source is estimated, a bounded Gutenberg-Richter recurrence law can be derived form the standard GutenbergRichter recurrence law (McGuire and Arabasz 1990): 


$$
\lambda_{m}=v \frac{\exp \left[-\beta\left(m-m_{o}\right)\right]-\exp \left[-\beta\left(m_{\max }-m_{o}\right)\right]}{1-\exp \left[-\beta\left(m_{\max }-m_{o}\right)\right]}, m_{\min } \leq m \leq m_{\max }
$$

Eq. 5-36

where $v=\exp \left(\alpha-\beta \cdot m_{o}\right)$

The resulting cumulative distribution function (CDF) and the probability distribution function (PDF) for the Gutenberg-Richter law with upper and lower bounds can be expressed as:

$$
\begin{gathered}
F_{M}(m)=P\left[M<m \backslash m_{o} \leq m \leq m_{\max }\right]=\frac{1-\exp \left[-\beta\left(m-m_{o}\right)\right]}{1-\exp \left[-\beta\left(m_{\max }-m_{o}\right)\right]} \\
f_{M}(m)=\frac{\beta \cdot \exp \left[-\beta\left(m-m_{o}\right)\right]}{1-\exp \left[-\beta\left(m_{\max }-m_{o}\right)\right]}
\end{gathered}
$$

\subsubsection{Temporal Uncertainty}

Earthquakes have been usually assumed to occur on a random basis. However, this assumption contradicts the elastic rebound theory. The elastic rebound theory implies that when an earthquake erupts, the built-up stress along a fault segment will be dissipated in the form of seismic energy carried away from that segment in forms of seismic waves (body waves, surface waves). Therefore, in order for another earthquake to erupt again from the same segment, sufficient time has to elapse to allow for the stress to build up. 
This implies that the likelihood of an earthquake occurring two consecutive times at the same fault segment is less than that of an earthquake occurring at a different segment.

Despite the contradiction, the temporal occurrence of an earthquake is described by a Poisson process which has no memory of time or size (Kramer 1999). The probability of a random variable $N$, representing the number of occurrences of a particular event during a given time interval is given by:

$$
P=[N=n]=\frac{(\lambda t)^{n} e^{-\lambda t}}{n !}
$$

where $\lambda$ is the average rate of occurrences of the event and $t$ is the time period of interest.

The probability of occurrence of at least one event in a period of time $t$ is given by:

$$
P[N \geq 1]=P[N=1]+P[N=2]+P[N=3]+\ldots+P[N=\infty]=1-P[N=0]=1-e^{-\lambda t}
$$

If $\lambda_{m}$ is the mean annual rate of exceeding a particular earthquake magnitude, then the Poison model can be combined with a suitable recurrence law to predict the probability of at lease one exceedance in a period of $t$ years by the expression:

$$
P[N \geq 1]=1-e^{-\lambda_{m} t}
$$




\subsubsection{Predictive (Attenuation) Relationship}

Ground motion parameters (acceleration, velocity and displacement) are usually estimated by means of empirical relationships. These relationships are referred to as attenuation relationships to reflect the fact that the amplitude of a ground motion decreases with increasing distance. Attenuation relationships usually express the amplitude of a ground motion as a function of earthquake magnitude and its hypocenter or epicenter distance and maybe some other parameters. They are developed by regression analysis and therefore vary according to the geographic and tectonic environment where the seismic data are recorded. A standard form of an attenuation equation is expressed as (Kramer 1999):

$$
\ln (A)=C_{1}+C_{2} \cdot M+C_{3} \cdot \ln \left(R+C_{4}\right)+C_{5} \cdot R+\varepsilon
$$

where:

$A$ is the amplitude of the ground motion

$M$ is the earthquake magnitude

$R$ is the hypocenter or epicenter distance

$\varepsilon$ is the error term

$C_{1} \ldots C_{5}$ are the coefficients obtained through regression 


\subsubsection{Seismic Hazard Analysis}

The sections above constitute the essential part in performing probabilistic seismic hazard analysis where the annual frequency of exceedance is evaluated for various ground motion levels based on the well-know equation:

$$
\lambda_{y^{*}} \approx \sum_{i=1}^{N_{S}} \sum_{j=1}^{N_{M}} \sum_{k=1}^{N_{R}} v_{i} \cdot P\left[Y>y^{*} \backslash m_{j}, r_{k}\right] \cdot P\left[M=m_{j}\right] \cdot P\left[R=r_{k}\right]
$$

where:

$\lambda_{y^{*}}$ is the mean annual frequency of exceeding $y^{*}$ ground motion

$v_{i}$ is the average rate of threshold magnitude exceedance

$Y$ is ground motion

$N_{S}$ is the numbers of earthquake sources

$N_{M}$ and $N_{R}$ are the numbers of earthquake magnitude and distance segments into which the "hazard space" is divided.

\subsubsection{Deaggregation}

When carrying out the conventional probabilistic seismic hazard analysis (PSHA), the hazard value is not associated with any particular earthquake magnitude or source-to-site distance due to the integrative nature of PSHA, i.e., the hazard value is based on the aggregate risk from potential earthquakes of many different magnitudes occurring at many different source-to-site distances. It is desired in this research that the hazard value be expressed as a function of magnitude and distance by means of deaggregation. 
Deaggregation of the hazard value means "decomposing" the hazard value into its original components in terms of magnitude and distance, it is a very useful technique as it shows the hazard values associated with different earthquake magnitudes and source-tosite distances that sum up to the total hazard value (Harmsen, et al. 1999, and Bazzurro and Cornell 1999). The deaggregation equation can be expressed as (Kramer 1999):

$$
\lambda_{y^{*}}\left(m_{j}, r_{k}\right) \approx P\left[M=m_{j}\right] \cdot P\left[R=r_{k}\right] \sum_{i=1}^{N_{s}} v_{i} P\left[Y>y^{*} \backslash m_{j}, r_{k}\right]
$$

\subsubsection{EZ-FIRSK Software}

Due to the vast seismic information needed to carry out the previous steps for many case histories, the commercial software EZ-FIRSK is utilized. EZ-FIRSK is a proprietary software product of Risk Engineering Inc. It has different capabilities for seismic hazard analysis techniques. It also contains up-to-date seismic data for Canada and United States (EZ-FRISK). By inputting the longitude and latitude of the site, EZ-FRISK enables us to select the seismic sources surrounding that site and the recurrence law associated with it with the capabilities of defining other seismic sources that are not predefined. Attenuation equations can also be defined that most suit the region where the site of interest lies. The spatial distribution of site-to-source distance is automatically evaluated once the seismic source is defined.

EZ-FIRSK calculates the annual frequencies of exceedance of various ground motion levels at the site of interest. EZ-FRISK also has the capability of deaggregation of the seismic hazard as we shall see in the subsequent sections. 


\subsection{CASE HISTORIES}

The following subsections discuss three case histories to illustrate the approach developed earlier. Moreover, the data obtained from the analyses of the case histories will be examined to evaluate the performance of these past liquefaction/non-liquefaction records during the earthquakes they experienced. Performance evaluation of those past liquefaction/non-liquefaction records may help choosing reliable hazard levels for design against liquefaction for future events in those sites.

\subsubsection{The Marina District Site}

Heavy and widespread damage to structures in the Marina District of San Francisco, California, was caused by the $M_{w} 6.9$ Loma Prieta earthquake of October 17, 1989. Field evidence indicated that liquefaction occurred in the district (Bennett 1990). The site investigation was located at latitude $=37^{\circ} 48^{\prime} 14^{\prime \prime} \mathrm{N}$ and longitude $=-122^{\circ} 26^{\prime} 17^{\prime \prime}$. Table 5-3 shows the soil and seismic parameters reported at the site.

The probability of soil liquefaction failure based on the statistical distribution of soil and seismic parameters was obtained earlier. The next step is to estimate the probability of occurrence of an earthquake of magnitude $M$ at distant $R$. This is achieved via deaggregation of seismic hazard for the Marina District site at zero ground motion. Figure 5-14 shows the seismic activity matrix for the Marian District site. 


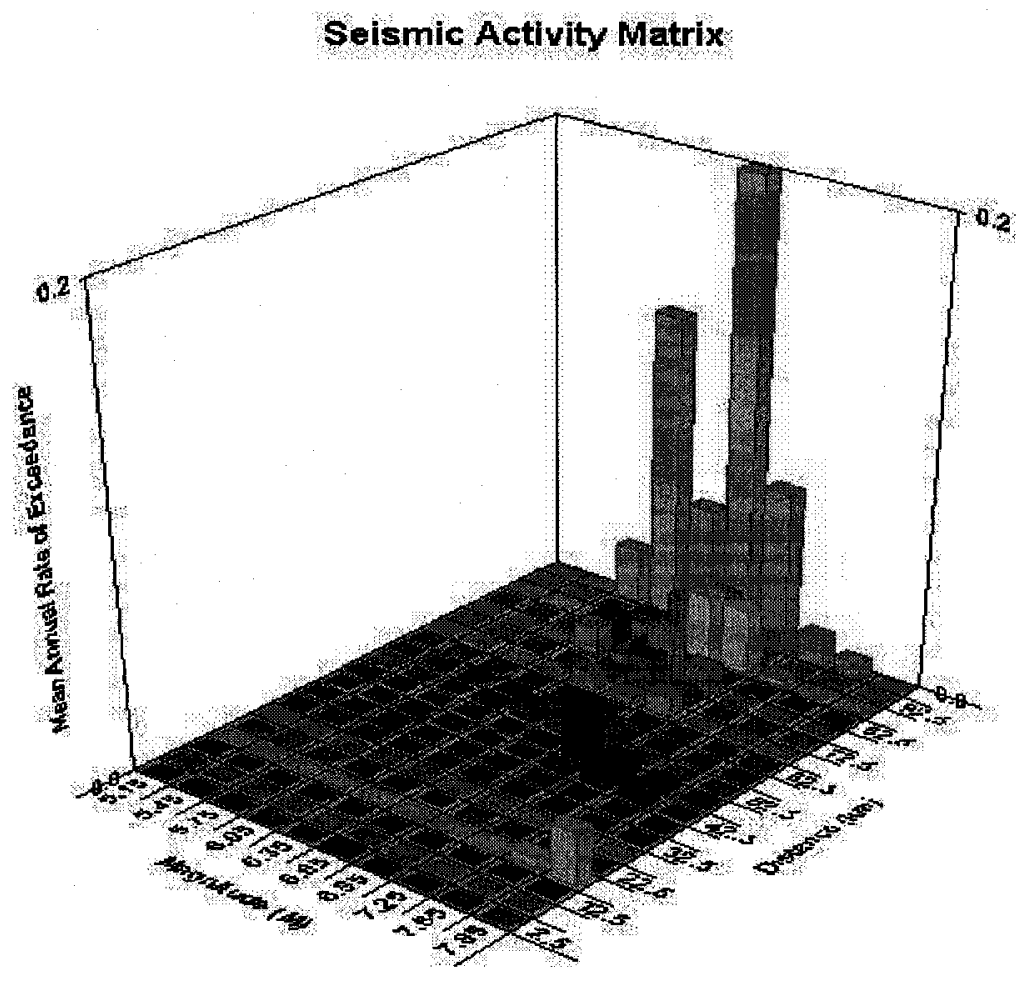

Figure 5-14: Seismic Activity Matrix for the Marina District site

Table 5-3: Soil and seismic parameters and the probability of liquefaction failure for several sites at the Marina District

\begin{tabular}{|c|c|c|c|c|c|c|c|c|}
\hline $\mathrm{M}_{\mathrm{W}}$ & $\begin{array}{c}\mathrm{R} \\
(\mathrm{km})\end{array}$ & $\begin{array}{c}\sigma_{0}{ }^{\prime} \\
(\mathrm{kPa})\end{array}$ & $\left(\mathrm{N}_{1}\right)_{60}$ & $\mathrm{P} 1$ & $\mathrm{P}(\mathrm{M}) \times \mathrm{P}(\mathrm{R})$ & $\mathbf{P}_{\text {Liq }}$ & $\begin{array}{c}\text { Return } \\
\text { Period } \\
(\text { Years })\end{array}$ & $\begin{array}{c}\text { Liquefaction } \\
\text { Performance }\end{array}$ \\
\hline 6.9 & 89.8 & 160 & 7.32 & 0.7842 & 0.00553 & 0.004337 & 231 & 1 \\
\hline 6.9 & 89.8 & 80 & 7.91 & 0.7772 & 0.00553 & 0.004298 & 233 & 1 \\
\hline 6.9 & 89.8 & 140 & 7.28 & 0.7972 & 0.00553 & 0.004409 & 227 & 1 \\
\hline 6.9 & 89.8 & 100 & 7.56 & 0.8022 & 0.00553 & 0.004436 & 225 & 1 \\
\hline 6.9 & 89.8 & 140 & 7.28 & 0.7856 & 0.00553 & 0.004344 & 230 & 1 \\
\hline 6.9 & 89.8 & 100 & 7.56 & 0.8015 & 0.00553 & 0.004432 & 226 & 1 \\
\hline 6.9 & 74.1 & 140 & 9.6 & 0.6383 & 0.0134 & 0.008553 & 117 & 1 \\
\hline 6.9 & 74.1 & 100 & 11.29 & 0.5325 & 0.0134 & 0.007136 & 140 & 1 \\
\hline 6.9 & 74.1 & 278 & 12.66 & 0.3134 & 0.0134 & 0.0042 & 238 & 0 \\
\hline 6.9 & 74.1 & 186 & 15.85 & 0.1924 & 0.0134 & 0.002578 & 388 & 0 \\
\hline 6.9 & 74.1 & 168 & 18.31 & 0.1287 & 0.0134 & 0.001725 & 580 & 0 \\
\hline 6.9 & 74.1 & 260 & 21.17 & 0.0669 & 0.0134 & 0.000896 & 1115 & 0 \\
\hline 6.9 & 74.1 & 214 & 24.69 & 0.0401 & 0.0134 & 0.000537 & 1861 & 0 \\
\hline 6.9 & 74.1 & 176 & 28.65 & 0.0273 & 0.0134 & 0.000366 & 2734 & 0 \\
\hline 6.9 & 74.1 & 86 & 30.91 & 0.0296 & 0.0134 & 0.000397 & 2521 & 0 \\
\hline 6.9 & 74.1 & 158 & 31.85 & 0.0206 & 0.0134 & 0.000276 & 3623 & 0 \\
\hline
\end{tabular}




\begin{tabular}{|c|c|c|c|c|c|c|c|c|}
\hline $\mathrm{M}_{\mathrm{w}}$ & $\underset{(\mathrm{km})}{\mathrm{R}}$ & $\begin{array}{c}\sigma_{0}{ }^{\prime} \\
(\mathrm{kPa})\end{array}$ & $\left(\mathrm{N}_{1}\right)_{60}$ & P1 & $\mathrm{P}(\mathrm{M}) \times \mathrm{P}(\mathrm{R})$ & $P_{\text {Liq }}$ & $\begin{array}{c}\text { Return } \\
\text { Period } \\
\text { (Years) }\end{array}$ & $\begin{array}{l}\text { Liquefaction } \\
\text { Performance }\end{array}$ \\
\hline 6.9 & 74.1 & 232 & 34.99 & 0.0128 & 0.0134 & 0.000172 & 5830 & 0 \\
\hline 6.9 & 74.1 & 204 & 36.85 & 0.0113 & 0.0134 & 0.000151 & 6604 & 0 \\
\hline 6.9 & 74.1 & 196 & 38.36 & 0.0107 & 0.0134 & 0.000143 & 6974 & 0 \\
\hline 6.9 & 74.1 & 222 & 50.39 & 0.005 & 0.0134 & 0.000067 & 14925 & 0 \\
\hline 6.9 & 74.1 & 268 & 57.07 & 0.0035 & 0.0134 & $4.69 \mathrm{E}-05$ & 21322 & 0 \\
\hline 6.9 & 74.1 & 76 & 61.08 & 0.0043 & 0.0134 & $5.76 \mathrm{E}-05$ & 17355 & 0 \\
\hline 6.9 & 74.1 & 250 & 73.64 & 0.0024 & 0.0134 & $3.22 \mathrm{E}-05$ & 31095 & 0 \\
\hline 6.9 & 74.1 & 120 & 7.74 & 0.8016 & 0.0134 & 0.010741 & 93 & 1 \\
\hline 6.9 & 74.1 & 170 & 7.8 & 0.775 & 0.0134 & 0.010385 & 96 & 1 \\
\hline 6.9 & 74.1 & 222 & 15.27 & 0.202 & 0.0134 & 0.002707 & 369 & 0 \\
\hline 6.9 & 74.1 & 204 & 17.15 & 0.1467 & 0.0134 & 0.001966 & 509 & 0 \\
\hline 6.9 & 74.1 & 112 & 21.55 & 0.0881 & 0.0134 & 0.001181 & 847 & 0 \\
\hline 6.9 & 74.1 & 214 & 24.9 & 0.0408 & 0.0134 & 0.000547 & 1829 & 0 \\
\hline 6.9 & 74.1 & 104 & 24.91 & 0.0548 & 0.0134 & 0.000734 & 1362 & 0 \\
\hline 6.9 & 74.1 & 196 & 40.96 & 0.0089 & 0.0134 & 0.000119 & 8385 & 0 \\
\hline 6.9 & 74.1 & 86 & 46.11 & 0.009 & 0.0134 & 0.000121 & 8292 & 0 \\
\hline 6.9 & 74.1 & 94 & 62.99 & 0.0039 & 0.0134 & $5.23 \mathrm{E}-05$ & 19135 & 0 \\
\hline 6.9 & 74.1 & 76 & 72.3 & 0.0029 & 0.0134 & $3.89 \mathrm{E}-05$ & 25733 & 0 \\
\hline 6.9 & 74.1 & 68 & 74.56 & 0.003 & 0.0134 & $4.02 \mathrm{E}-05$ & 24876 & 0 \\
\hline 6.9 & 71.2 & 150 & 10.18 & 0.5835 & 0.000532 & 0.00031 & 3221 & 1 \\
\hline 6.9 & 71.2 & 176 & 11.43 & 0.4598 & 0.000532 & 0.000245 & 4088 & 0 \\
\hline 6.9 & 71.2 & 100 & 11.72 & 0.5042 & 0.000532 & 0.000268 & 3728 & 1 \\
\hline 6.9 & 71.2 & 166 & 13.64 & 0.3146 & 0.000532 & 0.000167 & 5975 & 0 \\
\hline 6.9 & 71.2 & 60 & 14.4 & 0.3793 & 0.000532 & 0.000202 & 4956 & 0 \\
\hline 6.9 & 71.2 & 186 & 18.27 & 0.1269 & 0.000532 & $6.75 \mathrm{E}-05$ & 14812 & 0 \\
\hline 6.9 & 71.2 & 208 & 19.3 & 0.1006 & 0.000532 & $5.35 \mathrm{E}-05$ & 18685 & 0 \\
\hline 6.9 & 71.2 & 76 & 22.56 & 0.0894 & 0.000532 & $4.76 \mathrm{E}-05$ & 21026 & 0 \\
\hline 6.9 & 71.2 & 68 & 26.06 & 0.057 & 0.000532 & $3.03 \mathrm{E}-05$ & 32977 & 0 \\
\hline 6.9 & 71.2 & 94 & 27.4 & 0.0453 & 0.000532 & $2.41 \mathrm{E}-05$ & 41494 & 0 \\
\hline 6.9 & 71.2 & 86 & 31.98 & 0.0265 & 0.000532 & $1.41 \mathrm{E}-05$ & 70932 & 0 \\
\hline 6.9 & 71.2 & 196 & 41.92 & 0.0084 & 0.000532 & $4.47 \mathrm{E}-06$ & 223774 & 0 \\
\hline 6.9 & 71.2 & 160 & 9.88 & 0.608 & 0.000532 & 0.000323 & 3092 & 1 \\
\hline 6.9 & 71.2 & 106 & 11.49 & 0.519 & 0.000532 & 0.000276 & 3622 & 1 \\
\hline 6.9 & 71.2 & 96 & 22.56 & 0.085 & 0.000532 & $4.52 \mathrm{E}-05$ & 22114 & 0 \\
\hline 6.9 & 71.2 & 106 & 28.71 & 0.035 & 0.000532 & $1.86 \mathrm{E}-05$ & 53706 & 0 \\
\hline 6.9 & 71.2 & 88 & 41.51 & 0.0111 & 0.000532 & $5.91 \mathrm{E}-06$ & 169342 & 0 \\
\hline 6.9 & 71.2 & 188 & 43.96 & 0.0076 & 0.000532 & $4.04 \mathrm{E}-06$ & 247329 & 0 \\
\hline 6.9 & 71.2 & 70 & 48.43 & 0.008 & 0.000532 & $4.26 \mathrm{E}-06$ & 234962 & 0 \\
\hline 6.9 & 71.2 & 170 & 49.61 & 0.006 & 0.000532 & $3.19 \mathrm{E}-06$ & 313283 & 0 \\
\hline 6.9 & 58.7 & 100 & 6.19 & 0.9271 & 0.000532 & 0.000493 & 2028 & 1 \\
\hline 6.9 & 58.7 & 160 & 6.25 & 0.9057 & 0.000532 & 0.000482 & 2075 & 1 \\
\hline 6.9 & 58.7 & 134 & 36.94 & 0.0165 & 0.000532 & $8.78 \mathrm{E}-06$ & 113921 & 0 \\
\hline 6.9 & 58.7 & 124 & 39.67 & 0.0134 & 0.000532 & $7.13 \mathrm{E}-06$ & 140276 & 0 \\
\hline 6.9 & 58.7 & 152 & 45.76 & 0.0082 & 0.000532 & $4.36 \mathrm{E}-06$ & 229232 & 0 \\
\hline 6.9 & 58.7 & 142 & 48.71 & 0.0074 & 0.000532 & $3.94 \mathrm{E}-06$ & 254013 & 0 \\
\hline 6.9 & 58.7 & 116 & 54.21 & 0.0059 & 0.000532 & $3.14 \mathrm{E}-06$ & 318593 & 0 \\
\hline
\end{tabular}


The performances evaluated for these previous cases could serve as baselines for future liquefaction designs. In other words, in a similar seismic environment to the site above and similar soil conditions, one could base his/her designs on some lower-end values shown in the above table. For example, for a site with $\left(\mathrm{N}_{1}\right)_{60}$ of 18.31 and at a depth with an effective overburden stress of $168 \mathrm{kPa}$, one has to design for at least 580 years return period so that the site can withstand an earthquake of magnitude 6.9 occurring at distance of $74.1 \mathrm{~km}$. Increasing the SPT value of the soil will result in further increasing the liquefaction return period and therefore, increasing the safety against liquefaction. This is based on the previous performance of a similar site that experienced similar seismic event.

\subsubsection{The Telegraph Hill Site}

The San Francisco DC California earthquake which, occurred on March 22nd 1957, will be considered. The site was on the Telegraph Hill, Latitude $=37.8027 \mathrm{o} \mathrm{N}$, Longitude $=$ $122.4058 \mathrm{o}$ W. Soil investigation were carried out and some of the compiled data is presented in Table 5-4

Based on the statistical distributions of the soil and seismic parameters, the probability of liquefaction was explained and obtained earlier. In order to link that probability to the probability of earthquake magnitude and source-to-site distance, probabilistic seismic hazard calculation and deaggregation of the hazard was performed using the EZ-FRISK. The seismic activity matrix was also obtained and it is shown in Figure 5-14. 
Table 5-4: Soil and seismic parameters measured at the borings of the Telegraph Hill site

\begin{tabular}{|c|c|c|c|}
\hline $\mathrm{M}_{\mathrm{W}}$ & $\begin{array}{c}\mathrm{R} \\
(\mathrm{km})\end{array}$ & $\begin{array}{c}\sigma_{0}{ }^{\prime} \\
(\mathrm{kPa})\end{array}$ & $\left(\mathrm{N}_{1}\right)_{60}$ \\
\hline 5.3 & 18 & 85.96 & 5.7 \\
\hline 5.3 & 18 & 105.80 & 18.8 \\
\hline 5.3 & 16 & 64.47 & 5.1 \\
\hline 5.3 & 16 & 40.96 & 29 \\
\hline 5.3 & 14 & 82.68 & 3.3 \\
\hline 5.3 & 14 & 105.75 & 10.2 \\
\hline 5.3 & 18 & 62.52 & 4.7 \\
\hline 5.3 & 18 & 62.52 & 13.2 \\
\hline
\end{tabular}

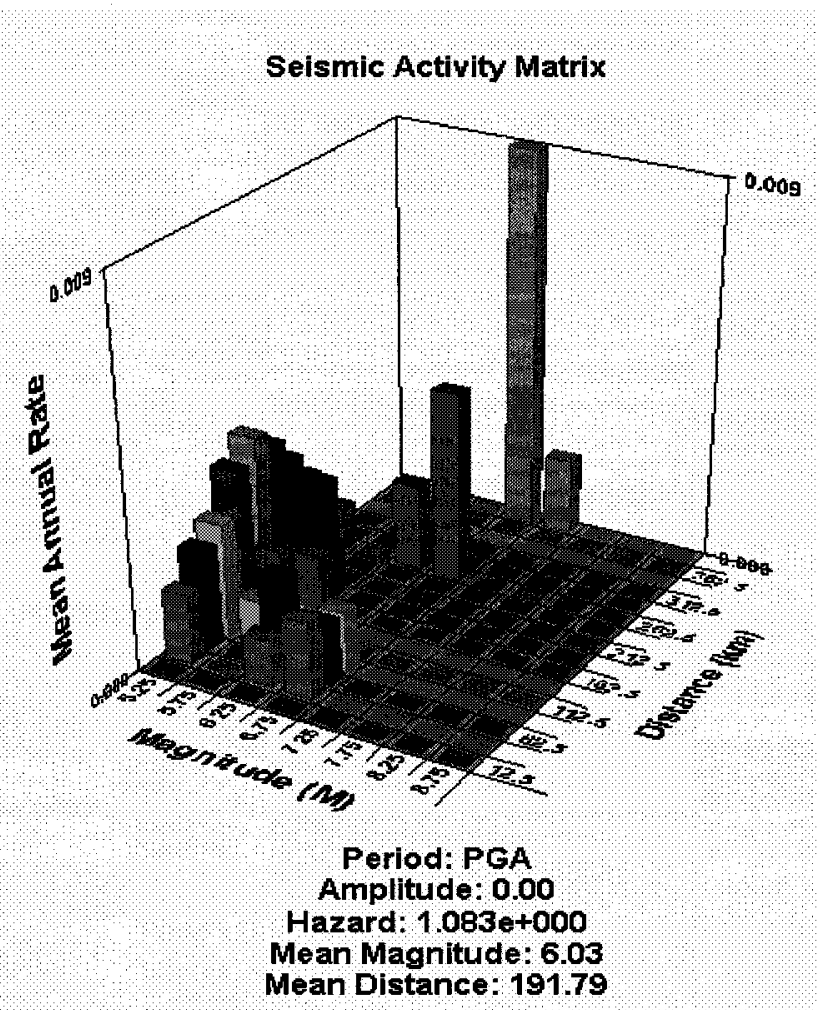

Figure 5-15: Seismic Activity Matrix for the Telegraph Hill Site

Table 5-5 shows the seismic parameters measured at the site, the probability of liquefaction based on the statistical distributions of soil and seismic parameters, the probability of earthquake occurrence and a particular distance, the total probability of soil 
liquefaction, the return period corresponding to that probability, and indication whether liquefaction did or did not occur where those measurements have been taken.

The performances of the above liquefaction records shown in

Table 5-5 could again be used as references for future liquefaction designs.

Table 5-5: Seismic parameters, probability inferred from the statistical distribution of soil and seismic parameters, the probability inferred from the spatial and temporal distribution of soil and seismic parameters, the total probability of liquefaction, the return period and the reliability index associated with the probability of liquefaction

\begin{tabular}{|c|c|c|c|c|c|c|c|c|}
\hline $\mathrm{M}_{\mathrm{W}}$ & $\begin{array}{c}\mathrm{R} \\
(\mathrm{km})\end{array}$ & $\begin{array}{c}\sigma_{0}{ }^{\prime} \\
(\mathrm{kPa})\end{array}$ & $\left(\mathrm{N}_{1}\right)_{60}$ & $\mathrm{P}_{1}$ & $\mathrm{P}(\mathrm{M}) \times \mathrm{P}(\mathrm{R})$ & $\mathrm{P}_{\mathrm{Liq}}$ & $\begin{array}{c}\text { Return } \\
\text { Period } \\
(\text { Year })\end{array}$ & $\begin{array}{c}\text { Liquefaction } \\
\text { Performance }\end{array}$ \\
\hline 5.3 & 18 & 85.96 & 5.7 & 0.80 & 0.0027359 & 0.002186 & 458 & 0 \\
\hline 5.3 & 18 & 105.80 & 18.8 & 0.044 & 0.0027359 & 0.00012 & 8318 & 0 \\
\hline 5.3 & 16 & 64.47 & 5.1 & 0.87 & 0.0012162 & 0.001057 & 946 & 0 \\
\hline 5.3 & 16 & 40.96 & 29 & 0.018 & 0.0012162 & $2.19 \mathrm{E}-05$ & 45709 & 0 \\
\hline 5.3 & 14 & 82.68 & 3.3 & 0.968 & 0.0013705 & 0.001326 & 754 & 0 \\
\hline 5.3 & 14 & 105.75 & 10.2 & 0.37 & 0.0013705 & 0.000507 & 1973 & 0 \\
\hline 5.3 & 18 & 62.52 & 4.7 & 0.90 & 0.0027359 & 0.002459 & 407 & 0 \\
\hline 5.3 & 18 & 62.52 & 13.2 & 0.183 & 0.0027359 & 0.0005 & 2000 & 0 \\
\hline
\end{tabular}




\subsubsection{The Westmorland Site}

The same procedure is applied again for this site and the results are summarized in Table 5-6.

Table 5-6: Soil and seismic parameters and the probability of liquefaction failure for several sites at Westmorland

\begin{tabular}{|c|c|c|c|c|c|c|c|c|}
\hline $\mathrm{M}_{\mathrm{W}}$ & $\begin{array}{c}\mathrm{R} \\
(\mathrm{km})\end{array}$ & $\begin{array}{c}\sigma_{\mathrm{o}}{ }^{\prime} \\
(\mathrm{kPa})\end{array}$ & $\left(\mathrm{N}_{1}\right)_{60}$ & $\mathrm{P} 1$ & $\mathrm{P}(\mathrm{M}) \times \mathrm{P}(\mathrm{R})$ & $\mathrm{P}_{\mathrm{Liq}}$ & $\begin{array}{c}\text { Return } \\
\text { Period } \\
(\text { Years })\end{array}$ & $\begin{array}{c}\text { Liquefaction } \\
\text { Performance }\end{array}$ \\
\hline 6 & 7.6 & 55.85 & 9.8 & 0.829 & 0.001442 & 0.001195 & 837 & 1 \\
\hline 6 & 10.2 & 41.79 & 11.5 & 0.703 & 0.001442 & 0.001014 & 986 & 1 \\
\hline 6 & 7.6 & 59.70 & 11.7 & 0.709 & 0.001442 & 0.001022 & 979 & 1 \\
\hline 6 & 8 & 60.10 & 15.1 & 0.485 & 0.001442 & 0.0007 & 1429 & 0 \\
\hline 6 & 50.5 & 50.92 & 6.1 & 0.821 & 0.000841 & 0.00069 & 1449 & 0 \\
\hline 6 & 15.7 & 40.57 & 18.2 & 0.232 & 0.001442 & 0.000335 & 2989 & 0 \\
\hline 6 & 16.6 & 21.35 & 11.2 & 0.678 & 0.000374 & 0.000254 & 3944 & 0 \\
\hline 6 & 16.6 & 60.48 & 18.5 & 0.180 & 0.000374 & $6.73 \mathrm{E}-05$ & 14868 & 0 \\
\hline
\end{tabular}




\section{Chapter 6}

\section{DEVELOPMENT OF A LOGISTIC REGRESSION \\ MODEL FOR EVALUATING PROBABILITY OF \\ LIQUEFACTION FAILURE}

\subsection{INTRODUCTION:}

A logistic regression model has been developed in a systematic approach for evaluating liquefaction probability. The development of the logistic model is based on a binary regression analysis of 363 case histories of liquefaction/non-liquefaction data. The model utilizes seismic parameters, namely, earthquake magnitude and hypocenter distance, and soil parameters, namely, standard penetration resistance and effective overburden stress, for evaluating the probability of soil liquefaction failure. Incorporation and representation of seismic and soil parameters in the logistic model have been justified based on selected diagnostic techniques that are commonly used in conjunction with logistic models. Other diagnostic techniques were also used to check the adequacy and the validity of the developed logistic model. Interpretation of the developed logistic model is also presented to help understand the physical meaning of all the included parameters and their coefficients. 
Liquefaction probability curves based on varying seismic and soil parameters have been developed using the proposed model. Moreover, the developed model is appropriate for use in a performance-based approach for liquefaction hazard evaluation as the model directly utilizes the earthquake magnitude and the hypocenter distance, which are the intrinsic parameters of any seismic event.

The motivation behind the development of this model is threefold. First, it is desirable to derive a closed-form equation for estimating the probability of liquefaction based on given seismic and soil parameters. Second, it is of vital importance to validate the results obtained from the reliability-based analysis presented in the previous chapter. Third, the developed model can be implemented in a performance-based liquefaction hazard evaluation.

The method used in this analysis is called the logistic regression analysis. A brief discussion of the method is presented in Appendix D. However, a step-by-step derivation of the model is given here to arrive at the "best" model that describes the data used in the regression.

\subsection{CONSTRUCTING THE LOGISTIC REGRESSION MODEL:}

The basic principles of the logistic regression discussed in Appendix D are applied to construct a linear logistic model to infer the probability of liquefaction failure. All the 
procedures outlined in Appendix D have been programmed using the computational platform MATLAB. Input and output files can be found in Appendix A.

\subsubsection{Strategy for Building the Model:}

The strategy of building the model is based on a step-by-step procedure. Among the primary objectives one usually seeks when developing a model is to have the simplest model possible, since simple models are usually easy to interpret. Therefore, the procedure for developing the model starts off with only one explanatory variable believed to represent the data. Then, adding one explanatory variable at a time to the model to compare (the nested models) it with the previous one in terms of its deviance (maximum likelihood). If the reduction in the deviance due to the inclusion of the new term (explanatory variable) is found to be significant based on the chi-square test of significance, the new model is said to better describe the response variable. If the reduction in the deviance is not found to be significant, the added explanatory variable, in its present expression, is not significant in predicting the response (dependent) variable. Transformation of the variable prior to inclusion in the model may be more appropriate to capture the response of the dependent variable. Transformation of explanatory variables is explained in subsequent sections.

Furthermore, the Wald test (described in Appendix D) for the estimated coefficients can also be used as an extra criterion to either accept or reject the significance of the added independent variable to describe the dependent variable. 
After arriving at the best model that explains the data, more procedures (diagnostics) are used to check the adequacy of the model. These procedures are also discussed in Appendix D.

\section{M1 A Model Containing the Standard Penetration Resistance $\left(\mathrm{N}_{1}\right)$ :}

As our objective is to come up with the best and simplest model to describe our compiled data, we start off with a simple model that contains only one explanatory variable which is the standard penetration resistance $\mathrm{N}$. The model is expressed as:

$$
\operatorname{logit}[\pi(x)]=g(x)=\beta_{0}+\beta_{1} \cdot N
$$

Eq. 6-1

With some arrangements to Eq. $6-1, \pi(x)$ can also be expressed as:

$$
\pi(x)=\frac{1}{1+e^{-\left(\beta_{0}+\beta_{1} \cdot N\right)}}
$$

Eq. 6-2

As discussed above, in order to fit the linear logistic model to the data, the values of $\beta$ s that maximize the likelihood function need to be found.

Table 6-1 lists the coefficient estimates of model M1, their standard errors and the $\mathrm{z}$ values (the estimated coefficients divided by their standard errors), the confidence intervals and the Wald tests. Also given in the table are the number of the degrees of freedom, which is the number of the regressed data minus the number of the unknown 
parameters included in the linear logistic model, and the deviance (or the likelihood ratio) which is a crucial statistic that will help us improve the model.

Table 6-1: Estimated Coefficients for the Logistic Regression Model Using the Standard Penetration Resistance $\mathbf{N}$

\begin{tabular}{|c|c|c|c|c|c|c|}
\hline \multirow{2}{*}{ Variable } & \multirow{2}{*}{ Coefficient } & \multirow{2}{*}{ Std. Err. } & \multicolumn{2}{|l|}{ Confidence Int ${ }^{*}}$. & $\mathbf{z}$ & \multirow{2}{*}{$\mathbf{P}>|\mathbf{z}|$} \\
\cline { 4 - 5 } & & & L.C.I & U.C.I & & \\
\hline Constant & 3.0707 & 0.3618 & 2.3617 & 3.7798 & 8.4879 & $0.2105 \times 1^{-16}$ \\
\hline $\mathbf{N}$ & -0.2250 & 0.0254 & -0.27475 & 0.17518 & -8.8564 & $0.0083 \times 1^{-16}$ \\
\hline d.f. & 361 & & & & & \\
\hline Deviance & 332.4111 & & & & & \\
\end{tabular}

"Confidence Int.=Confidence Interval; L.C.I=Lower Confidence Interval, U.C.I=Upper Confidence Interval

In testing the significance of the estimated coefficients, it is customary to set the significance level to 0.05 as a criterion to accept or reject the null hypothesis. If the $[P>|z|]<0.05$, we reject the null hypothesis and conclude that the coefficient is different from zero. It is shown in Table 6-1 that all the coefficients obtained are significant.

It is also desirable to have some idea about the correlation between the estimated coefficients to see how a change in one coefficient will lead to a linear change in the other one. Table 6-2 shows the correlation coefficients. 
Table 6-2: Correlation Matrix for the Coefficients

\begin{tabular}{|c|c|c|}
\hline & Constant & $\mathbf{N}$ \\
\hline Constant & 1 & -0.9253 \\
\hline $\mathbf{N}$ & -0.9253 & 1 \\
\hline
\end{tabular}

As discussed in the previous section, the deviance by itself is not adequate to test the overall goodness of fit for a binary model. Therefore, to evaluate the overall goodness of fit of the present model, it has to be compared with another model containing additional explanatory variables. The first model in this case is said to be nested in the second model.

M2 A Model Containing the Standard Penetration Resistance $(\mathrm{N})$ and the Earthquake Magnitude (M):

Now, we include the earthquake magnitude as a second explanatory variable to our model and check whether it would improve it or not:

$$
\log i t[\pi(x)]=g(x)=\beta_{0}+\beta_{1} \cdot N+\beta_{2} \cdot M
$$

Eq. 6-3

where $\pi(x)$ is given as:

$$
\pi(x)=\frac{1}{1+e^{-\left(\beta_{0}+\beta_{1} \cdot N+\beta_{2} \cdot M\right)}}
$$

Eq. 6-4 
We carry out the same analysis we did for the previous model. Tables 6-3 and 6-4 list the results obtained for the model M2. Again, all the estimated coefficients are significant as shown in the last column of Table 6-3.

Furthermore, there is a reduction in the deviance, $G=322.4111-256.2048=66.2063$, the difference in the deviance follows the chi-squared distribution (Collet 1991, and Hosmer and Leeshow 2003) with one degree of freedom and therefore, it has the p-value of $p[\chi 2(1)>66.2063]<0.05$. Hence, the reduction in the deviance due to the inclusion of the earthquake magnitude as an explanatory variable is significant. It is concluded then, a model containing the standard penetration resistance and the earthquake magnitude is better than a model containing only the standard penetration resistance. 
Table 6-3: Estimated Coefficients for the Logistic Regression Model Using the Standard Penetration Resistance $N$ and the Earthquake Magnitude $M$ as Explanatory Variables

\begin{tabular}{|c|c|c|c|c|c|c|}
\hline \multirow{2}{*}{ Variable } & \multirow{2}{*}{ Coefficient } & \multirow{2}{*}{ Std. Err. } & \multicolumn{2}{|c|}{ Confidence Int. } & \multirow[t]{2}{*}{$\mathbf{z}$} & \multirow{2}{*}{$\mathbf{P}>|\mathbf{z}|$} \\
\hline & & & L.C.I & U.C.I & & \\
\hline Constant & -8.8782 & 1.7477 & -12.304 & -5.4526 & -5.0798 & $<0.05$ \\
\hline $\mathbf{N}$ & -0.3050 & 0.0352 & -0.37402 & -0.23588 & -8.6538 & $<0.05$ \\
\hline $\mathbf{M}$ & 1.8026 & 0.2706 & 1.2722 & 2.3331 & 6.6607 & $<0.05$ \\
\hline d.f. & 360 & & & & & \\
\hline Deviance & 256.2048 & & & & & \\
\hline
\end{tabular}

Table 6-4: Correlation Matrix for the Coefficients

\begin{tabular}{|c|c|c|c|}
\hline & Constant & $\mathbf{N}$ & $\mathbf{M}$ \\
\hline Constant & 1 & 0.3381 & -0.9708 \\
\hline $\mathbf{N}$ & 0.3381 & 1 & -0.5413 \\
\hline $\mathbf{M}$ & -0.9708 & -0.5413 & 1 \\
\hline
\end{tabular}

The next step now is to investigate whether including the hypocenter distance to our model would further improve it. 


\section{M3 A Model Containing Standard Penetration Resistance $\left(\mathrm{N}_{1}\right)$,}

\section{Earthquake Magnitude (M), and Hypocenter Distance (R):}

The next step is to check whether the inclusion of the hypocenter distance as an explanatory variable would further improve the previous model (Model M2). A model containing the hypocenter distance is expressed as:

$$
\operatorname{logit}[\pi(x)]=g(x)=\beta_{0}+\beta_{1} \cdot N+\beta_{2} \cdot M+\beta_{3} \cdot R
$$

Eq. 6-5

where:

$$
\pi(x)=\frac{1}{1+e^{-\left(\beta_{0}+\beta_{1} \cdot N+\beta_{2} \cdot M+\beta_{3} \cdot R\right)}}
$$

Eq. 6-6

From the results summarized in the last column of Table 6-5 it can be concluded that all coefficients are significant in the model. The difference in the deviance is of about $G=41.9913$, with one degree of freedom, has a p-value of $p[\chi 2(1)>41.9913]<0.05$, which means a significant reduction and therefore, a model containing the hypocenter distance as an explanatory variable, along with $N$ and $M$, is better than a model that does not.

Table 6-6 shows the correlation matrix for the estimated coefficient. 
Table 6-5: Estimated Coefficients for the Logistic Regression Model Using the Standard Penetration Resistance N, the Earthquake Magnitude M, and the Hypocenter Distance as Explanatory Variables

\begin{tabular}{|c|c|c|c|c|c|c|}
\hline \multirow{2}{*}{ Variable } & \multirow{2}{*}{ Coefficient } & \multirow{2}{*}{ Std. Err. } & \multicolumn{2}{|c|}{ Confidence Int. } & $\mathbf{z}$ & \multirow{2}{*}{ P>|z| } \\
\cline { 4 - 6 } & & & L.C.I & U.C.I & & \\
\hline Constant & -12.5690 & 2.1331 & -16.75 & -8.3882 & -5.8925 & $<0.05$ \\
\hline $\mathbf{N}$ & -0.4081 & 0.0484 & -0.50296 & -0.31316 & -8.4279 & $<0.05$ \\
\hline $\mathbf{M}$ & 2.7708 & 0.3755 & 2.0349 & 3.5067 & 7.3795 & $<0.05$ \\
\hline R & -0.0283 & 0.0052 & -0.03844 & -0.018111 & -5.4521 & $<0.05$ \\
\hline d.f. & 359 & & & & &
\end{tabular}

Table 6-6: Correlation Matrix for the Coefficients

\begin{tabular}{|c|c|c|c|c|}
\hline & Constant & $\mathbf{N}$ & $\mathbf{M}$ & $\mathbf{R}$ \\
\hline Constant & 1 & 0.5086 & -0.9581 & 0.4168 \\
\hline $\mathbf{N}$ & 0.5086 & 1 & -0.7102 & 0.5724 \\
\hline $\mathbf{M}$ & -0.9581 & -0.7102 & 1 & -0.5924 \\
\hline $\mathbf{R}$ & 0.4168 & 0.5724 & -0.5924 & 1 \\
\hline
\end{tabular}




\section{M4 A Model Containing Standard Penetration Resistance $\left(\mathrm{N}_{1}\right)$,}

Earthquake Magnitude (M), Hypocenter Distance (R) and the Effective

\section{Overburden Stress $\left(\sigma_{0}\right)^{\prime}$ :}

The effective overburden stress is now included in the model to check whether it would improve it or not. The model is expressed as:

$$
\operatorname{logit}[\pi(x)]=g(x)=\beta_{0}+\beta_{1} \cdot N+\beta_{2} \cdot M+\beta_{3} \cdot R+\beta_{4} \cdot \sigma_{0}^{\prime}
$$

Eq. 6-7

where:

$$
\pi(x)=\frac{1}{1+e^{-\left(\beta_{0}+\beta_{1} \cdot N+\beta_{2} \cdot M+\beta_{3} \cdot R+\beta_{4} \cdot \sigma_{0}^{\prime}\right)}}
$$

Tables 6-7 and 6-8 list the results obtained for Model M-4. Again, all the obtained coefficients are significant, based on the Wald test shown in the last column of Table 6-7. It should be noted that the correlation coefficients may not necessarily have physical meanings.

In addition, the difference in the deviance, due to the inclusion of the effective overburden stress, is of about $G=14.4448$, with one degree of freedom, has a p-value of $p\left[\chi^{2}(1)>14.4448\right]<0.05$, which means a significant reduction. Therefore, the effective overburden stress should be included in our model. 
Table 6-7: : Estimated Coefficients for the Logistic Regression Model Using the Standard Penetration Resistance N, the Earthquake Magnitude M, the Hypocenter Distance, and the effective overburden stress as Explanatory Variables

\begin{tabular}{|c|c|c|c|c|c|c|}
\hline \multirow{2}{*}{ Variable } & \multirow{2}{*}{ Coefficient } & \multirow{2}{*}{ Std. Err. } & \multicolumn{2}{|c|}{ Confidence Int. } & \multirow[t]{2}{*}{$\mathbf{z}$} & \multirow{2}{*}{$\mathbf{P}>|\mathbf{z}|$} \\
\hline & & & L.C.I & U.C.I & & \\
\hline Constant & -12.5921 & 2.2588 & -17.0194 & -8.1649 & -5.5747 & $<0.05$ \\
\hline $\mathbf{N}$ & -0.4422 & 0.0543 & -0.5486 & -0.3359 & -8.1485 & $<0.05$ \\
\hline $\mathbf{M}$ & 3.0880 & 0.4219 & 2.2612 & 3.9148 & 7.3201 & $<0.05$ \\
\hline $\mathbf{R}$ & -0.0324 & 0.0056 & -0.0435 & -0.0214 & -5.7529 & $<0.05$ \\
\hline$\sigma_{0}^{\prime}$ & -0.0195 & 0.0054 & -0.0301 & -0.0089 & -3.6152 & $<0.05$ \\
\hline d.f. & 358 & & & & & \\
\hline Deviance & 199.7687 & & & & & \\
\hline
\end{tabular}


Table 6-8: Correlation Matrix for the Coefficients

\begin{tabular}{|c|c|c|c|c|c|}
\hline & Constant & $\mathbf{N}$ & $\mathbf{M}$ & $\mathbf{R}$ & $\sigma_{0}{ }^{\prime}$ \\
\hline Constant & 1 & 0.5318 & -0.9363 & 0.4492 & 0.1164 \\
\hline $\mathbf{N}$ & 0.5318 & 1 & -0.7514 & 0.6128 & 0.3348 \\
\hline $\mathbf{M}$ & -0.9363 & -0.7514 & 1 & -0.6438 & -0.3416 \\
\hline $\mathbf{R}$ & 0.4492 & 0.6128 & -0.6438 & 1 & 0.3007 \\
\hline$\sigma_{\mathbf{0}}{ }^{\prime}$ & 0.1164 & 0.3348 & -0.3416 & 0.3007 & 1 \\
\hline
\end{tabular}

Table 6-9 summarizes the statistics of the four nested models discussed above.

Table 6-9: Summary Statistics of Four Nested Models

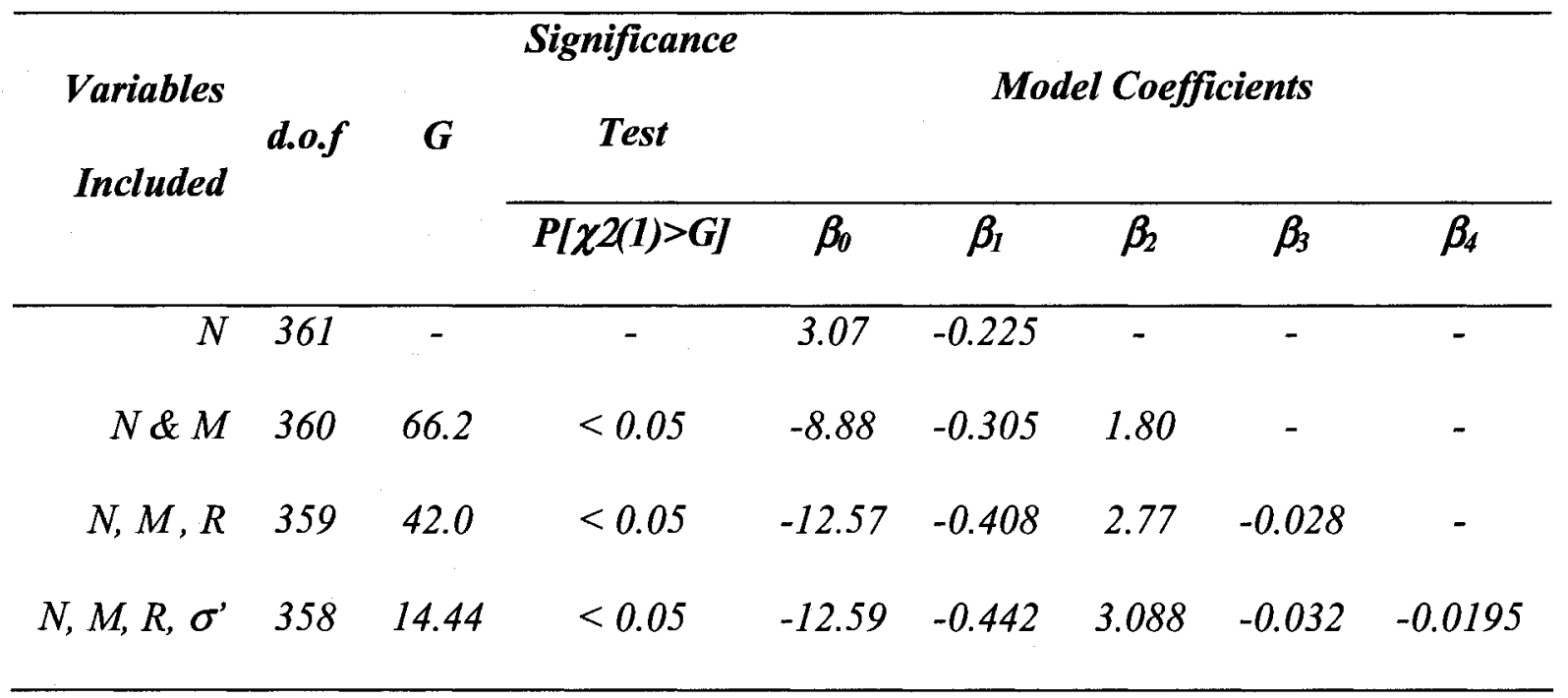




\subsection{MODEL CHECKING (DIAGNOSTICS):}

After the model has been developed with all the relevant variables deemed to be crucial in modeling the response variable, several diagnostic procedures should be carried out to verify whether the developed model is an accurate and correct model. These diagnostics pertain to several aspects of the model such as the form of the linear predictor, the forms of the explanatory variables used in the model and the adequacy of the link function used in the transformation. Many procedures can be used for checking the form of the linear predictor. The half-normal probability plot with simulated envelopes will be employed in this study due to its ease of interpretation.

It is also vital to know for each explanatory variable whether it was included in the model in the right form. So far we have included all the explanatory variables without any transformation. However, a transformation of the variable may be necessary to increase the accuracy of the model. Some of these transformations may include the logarithmic, the reciprocal or the squared root transformation.

The logit transformation has been used in the analysis without checking whether it suited the model or not. It could have been that the complementary log-log transformation is a better choice for the transformation. Therefore, a procedure to investigate the adequacy of the logit link function is also carried out. The reader is referred to Collette (1991) and Hosmer and Lemeshow (2003) for further reading on diagnostic techniques. 
A key statistic in the diagnostic procedure is the residual, which is explained in Appendix D along with all the diagnostic techniques employed in the development of the model.

\section{The constructed variable plot for $N$ :}

The constructed variable plot for the standard penetration resistance is shown in Figure 6-1. It is usually rather difficult, when modeling binary data, to interpret a plot of residuals as it is extremely scattered. Therefore, a smoothing technique will be applied to the data to facilitate the interpretation process. A smoothing algorithm proposed by Cleveland (1979) is used in this study as it is already implemented in MATLAB. After smoothing the data, Figure 6-2, a fit is applied to them to check whether a non-linear term of $N$ should be included rather than $N$. The slope of the fitted line is 0.3 so the power $\lambda$, to which $N$ should be raised is estimated to be 1.3, which is not far from 1 . Therefore, we can conclude that no transformation of $N$ needed in the model. To be sure, the transformation of $N$ to $N^{1.5}$ was carried out anyway and the resulting deviance was of about 198.57, which is not a significant reduction from the previous deviance (199.77). Therefore, no transformation of $N$ is necessary. 


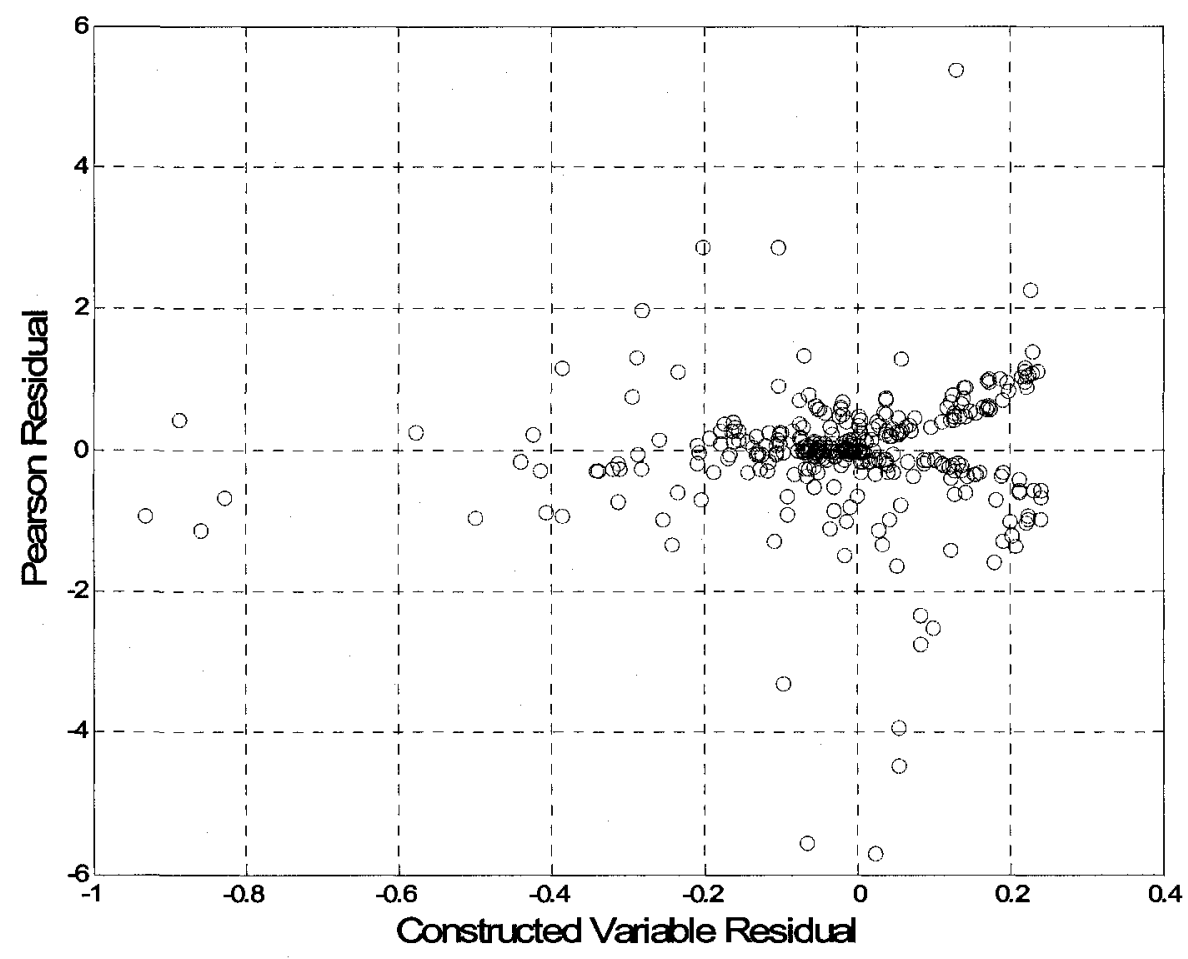

Figure 6-1: Constructed variable plot for $\mathrm{N}$ in a linear logistic regression model fitted to the compiled data 


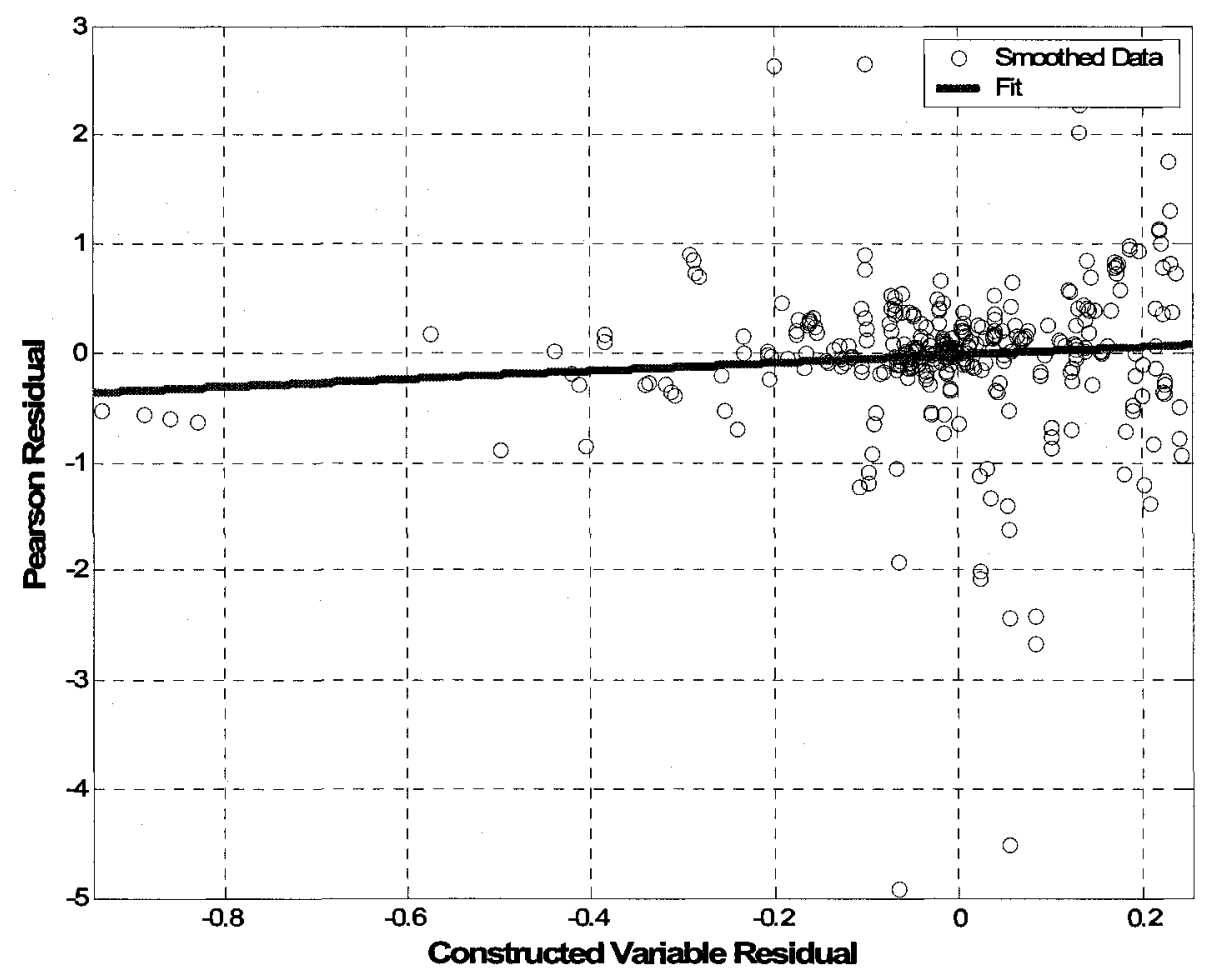

Figure 6-2: Constructed variable plot for $N$ in a linear logistic regression model fitted to the compiled data after smoothing them out

\section{The constructed variable plot for M:}

Now we move on to check on the explanatory variable $M$ (earthquake magnitude) whether it needs to be transformed or not. The smoothed data of the constructed variable residuals are shown in Figure 6-3. A fitted line is also shown on the same figure. It should be noted that it is sometimes necessary to exclude some of the outliers before fitting the line. In this particular case, two data having Pearson residuals smaller than -5 were excluded. The slope of the flitted line is -3 , therefore, the power $\lambda$, to which $\mathrm{M}$ should be raised, is estimated to be -2 , i.e., $\mathrm{M}$ should be included in the model as $\mathrm{M}^{-2}$. 
After the transformation of the variable is made, the coefficients of the model are reestimated again, Tables 6-10 and 6-11. We can see that the transformation of $M$ has reduced the deviance to 190.85 from 199.77 which is considered a significant improvement to the model.

Now to check whether the transformation was successful or not, the constructed variable residuals of the (transformed) explanatory variable $\mathrm{M}$ are plotted again against Pearson residuals, Figure 6-4. We can see that the slope of the fitted line is 0.1 and therefore $\lambda$ is about 1.1 suggesting that there is no linear trend in the data anymore and therefore, the transformation of $\mathrm{M}$ was successful.

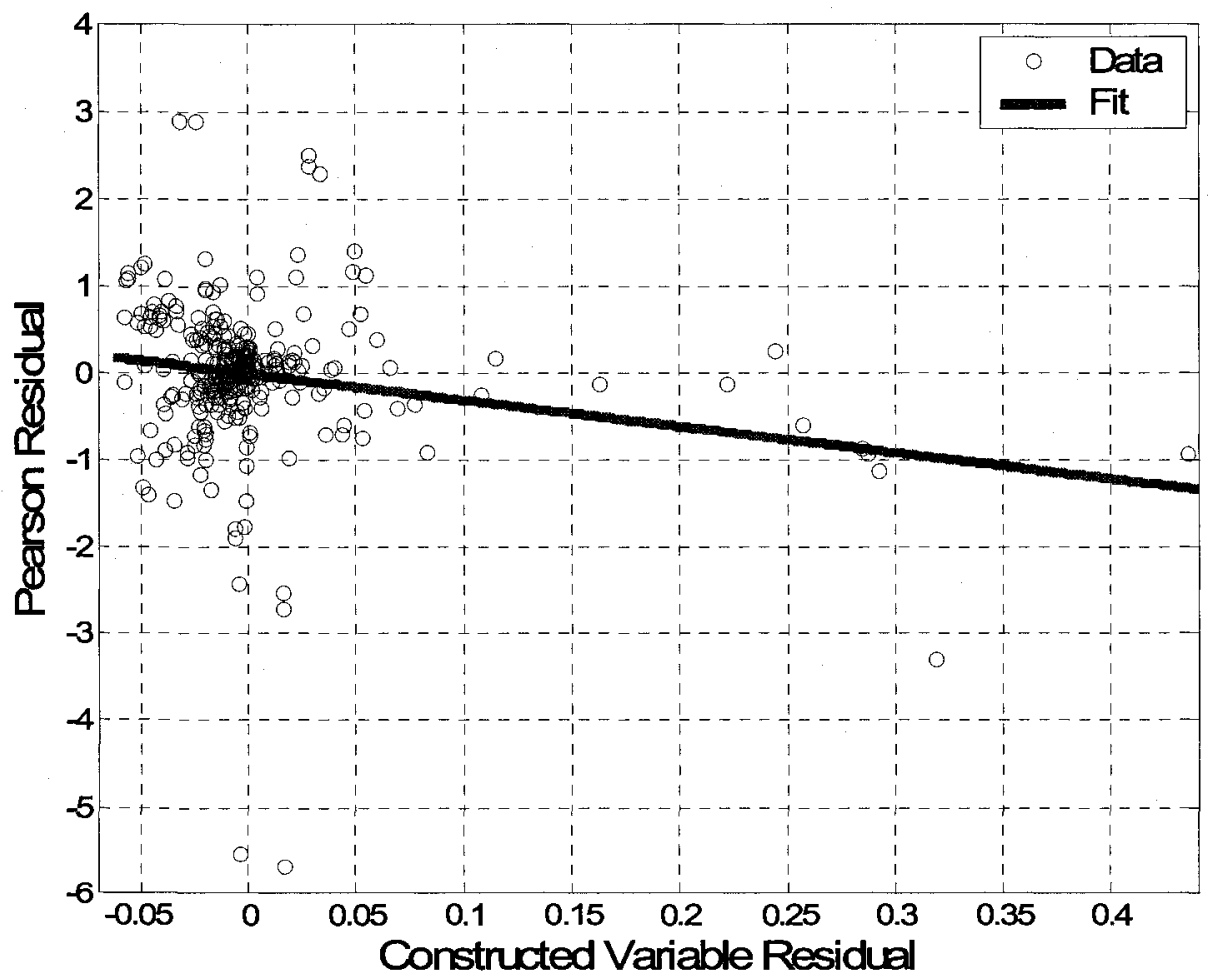

Figure 6-3: Constructed variable residuals of the earthquake magnitude $M$ 


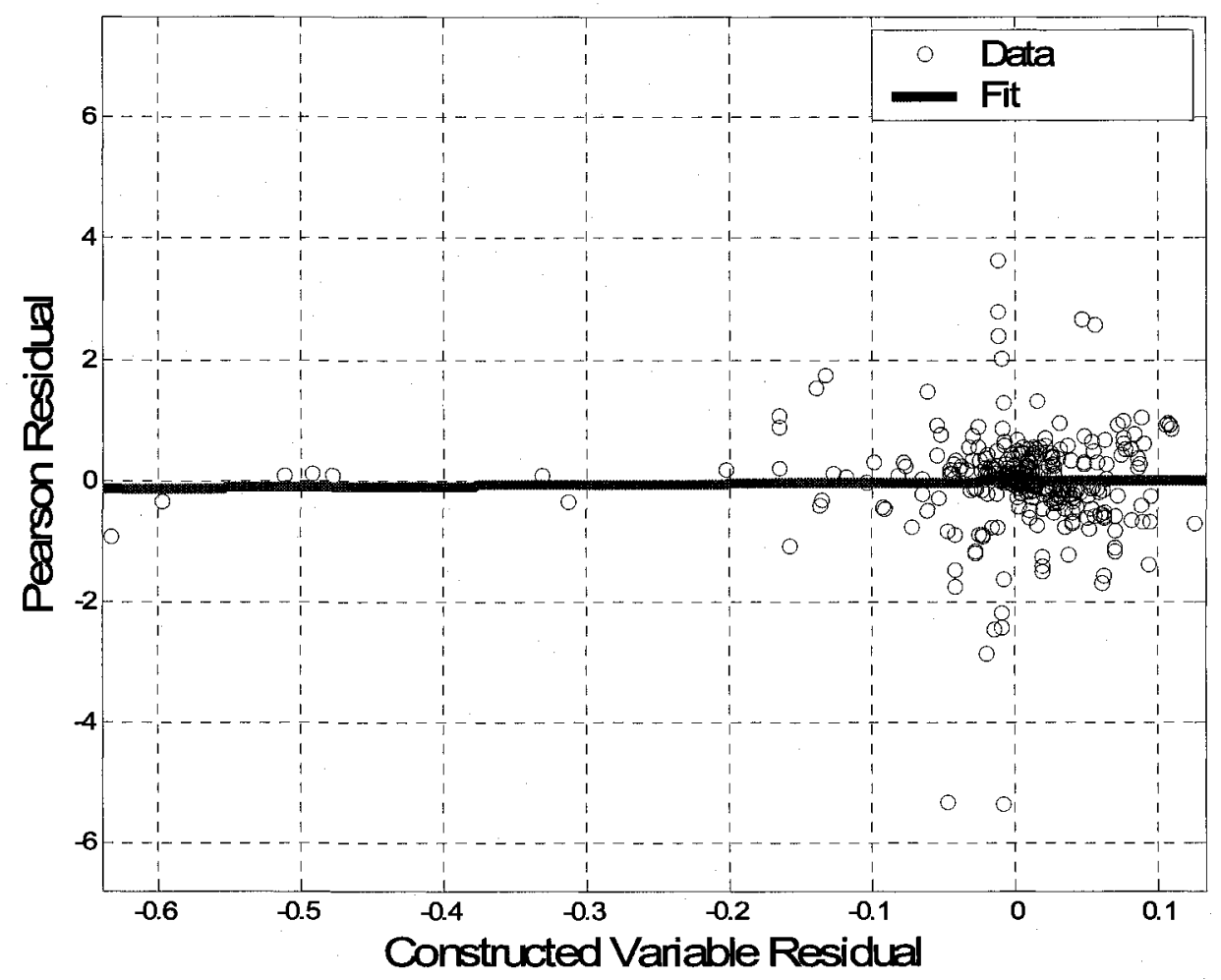

Figure 6-4: Constructed variable residuals of $M$ after transformation 
Table 6-10: Estimated Coefficients for the Logistic Regression Model Using the Standard Penetration Resistance N, the Earthquake Magnitude as $\mathbf{M}^{-2}$, the Hypocenter Distance, and the effective overburden stress as Explanatory Variables

\begin{tabular}{|c|c|c|c|c|c|c|}
\hline \multirow{2}{*}{ Variable } & \multirow{2}{*}{ Coefficient } & \multirow{2}{*}{ Std. Err. } & \multicolumn{2}{|c|}{ Confidence Int. } & \multirow[t]{2}{*}{$\mathbf{z}$} & \multirow{2}{*}{$\mathbf{P}>|\mathbf{z}|$} \\
\hline & & & L.C.I & U.C.I & & \\
\hline Constant & 20.6548 & 2.4984 & 15.7580 & 25.5516 & 8.2673 & $<0.05$ \\
\hline $\mathbf{N}$ & -0.4507 & 0.0549 & -0.5583 & -0.3431 & -8.2089 & $<0.05$ \\
\hline $\mathbf{M}^{-2}$ & -538.5077 & 73.3086 & -682.19 & -394.82 & -7.3458 & $<0.05$ \\
\hline $\mathbf{R}$ & -0.0331 & 0.0058 & -0.0444 & -0.0217 & -5.7155 & $<0.05$ \\
\hline$\sigma_{0}^{\prime}$ & -0.0218 & 0.0056 & -0.0327 & -0.0109 & -3.9142 & $<0.05$ \\
\hline d.f. & 358 & & & & & \\
\hline Deviance & 190.85 & & & & & \\
\hline
\end{tabular}


Table 6-11: Correlation Matrix for the Coefficients

\begin{tabular}{|c|c|c|c|c|c|}
\hline & Constant & $\mathbf{N}$ & $\mathbf{M}^{-2}$ & $\mathbf{R}$ & $\mathbf{\sigma}_{\mathbf{0}}$ \\
\hline Constant & 1 & & & & \\
\hline $\mathbf{N}$ & -0.8534 & 1 & & & \\
\hline $\mathbf{M}^{-2}$ & -0.9343 & 0.7013 & 1 & & \\
\hline $\mathbf{R}$ & -0.7416 & 0.6153 & 0.6042 & 1 & \\
\hline $\mathbf{\sigma}_{\mathbf{0}}{ }^{\prime}$ & -0.5333 & 0.3586 & 0.3533 & 0.3240 & 1 \\
\hline
\end{tabular}

\section{The constructed variable plot for $R$ :}

Figure 6-5 shows the constructed variable plot for the hypocenter distance $R$. The slope of the fitted line is -0.82 and therefore $\lambda=0.18$, which is not far from zero, suggesting that $R$ should be subject to the logarithmic transformation. The estimated coefficients and the other statistics resulting from fitting a model that contain $\ln (R)$ instead of $R$ are shown in Tables 6-12 and 6-13. The resulting deviance is 178.96 indicating a reduction of about 11.89 which is a significant reduction.

Again, a successful transformation is verified by re-plotting the constructed variable residuals and making sure that there is no linear trend in the data, Figure 6-6. The slope 
of the line is 0.3 and therefore $\lambda=1.3$ which is close to one, suggesting that the transformation was successful.

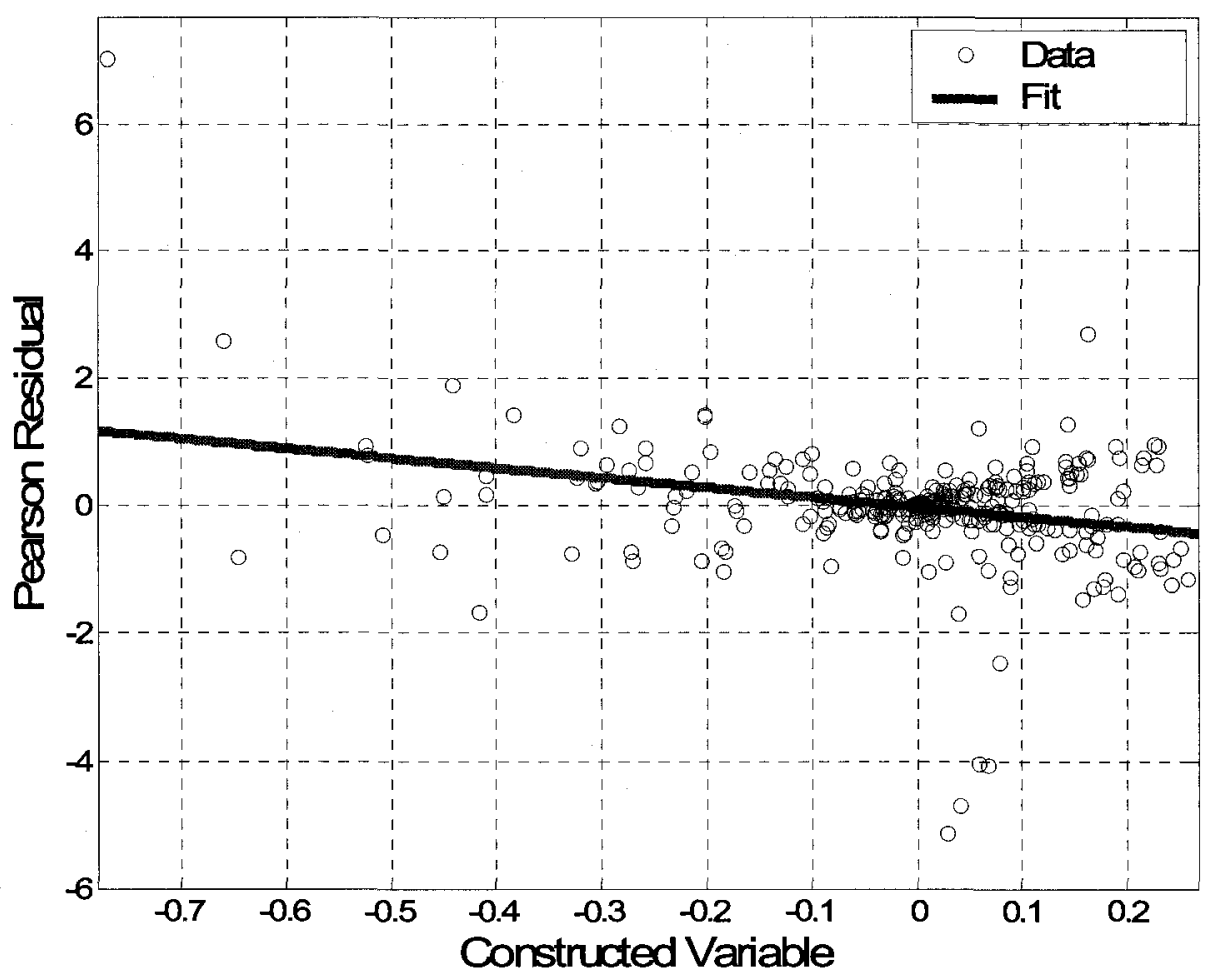

Figure 6-5: Constructed variable plot for the explanatory variable $R$ 


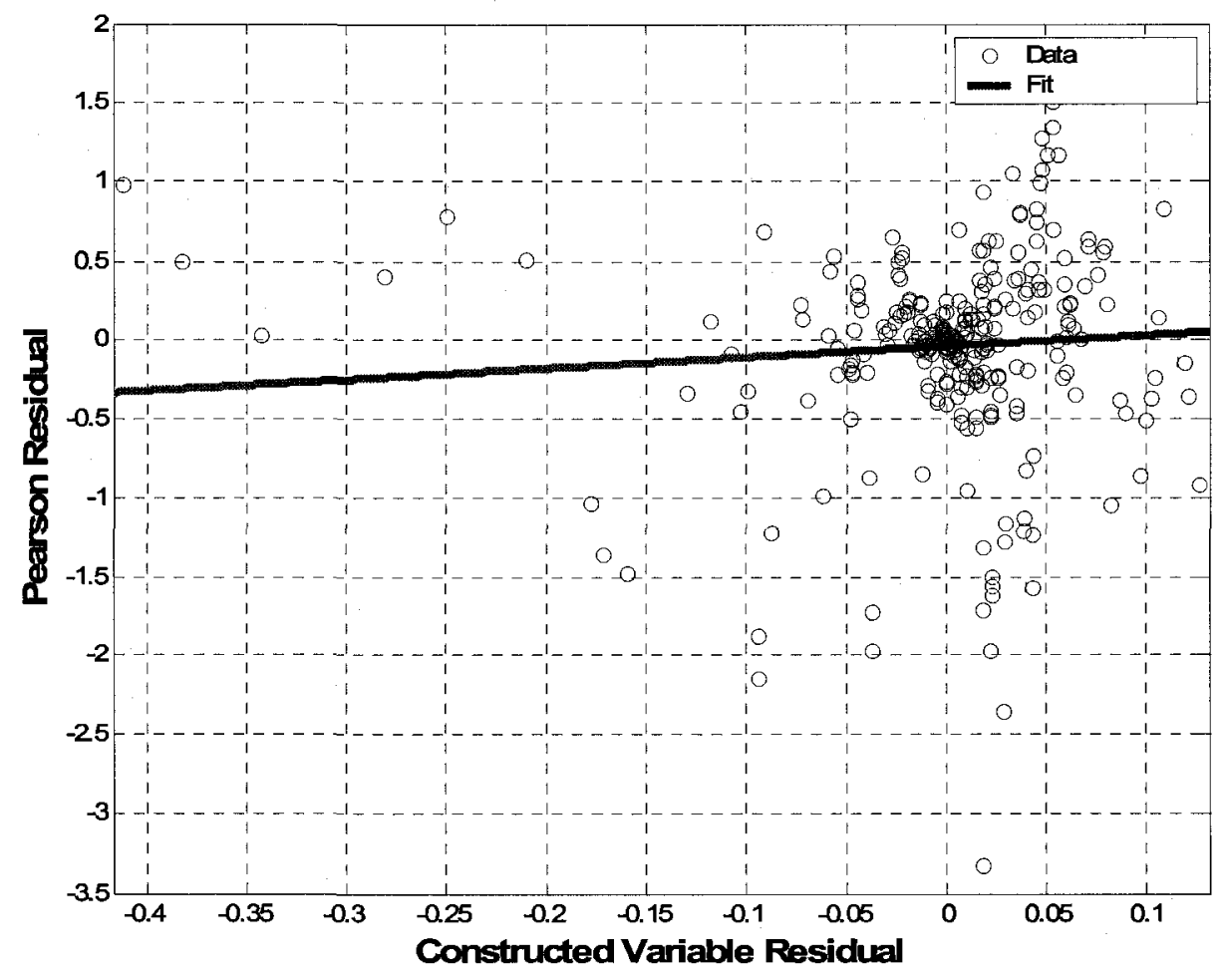

Figure 6-6: Constructed variable plot for the transformed $R$ 
Table 6-12: Estimated Coefficients for the Logistic Regression Model Using the Standard Penetration Resistance $\mathbf{N}$, the Earthquake Magnitude as $M^{-2}$, the Hypocenter Distance as $\ln (R)$, and the effective overburden stress as Explanatory Variables

\begin{tabular}{|c|c|c|c|c|c|c|}
\hline \multirow{2}{*}{ Variable } & \multirow{2}{*}{ Coefficient } & \multirow{2}{*}{ Std. Err. } & \multicolumn{2}{|c|}{ Confidence Int. } & \multirow[t]{2}{*}{$\mathbf{z}$} & \multirow{2}{*}{$\mathbf{P}>|\mathbf{z}|$} \\
\hline & & & L.C.I & U.C.I & & \\
\hline Constant & 29.7847 & 3.7487 & 22.4373 & 37.1322 & 7.9454 & $<0.05$ \\
\hline $\mathbf{N}$ & -0.5011 & 0.0634 & -0.6253 & -0.3768 & -7.9040 & $<0.05$ \\
\hline $\mathbf{M}^{-2}$ & -616.0268 & 83.5921 & -779.87 & -452.19 & -7.3694 & $<0.05$ \\
\hline $\operatorname{Ln}(\mathbf{R})$ & -2.3356 & 0.3711 & -3.0629 & -1.6083 & -6.2941 & $<0.05$ \\
\hline$\sigma_{0}^{\prime}$ & -0.0204 & 0.0056 & -0.0314 & -0.0094 & -3.6236 & $<0.05$ \\
\hline d.f. & 358 & & & & & \\
\hline Deviance & 178.96 & & & & & \\
\hline
\end{tabular}


Table 6-13: Correlation Matrix for the Coefficients

\begin{tabular}{|c|c|c|c|c|c|}
\hline & Constant & $\mathbf{N}$ & $\mathbf{M}^{-2}$ & $\operatorname{In}(\mathbf{R})$ & $\mathbf{\sigma}_{0}{ }^{\prime}$ \\
\hline Constant & 1 & - & - & - & - \\
\hline $\mathbf{N}$ & -0.8565 & 1 & - & - & - \\
\hline $\mathbf{M}^{-2}$ & -0.9229 & 0.7608 & 1 & - & - \\
\hline $\ln (\mathbf{R})$ & -0.8847 & 0.6642 & 0.7004 & 1 & - \\
\hline$\sigma_{0}{ }^{\prime}$ & -0.4524 & 0.3359 & 0.3393 & 0.2840 & 1 \\
\hline
\end{tabular}

\section{The constructed variable plot for $\sigma_{o}^{\prime}$}

Figure 6-7 shows the constructed variable plot for the effective overburden stress $\sigma_{0}^{\tilde{r}}$ The line fitted to the data has a slope of 1.7 and therefore $\lambda=2.5$. Implementing the above transformation results in a deviance of 174.21 which indicates a reduction of about 4.75 from the previous model. However, some numerical difficulties were encountered during the maximization process. Therefore, it was concluded that a model containing a transformed $\sigma_{0}$ ' would just as good as the model that does not. Figure 6-8 also shows that the transformation was successful ( 0.15 slope). 


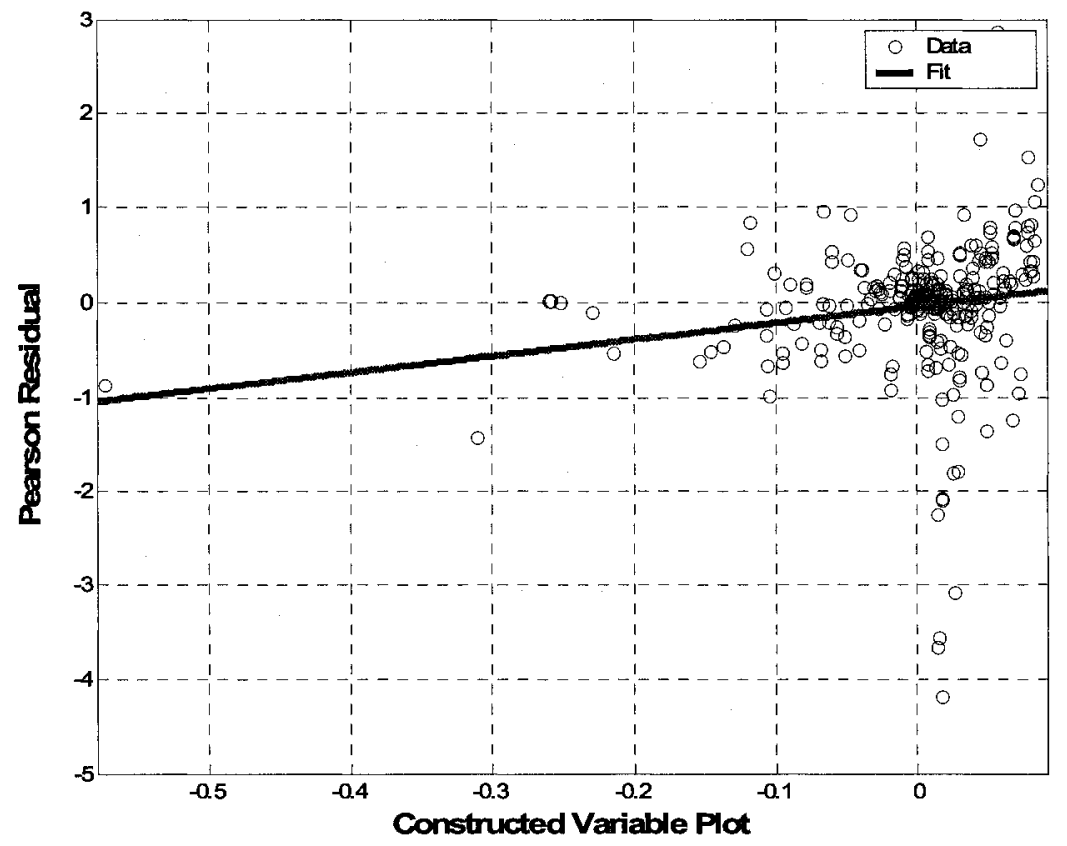

Figure 6-7: Constructed variable plot for the effective overburden stress

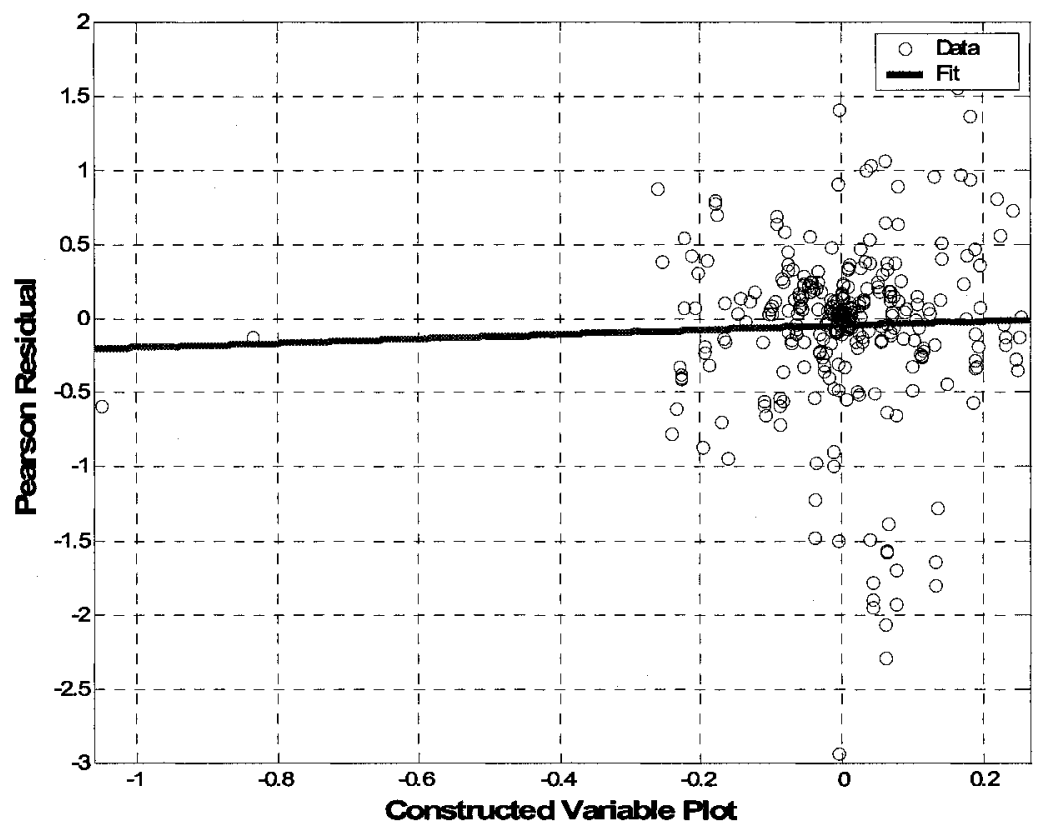

Figure 6-8: Constructed variable plot for the transformed $\sigma_{0}{ }^{\prime}$ 


\section{The added variable plot for $\sigma$}

We can also investigate, using the added variable plot (see Appendix D), whether another explanatory variable such as the total stress needs to be added to our model. Figure 6-9 shows the added variable plot for the total stress. It can be readily seen in the figure that no linear trend exists between Pearson residuals and the added variable residuals suggesting that the total stress is not important to be included in our model.

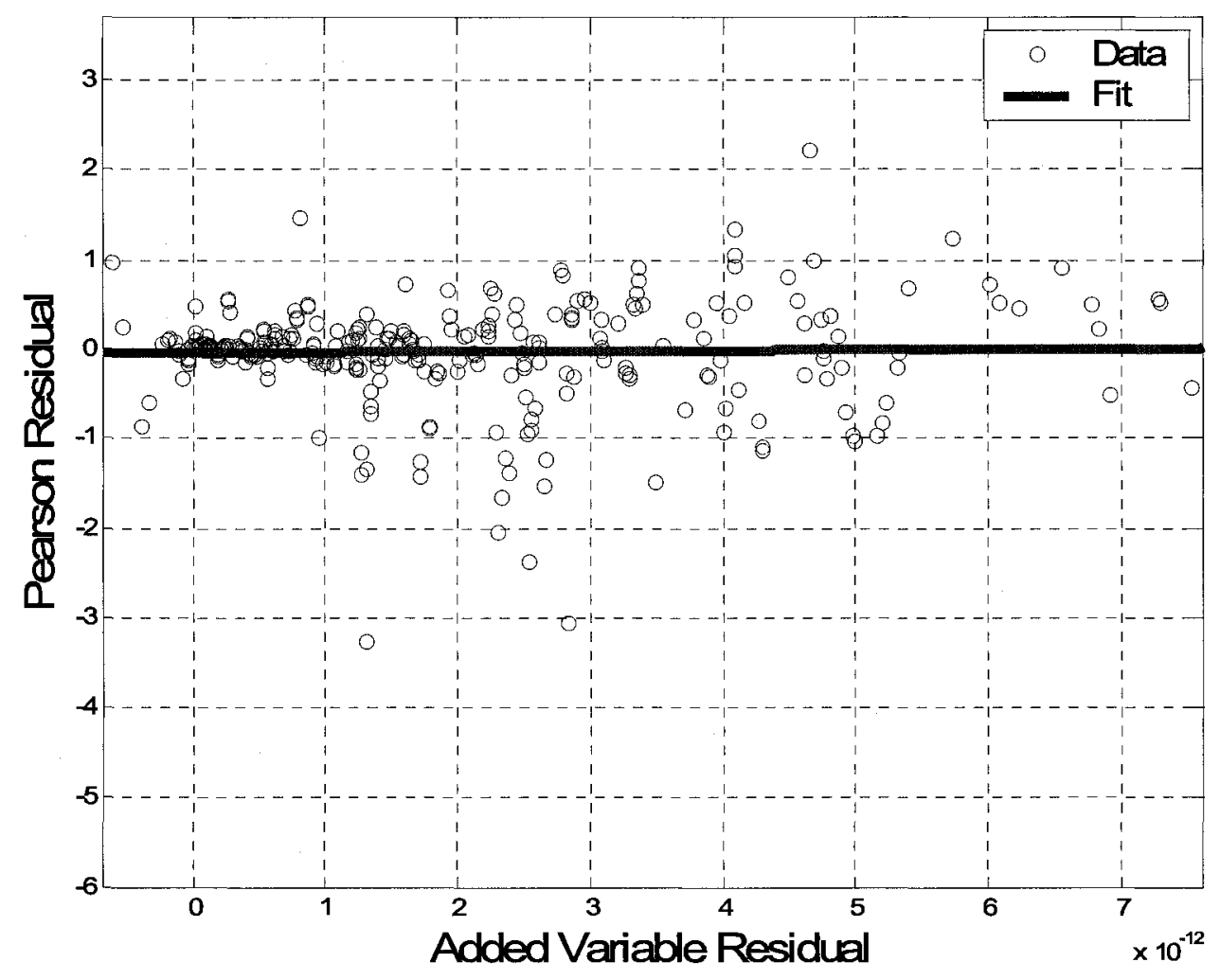

Figure 6-9: Added variable plot for the inclusion of the total stress $\sigma$ 


\section{Checking the adequacy of the link function:}

The procedure for checking the adequacy of the link function used in the regression analysis is carried out such that another constructed variable $z$ (defined in Appendix D) is added to the logistic regression model as an additional explanatory variable, then the reduction in the deviance is tested to check whether it is a significant reduction or not. If the reduction in deviance was significant, then we conclude that the logistic transformation we used was not a good choice and therefore, other link function should be considered, see Appendix D for more details.

When including the constructed variable $z_{i}$, defined above, to the model (updated model), the resulted deviance was 174.41 . That is, there was a reduction of about 3.78 , with one degree of freedom, has a $p$-value of $p[\chi 2(1)>3.78]=0.05191>0.05$ which means not a significant reduction. Moreover, the estimated coefficient of the added variable is -1.1852 and therefore, the parameter $\alpha=2$, which does not indicate any sensible value of the $\alpha$ parameter to use in a revised link function. Therefore, the logit function in our model is indeed satisfactory.

Figure 6-10 shows the half-normal probability plot and the simulated envelope for the developed model. It can be seen from the figure that all the plotted points of the standardized deviance residuals lie within the simulated envelope and the plot does not display any unusual features. Therefore, it can be concluded the developed model is appropriate. 


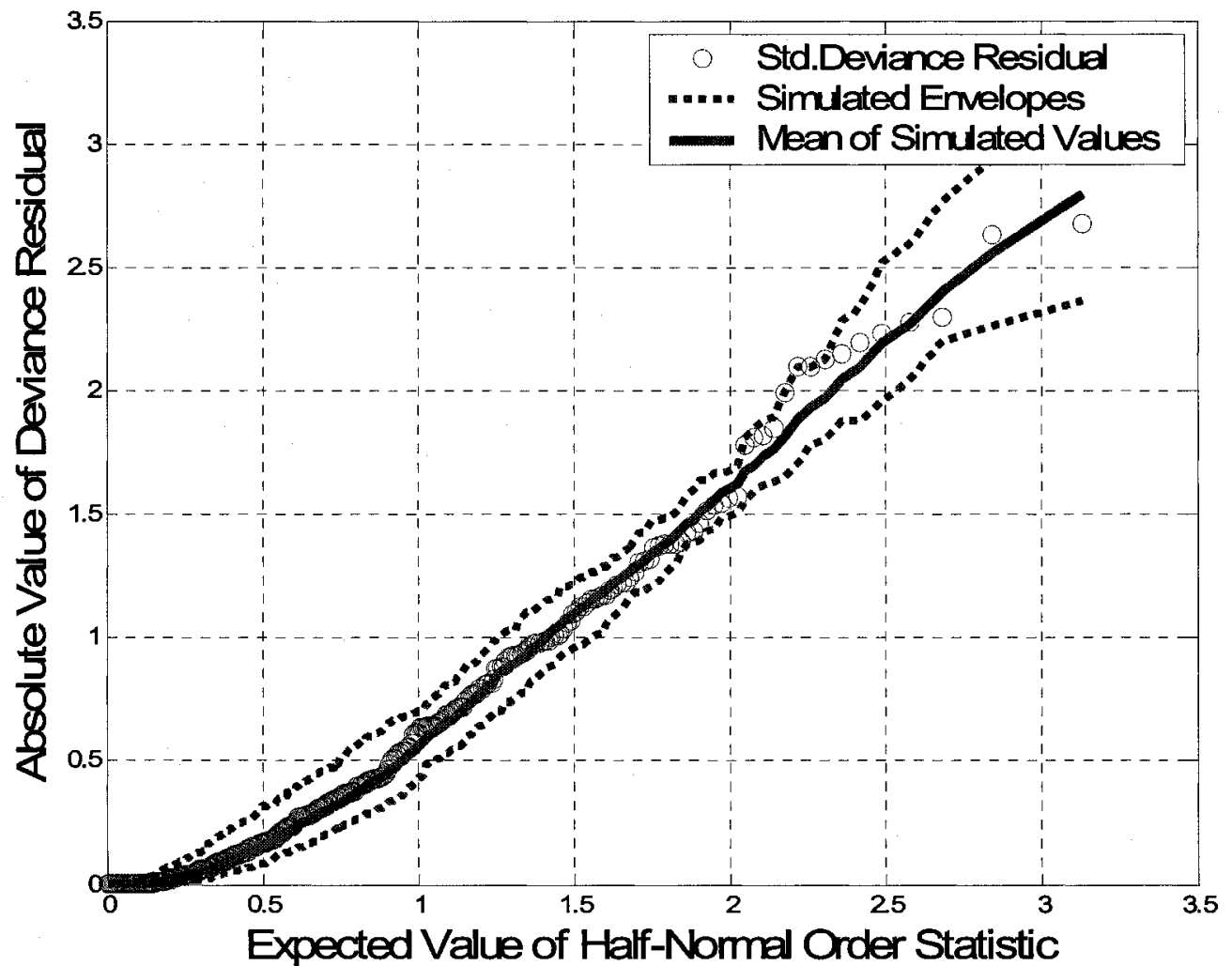

Figure 6-10: Half-normal plot of the standardized deviance residuals after fitting a logistic regression line to the complied data of liquefaction occurence 
Now that we have checked that the developed model is correct and determined the proper transformation of the explanatory variable included in the model, it is useful to re-write the final version of the updated model:

$$
\operatorname{logit}\left[P_{L i q}\right]=g(x)=\beta_{0}+\beta_{1} \cdot N+\beta_{2} \cdot \frac{1}{M^{2}}+\beta_{3} \cdot \ln (R)+\beta_{4} \cdot \sigma_{0}^{\prime}
$$

Eq. 6-9

where:

$$
P_{L i q}=\frac{1}{1+e^{-\left(\beta_{0}+\beta_{1} \cdot N+\beta_{2} \cdot \frac{1}{M^{2}}+\beta_{3} \cdot \ln (R)+\beta_{4} \cdot \sigma_{0}^{\prime}\right)}}
$$

and the coefficients of the model are presented in Table 11 and are repeated here as follows:

\begin{tabular}{c|c|c|c|c}
$\beta_{0}$ & $\beta_{1}$ & $\beta_{2}$ & $\beta_{3}$ & $\beta_{4}$ \\
\hline 29.78 & -0.50 & -616.03 & -2.34 & -0.020
\end{tabular}

\section{$6.4 \quad$ RESULTS}

Using the above model, probability curves were derived in terms of varying seismic and soil parameters. Refer to Appendix D for the plots of probability of liquefaction curves. 


\subsection{COMPARISON BETWEEN THE LOGISTIC REGRESSION MODEL AND THE RELIABILITY-BASED MODEL}

It is of interest to compare the probability of liquefaction obtained from the logistic model and the ones obtained from the reliability model. Table 6-14 summarizes some of the results obtained using both models.

Table 6-14: Comparison of Probabilities obtained from Logistic Model and Reliability Model

\begin{tabular}{|l|l|l|l|c|c|}
\hline$\left(\mathbf{N}_{\mathbf{1}} \mathbf{6}_{\mathbf{6}}\right.$ & $\mathbf{M}_{\mathbf{W}}$ & $\mathbf{R}(\mathbf{k m})$ & $\sigma_{\mathbf{0}}(\mathbf{k P a})$ & $\begin{array}{c}\text { Logistic } \\
\text { Model }\end{array}$ & $\begin{array}{c}\text { Reliability } \\
\text { Model }\end{array}$ \\
\hline 10.10 & 7.60 & 121.00 & 81.70 & 0.77 & 0.79 \\
\hline 10.14 & 7.60 & 49.00 & 47.55 & 0.98 & 0.91 \\
\hline 11.24 & 6.70 & 43.00 & 20.93 & 0.77 & 0.73 \\
\hline 11.29 & 6.90 & 74.10 & 74.13 & 0.41 & 0.56 \\
\hline 12.00 & 7.50 & 114.00 & 42.76 & 0.71 & 0.70 \\
\hline 12.14 & 7.50 & 62.00 & 75.84 & 0.83 & 0.76 \\
\hline 13.19 & 7.60 & 86.10 & 61.61 & 0.70 & 0.68 \\
\hline 13.78 & 9.20 & 94.50 & 54.35 & 0.98 & 0.96 \\
\hline 14.20 & 7.60 & 34.90 & 98.20 & 0.85 & 0.75 \\
\hline 14.20 & 7.50 & 114.00 & 40.24 & 0.46 & 0.57 \\
\hline 15.60 & 7.60 & 45.20 & 94.58 & 0.62 & 0.63 \\
\hline 15.93 & 7.60 & 68.00 & 57.79 & 0.53 & 0.58 \\
\hline
\end{tabular}




\begin{tabular}{|l|l|l|l|l|l|}
\hline 16.48 & 9.20 & 65.30 & 61.65 & 0.96 & 0.95 \\
\hline 17.30 & 7.90 & 72.00 & 56.90 & 0.52 & 0.61 \\
\hline 17.78 & 7.60 & 28.90 & 31.66 & 0.85 & 0.73 \\
\hline 20.73 & 7.60 & 16.60 & 70.12 & 0.68 & 0.64 \\
\hline 21.40 & 7.60 & 17.00 & 72.43 & 0.57 & 0.60 \\
\hline 22.02 & 7.60 & 17.20 & 44.69 & 0.63 & 0.63 \\
\hline 15.80 & 7.00 & 92.00 & 93.40 & 0.04 & 0.24 \\
\hline 15.85 & 6.90 & 74.10 & 116.49 & 0.03 & 0.23 \\
\hline 16.20 & 6.40 & 50.00 & 93.67 & 0.01 & 0.16 \\
\hline 16.40 & 8.20 & 181.00 & 30.45 & 0.41 & 0.63 \\
\hline 16.96 & 7.60 & 12.10 & 100.92 & 0.94 & 0.80 \\
\hline 17.15 & 6.90 & 74.10 & 123.55 & 0.01 & 0.17 \\
\hline 17.36 & 7.30 & 20.60 & 52.51 & 0.80 & 0.66 \\
\hline 17.59 & 7.60 & 65.00 & 37.16 & 0.45 & 0.55 \\
\hline 17.59 & 7.90 & 102.00 & 37.80 & 0.38 & 0.56 \\
\hline 18.43 & 7.60 & 58.00 & 32.47 & 0.43 & 0.55 \\
\hline 19.39 & 9.50 & 127.90 & 83.62 & 0.55 & 0.87 \\
\hline 20.84 & 7.60 & 11.20 & 69.05 & 0.84 & 0.72 \\
\hline 21.68 & 7.60 & 15.00 & 74.43 & 0.60 & 0.62 \\
\hline
\end{tabular}

Although the results shown in Table 6-14 are in close agreement, however, some differences may very well be found sometimes. However, these differences are not unexpected owing to the fact that the reliability-based analysis utilizes a predefined 
seismic energy model as a criterion for liquefaction failure and it also considers the variables (soil and seismic) used in the analysis as uncertain quantities, i.e., it accounts for the errors in the measurements of the variables. However, the logistic model is not based on any pre-defined model, it was built in a step-by-step manner as explained above and it is solely based on the field data and the logistic model treats the measurements (variables) as exact values with no uncertainties taken into consideration.

\subsection{AN ALTERNATIVE MODEL: A MODEL CONTAINING THE SEISMIC ENERGY AND THE STANDARD PENETRATION \\ RESISTANCE}

A simpler model can also be developed in terms of the seismic energy, which represents the combined effects of earthquake magnitude, hypocenter distance and the effective overburden stress, and the standard penetration resistance. The model is expressed as:

$$
\operatorname{logit}[\pi(x)]=g(x)=\beta_{0}+\beta_{1} \cdot N+\beta_{2} \cdot \ln (S)
$$

Eq. 6-11

where:

$$
\pi(x)=\frac{1}{1+e^{-\left(\beta_{0}+\beta_{1} \cdot N+\beta_{2} \cdot \ln (S)\right)}}
$$

where $\mathrm{S}$ is computed using Eq. 5-10. 
The advantages of this model is that it is rather simple and seismic energy and the standard penetration resistance of the soil are the only information need to find out the probability of liquefaction.

The estimated coefficients and the associated statistics are presented in Tables 6-15 and 6-16.

Table 6-15: Estimated Coefficients for the Logistic Regression Model Using the Standard Penetration Resistance $N$ and the Seismic Energy $S$

\begin{tabular}{|c|c|c|c|c|c|c|}
\hline \multirow{2}{*}{ Variable } & \multirow{2}{*}{ Coefficient } & \multirow{2}{*}{ Std. Err. } & \multicolumn{2}{|c|}{ Confidence Int. } & \multirow[t]{2}{*}{$\mathbf{z}$} & \multirow{2}{*}{$\mathbf{P}>|\mathbf{z}|$} \\
\hline & & & L.C.I & U.C.I & & \\
\hline Constant & -5.8922 & 1.1332 & -8.1132 & -3.6712 & -5.1997 & $<0.05$ \\
\hline $\mathbf{N}$ & -0.4554 & 0.0566 & -0.5664 & -0.3445 & -8.0456 & $<0.05$ \\
\hline $\ln (S)$ & 0.9447 & 0.1269 & 0.6960 & 1.1933 & 7.4464 & $<0.05$ \\
\hline d.f. & 360 & & & & & \\
\hline Deviance & 199.8972 & & & & & \\
\hline
\end{tabular}


Table 6-16: Correlation Matrix for the Coefficients

\begin{tabular}{|c|c|c|c|}
\hline & Constant & $\mathbf{N}$ & $\ln (\mathbf{S})$ \\
\hline Constant & 1 & - & - \\
\hline $\mathbf{N}$ & 0.4694 & 1 & - \\
\hline $\ln (\mathbf{S})$ & -0.9044 & -0.7888 & 1 \\
\hline
\end{tabular}

From the constructed variable plot of the seismic energy, Fig. 6-11, it can be seen that the seismic energy should be transformed to $1 / \ln (\mathrm{S})$, as the slop of the fitted line is around -1 . Tables 6-17 and 6-18 show the estimated coefficients after doing the transformation. There was a reduction of deviance of about 13.9 which is considered a good improvement from the last model. Figure 6-12 shows the half-normal probability plot of the simple model alongside with the simulated envelope. It is shown that all the data points fall within the simulated envelope and the curve does not display any unusual feature. Therefore, the developed model is appropriate. Figure 6-13 shows probability contours derived from the model.

Figure 6-14 compares the deterministic model that was developed by Law et al. (1990) and the probabilistic model ( 0.5 probability contour). Because of the way the probabilistic curve is plotted, they would be straight lines when using semi-log plot. In spite of this, the deterministic model is in relatively good agreement with the probabilistic model in the range between 5-35 where most of the data lie. Figure 6-15 shows probability contours superimposed on the data used in developing the logistic regression model. 


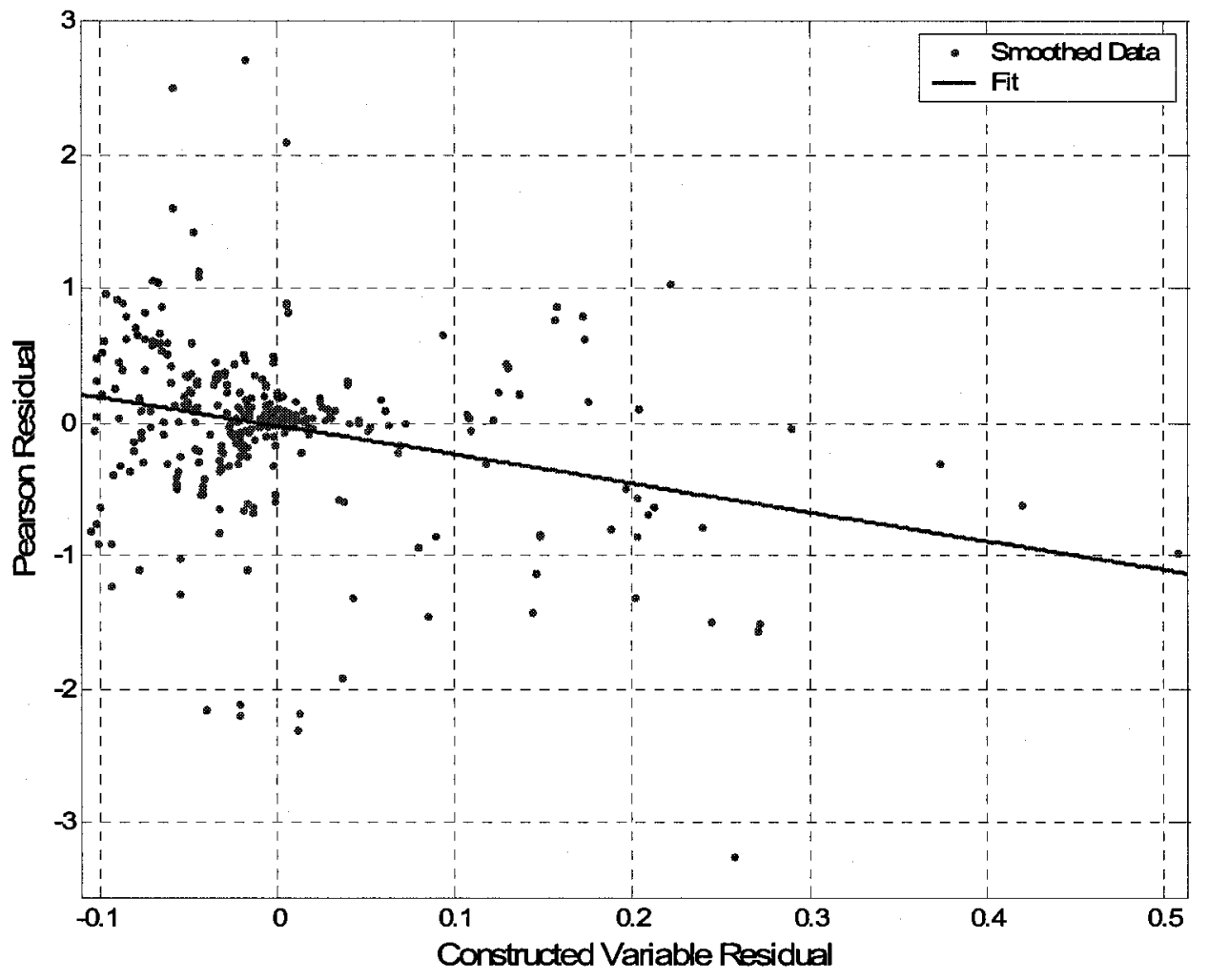

Figure 6-11: The constructed variable plot for the seismic energy 
Table 6-17: Estimated Coefficients for the Logistic Regression Model Using the Standard Penetration Resistance $\mathbf{N}$ and the Seismic Energy $S$

\begin{tabular}{|c|c|c|c|c|c|c|}
\hline \multirow{2}{*}{ Variable } & \multirow{2}{*}{ Coefficient } & \multirow{2}{*}{ Std. Err. } & \multicolumn{2}{|c|}{ Confidence Int. } & \multirow[t]{2}{*}{$\mathbf{z}$} & \multirow{2}{*}{$\mathbf{P}>|\mathbf{z}|$} \\
\hline & & & L.C.I & U.C.I & & \\
\hline Constant & 18.2323 & 2.229 & 13.864 & 22.601 & 8.1797 & $<0.05$ \\
\hline $\mathbf{N}$ & -0.4657 & 0.057341 & -0.578 & -0.353 & -8.1223 & $<0.05$ \\
\hline $1 / \ln (S)$ & -147.4778 & 19.867 & -186.42 & -108.54 & -7.4231 & $<0.05$ \\
\hline d.f. & 360 & & & & & \\
\hline Deviance & 185.9937 & & & & & \\
\hline
\end{tabular}

Table 6-18: Correlation Matrix for the Coefficients

\begin{tabular}{|c|c|c|c|}
\hline & Constant & $\mathbf{N}$ & $\mathbf{1 / n}(\mathbf{S})$ \\
\hline Constant & 1 & - & - \\
\hline $\mathbf{N}$ & -0.8787 & 1 & - \\
\hline $\mathbf{1 / n}(\mathbf{S})$ & -0.9694 & 0.7485 & 1 \\
\hline
\end{tabular}




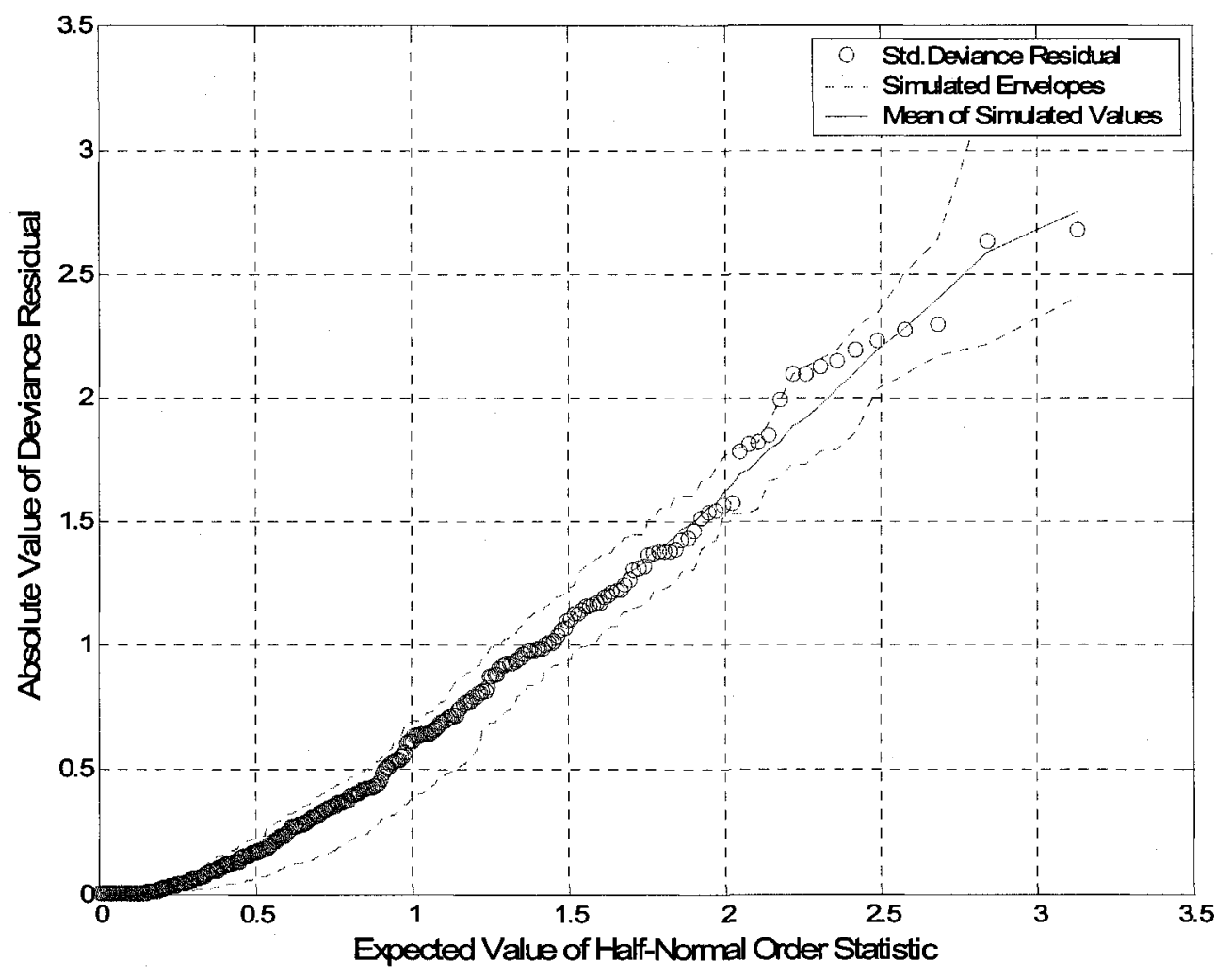

Figure 6-12: Half-normal probability plot with simulated envelope for the simple model 


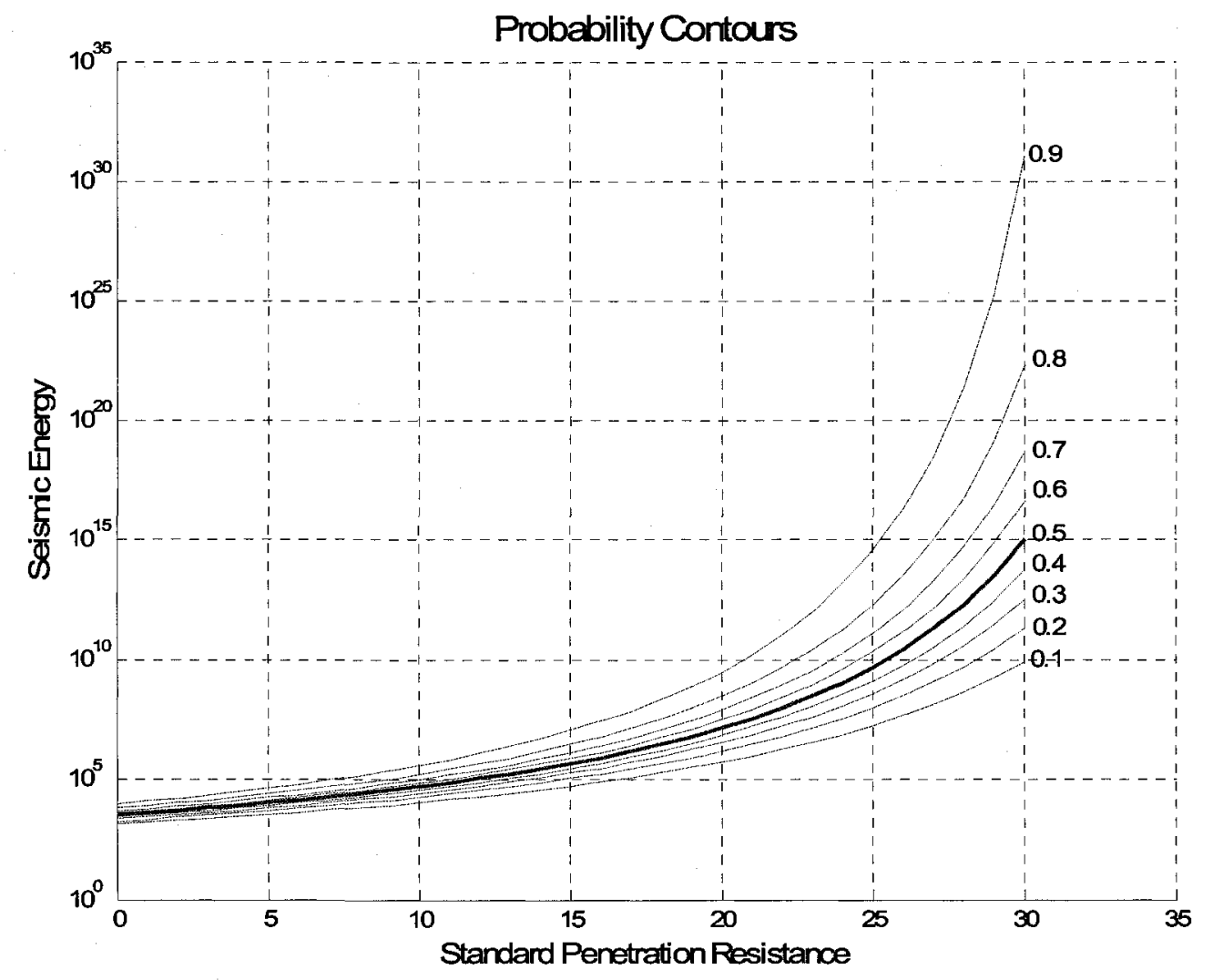

Figure 6-13: Probability contours derived from the simple model 


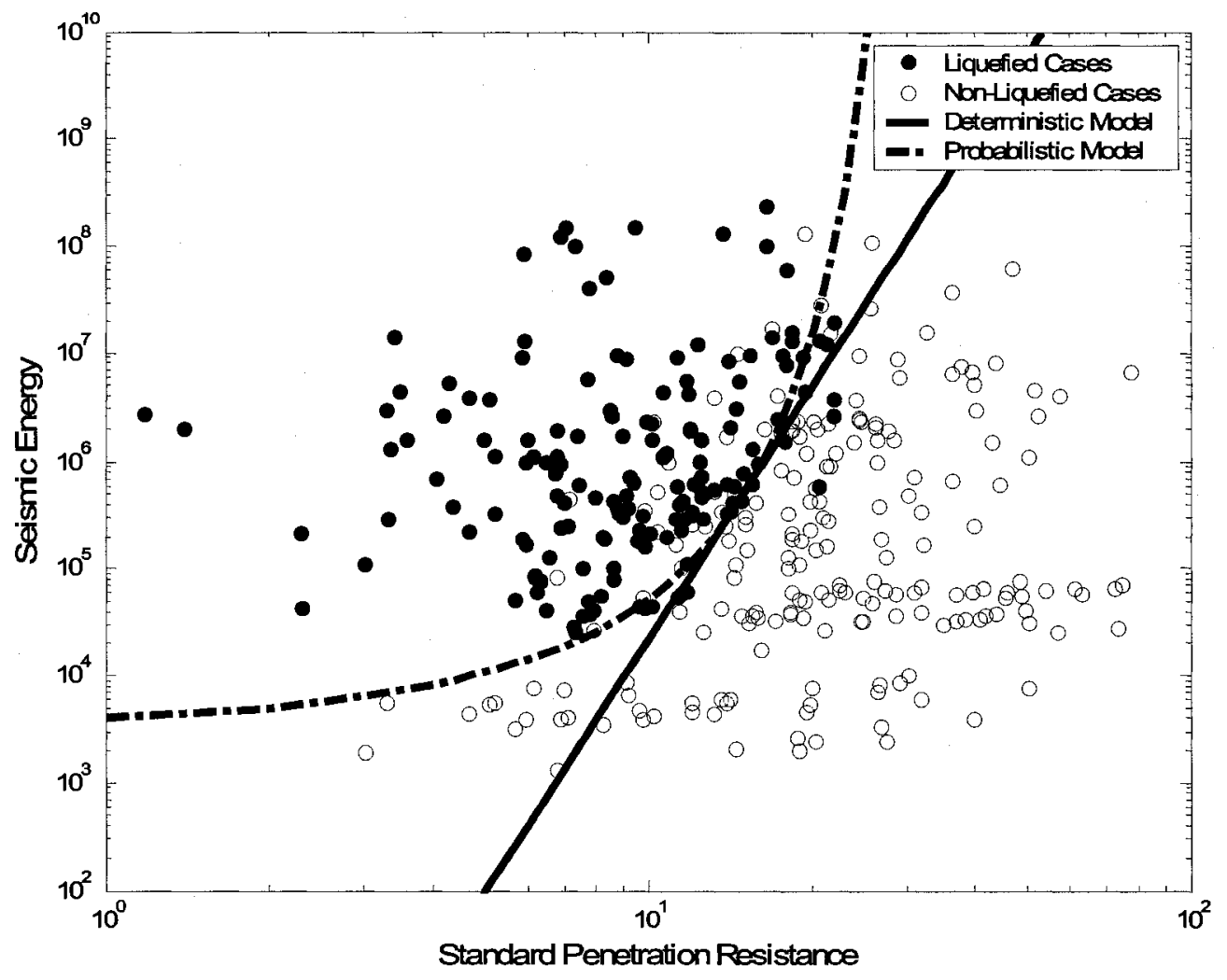

Figure 6-14: Comparison between the deterministic and probabilistic (0.5) models 


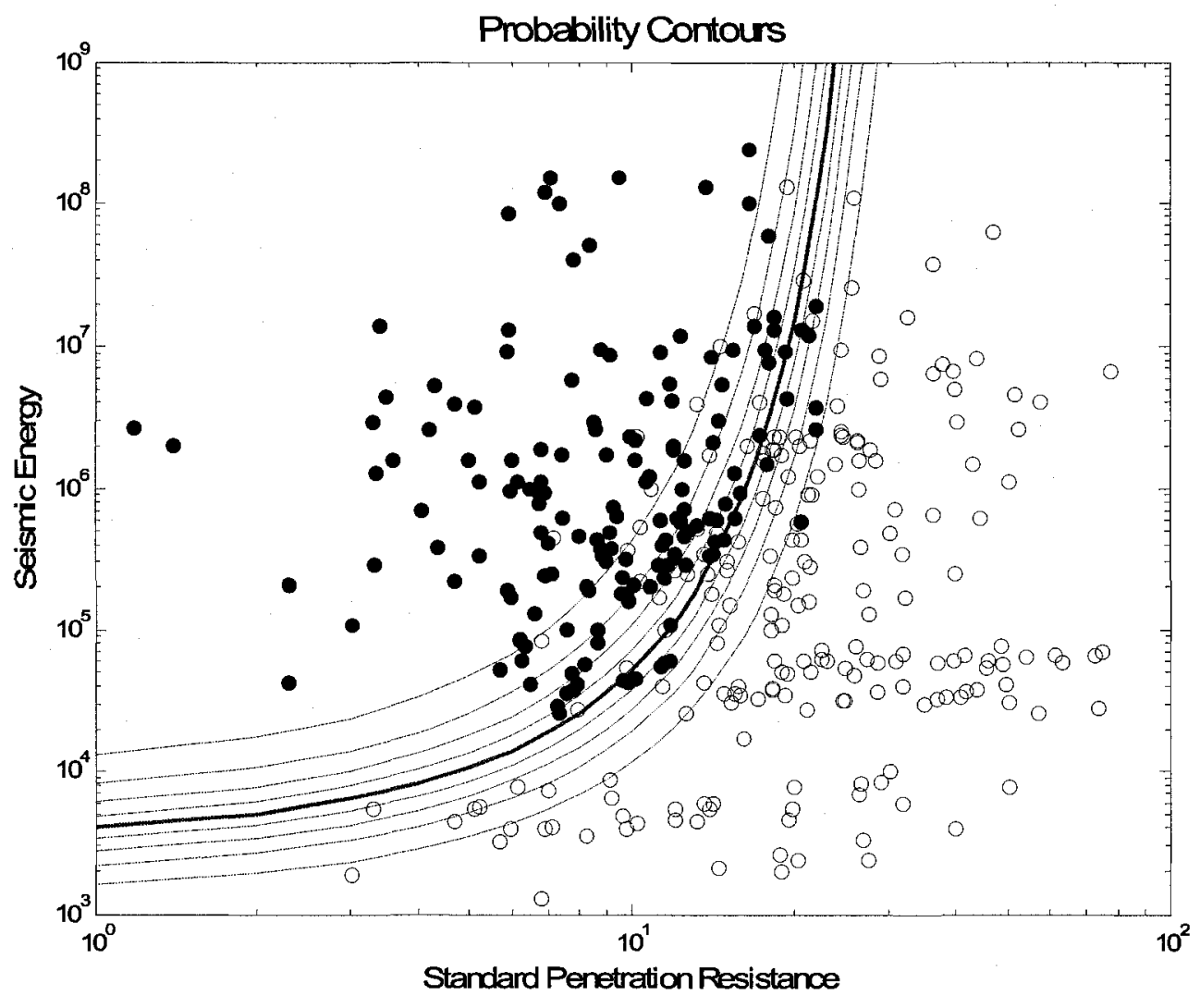

Figure 6-15: Probability contours imposed on the original data 


\title{
Chapter 7
}

\section{SUMMARY CONTRIBUTIONS AND}

\author{
CONCLUSIONS
}

\subsection{SUMMARY CONTRIBUTIONS}

The new changes and requirements introduced to the NBCC 2005, which are of relevance to liquefaction designs, specifically the new site classification system and the foundation (amplification) factors, as well as the return period were discussed alongside with their implications in selected Canadian cities. The rationales associated with these changes and requirements were tracked back and discussed such that ambiguity arising from these changes is eliminated. As demonstrated in Chapter 1 , the new return period has resulted in conservative liquefaction designs. The seismic hazard dissimilarities between Eastern and Western North America and the overstrength factor inherent in buildings were the two intertwined reasons behind adopting the new return period. The overstrength factor that exists in buildings does not exist in soil, therefore, the concept of overstrength cannot be incorporated in liquefaction designs to soften the impact of the new return period. However, another two intertwined concepts are introduced to reduce the unnecessary conservatism caused by the new return period. These concepts are the liquefaction return period and the uncertainty inherent in the Seed-Idriss liquefaction curves. 
Conventionally, the ground motion in the seismic provisions of building codes is often used inconsistently with the Seed-Idriss approach for liquefaction designs. The inconsistency arises from combining the probabilistically-evaluated ground motion and the deterministically-based liquefaction curves compiled by Seed and Idriss in their approach. This inconsistency is particularly acute in the NBCC 2005 and has caused conservative liquefaction designs especially in low seismicity areas such as Toronto. A proposed method is introduced which is based on quantifying the uncertainties inherent in Seed-Idriss liquefaction curves and designing for liquefaction return period rather than seismic event return period. Due to inherent uncertainties in Seed-Idriss liquefaction curves, the design return period is lengthened by a factor equal to the reciprocal of the probability of soil liquefaction failure considering only the statistical distributions of soil and seismic parameters as well as the liquefaction model. The proposed procedure meets the liquefaction performance of 2475 years and results in eliminating unnecessary conservatism in the design process. Illustration of the proposed procedure has been carried out for selected Canadian cities and a comparison with the NEHRP approach suggests that NEHRP approach does not yield the desired performance recommended by the NBCC 2005. The new PGA reduction ratios, $\rho_{\text {Proposed, }}$ might be used for design against liquefaction across Canadian cities to meet the uniform hazard level required by the NBCC 2005.

A fully probabilistic approach to evaluate soil liquefaction probability has been developed. The developed approach takes into account the statistical distributions of soil and seismic parameters as well as the spatial and temporal distributions of seismic 
parameters. The probability of liquefaction considering the statistical distributions of soil and seismic parameters was evaluated via a reliability-based model that incorporates the seismic energy approach developed by Law et al (1990) for evaluating soil liquefaction. This energy approach comprises four parameters: the earthquake magnitude, the hypocentral distance of the earthquake, the standard penetration resistance of the soil, and the effective overburden stress. Each of these parameters is modeled as a random variable characterized by a certain statistical distribution. The probability of the seismic parameters occurrences was estimated based on the spatial distribution of source-to-site distance and the temporal distribution of earthquakes occurrences. The method was used to evaluate the performances of previous case histories of liquefaction records at three different sites. The evaluated performances could be used as baselines for future liquefaction designs/evaluations.

A sensitivity analysis has been carried out using the reliability-based model to investigate the effects of increasing the value of each variable on the probability of liquefaction failure at various levels of the performance function. It was found that a $3 \%$ decrease in the probability of liquefaction was observed due to a $10 \%$ increase in the effective overburden stress at various levels of the random variables. The same type of effect was observed for the hypocenter distance, a decrease of probability of liquefaction between 4$7 \%$ was observed due to a $10 \%$ increase at various levels of the random variables. The somehow constant change (decrease or increase) in the probability of liquefaction failure suggests that the probability of liquefaction is somehow linear in terms of these variables. The variables that seem to have the most effect on the probability of liquefaction are the 
earthquake magnitude and the standard penetration resistance. A $10 \%$ increase in the earthquake magnitude may lead to an increase of probability of liquefaction between 24$48 \%$. Similarly, a $10 \%$ increase in the standard penetration resistance may lead to $16-$ $27 \%$ reduction in the probability of liquefaction. Again, as these changes are not constant, it can be concluded that the probability of liquefaction is not linear in terms of these variables.

A systematic approach utilizing 363 case histories of liquefaction/non-liquefaction data has been implemented to develop a logistic regression model for predicting liquefaction probability based on soil and seismic parameters. Incorporation and representation of seismic and soil parameters in the logistic model have been justified based on selected diagnostic techniques that are commonly used in conjunction with logistic models. Other diagnostic techniques were also used to check the adequacy and the validity of the developed logistic model. Liquefaction probability curves based on varying soil and seismic parameters were developed based on the developed model.

The use of the above probability methods should be used with discretion as there exists fundamental differences among them. The reliability-based analysis utilizes a predefined seismic energy model as a criterion for liquefaction failure and it also considers the variables (soil and seismic) used in the analysis as uncertain quantities, i.e., it accounts for the errors in the measurements of the variables. Therefore, when evaluating the probability of liquefaction failure based on the calculated factor of safety, the factor of safety must be calculated using the seismic energy model that was utilized in the 
reliability-based model. However, the logistic model is not based on any pre-defined model, it was built in a step-by-step manner and it is solely based on the field data and it treats the measurements (variables) as exact values with no uncertainties taken into consideration. Finally, when quantifying the uncertainties inherent in Seed-Idriss liquefaction curves, one must use a Bayesian approach to infer the probability of liquefaction failure rather than other approaches such as a logistic approach. The reason behind that lies in the fundamental difference between the two approaches. The logistic approach is related to the classical (frequentist) statistics, while Bayesian belongs to the degree-of-believe statistics, see Baecher and Chrsitian (2003b). In other words, the logistic model addresses the probability of the data given the state of nature (liquefaction occurrence), i.e. P[datalliquefaction] which means that if a new site were to liquefy during an earthquake, there is $\mathrm{P} \%$ probability that these data would be measured at the site. However, Bayesian analysis addresses the reverse question, it gives the probability of state of nature (liquefaction) given the data, i.e. P[liquefactionldata].

\subsection{CONCLUSIONS}

Based on the above studies, the following conclusions can be drawn:

1. The differences between the seismic event return period and liquefaction return period for anti-liquefaction designs should be identified.

2. An inconsistency arises when applying the $2 \%$ in 50 years PGA proposed by the NBCC 2005 to the Seed and Idriss approach. This inconsistency which stems from the uncertainties associated with the Seed and Idriss liquefaction curves may yield a 
liquefaction return period twice that of the ground motion return period recommended by NBCC 2005 .

3. Using the return period suggested by the NBCC 2005 for anti-liquefaction designs is conservative as this return period will be lengthened by a factor equal to the reciprocal of the probability of soil liquefaction corresponding to the soil and seismic parameters at the site.

4. Quantifying the probability of liquefaction occurrence $\left(\mathrm{P}_{\text {Seed }}\right)$ stemming from the uncertainties associated with Seed and Idriss liquefaction curves is essential for antiliquefaction designs against future earthquakes.

5. From the reliability-based model proposed in this thesis, the effective overburden stress and the hypocenter distance have lesser effects on the probability of soil liquefaction as opposed to earthquake magnitude and standard penetration resistance. Therefore, these two parameters can be treated as fixed variables in the model without undermining the accuracy of the model. However, the earthquake magnitude and the standard penetration resistance have significant effect on the probability of liquefaction, therefore, refining the measurements of these two variable will contribute to the accuracy of the probability predicted by the reliability-based mode.

6. When evaluating liquefaction probability one has to account for both, the statistical distribution of soil and seismic parameters and the special and temporal distributions of seismic parameters.

7. When using the Seed and Idriss approach for liquefaction design/evaluation, the representative earthquake magnitude should be selected as the modal earthquake as it is the most contributing to the peak ground acceleration (seismic hazard). 


\section{REFERENCES}

[1] Adams, J., and Halchuk S. 2004. A review of NBCC 2005 Seismic Hazard Results for Canada- The interface to the ground and prognosis for urban risk mitigation. The $57^{\text {th }}$ Canadian Geotechnical Conference $-5^{\text {th }}$ Joint CGS-CNC Conference, Session 6C.

[2] Adams, J., and Halchuk, S. 2003. Fourth generation seismic hazard maps of Canada: Values for over 650 Canadian localities intended for the 2005 National Building Code of Canada. Geological Survey of Canada Open File 4459. 155 p. Available from http://www.seismo.nrcan.gc.ca as of 1 April 2003.

[3] Adams, J., Halchuk, S. and Weichert, D.H. 2000. Lower probability hazard, better performance? Understanding the shape of the hazard curves from Canada's fourth generation seismic hazard results. Paper 1555 on CD-ROM, 12th World Conference on Earthquake Engineering, Auckland, Jan 2000.

[4] Aranda-Ordaz, F. J., 1981. On two families of transformations to additivity for binary response data. Biometrika, 68,357-363.

[5] Atkinson, A. C. 1981. Two graphical displays for outlying and influential observations in regression. Biometrika, 68, 13-20.

[6] Atkinson, G.M. and Boore, D.M. 1995. Ground-motion relations for Eastern North America. Bulletin of the Seismological Society of America, Vol. 85, No. 1, pp. 17-30.

[7] Atkinson, G.M. and Silva, W. 2000. Stochastic modeling of California ground motions. Bulletin of the Seismological Society of America, Vol. 90, No. 2, pp. 255274. 
[8] Baecher, B., and Christian, T. 2003. Reliability and Statistics in Geotechnical Engineering. John Wiley \& Sons Ltd., The Atrium. Southern Gate, Chichester. West Sussex PO19 8SQ, England.

[9] Baecher, B., and Christian, T. 2003b. Discussion of 'Evaluating site investigation quality using GIS and geostatistics' by R. L. Parsons and J. D. Frost." J.Geotech. Geoenviron.Eng., 129(9), 867-868.

[10] Bazzurro, P. and Cornell, A. Disaggregation of Seismic Hazard. 1999. Bulletin of the Seismological Society of America, 89, 2, pp.501-520, April 1999.

[11] Bennett, M. J. 1990. Ground deformation and liquefaction of soil in the Marina District. Effect of the Loma Prieta Earthquake on the Marina District, San Francisco, California, Open File Report 90-253, Department of the Interior, U. S. Geological Survey, Chameau, J. L., 1983. Seismic response of San Francisco waterfront fills. Journal of Geotechnical Engineering, Vol. 109, No. 4, pp. 491-506.

[12] Borcherdt, R.D. 1994. Estimates of site-dependent response spectra for design (methodology and justification). Earthquake Spectra, 10(4): 617-653.

[13] Borcherdt, R.D. 2002. Empirical Evidence for Acceleration-Dependent Amplification Factors. Bulletin of the Seismological Society of America, Vol. 92. No. 2, pp.761-782, March 2002.

[14] Borcherdt, R.D. 2002. Empirical Evidence for Site Coefficients in Building Code Provisions. Earthquake Spectra, Vol. 18. No. 2, pages 189-217, May 2002.

[15] Box, G. E. P. and Cox, D. R. 1964. An analysis of transformations (with discussion). Journal of the Royal Statistical Society, B26, 211-252. 
[16] Cetin KO. 2000. Reliability-based assessment of seismic soil liquefaction initiation hazard. dissertation submitted in partial satisfaction of the requirements for the degree of Doctor of Philosophy. University of California at Berkeley.

[17] Cetin, K. O., Der Kiureghian, A., and Seed, R. B. 2002. "Probabilistic models for the initiation of seismic soil liquefaction." Structural Safety, 24(1), 67-82.

[18] Chen, C.J., JUang, C.H. 2000. "Calibration of SPT- and CPT-Based Liquefaction Evaluation Methods." Innovations and Applications in Geotechnical Site Characterization, ASCE Geotechnical Special Publication No. 97, 49-64.

[19] Christian, T. 2004. Geotechnical Engineering Reliability: How Well Do We Know What We Are Doing? Journal of Geotechnical and Geoenvironmental Engineering, American Society of Civil Engineering, October 2004, DOI: 10.1061(ASCE)1090-0241(2004)130:10(985).

[20] Cleveland, W. S. 1979. Robust locally weighted regression and smoothing scatterplots. Journal of the American Statistical Association, 74, 829-836.

[21] Collett D. 1999. Modelling Binary Data. Chapman \& Hall/CRC. pp369.

[22] Collett, D. 1991. Modelling Binary Data. Chapman \& Hall. pp369.

[23] Compartin, C.D., Greene, M., Tubbesing, S.K. 1995. "The Hyogoken-Nambu Earthquake Preliminary Reconnaissance Report." EERI Report No. 95-40, Earthquake Engineering Research Institute, Palo Alto, CA.

[24] Cornell, C. A. 1994. Risk-Based Structural Design, Proceedings of Symposium on Risk Analysis, Ann Arbor: University of Michigan.

[25] Das, B. M. 1998. Principles of Geotechnical Engineering, Fourth Edition, Chapter 15. PWS Publishing Company. 
[26] Davis, R.O. and Berrill, J.B. 1982. Energy dissipation and seismic liquefaction in sands. Earthquake Engineering and Structural Dynamics, Vol. 10, No. 1, pp. 59-68.

[27] DeVall, R.H. 2006. The "1 in 2475" earthquake and how it affects the way structural engineers think about seismic structural design of buildings and is this thinking applicable to aspects of geotechnical engineering: a personal perspective.

[28] Dewey, J.W. 1979. A consumer's guide to instrumental methods for determination of hypocenters. A.W. Hatheway and C.R. McClure, Jr., eds., Geology in the Sitting of Nuclear Power Plants, Geological Society of America Reviews in Engineering Geology, Vol.4, pp.109-117.

[29] Ditlevsen, O., and Madsen, H.O. 2005. Structural Reliability Methods. Internet edition 2.2.2: http://www.mek.dtu.dk/staff/od/books.htm, January, 2005.

[30] Dobry, R., Martin, G. R., parra, E., and Bhattacharyya, A. 1992. Development of site-dependent ratios of elastic response spectra (RRS) and site categories for building seismic codes. In Proceedings of the NCEER, SEAOC, BSSC Workshop on Site Response During Earthquakes and Seismic Code Provisions, 18-20, Nov. 1992, University of Southern California, Los Angeles, Calif. Edited by G.R. Martin.

[31] Ellingwood, B. R. 1994. "Probability-based Codified Design for Earthquakes." Engineering Structures 17(7).

[32] Espinosa, A.F. 1982. "ML and M0 Determination from Strong-Motion Accelerograms, and Expected Intensity Distribution." Geological Survey Professional Paper 1254 "The Imperial Valley, California, Earthquake of Octber 15, 1979", The United States Government Printing Office, Washington, DC.

[33] EZ-FRISK 7.1, 7.11, 7.12, 7.14 User Manuals. 
[34] Finn, W.D. L and Wightman, A. 2003. Ground motion amplification factors for the proposed 2005 edition of the National Building Code of Canada. Canadian Journal of Civil Engineering, Volume 30, Number 2, Pages272-278, April 2003, Special Issue: Proposed Earthquake Design Requirements of the National Building Code of Canada, 2005 edition.

[35] Finn, W.D. L and Wightman, A. 2003. The Application of NBCC2005 Probabilistic Ground Motions to Liquefaction Assessments. The 59th Canadian Geotechnical Conference, October 1-4, 2006, Vancouver, BC., pp1279-1287.

[36] Gutenberg, B. and Richter, C. F. 1956. Earthquake magnitude, intensity, energy, and acceleration. Bulletin of the Seismological Society of America, Vol. 46, pp.104145.

[37] Halchuk, S., Adams, J., and Anglin, F. 2007. Revised Deaggregation of Seismic Hazard for Selected Canadian Cities. Ninth Canadian Conference on Earthquake Engineering, Ottawa, Ontario, Canada. June 26-29.Paper 1188.

[38] Hanks, T.C. and Kanamori, H. 1979. A moment magnitude scale. Journal of Geophysical Research, Vol. 84, pp.2348-2350.

[39] Harmsen, S., Perkins, D., and Frankel., A. 1999. Deaggregation of Probabilistic Ground Motions in the Central and Eastern United States, Bulletin of the Seismological Society of America, 89, No.1, pp.1-13, February 1999.

[40] Harr, M.E. 1987. Reliability-Based Design in Civil Engineering. McGraw-Hill Book Company. 
[41] Hasegawa, H.S., Basham, P.W., and Berry, M.J. 1981. Attenuation relations for strong seismic ground motion in Canada. Bulletin of the Seismological Society of America, Vol. 71, pp. 1943-1962.

[42] Heidebrecht A.C. 2003. Overview of seismic provisions of the proposed 2005 edition of the National Building Code of Canada. Canadian Journal of Civil Engineering 30: 241-254.

[43] Hilldale (Cunningham), C. 1971.A Probabilistic Approach to Estimating Differential Sttlement, MS Thesis, Department of Civil Engineering, Massachusetts Institute of Technology.

[44] Hosmer, David W. and Lemeshow, S. 2003. Applied Logistic Regression. John Wiley \& Sons, INC. pp373.

[45] Housner, G. W. 1989. Competing against time. Report to Governor Deukmejian of California, governor's Board of Inquiry on the 1989 Loma Prieta Earthquake.

[46] Humar, J. and Mahgoub, A. M. 2003. Determination of seismic design forces by equivalent static load method. Canadian Journal of Civil Engineering, Volume 30, Number 2, Pages 287-307, April 2003, Special Issue: Proposed Earthquake Design Requirements of the National Building Code of Canada, 2005 edition.

[47] Idriss, I. M. 1999. "Presentation Notes: An Update of the Seed-Idriss Simplified Procedure for Evaluating Liquefaction Potential." Proceedings, TRB Workshop on New Approaches to Liquefaction Analysis. Publication no. FHWA-RD-99-165, Federal Highway Administration, Washington.

[48] Idriss, I.M. 1985. Evaluating seismic risk in engineering practice, Proc. 11th Int. Conf. on Soil Mech. And Found. Engrg., Vol 1, 255-320. 
[49] Jarpe, S., Hutchings, L., Hauk, T., and Shakal, A. 1989. Selected strong- and weak-motion data from the Loma Prieta earthquake sequence. Seismological Research Letters, 60: 167-176.

[50] Jarpe, S., Hutchings, L., Hauk, T., and Shakal, A. 1989. Selected strong-and weak-motion data from the Loma Prieta earthquake sequence. Seismological Research Letters. 60: 167-176.

[51] Jones, L. Allen, Kramer Steven L. Kramer, and Arduino Pedro. 2002. Estimation of Uncertainty in Geotechnical Properties for Performance-Based Earthquake Engineering.

[52] Joyner, W.B., Warrick, R.E., and Fumal, T.E. 1981. "The effect of Quaternary alluvium on strong ground motion in the Coyote Lake, California earthquake of 1979," Bull. Seism. Soc. Am., 71, 1333-1349.

[53] Juang, C. H., Caroline J. and Tao Jiang. 2001. Probabilistc Framework for Liquefaction Potential by Shear Wave velocity. Journal of Geotechnical and Geoenvironmental Engineering, August 2001.

[54] Juang, C. H., Chen, C. J., and Jiang, T. 2001. Probabilistic Framework for Liquefaction Potential by Shear Wave Velocity. Journal of Geotechnical and Geoenvironmental Engineering/ August 2001, p670-678.

[55] Juang, C. H., Chen, C. J., J., Rosowsky, D. V., and Tang, W. H. 2000. CPT-based liquefaction analysis, Part 2: Reliability for design. Geotechnique, London, 50(5), 593-599. 
[56] Juang, C. H., Chen, C. J., J., Tang, W. H., and Rosowsky, D. V. 2000. CPT-based liquefaction analysis, Part 1: Determination of limit state function. Geotechnique, London, 50(5), 583-592.

[57] Juang, C. H., Rosowsky, D.V., and Tang, Wilson. 1999. Reliability-Based Method for Assessing Liquefaction Potential of Soils. Journal of the Geotechnical and Geoenvironmental Engineering , August 1999, pp.684-689.

[58] Kanamori, H. 1977. The energy release in great earthquakes. Journal of Geophysical Research, Vol. 82, pp. 2981-1987.

[59] Kennedy, R. P. and S. A. Short. 1994. Basis for Seismic Provisions of DOE-STD1020, UCRL-CR-111478. Prepared for Lawrence Livermore National Laboratory. Livermore: University of California.

[60] Kramer, S. 1996. Geotechnical Earthquake Engineering. Pearson Education, Inc.

[61] Kramer, S., and Elgamal A.W. 2001. Modeling Soil Liquefaction Hazards for Performance-Based Earthquake Engineering. PEER REPORT 2001/13, Pacific Earthquake Engineering Research Center, College of Engineering, University of California, Berkeley, February 2001.

[62] Kramer, S., and Mayfield, R. 2005. Performance-Based Liquefaction Hazard Evaluation. Geo-Frontiers 2005. Geotechnical Special Publications 130-142 AND FRI-18.

[63] Kramer, S.L. and Mayfield, R.T. 2006. Performance based liquefaction hazard evaluation: implications for codes and standards, 100th Anniversary Earthquake Conference, San Francisco, CA. 
[64] Kramer, S.L., and Mayfield, R.T. 2005. Performance-Based Hazard Evaluation. American Society of Civil Engineers, Geotechnical Special Publications 130-142 and GRI-18. January 24-26, 2005, Austin, Texas.

[65] Law, K. T. and Salloum, T. 2006. Probabilistic Evaluation of Past Liquefaction Hazards, Part II: The Spatial and Temporal Distributions of Seismic Parameters. The 59th Canadian Geotechnical Conference, October 1-4, 2006, Vancouver, BC.

[66] Law, K. T., Cao, Y. L., and He, G. N. 1990. An Energy Approach for Assessing Seismic Liquefaction Potential. Canadian Geotechnical Journal, Vol. 27, 1990, pp. 320-329.

[67] Liao, S. S. C., Veneziano, D., Whitman, R.V. 1988. Regression Models for Evaluating Liquefaction Probability. Journal of Geotechnical Engineering, ASCE, Vol. 114, No. 4, pp. 389-409.

[68] Liao, S. S. C., Whitman, R. V. 1986. Overburden Correction Factor for SPT in Sand. Journal of Geotechnical Engineering, ASCE, Vol. 112, No. 3, March 1986, pp. 373-377.

[69] Lock, Y. B. 2001. A Novel Method to Assess Past Earthquake Characteristics. PhD. Dissertation, Carleton University, 208 pp.

[70] McGuire, R.K., and Arabasz, W.J. 1990. An introduction to probabilistic seismic hazard analysis. in S.H. Ward, ed. Geotechnical and Environmental Geophysics, Society of Exploration Geophysicists, Vol. 1, pp.333-353.

[71] Mitchell, D., Tremblay, R., Karacabeyli, E., Paultre, P., Saatcioglu, M., and Anderson, D. L. 2003. Seismic force modification factors for the proposed 2005 edition of the National Building Code of Canada. Canadian Journal of Civil 
Engineering, Volume 30, Number 2, Pages308-327, April 2003, Special Issue: Proposed Earthquake Design Requirements of the National Building Code of Canada, 2005 edition.

[72] Moss, R.E.S. 2003. CPT-Based Probabilistic Assessment of Seismic Soil Liquefaction Initiation. PhD Dissertation, University of California, Berkeley, May 2003.

[73] Murphy, J.R. and O'Brien, L.J., 1977. The correlation of peak ground acceleration amplitude with seismic intensity and other physical parameters. Bulletin of the Seismological Society of America, Vol. 67, pp. 877-915.

[74] National Building Code of Canada 1995. National Research Council Canada, Institute for Research in Construction. User's Guide-NBCC 1995 Structural Commentaries (Part 4): 1-135.

[75] NCEER 1997. Proceedings of the NCEER Workshop on Evaluation of Liquefaction Resistance of Soils, Edited by Youd, T. L., Idriss, I. M., Technical Report No. NCEER-97-0022, December 31, 1997.

[76] NEHRP 1994. Recommended provisions for seismic regulations of new buildings: Part 1, provisions. FEMA 222A, National Earthquake Hazard Reduction Program, Federal Emergency Management Agency, Washington, D.C.

[77] NEHRP 1997. The National Earthquake Hazard Reduction Program. NEHRP Recommended Provisions for Seismic Regulations for New Buildings and Other Structures, 1997 Edition.

[78] NEHRP 2003. Recommended Provisions for Seismic Regulations for New Buildings and Other Structures (FEMA 450). 
[79] Nuttli, O.W. 1979. The relation of sustained maximum ground acceleration and velocity to earthquake intensity and magnitude. US Army Engineer Waterways Experiment Station, Miscellaneous Pager S-76-1, Report 16, p. 74.

[80] Okamoto, S. 1973. Introduction to Earthquake Engineering. University of Tokyo Press, Tokyo, Japan.

[81] Pampel, Fred C. 2000. Logistic Regression: A Primer. Sage Publications, Inc. pp86.

[82] Phoon, K K. and Kulhawy, F. H. 1996. "On quantifying inherent soil variability". Uncertainty in the Geologic Environment, Madison, WI, ASCE: 326-340.

[83] Phoon, K K. and Kulhawy, F. H. 1999. "Characterization of geotechnical variability". Canadian Geotechnical Journal 36(4):612-624.

[84] Robertson, P. K. and Wride, C. E. 1997. "Cyclic Liquefaction and its Evaluation Based on the SPT and CPT." NCEER-97-0022, Proceedings of the NCEER Workshop on Evaluation of Liquefaction Resistance of Soils.

[85] Robertson, P.K. and Campanella, R.G. 1985. Liquefaction potential of sands using the CPT. Journal of Geotechnical Engineering, Vol. 111, No. 3, March, pp. $384-403$.

[86] Robertson, P.K. and Wride, C.E. 1998. Evaluating cyclic liquefaction potential using the cone penetration test. Canadian Geotechnical Journal, Vol. 35, pp.442-459.

[87] Saatcioglu, M., and Humar, J. 2003. Dynamic analysis of buildings for earthquake-resistant design. Canadian Journal of Civil Engineering, Volume 30, Number 2, Pages 338-359, April 2003, Special Issue: Proposed Earthquake Design Requirements of the National Building Code of Canada, 2005 edition. 
Hazards, Part I: The Statistical distributions of Soil and Seismic Parameters. The 59th Canadian Geotechnical Conference, October 1-4, 2006, Vancouver, BC.

[89] Seed, H. B., and Idriss, I. M. 1982. "Ground motions and soil liquefaction during earthquakes." Earthquake Engineering Research Institute Monograph, Oakland, Calif.

[90] Seed, H. B., Tokimatsu, K., Harder, L. F., and Chung, R. 1975. "Influence of SPT Procedures in Soil Liquefaction Resistance Evaluations." Journal of Geotechnical Engineering, ASCE, vol. 111, no. 12, pp. 1425-1445.

[91] Seed, H.B. and Idriss, I.M. 1971. "Simplified procedure for evaluation soil liquefaction potential", Journal of Soil Mechanics and Foundations Division, ASCE, 107 (SM9), 1249-1274.

[92] Seed, H.B., Ugas, C., and Lysmer, J. 1976. Site-dependent spectra for earthquakeresistant design. Bulletin of the Seismological Society of America, 66(1): 221-243.

[93] Seed, R.B. 1992. Site effects on strong shaking: recent developments for seismic design codes and practice. In Proceedings of the NCEER, SEAOC, BSSC Workshop on Site Response During Earthquakes and Seismic Code Provisions, 18-20 Nov. 1992, University of Southern California, Los Angeles, Calif. Edited by G.R. Martin.

[94] Stewart, P., Liu, H., Choi, Y., and Baturay, B. 2001. Amplification Factors for Spectral Acceleration in Active Regions. A report on research conducted under Grant no. EEC-9701568 from the National Science Foundation and Grant No. 1098-712 from the California Strong Motion Instrumentation Program. PEER Report 2001/10 Pacific Earthquake Engineering Research Center College of Engineering, University of California, Berkeley. December 2001.pp101. 
[95] Task Force Report. 2007. Geotechnical Design Guidelines for Buildings on Liquefiable Sites in Accordance with NBC 2005 for Greater Vancouver Region, May $8,2007$.

[96] Toprak, S., Holzer, T. L. Bennett, M. J., and Tinsley, J. C., 1999. "CPT and SPTbased probabilistic assessment of liquefaction potential." Proc., 7th U.S.-Japan Workshop on Earthquake Resistant Design of Lifeline Facilities and Countermeasures against Liquefaction, Seattle.

[97] Trifunac MD. 1995. Empirical criteria for liquefaction in sands via standard penetration tests and seismic wave energy. Soil Dyn Earthquake Eng.,14:419-26.

[98] Uzielli M. 2004. Fuzzy modeling of CPT variability and possibilistic assessment of seismic liquefaction initiation, Ph.D. dissertation, University of Florence, Italy, 2004.

[99] Whitman, R.V. (Editor). 1990. Proceedings of the Workshop on Ground Motion Parameters for Seismic Hazard Mapping, 17-18 July 1989, Buffalo, N.Y. Technical Report NCEER-89-0038.

[100] Youd, T.L. et al. 2001. Liquefaction Resistance of Soils: Summary Report from the 1996 NCEER and 1998 NCEER/NSF Workshops on Evaluation of Liquefaction Resistance of Soils. Journal of Geotechnical and Geoenvironmental Engineering, ASCE, v127, No. 10. 


\section{Appendix A}

\section{MATLAB INPUT FILES}

THIS MATLAB CODE IS TO CONDUCT A LOGISTIC REGRESSION

ANALYSIS FOR THE LIQUEFACTION BINARY DATA. IT ALSO CONTAINS

THE CODE TO CALCULATE THE PEARSON RESIDUALS AND PLOTTING

THEM

$\%$

\% B IS THE VECTOR OF COEFFICIENTS, DEV IS THE DEVIANCE, STATS IS

\%ALL \%THE RELEVANT STATISTICS ASSOCIATED WITH THE ANALYSIS

$\% \quad \mathrm{X}$ IS THE INDEPENDENT VARIABLES, STANDARD PENETRATION \%RESISTANCE,

$\%$ EARTHQUAKE MAGNITUDE, HYPOCENTER DISTANCE AND THE \%EFFECTIVE \%OVERBURDEN

$\%$ STRESS

$\% \mathrm{R}$ IS THE RESPONSE VARIABLE WHICH IS BINARY, ONE IS THE SAMPLE \%MATRIX

$\% * * * * * * * * * * * * * * * * * * * * * * * * * * * * * * * * * * * * * * * * * * * * * * * * * * * * * * * * * * * * * * * * * * * * * *$

$\%$ Create a matrix of ones

One=ones $(363,1)$,

$\%$ Excelfile.xls is the excel file that contains the explanatory variables

D=xlsread('Excelfile.xls'),

$\%$ binaryl is the excel file that contains the liquefaction index information $(0$ or 1$)$ 


\section{R=xlsread('binary1.xls'),}

$\%$ In this case, the logit link or transformation function is used

$\%$ The general linear model is called

[B1 dev stats]=glmfit(D, [R One], 'binomial'),

\% CREATING THE EXTENDED DESIGN MATRIX, WHERE THE FIRST \%COLOUMN IS 1 AND THE REST IS THE EXPLANATROY VARIABLES

$\mathbf{X}=[$ One D $]$,

$\% * * * * * * * * * * * * * * * * * * * * * * * * * * * * * * * * * * * * * * * * * * * * * * * * * * * * * * * * * * * * * * * * *$

\%ESTIMATING THE CONFIDENCE INTERVALS OF THE ESTIMATED

COEFFICIENTS

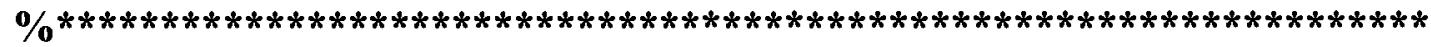

$\%$ Counting the number of the elements in the coefficient vector

n=numel(stats.beta),

\% CREATING A MATRIX OF ZEROS TO STORE THE LOWER AND UPPER CONFIDENCE INTERVALS IN IT

CON_I=zeros(2,n),

for $\mathrm{i}=1: \mathrm{n}$

\%Lower Confidence Interval...1.96 is the area under the standard normal curve that equals (1-alfa) or $95 \%$

LCI (i) $=$ stats.beta(i)-1.96*stats.se(i),

\%Upper Confidence Interval...

UCI(i)=stats.beta(i)+1.96*stats.se(i),

\%STORING THE LOWER CONFIDENCE INTERVAL IN THE MATRIX CON_I 
CON_I $(1, \mathbf{i})=\mathbf{L C I}(\mathbf{i})$,

\%STORING THE UPPER CONFIDENCE INTERVAL IN THE MATRIX CON_I

CON_I (2,i) $=$ UCI(i),

end

\%THE FOLLOWING BLOCK IS FOR CALCULATING THE VARIANCE AND

\%THE STANDARD

\% ERROR AND THE CORRELATION COEFFICIENTS OF THE ESTIMATED

\%COEFFICIENTS

$\% * * * * * * * * * * * * * * * * * * * * * * * * * * * * * * * * * * * * * * * * * * * * * * * * * * * * * * * * * * * * * * * * * * * * *$

$\%$ This is the transpose of the previous matrix

$\mathbf{X} \mathbf{t}_{-}=\mathbf{X}$,

$\%$ Calculating the probability to construct the $\mathrm{V}$ matrix

y = glmval(B1,D,'logit'),

$\%$ This is needed to construct the V matrix

$\mathbf{y 1}=\mathbf{y} \cdot *(1 .-y)$,

$\%$ Creating the diagonal matrix whish is $\mathrm{n} * \mathrm{n}$ matrix

$\mathbf{W}=\operatorname{diag}(\mathbf{y} 1)$,

\% OBSERVED INFORMATION MATRIX

$\mathbf{O I}=\left(\mathbf{X} \_\mathbf{t}\right) * \mathbf{W}^{*} \mathbf{X}$,

\% THE COVARIACE MATRIX ---INVERS OF THE OBSERVED IFORMATION

\%MATRIX

OI_t $\mathbf{t}=(O I)^{\wedge}-1$,

$\%$ VARIANCES OF THE COEFFICIENTS 
VAR=diag(OI_t $)$,

\% STANDAR ERROR OF THE COEFFICIENTS

SE $=$ VAR.^0.5,

$\% \% \%$ THE CONSTRUCTED VARIABLE PLOT $\% \% \% \% \% \% \% \%$

$\% \% \%$ CREATING THE HAT MATRIX

$H=\left(W^{\wedge} 0.5\right)^{*} X^{\star}\left(\left(X^{*} W^{*} X\right)^{\wedge}-1\right)^{*} X^{\prime *}\left(W^{\wedge} 0.5\right)$,

\%CONSTRUCTING THE DIAGONAL ELEMENTS

$\mathbf{h}=\operatorname{diag}(\mathbf{H})$,

\%CONSTRUCTING THE EYE MATRIX

$I=\operatorname{eye}(363,363)$,

\%THE CONSTRUCTED VARIABLE

$\mathrm{z}=\mathrm{B} 1(3) * \mathrm{D}(:, 2) .{ }^{*} \log (\mathrm{D}(:, 2))$,

\%CALCULATING THE RESIDUALS

c_resid $=(\mathbf{I}-\mathbf{H}){ }^{*} \operatorname{sqrt}(\mathbf{W})^{*} \mathbf{z}$,

\%CALCULATING THE PEARSON RESIDUALS

per=stats.residp,

\%PLOTING RESIDUALS

plot(c_resid, stats.residp,'o')

\%FORMATTING PLOTS

xlabel('Constructed Variable Residual','fontsize',12,'color',[0.0 0.0 0.0])

ylabel('Pearson Residual','fontsize',12,'color',[0.0 0.0 0.0])

grid on

\%CALCULATING RESIDUALS 
pa_resid=B1(3).*D(:,2)+(R-y)./y1,

\%PLOTTING RESIDUALS

$\operatorname{plot}(\mathrm{D}(:, 2)$, pa_resid,'o')

\%A MATLAB CODE TO CONSTRUCT THE HALF-NORMAL PROBABILITY

\%PLOT.

$* * * * * * * * * * * * * * * * * * * * * * * * * * * * * * * * * * * * * * * * * * * * * * * * * * * * * * * * * * * * * * * * * * * * * * *$

\%\%CREATING A MATRIX OF ZEROS TO STORE THE SIMULATED RESPONSES

$\operatorname{RB1}=\operatorname{zeros}(363,19)$,

for $i=1: 363$

\%\%SIMULATE RESPONSES FROM THE ORIGINAL FITTED LINE Y. WE NEED

$\% \% 19$ VALUES AND WE WILL ADD THE 20TH IN THE NEXT LINE

RB1(i,:)=binornd $(1, y(i), 1,19)$,

end

\% CREATING ONE MATRIX CONTAINING THE ORIGINAL DATA FROM THE FIRST REGRESSION PLUS THE SIMULATED VALUES

$\mathbf{R B}=[\mathbf{R} \mathbf{R B} 1]$,

\% CREATING A MATRIX OF ZEROS TO STORE THE OBTAINED REGRESSION

\%COEFFICIENTS

$\operatorname{coeff}=$ zeros $(20, n)$,

\% CREATING A MATRIX OF ZEROS TO STORE THE OBTAINED DEVIANCE

\%RESIDUALS

sresid=zeros $(363,20)$, 
\% FITTING A LOGISTIC REGRESSION MODELS TO THE ORIGINAL DATA \%AND THE SIMULATED DATA

for $i=1: 20$

[b, dev, stats] $=$ glmfit(D, [RB(:,i) One],'binomial'), \%GETTING THE PROBABILITY VALUES FOR EACH REGRESSION MODEL SO \%THAT WE CAN FIND THE WEIGHT AND HAT MATRIX

$$
\text { y=glmval(b, D,'logit'), }
$$

\%SOME MANIBULATION TO GET THE WIEGHT MATRIX

$\mathbf{y 1}=\mathbf{y} \cdot{ }^{*}(1 .-\mathbf{y})$,

\%CREATING THE WEIGHT MATRIX WHICH IS DIAGONAL MATRIX

$\mathbf{W}=\operatorname{diag}(\mathbf{y} 1)$,

$\%$ CREATING THE HAT MATRIX

$\mathbf{H}=\left(\mathbf{W}^{\wedge} 0.5\right)^{*} \mathbf{X}^{*}\left(\left(\mathbf{X}^{\prime *} \mathbf{W}^{*} \mathbf{X}\right)^{\wedge}-1\right)^{*} \mathbf{X}^{* *}\left(\mathbf{W}^{\wedge} \mathbf{0 . 5}\right)$

\%THIS VECTOR IS VERY IMPORTANT IN CALCULATING THE \%STANDARDIZED DEVIANCES AND IT IS CALLED THE LEAVERGE

$h=\operatorname{diag}(\mathbf{H})$,

\%STORING THE REGRESSION COEFFICIENTS: THE CONSTANT

for $j=1: n$

$\operatorname{coeff}(\mathbf{i}, \mathbf{j})=b(\mathbf{j})$,

$\%$ SOME MANIPULATIONS TO:STORING THE OBTAINED DEVIANCE \%RESIDUALS IN S_DEV MATRIX

s_dev=stats.residd,

\%CALCULATING THE STANDARDIZED DEVIANCE RESIDUALS 
s_dev=s_dev./((1.-h).^(0.5),

\%GETTING THE ABS VALUES AND SORTING THE DEVIANCE RESIDUALS

$\operatorname{sresid}(:, \mathbf{i})=\operatorname{sort}\left(\mathbf{a b s}\left(\left[\mathbf{s} \_\right.\right.\right.$dev $\left.\left.]\right)\right)$,

end

end

$\% \% \%$ CREATING MATIX OF ZEROS TO STORE THE MIN VLUES OF $\%$ RESIDUALS

minimum=zeros(1,363),

\%CREATING MATIX OF ZEROS TO STORE THE MEAN VLUES OF RESIDUALS

meanav=zeros $(1,363)$,

\%CREATING MATIX OF ZEROS TO STORE THE MAX VLUES OF RESIDUALS

maximum=zeros $(1,363)$,

for $i=1: 363$

\% GETTING THE VECTOR OF MIN VALUES OF THE DEVIANCE RESIDUALS

$\operatorname{minimum}(1, \mathbf{i})=\min (\operatorname{sresid}(\mathbf{i},:))$,

\%GETTING THE VECTOR OF MEAN VALUES OF THE DEVIANCE $\%$ RESIDUALS

$\operatorname{meanav}(1, \mathbf{i})=\operatorname{mean}(\operatorname{sresid}(\mathbf{i}, \mathbf{i}))$,

\%GETTING THE VECTOR OF MAX VALUES OF THE DEVIANCE RESIDUALS

$\operatorname{maximum}(1, \mathbf{i})=\max (\operatorname{sresid}(\mathbf{i},:))$,

end

$\%$ MANIPULATIONG TO TRANSPOSE THE VECTOR OF MIN VALUES OF \%DEVIANCE RESIDUALS 
minimum=minimum', \% MANIPULATIONG TO TRANSPOSE THE VECTOR OF MEAN VALUES OF \%DEVIANCE RESIDUALS

meanav=meanav', \% MANIPULATIONG TO TRANSPOSE THE VECTOR OF MAX VALUES OF \%DEVIANCE RESIDUALS

maximum=maximum', \%HALF-NORMAL PROBABILITY PLOTS WITH THE SIMULATED \%ENVELOPE for $i=1: 363$

E_half(i) $=\operatorname{norminv}((\mathbf{i}+363-0.125) /(2 * 363+0.5), 0,1)$, end

PLT1=plot(E_half,sresid(:,1),'o'), hold on

PLT2=plot(E_half,minimum, ':','linewidth',1,'color', [l 0.00 .50 .0$]$ ), hold on

PLT3=plot(E_half,meanav,'-','linewidth',1,'color', [1.0 0.00 .0$]$, hold on

PLT4=plot(E_half,maximum, ':','linewidth',1,'color',[[0.0 0.5 0.0])

PLT=plot(E_half,sresid(:,1),'o','linewidth',1, E_half,minimum,':',E_half,meanav,'',E_half,maximum,':'),

grid on

xlabel('Expected Value of Half-Normal Order Statistic','fontsize',12,'color',[0.0 0.0 0.0]) 
ylabel('Absolute Value of Deviance Residual','fontsize',12,'color',[ [0.0 0.0 0.0])

PLTL=legend('Std.Deviance Residual','Simulated Envelopes','Mean of Simulated Values'),

\section{\%THIS IS THE CODE FOR CALCULATING THE RELIABILITY \%INDEX}

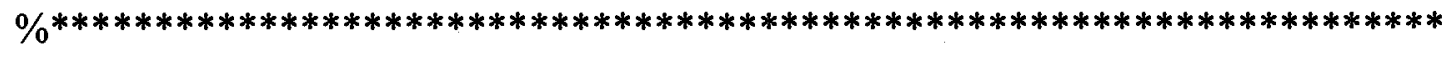

\%READING THE EXCEL FILE THAT CONTAINS THE SEISMIC AND SOIL \%MEASUREMENTS

D=xlsread('EXCELFILE.xls'), \%STARTING A LOOP TO GENERATE NORMALLY DISTRIBUTED NUMBERS \%FOR \%EACH RANDOM VARIABLE

\%200 IS THE NUMBER OF THE MEASUREMENTS

\%M IS THE EARTHQUAKE MAGNITUDE

\%R IS THE HYPOCENTER DISTANCE

$\%$ N IS THE STANDARD PENETRATION RESISTANCÈ

\%SIG IS THE EFFECTIVE OVERBURDEN STRESS

for $i=1: 200$

$M=\operatorname{random}(' N o r m a l ', D(i, 1), \operatorname{abs}(\operatorname{sqrt}(0.5-0.45 * \log 10(D(i, 1)))), 1,50000)$,

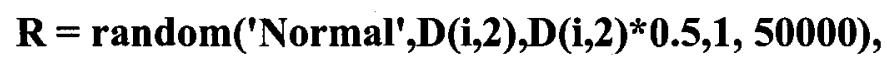

$\mathrm{Sig}=$ random('Normal',D(i,3),D(i,3)*0.15,1, 50000), \%\% c.o.v for density is $5-10 \%$

$\mathrm{N}=\operatorname{random}\left({ }^{\prime}\right.$ Normal', $\left.\mathbf{D}(\mathbf{i}, 4), \mathrm{D}(\mathbf{i}, \mathbf{4}) * 0.3,1,50000\right)$,

\%CONSIDEREING THE CORRELATION BETWEEN N AND SIGMA 
$\mathrm{CN}=0.1076 .{ }^{*}+0.994 .{ }^{*} \mathrm{Sig}, \%$ Generating values of Sig that is correlated to $\mathrm{N}$ \%CONSTRUCTING THE PERFORMANCE FUNCTION

$\mathbf{f 1}=0.000349 . * \mathrm{CN}$,

$\mathbf{f} \mathbf{2}=\mathbf{R}^{\wedge}{ }^{\wedge} \mathbf{2}$

$\mathbf{f 3}=\mathbf{f 1}{ }^{*} \mathbf{f} 2$,

f4=1.5.*M,

$\mathbf{f 5}=10 .^{\wedge} \mathbf{f} 4$,

$f 6=f 5 . / f 3$,

$\mathbf{f} 7=\mathbf{f 6} .^{\wedge} \mathbf{0 . 1 2 8}$,

$\mathbf{Z}=\mathbf{N}-\mathbf{f}$,

\%CALCULATING THE STANDARD DEVIATION, THE MEAN, AND THE \%RELIABILITY INDEX BETA

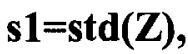

s2=mean $(Z)$,

$\operatorname{Rel}(\mathbf{i})=\mathbf{s} 2 / \mathbf{s 1}$,

\%CALCULATING THE PROBABILITY OF LIQUEFACTION

$P(i)=1-n o r m c d f(\operatorname{Rel}(\mathbf{i}), \mathbf{0}, \mathbf{1})$,

end

\%PLOTTING THE RELIABILITY INDEX VS. THE PROBABILITY OF

\%LIQUEFACTION

$\operatorname{plot}\left(\operatorname{Rel}, \mathbf{P}, \mathbf{o}^{\prime}\right)$

\%CALCULATIONG THE FACTOR OF SAFETY

fs1 $=0.000349 . * D(:, 3)$, 
fs2 $=D(:, 2) . \wedge 2$,

$\mathbf{f s} 3=\mathbf{f s} 1 .{ }^{*} \mathbf{f s} 2$,

fs4=1.5. ${ }^{*}(:, 1)$,

fs5=10.^fs4,

fs6 $=$ fs5./fs3,

fs7 $=\mathbf{f s 6} .^{\wedge} \mathbf{0 . 1 2 8}$,

$F S=D(:, 4) . / f s 7$,

\%MAPPING THE FACTOR OF SAFETY AND THE PROBABILITY OF \%LIQUEFACTION FAILURE

$\operatorname{plot}\left(\mathbf{F S}, \mathbf{P}, \mathbf{\prime}^{\prime}\right)$

grid on

Result=[Rel' P'],

\%CONSTRUCTING THE HISTOGRAM OF THE PERFORMANCE FUNCTION

$\mathbf{x}=-\mathbf{2 . 9 : 0 . 3 : 5}$

hist $(\mathbf{Z}, \mathbf{x})$,

O 


\section{Appendix B}

\section{CASE HISTORIES OF LIQUEFACTION/NON-}

\section{LIQUEFACTION RECORDS}

\begin{tabular}{|c|c|c|c|c|c|c|c|c|}
\hline Earthquake & Date & $\mathbf{M}$ & $\mathbf{R}$ & $\begin{array}{c}\text { Dw } \\
\text { Dept } \\
\text { h of } \\
\text { Wate } \\
\text { r } \\
\text { Tabl } \\
\text { e }\end{array}$ & $\begin{array}{c}\text { D } \\
\text { Dept } \\
h \text { of } \\
\text { Sand }\end{array}$ & $\left(N_{1}\right)_{60}$ & $\begin{array}{c}\text { S } \\
\text { Seismic } \\
\text { Energy }\end{array}$ & $\begin{array}{c}\text { Liq } \\
?\end{array}$ \\
\hline Mino-Owari & $10 / 27 / 91$ & 7.8 & 30 & 0.8 & 13.7 & 19.4 & $4.30 \mathrm{E}+06$ & 1 \\
\hline Mino-Owari & $10 / 27 / 91$ & 7.8 & 30 & 2 & 9.1 & 11.8 & $5.50 \mathrm{E}+06$ & 1 \\
\hline Mino-Owari & $10 / 27 / 91$ & 7.8 & 30 & 2.4 & 5 & 18 & $7.70 \mathrm{E}+06$ & 1 \\
\hline Mino-Owari & $10 / 27 / 91$ & 7.8 & 51.7 & 0.9 & 13.7 & 17.83 & $1.50 E+06$ & 1 \\
\hline Mino-Owari & $10 / 27 / 91$ & 7.8 & 51.4 & 1.8 & 9.1 & 11.96 & $2.00 \mathrm{E}+06$ & 1 \\
\hline Mino-Owari & $10 / 27 / 91$ & 7.8 & 51.4 & 1.8 & 7.6 & 24.64 & $2.30 \mathrm{E}+06$ & 0 \\
\hline Mino-Owari & $10 / 27 / 91$ & 7.8 & 51.4 & 2.4 & 6.1 & 22.09 & $2.60 \mathrm{E}+06$ & 1 \\
\hline San Francisco & $8 / 20 / 06$ & 7.9 & 54 & 2.4 & 7.6 & 8.47 & $2.90 \mathrm{E}+06$ & 1 \\
\hline San Francisco & $8 / 20 / 06$ & 7.9 & 54 & 5 & 7 & 18.8 & $2.30 \mathrm{E}+06$ & 0 \\
\hline San Francisco & $8 / 20 / 06$ & 7.9 & 54 & 2 & 4.5 & 5.1 & $3.70 \mathrm{E}+06$ & 1 \\
\hline San Francisco & $8 / 20 / 06$ & 7.9 & 54 & 1.8 & 2.3 & 29 & $5.90 \mathrm{E}+06$ & 0 \\
\hline San Francisco & $8 / 20 / 06$ & 7.9 & 54 & 3.7 & 4.6 & 3.3 & $2.90 \mathrm{E}+06$ & 1 \\
\hline San Francisco & $8 / 20 / 06$ & 7.9 & 54 & 4.1 & 6.5 & 10.2 & $2.30 \mathrm{E}+06$ & 0 \\
\hline San Francisco & $8 / 20 / 06$ & 7.9 & 185.7 & 2 & 7.6 & 2.3 & $2.10 \mathrm{E}+05$ & 1 \\
\hline San Francisco & $8 / 20 / 06$ & 7.9 & 54 & 1.7 & 4.6 & 4.7 & $3.90 \mathrm{E}+06$ & 1 \\
\hline San Francisco & $8 / 20 / 06$ & 7.9 & 54 & 1.7 & 4.6 & 13.2 & $3.90 \mathrm{E}+06$ & 0 \\
\hline Tokyo & $6 / 20 / 18$ & 7.6 & 65 & 0 & 4.5 & 17.59 & $1.60 \mathrm{E}+06$ & 0 \\
\hline Tokyo & $6 / 20 / 18$ & 7.6 & 58 & 0.5 & 3.5 & 18.43 & $2.30 \mathrm{E}+06$ & 0 \\
\hline Kwanto & $9 / 1 / 23$ & 7.9 & 72 & 4 & 6 & 3.35 & $1.30 \mathrm{E}+06$ & 1 \\
\hline Kwanto & $9 / 1 / 23$ & 7.9 & 72 & 4 & 4.3 & 6.77 & $1.90 \mathrm{E}+06$ & 1 \\
\hline Kwanto & $9 / 1 / 23$ & 7.9 & 72 & 1 & 5 & 17.3 & $2.40 \mathrm{E}+06$ & 1 \\
\hline Kwanto & $9 / 1 / 23$ & 7.9 & 102 & 0 & 4.5 & 17.59 & $1.80 \mathrm{E}+06$ & 0 \\
\hline Kwanto & $9 / 1 / 23$ & 7.9 & 105 & 0.5 & 3.5 & 18.43 & $1.90 \mathrm{E}+06$ & 0 \\
\hline Kwanto & $9 / 1 / 23$ & 7.9 & 96 & 1 & 8 & 6.48 & $1.00 \mathrm{E}+06$ & 1 \\
\hline Kwanto & $9 / 1 / 23$ & 7.9 & 77 & 1 & 7.5 & 9 & $1.70 \mathrm{E}+06$ & 1 \\
\hline Nishi-Saitama & $9 / 21 / 31$ & 6.6 & 20 & 2.5 & 3.5 & 8.79 & $3.70 \mathrm{E}+05$ & 1 \\
\hline Nishi-Saitama & $9 / 21 / 31$ & 6.6 & 19 & 0 & 4.5 & 14.4 & $5.90 \mathrm{E}+05$ & 1 \\
\hline Nishi-Saitama & $9 / 21 / 31$ & 6.6 & 34 & 0.5 & 3.5 & 18.43 & $2.10 \mathrm{E}+05$ & 0 \\
\hline Nishi-Saitama & $9 / 21 / 31$ & 6.6 & 51 & 1 & 8 & 6.48 & $4.10 \mathrm{E}+04$ & 1 \\
\hline Nishi-Saitama & $9 / 21 / 31$ & 6.6 & 65 & 1 & 7.6 & 7.95 & $2.70 E+04$ & 0 \\
\hline
\end{tabular}

B-1 


\begin{tabular}{|c|c|c|c|c|c|c|c|c|}
\hline Earthquake & Date & $\mathbf{M}$ & $\mathbf{R}$ & $\begin{array}{c}\text { Dw } \\
\text { Dept } \\
\text { h of } \\
\text { Wate } \\
r \\
\text { Tabl } \\
\text { e } \\
\end{array}$ & $\begin{array}{c}\text { D } \\
\text { Dept } \\
h \text { of } \\
\text { Sand }\end{array}$ & $\left(N_{1}\right)_{60}$ & $\begin{array}{c}\text { S } \\
\text { Seismic } \\
\text { Energy }\end{array}$ & $\begin{array}{c}\text { Liq. } \\
?\end{array}$ \\
\hline El Centro & $5 / 19 / 40$ & 7 & 12.8 & 4.6 & 4.6 & 9.92 & $2.30 \mathrm{E}+06$ & 1 \\
\hline El Centro & $5 / 19 / 40$ & 7 & 12.8 & 6.1 & 7.6 & 3.59 & $1.60 \mathrm{E}+06$ & 1 \\
\hline El Centro & $5 / 19 / 40$ & 7 & 12.8 & 1.5 & 6.1 & 1.18 & $2.70 \mathrm{E}+06$ & 1 \\
\hline Tonankai & $12 / 7 / 44$ & 8 & 165 & 2 & 2.4 & 5.96 & $9.70 \mathrm{E}+05$ & 1 \\
\hline Tonankai & $12 / 7 / 44$ & 8 & 165 & 0.5 & 3.7 & 6.74 & $9.20 \mathrm{E}+05$ & 1 \\
\hline Tonankai & $12 / 7 / 44$ & 8 & 165 & 2.5 & 3 & 8.63 & $4.30 \mathrm{E}+05$ & 1 \\
\hline Tonankai & $12 / 7 / 44$ & 8 & 200 & 2 & 7 & 12.6 & $2.90 \mathrm{E}+05$ & 1 \\
\hline Tonankai & $12 / 7 / 44$ & 8 & 163.8 & 1.5 & 4 & 6.76 & $7.80 \mathrm{E}+05$ & 1 \\
\hline Tonankai & $12 / 7 / 44$ & 8 & 163.8 & 0.6 & 2.4 & 5 & $1.60 \mathrm{E}+06$ & 1 \\
\hline Fukui & $6 / 28 / 48$ & 7.3 & 21 & 1.2 & 3 & 4.3 & $5.30 \mathrm{E}+06$ & 1 \\
\hline Fukui & $6 / 28 / 48$ & 7.3 & 20.6 & 0.8 & 8 & 40.2 & $2.90 \mathrm{E}+06$ & 0 \\
\hline Fukui & $6 / 28 / 48$ & 7.3 & 20.6 & 0.9 & 6 & 17.36 & $4.00 \mathrm{E}+06$ & 0 \\
\hline Fukui & $6 / 28 / 48$ & 7.3 & 20.6 & 1.8 & 3 & 3.5 & $4.40 \mathrm{E}+06$ & 1 \\
\hline Fukui & $6 / 28 / 48$ & 7.3 & 16.3 & 3.4 & 7 & 22.08 & $3.70 \mathrm{E}+06$ & 1 \\
\hline Fukui & $6 / 28 / 48$ & 7.3 & 16.3 & 0.9 & 7 & 40.01 & $5.00 \mathrm{E}+06$ & 0 \\
\hline Fukui & $6 / 28 / 48$ & 7.3 & 16.3 & 1.3 & 3.1 & 5.86 & $9.30 \mathrm{E}+06$ & 1 \\
\hline Fukui & $6 / 28 / 48$ & 7.3 & 16.3 & 0.9 & 6.1 & 7.72 & $5.80 \mathrm{E}+06$ & 1 \\
\hline San Francisco & $3 / 22 / 57$ & 5.3 & 18 & 2.4 & 7.6 & 5.7 & $3.20 \mathrm{E}+03$ & 0 \\
\hline San Francisco & $3 / 22 / 57$ & 5.3 & 18 & 5 & 7 & 18.8 & $2.60 \mathrm{E}+03$ & 0 \\
\hline San Francisco & $3 / 22 / 57$ & 5.3 & 16 & 2 & 4.5 & 5.1 & $5.40 \mathrm{E}+03$ & 0 \\
\hline San Francisco & $3 / 22 / 57$ & 5.3 & 16 & 1.8 & 2.3 & 29 & $8.50 \mathrm{E}+03$ & 0 \\
\hline San Francisco & $3 / 22 / 57$ & 5.3 & 14 & 3.7 & 4.6 & 3.3 & $5.50 E+03$ & 0 \\
\hline San Francisco & $3 / 22 / 57$ & 5.3 & 14 & 4.1 & 6.5 & 10.2 & $4.30 \mathrm{E}+03$ & 0 \\
\hline San Francisco & $3 / 22 / 57$ & 5.3 & 18 & 1.7 & 4.6 & 4.7 & $4.40 E+03$ & 0 \\
\hline San Francisco & $3 / 22 / 57$ & 5.3 & 18 & 1.7 & 4.6 & 13.2 & $4.40 \mathrm{E}+03$ & 0 \\
\hline Chile & $5 / 21 / 60$ & 9.5 & 127.9 & 3.7 & 4.6 & 7.08 & $1.50 \mathrm{E}+08$ & 1 \\
\hline Chile & $5 / 21 / 60$ & 9.5 & 127.9 & 3.7 & 4.6 & 9.44 & $1.50 \mathrm{E}+08$ & 1 \\
\hline Chile & $5 / 21 / 60$ & 9.5 & 127.9 & 3.7 & 6.1 & 19.39 & $1.30 \mathrm{E}+08$ & 0 \\
\hline Alaska & $3 / 27 / 64$ & 9.2 & 157 & 0 & 9.9 & 25.63 & $2.60 E+07$ & 0 \\
\hline Alaska & $3 / 27 / 64$ & 9.2 & 143 & 0 & 6.1 & 8.35 & $5.10 \mathrm{E}+07$ & 1 \\
\hline Alaska & $3 / 27 / 64$ & 9.2 & 147 & 0 & 7.6 & 36.53 & $3.80 E+07$ & 0 \\
\hline Alaska & $3 / 27 / 64$ & 9.2 & 93 & 0 & 7 & 16.54 & $1.00 \mathrm{E}+08$ & 1 \\
\hline Alaska & $3 / 27 / 64$ & 9.2 & 133 & 0 & 6 & 18.03 & $5.90 \mathrm{E}+07$ & 1 \\
\hline Alaska & $3 / 27 / 64$ & 9.2 & 142 & 2.3 & 5.6 & 7.82 & $4.00 \mathrm{E}+07$ & 1 \\
\hline Alaska & $3 / 27 / 64$ & 9.2 & 72 & 2 & 10 & 7.36 & $1.00 \mathrm{E}+08$ & 1 \\
\hline Alaska & $3 / 27 / 64$ & 9.2 & 74 & 4.5 & 6 & 25.98 & $1.10 \mathrm{E}+08$ & 0 \\
\hline Alaska & $3 / 27 / 64$ & 9.2 & 102 & 0 & 6.1 & 6.89 & $1.20 \mathrm{E}+08$ & 1 \\
\hline Alaska & $3 / 27 / 64$ & 9.2 & 102 & 2.4 & 6.1 & 5.9 & $8.40 \mathrm{E}+07$ & 1 \\
\hline Alaska & $3 / 27 / 64$ & 9.2 & 117.7 & 0 & 7.6 & 47.2 & $6.30 \mathrm{E}+07$ & 0 \\
\hline Alaska & $3 / 27 / 64$ & 9.2 & 94.5 & 6.1 & 6.1 & 13.78 & $1.30 \mathrm{E}+08$ & 1 \\
\hline Alaska & $3 / 27 / 64$ & 9.2 & 65.3 & 1.5 & 6.1 & 16.48 & $2.40 E+08$ & 1 \\
\hline Niigata & $6 / 16 / 64$ & 7.5 & 62 & 0 & 4.3 & 10.68 & $1.10 \mathrm{E}+06$ & 1 \\
\hline Niigata & $6 / 16 / 64$ & 7.5 & 62 & 9 & 12.5 & 10.36 & $2.20 \mathrm{E}+05$ & 0 \\
\hline Niigata & $6 / 16 / 64$ & 7.5 & 62 & 5 & 7 & 4.38 & $3.90 \mathrm{E}+05$ & 1 \\
\hline
\end{tabular}




\begin{tabular}{|c|c|c|c|c|c|c|c|c|}
\hline Earthquake & Date & $\mathbf{M}$ & $\mathbf{R}$ & $\begin{array}{c}\text { Dw } \\
\text { Dept } \\
\text { h of } \\
\text { Wate } \\
\text { r } \\
\text { Tabl } \\
\text { e } \\
\end{array}$ & $\begin{array}{c}\text { D } \\
\text { Dept } \\
h \text { of } \\
\text { Sand }\end{array}$ & $\left(N_{1}\right)_{60}$ & $\begin{array}{c}\mathbf{S} \\
\text { Seismic } \\
\text { Energy }\end{array}$ & $\begin{array}{c}\text { Liq. } \\
?\end{array}$ \\
\hline Niigata & $6 / 16 / 64$ & 7.5 & 62 & 1.4 & 14 & 9 & $3.00 \mathrm{E}+05$ & 1 \\
\hline Niigata & $6 / 16 / 64$ & 7.5 & 62 & 1 & 10 & 14.3 & $4.20 \mathrm{E}+05$ & 1 \\
\hline Niigata & $6 / 16 / 64$ & 7.5 & 62 & 1 & 9 & 8 & $4.60 \mathrm{E}+05$ & 1 \\
\hline Niigata & $6 / 16 / 64$ & 7.5 & 62 & 1.4 & 5 & 12.5 & $7.20 \mathrm{E}+05$ & 1 \\
\hline Niigata & $6 / 16 / 64$ & 7.5 & 62 & 2.5 & 7 & 6.8 & $4.90 \mathrm{E}+05$ & 1 \\
\hline Niigata & $6 / 16 / 64$ & 7.5 & 62 & 2.5 & 5 & 13.9 & $6.20 E+05$ & 1 \\
\hline Niigata & $6 / 16 / 64$ & 7.5 & 62 & 2.5 & 5 & 44.42 & $6.20 \mathrm{E}+05$ & 0 \\
\hline Niigata & $6 / 16 / 64$ & 7.5 & 62 & 2.3 & 8.5 & 20.63 & $4.30 \mathrm{E}+05$ & 0 \\
\hline Niigata & $6 / 16 / 64$ & 7.5 & 62 & 0.8 & 10 & 11.62 & $4.30 \mathrm{E}+05$ & 1 \\
\hline Niigata & $6 / 16 / 64$ & 7.5 & 62 & 1.2 & 6.4 & 12.14 & $6.10 \mathrm{E}+05$ & 1 \\
\hline Niigata & $6 / 16 / 64$ & 7.5 & 62 & 5.2 & 10 & 15.08 & $3.00 \mathrm{E}+05$ & 0 \\
\hline Niigata & $6 / 16 / 64$ & 7.5 & 62 & 1.2 & 9.5 & 20.74 & $4.30 \mathrm{E}+05$ & 0 \\
\hline Niigata & $6 / 16 / 64$ & 7.5 & 62 & 0 & 2.5 & 18.22 & $1.90 \mathrm{E}+06$ & 0 \\
\hline Niigata & $6 / 16 / 64$ & 7.5 & 62 & 3.5 & 9.5 & 9.83 & $3.60 E+05$ & 0 \\
\hline Niigata & $6 / 16 / 64$ & 7.5 & 62 & 0.1 & 9.3 & 14.34 & $4.90 \mathrm{E}+05$ & 0 \\
\hline Niigata & $6 / 16 / 64$ & 7.5 & 94 & 0 & 9 & 4.7 & $2.20 E+05$ & 1 \\
\hline Niigata & $6 / 16 / 64$ & 7.5 & 62 & 1 & 15 & 3.34 & $2.90 E+05$ & 1 \\
\hline Niigata & $6 / 16 / 64$ & 7.5 & 65.2 & 0.9 & 6.1 & 9.26 & $7.30 \mathrm{E}+05$ & 1 \\
\hline Niigata & $6 / 16 / 64$ & 7.5 & 65.2 & 0.9 & 7.6 & 20.71 & $5.80 \mathrm{E}+05$ & 1 \\
\hline Niigata & $6 / 16 / 64$ & 7.5 & 65.2 & 0.9 & 6.1 & 18.52 & $7.30 \mathrm{E}+05$ & 0 \\
\hline Niigata & $6 / 16 / 64$ & 7.5 & 65.2 & 3.7 & 7.6 & 7.17 & $4.40 E+05$ & 0 \\
\hline Caracas & $7 / 29 / 67$ & 6.5 & 58.3 & 0.9 & 0.9 & 7.55 & $1.00 E+05$ & 1 \\
\hline Tokachioki & $5 / 16 / 68$ & 8.2 & 291 & 1 & 6 & 12 & $3.40 \mathrm{E}+05$ & 1 \\
\hline Tokachioki & $5 / 16 / 68$ & 8.2 & 181 & 1 & 2 & 16.4 & $2.00 \mathrm{E}+06$ & 0 \\
\hline Tokachioki & $5 / 16 / 68$ & 8.2 & 181 & 1.5 & 2 & 19 & $1.70 \mathrm{E}+06$ & 0 \\
\hline Tokachioki & $5 / 16 / 68$ & 8.2 & 181 & 1 & 2 & 20.5 & $2.00 \mathrm{E}+06$ & 0 \\
\hline Tokachioki & $5 / 16 / 68$ & 8.2 & 181 & 1.5 & 2.5 & 14 & $1.70 E+06$ & 0 \\
\hline Tokachioki & $5 / 16 / 68$ & 8.2 & 181 & 1 & 2 & 1.4 & $2.00 \mathrm{E}+06$ & 1 \\
\hline Tokachioki & $5 / 16 / 68$ & 8.2 & 178.1 & 0.9 & 3.7 & 26.47 & $1.60 E+06$ & 0 \\
\hline Tokachioki & $5 / 16 / 68$ & 8.2 & 74.7 & 0.9 & 3.7 & 11.34 & $9.30 \mathrm{E}+06$ & 1 \\
\hline Tokachioki & $5 / 16 / 68$ & 8.2 & 178.1 & 1.5 & 3.1 & 28.36 & $1.60 \mathrm{E}+06$ & 0 \\
\hline Tokachioki & $5 / 16 / 68$ & 8.2 & 162.2 & 0.9 & 4.6 & 10.15 & $1.60 \mathrm{E}+06$ & 1 \\
\hline Santa Rosa & $10 / 1 / 69$ & 4.8 & 80.6 & 1.7 & 4.6 & 4.7 & $3.90 \mathrm{E}+01$ & 0 \\
\hline Santa Rosa & $10 / 1 / 69$ & 4.8 & 80.6 & 1.7 & 4.6 & 13.2 & $3.90 \mathrm{E}+01$ & 0 \\
\hline San Fernando & $2 / 9 / 71$ & 6.6 & 18.8 & 0 & 13.7 & 9.88 & $1.60 \mathrm{E}+05$ & 1 \\
\hline San Fernando & $2 / 9 / 71$ & 6.6 & 11.6 & 4.6 & 6.1 & 7.45 & $6.20 \mathrm{E}+05$ & 1 \\
\hline Haicheng & $2 / 4 / 75$ & 7 & 56.6 & 1.5 & 8.2 & 11.74 & $1.10 \mathrm{E}+05$ & 1 \\
\hline Haicheng & $2 / 4 / 75$ & 7 & 69 & 1.5 & 9.1 & 9.42 & $6.40 \mathrm{E}+05$ & 1 \\
\hline Haicheng & $2 / 4 / 75$ & 7 & 92 & 1.5 & 8.2 & 15.8 & $4.00 \mathrm{E}+04$ & 0 \\
\hline Guatemala & $2 / 4 / 76$ & 7.4 & 170 & 1.5 & 8.8 & 2.3 & $4.20 \mathrm{E}+04$ & 1 \\
\hline Guatemala & $2 / 4 / 76$ & 7.4 & 170 & 2.6 & 5.8 & 5.7 & $5.20 \mathrm{E}+04$ & 1 \\
\hline Tangshan & $7 / 27 / 76$ & 7.6 & 118 & 3.5 & 7.6 & 21.32 & $1.60 \mathrm{E}+05$ & 0 \\
\hline Tangshan & $7 / 27 / 76$ & 7.6 & 121 & 3.3 & 6.5 & 14.04 & $1.80 \mathrm{E}+05$ & 0 \\
\hline Tangshan & $7 / 27 / 76$ & 7.6 & 121 & 2 & 5 & 12.76 & $2.50 \mathrm{E}+05$ & 0 \\
\hline
\end{tabular}

B-3 


\begin{tabular}{|c|c|c|c|c|c|c|c|c|}
\hline Earthquake & Date & $\mathbf{M}$ & $\mathbf{R}$ & $\begin{array}{c}\text { Dw } \\
\text { Dept } \\
\text { h of } \\
\text { Wate } \\
\text { r } \\
\text { Tabl } \\
\text { e }\end{array}$ & $\begin{array}{c}\text { D } \\
\text { Dept } \\
\text { h of } \\
\text { Sand }\end{array}$ & $\left(\mathbf{N}_{1}\right)_{60}$ & $\begin{array}{c}\mathbf{S} \\
\text { Seismic } \\
\text { Energy }\end{array}$ & $\begin{array}{c}\text { Liq. } \\
?\end{array}$ \\
\hline Tangshan & $7 / 27 / 76$ & 7.6 & 119 & 3.3 & 6 & 5.85 & $1.90 \mathrm{E}+05$ & 1 \\
\hline Tangshan & $7 / 27 / 76$ & 7.6 & 121 & 3 & 5 & 10.1 & $2.10 \mathrm{E}+05$ & 1 \\
\hline Tangshan & $7 / 27 / 76$ & 7.6 & 119 & 3.2 & 6 & 8.3 & $1.90 \mathrm{E}+05$ & 1 \\
\hline Tangshan & $7 / 27 / 76$ & 7.6 & 121 & 1.3 & 9 & 32.24 & $1.70 \mathrm{E}+05$ & 0 \\
\hline Tangshan & $7 / 27 / 76$ & 7.6 & 30 & 3.1 & 7.5 & 52.39 & $2.60 E+06$ & 0 \\
\hline Tangshan & $7 / 27 / 76$ & 7.6 & 26.5 & 1.8 & 13.5 & 20.19 & $2.30 \mathrm{E}+06$ & 0 \\
\hline Tangshan & $7 / 27 / 76$ & 7.6 & 23.6 & 5.2 & 6.2 & 57.42 & $4.00 \mathrm{E}+06$ & 0 \\
\hline Tangshan & $7 / 27 / 76$ & 7.6 & 15 & 3.7 & 4.5 & 16.88 & $1.40 \mathrm{E}+07$ & 1 \\
\hline Tangshan & $7 / 27 / 76$ & 7.6 & 16 & 7.3 & 8 & 36.35 & $6.40 \mathrm{E}+06$ & 0 \\
\hline Tangshan & $7 / 27 / 76$ & 7.6 & 16.1 & 4.3 & 6 & 24.6 & $9.40 \mathrm{E}+06$ & 0 \\
\hline Tangshan & $7 / 27 / 76$ & 7.6 & 15.4 & 4.5 & 6 & 14.6 & $1.00 \mathrm{E}+07$ & 0 \\
\hline Tangshan & $7 / 27 / 76$ & 7.6 & 15 & 3 & 4.5 & 21.68 & $1.50 \mathrm{E}+07$ & 0 \\
\hline Tangshan & $7 / 27 / 76$ & 7.6 & 12.1 & 3.8 & 6.5 & 16.96 & $1.70 \mathrm{E}+07$ & 0 \\
\hline Tangshan & $7 / 27 / 76$ & 7.6 & 11.2 & 2.1 & 4.8 & 20.84 & $2.90 \mathrm{E}+07$ & 0 \\
\hline Tangshan & $7 / 27 / 76$ & 7.6 & 16.1 & 1.5 & 4.5 & 32.7 & $1.60 \mathrm{E}+07$ & 0 \\
\hline Tangshan & $7 / 27 / 76$ & 7.6 & 18.8 & 1.9 & 3.5 & 18.37 & $1.30 \mathrm{E}+07$ & 1 \\
\hline Tangshan & $7 / 27 / 76$ & 7.6 & 18.6 & 1.5 & 6.5 & 19.3 & $9.10 \mathrm{E}+06$ & 1 \\
\hline Tangshan & $7 / 27 / 76$ & 7.6 & 14.6 & 3 & 6.5 & 12.3 & $1.20 \mathrm{E}+07$ & 1 \\
\hline Tangshan & $7 / 27 / 76$ & 7.6 & 15.2 & 2.2 & 5.8 & 3.4 & $1.40 \mathrm{E}+07$ & 1 \\
\hline Tangshan & $7 / 27 / 76$ & 7.6 & 15.9 & 1.5 & 9 & 8.8 & $9.50 \mathrm{E}+06$ & 1 \\
\hline Tangshan & $7 / 27 / 76$ & 7.6 & 17.2 & 0.9 & 3.5 & 22.02 & $1.90 \mathrm{E}+07$ & 1 \\
\hline Tangshan & $7 / 27 / 76$ & 7.6 & 18.8 & 1.6 & 6.5 & 9.1 & $8.80 \mathrm{E}+06$ & 1 \\
\hline Tangshan & $7 / 27 / 76$ & 7.6 & 23.6 & 1.3 & 3.5 & 15.39 & $9.40 \mathrm{E}+06$ & 1 \\
\hline Tangshan & $7 / 27 / 76$ & 7.6 & 26.1 & 1.2 & 11 & 14.5 & $3.00 \mathrm{E}+06$ & 1 \\
\hline Tangshan & $7 / 27 / 76$ & 7.6 & 20.7 & 0.6 & 4 & 5.9 & $1.30 \mathrm{E}+07$ & 1 \\
\hline Tangshan & $7 / 27 / 76$ & 7.6 & 17 & 1.1 & 6 & 21.4 & $1.20 \mathrm{E}+07$ & 1 \\
\hline Tangshan & $7 / 27 / 76$ & 7.6 & 45.2 & 0.7 & 8.5 & 15.6 & $1.30 \mathrm{E}+06$ & 1 \\
\hline Tangshan & $7 / 27 / 76$ & 7.6 & 41.4 & 0.7 & 8.5 & 12.5 & $1.60 \mathrm{E}+06$ & 1 \\
\hline Tangshan & $7 / 27 / 76$ & 7.6 & 45.2 & 0.8 & 9.5 & 10.8 & $1.20 \mathrm{E}+06$ & 1 \\
\hline Tangshan & $7 / 27 / 76$ & 7.6 & 49 & 0.7 & 11 & 21.68 & $8.90 \mathrm{E}+05$ & 0 \\
\hline Tangshan & $7 / 27 / 76$ & 7.6 & 52.3 & 1 & 5 & 23.97 & $1.50 \mathrm{E}+06$ & 0 \\
\hline Tangshan & $7 / 27 / 76$ & 7.6 & 49 & 1.8 & 3 & 10.14 & $2.20 \mathrm{E}+06$ & 1 \\
\hline Tangshan & $7 / 27 / 76$ & 7.6 & 43.3 & 2.1 & 3 & 8.59 & $2.60 \mathrm{E}+06$ & 1 \\
\hline Tangshan & $7 / 27 / 76$ & 7.6 & 34.9 & 3.7 & 6 & 14.2 & $2.10 \mathrm{E}+06$ & 1 \\
\hline Tangshan & $7 / 27 / 76$ & 7.6 & 47.1 & 4.5 & 10 & 14.9 & $7.80 \mathrm{E}+05$ & 1 \\
\hline Tangshan & $7 / 27 / 76$ & 7.6 & 47.1 & 3.5 & 4 & 43.1 & $1.50 \mathrm{E}+06$ & 0 \\
\hline Tangshan & $7 / 27 / 76$ & 7.6 & 49 & 4.5 & 7.2 & 21.36 & $8.90 \mathrm{E}+05$ & 0 \\
\hline Tangshan & $7 / 27 / 76$ & 7.6 & 39.6 & 2.8 & 3.5 & 24.53 & $2.50 \mathrm{E}+06$ & 0 \\
\hline Tangshan & $7 / 27 / 76$ & 7.6 & 47.1 & 1.1 & 5 & 11.99 & $1.90 \mathrm{E}+06$ & 1 \\
\hline Tangshan & $7 / 27 / 76$ & 7.6 & 42.4 & 3.6 & 9.5 & 5.22 & $1.10 \mathrm{E}+06$ & 1 \\
\hline Tangshan & $7 / 27 / 76$ & 7.6 & 41.2 & 1.1 & 5.5 & 26.33 & $2.20 \mathrm{E}+06$ & 0 \\
\hline Tangshan & $7 / 27 / 76$ & 7.6 & 47.1 & 3.1 & 6.5 & 22.16 & $1.20 \mathrm{E}+06$ & 0 \\
\hline Tangshan & $7 / 27 / 76$ & 7.6 & 42.4 & 1.4 & 4 & 4.19 & $2.60 \mathrm{E}+06$ & 1 \\
\hline Tangshan & 7/27/76 & 7.6 & 72.4 & 0.9 & 2 & 7.4 & $1.70 \mathrm{E}+06$ & 1 \\
\hline
\end{tabular}




\begin{tabular}{|c|c|c|c|c|c|c|c|c|}
\hline Earthquake & Date & $\mathbf{M}$ & $\mathbf{R}$ & $\begin{array}{c}\text { Dw } \\
\text { Dept } \\
\text { h of } \\
\text { Wate } \\
\mathbf{r} \\
\text { Tabl } \\
\mathbf{e} \\
\end{array}$ & $\begin{array}{c}\text { D } \\
\text { Dept } \\
\text { h of } \\
\text { Sand }\end{array}$ & $\left(N_{1}\right)_{60}$ & $\begin{array}{c}\text { S } \\
\text { Seismic } \\
\text { Energy }\end{array}$ & $\begin{array}{c}\text { Liq. } \\
?\end{array}$ \\
\hline Tangshan & $7 / 27 / 76$ & 7.6 & 66.5 & 2 & 8.7 & 10.42 & $5.30 \mathrm{E}+05$ & 0 \\
\hline Tangshan & $7 / 27 / 76$ & 7.6 & 63.6 & 1.6 & 3.5 & 19.6 & $1.20 \mathrm{E}+06$ & 0 \\
\hline Tangshan & $7 / 27 / 76$ & 7.6 & 71.4 & 1.1 & 4.2 & 6.9 & $9.30 \mathrm{E}+05$ & 1 \\
\hline Tangshan & $7 / 27 / 76$ & 7.6 & 94.6 & 0.6 & 5 & 12.67 & $5.00 \mathrm{E}+05$ & 1 \\
\hline Tangshan & $7 / 27 / 76$ & 7.6 & 93.1 & 0.7 & 3.5 & 4.07 & $6.90 \mathrm{E}+05$ & 1 \\
\hline Tangshan & $7 / 27 / 76$ & 7.6 & 92.1 & 0.7 & 5 & 13.2 & $5.20 \mathrm{E}+05$ & 0 \\
\hline Tangshan & $7 / 27 / 76$ & 7.6 & 66.3 & 2.3 & 3 & 6.78 & $1.10 \mathrm{E}+06$ & 1 \\
\hline Tangshan & $7 / 27 / 76$ & 7.6 & 71.4 & 2.3 & 9.5 & 15.78 & $4.20 \mathrm{E}+05$ & 0 \\
\hline Tangshan & $7 / 27 / 76$ & 7.6 & 59.7 & 2.5 & 4.3 & 10.9 & $1.00 \mathrm{E}+06$ & 0 \\
\hline Tangshan & $7 / 27 / 76$ & 7.6 & 68 & 2.3 & 3.5 & 15.93 & $9.40 \mathrm{E}+05$ & 1 \\
\hline Tangshan & $7 / 27 / 76$ & 7.6 & 66 & 2.3 & 7 & 15.6 & $6.10 \mathrm{E}+05$ & 1 \\
\hline Tangshan & $7 / 27 / 76$ & 7.6 & 67.5 & 2.9 & 6.5 & 11.3 & $5.90 \mathrm{E}+05$ & 1 \\
\hline Tangshan & $7 / 27 / 76$ & 7.6 & 81.2 & 1.4 & 4 & 30.85 & $7.10 \mathrm{E}+05$ & 0 \\
\hline Tangshan & $7 / 27 / 76$ & 7.6 & 84.5 & 1.2 & 5 & 20.34 & $5.70 \mathrm{E}+05$ & 0 \\
\hline Tangshan & $7 / 27 / 76$ & 7.6 & 80 & 0.8 & 6 & 12.32 & $5.80 \mathrm{E}+05$ & 1 \\
\hline Tangshan & $7 / 27 / 76$ & 7.6 & 83.2 & 1.4 & 6.5 & 12.55 & $4.60 \mathrm{E}+05$ & 1 \\
\hline Tangshan & $7 / 27 / 76$ & 7.6 & 86.1 & 1.2 & 5 & 13.19 & $5.50 \mathrm{E}+05$ & 1 \\
\hline Tangshan & $7 / 27 / 76$ & 7.6 & 78.7 & 0.8 & 4.5 & 24.25 & $3.77 \mathrm{E}+06$ & 0 \\
\hline Tangshan & $7 / 27 / 76$ & 7.6 & 83.6 & 1 & 4.5 & 36.46 & $6.50 \mathrm{E}+05$ & 0 \\
\hline Tangshan & $7 / 27 / 76$ & 7.6 & 78.3 & 0.5 & 2 & 6 & $1.60 \mathrm{E}+06$ & 1 \\
\hline Tangshan & $7 / 27 / 76$ & 7.6 & 87.1 & 1.6 & 2.3 & 17.59 & $8.50 \mathrm{E}+05$ & 0 \\
\hline Tangshan & $7 / 27 / 76$ & 6.7 & 22.5 & 2.1 & 3.6 & 28.91 & $8.70 \mathrm{E}+06$ & 0 \\
\hline IzuOhshima Kinki & $1 / 14 / 78$ & 6.7 & 40.3 & 2 & 7 & 6.32 & $7.70 \mathrm{E}+04$ & 1 \\
\hline IzuOhshima Kinki & $1 / 14 / 78$ & 6.4 & 40.3 & 2 & 6 & 6.2 & $8.60 \mathrm{E}+04$ & 1 \\
\hline Miyagiken-Oki 1 & $2 / 20 / 78$ & 6.4 & 131 & 0 & 3 & 20 & $7.70 \mathrm{E}+03$ & 0 \\
\hline Miyagiken-Oki 1 & $2 / 20 / 78$ & 6.4 & 130 & 0 & 4 & 14.2 & $5.90 \mathrm{E}+03$ & 0 \\
\hline Miyagiken-Oki 1 & $2 / 20 / 78$ & 6.4 & 130 & 1.8 & 5 & 8.24 & $3.50 \mathrm{E}+03$ & 0 \\
\hline Miyagiken-Oki 1 & $2 / 20 / 78$ & 6.4 & 130 & 0.9 & 3.3 & 5.2 & $5.60 \mathrm{E}+03$ & 0 \\
\hline Miyagiken-Oki 1 & $2 / 20 / 78$ & 6.4 & 130 & 1.7 & 4.3 & 6.9 & $3.90 \mathrm{E}+03$ & 0 \\
\hline Miyagiken-Oki 1 & $2 / 20 / 78$ & 6.4 & 130 & 0.3 & 4 & 13.94 & $5.50 \mathrm{E}+03$ & 0 \\
\hline Miyagiken-Oki 1 & $2 / 20 / 78$ & 6.4 & 130 & 0.9 & 5 & 7.11 & $4.00 \mathrm{E}+03$ & 0 \\
\hline Miyagiken-Oki 1 & $2 / 20 / 78$ & 6.4 & 98 & 4.3 & 6.3 & 9.8 & $3.90 \mathrm{E}+03$ & 0 \\
\hline Miyagiken-Oki 1 & $2 / 20 / 78$ & 6.4 & 98 & 2.4 & 6.3 & 9.6 & $4.80 \mathrm{E}+03$ & 0 \\
\hline Miyagiken-Oki 1 & $2 / 20 / 78$ & 6.4 & 96 & 0 & 5 & 9.1 & $8.60 E+03$ & 0 \\
\hline Miyagiken-Oki 1 & $2 / 20 / 78$ & 6.4 & 96 & 0 & 6 & 7 & $7.20 \mathrm{E}+03$ & 0 \\
\hline Miyagiken-Oki 1 & $2 / 20 / 78$ & 6.4 & 130 & 2.7 & 10 & 3.02 & $1.90 \mathrm{E}+03$ & 0 \\
\hline Miyagiken-Oki 1 & $2 / 20 / 78$ & 6.4 & 96 & 0 & 9.3 & 19.58 & $4.60 \mathrm{E}+03$ & 0 \\
\hline Miyagiken-Oki 1 & $2 / 20 / 78$ & 6.4 & 130 & 0.5 & 3.3 & 9.2 & $6.40 \mathrm{E}+03$ & 0 \\
\hline Miyagiken-Oki 1 & $2 / 20 / 78$ & 6.4 & 130 & 1.3 & 3.3 & 12 & $5.50 \mathrm{E}+03$ & 0 \\
\hline Miyagiken-Oki 1 & $2 / 20 / 78$ & 6.4 & 98 & 2.5 & 8 & 5.96 & $3.90 \mathrm{E}+03$ & 0 \\
\hline Miyagiken-Oki 1 & $2 / 20 / 78$ & 6.4 & 130 & 0.9 & 3.3 & 32 & $5.90 \mathrm{E}+03$ & 0 \\
\hline Miyagiken-Oki 1 & $2 / 20 / 78$ & 6.4 & 130 & 0.9 & 3.3 & 13.61 & $5.90 \mathrm{E}+03$ & 0 \\
\hline Miyagiken-Oki 1 & $2 / 20 / 78$ & 6.4 & 130 & 2.2 & 5.3 & 27 & $3.30 \mathrm{E}+03$ & 0 \\
\hline Miyagiken-Oki 1 & $2 / 20 / 78$ & 6.4 & 96 & 1.5 & 8 & 12.04 & $4.50 \mathrm{E}+03$ & 0 \\
\hline
\end{tabular}




\begin{tabular}{|c|c|c|c|c|c|c|c|c|}
\hline Earthquake & Date & $\mathbf{M}$ & $\mathbf{R}$ & $\begin{array}{c}\text { Dw } \\
\text { Dept } \\
\text { h of } \\
\text { Wate } \\
r \\
\text { Tabl } \\
\text { e }\end{array}$ & $\begin{array}{c}\text { D } \\
\text { Dept } \\
h \text { of } \\
\text { Sand }\end{array}$ & $\left(N_{1}\right)_{60}$ & $\begin{array}{c}\mathbf{S} \\
\text { Seismic } \\
\text { Energy }\end{array}$ & $\begin{array}{c}\text { Liq. } \\
?\end{array}$ \\
\hline Miyagiken-Oki 1 & $2 / 20 / 78$ & 6.4 & 130 & 2.5 & 7.2 & 20.32 & $2.40 \mathrm{E}+03$ & 0 \\
\hline Miyagiken-Oki 1 & $2 / 20 / 78$ & 6.4 & 131 & 4 & 7.3 & 14.55 & $2.10 \mathrm{E}+03$ & 0 \\
\hline Miyagiken-Oki 1 & $2 / 20 / 78$ & 6.4 & 131 & 4.3 & 7.3 & 18.95 & $2.00 \mathrm{E}+03$ & 0 \\
\hline Miyagiken-Oki 1 & $2 / 20 / 78$ & 6.4 & 131 & 3.4 & 6.3 & 27.55 & $2.40 \mathrm{E}+03$ & 0 \\
\hline Miyagiken-Oki 1 & $2 / 20 / 78$ & 6.4 & 130 & 8 & 10 & 6.8 & $1.30 \mathrm{E}+03$ & 0 \\
\hline Miyagiken-Oki 1 & $2 / 20 / 78$ & 6.4 & 129 & 0.8 & 6.3 & 40.02 & $3.90 \mathrm{E}+03$ & 0 \\
\hline Miyagiken-Oki 1 & $2 / 20 / 78$ & 6.4 & 98 & 0 & 5 & 26.71 & $8.30 \mathrm{E}+03$ & 0 \\
\hline Miyagiken-Oki 1 & $2 / 20 / 78$ & 6.4 & 98 & 0 & 4 & 30.27 & $1.00 \mathrm{E}+04$ & 0 \\
\hline Miyagiken-Oki 1 & $2 / 20 / 78$ & 6.4 & 98 & 3.4 & 5.3 & 19.9 & $5.40 \mathrm{E}+03$ & 0 \\
\hline Miyagiken-Oki 2 & $6 / 12 / 78$ & 7.5 & 114 & 0 & 4 & 14.2 & $3.40 \mathrm{E}+05$ & 1 \\
\hline Miyagiken-Oki 2 & $6 / 12 / 78$ & 7.5 & 113 & 1.8 & 5 & 8.24 & $2.00 \mathrm{E}+05$ & 1 \\
\hline Miyagiken-Oki 2 & $6 / 12 / 78$ & 7.5 & 113 & 0.9 & 3.3 & 5.2 & $3.30 \mathrm{E}+05$ & 1 \\
\hline Miyagiken-Oki 2 & $6 / 12 / 78$ & 7.5 & 112 & 1.7 & 4.3 & 6.9 & $2.40 \mathrm{E}+05$ & 1 \\
\hline Miyagiken-Oki 2 & $6 / 12 / 78$ & 7.5 & 112 & 0.3 & 4 & 13.94 & $3.30 \mathrm{E}+05$ & 1 \\
\hline Miyagiken-Oki 2 & $6 / 12 / 78$ & 7.5 & 110 & 0.9 & 5 & 7.11 & $2.50 \mathrm{E}+05$ & 1 \\
\hline Miyagiken-Oki 2 & $6 / 12 / 78$ & 7.5 & 96 & 4.3 & 6.3 & 9.8 & $1.80 \mathrm{E}+05$ & 1 \\
\hline Miyagiken-Oki 2 & $6 / 12 / 78$ & 7.5 & 95 & 2.4 & 6.3 & 9.6 & $2.30 \mathrm{E}+05$ & 1 \\
\hline Miyagiken-Oki 2 & $6 / 12 / 78$ & 7.5 & 85 & 0 & 5 & 9.1 & $4.90 \mathrm{E}+05$ & 1 \\
\hline Miyagiken-Oki 2 & $6 / 12 / 78$ & 7.5 & 85 & 0 & 6 & 7 & $4.10 \mathrm{E}+05$ & 1 \\
\hline Miyagiken-Oki 2 & $6 / 12 / 78$ & 7.5 & 111 & 2.7 & 10 & 3.02 & $1.10 \mathrm{E}+05$ & 1 \\
\hline Miyagiken-Oki 2 & $6 / 12 / 78$ & 7.5 & 114 & 0.5 & 3.3 & 9.2 & $3.70 \mathrm{E}+05$ & 1 \\
\hline Miyagiken-Oki 2 & $6 / 12 / 78$ & 7.5 & 114 & 1.3 & 3.3 & 12 & $3.20 \mathrm{E}+05$ & 1 \\
\hline Miyagiken-Oki 2 & $6 / 12 / 78$ & 7.5 & 100 & 2.5 & 8 & 5.96 & $1.70 \mathrm{E}+05$ & 1 \\
\hline Miyagiken-Oki 2 & $6 / 12 / 78$ & 7.5 & 114 & 0.9 & 3.3 & 32 & $3.40 \mathrm{E}+05$ & 0 \\
\hline Miyagiken-Oki 2 & $6 / 12 / 78$ & 7.5 & 114 & 0.9 & 3.3 & 13.61 & $3.40 \mathrm{E}+05$ & 0 \\
\hline Miyagiken-Oki 2 & $6 / 12 / 78$ & 7.5 & 113 & 2.2 & 5.3 & 27 & $1.90 \mathrm{E}+05$ & 0 \\
\hline Miyagiken-Oki 2 & $6 / 12 / 78$ & 7.5 & 85 & 1.5 & 8 & 12.04 & $2.60 \mathrm{E}+05$ & 0 \\
\hline Miyagiken-Oki 2 & $6 / 12 / 78$ & 7.5 & 112 & 2.5 & 7.2 & 20.32 & $1.50 \mathrm{E}+05$ & 0 \\
\hline Miyagiken-Oki 2 & $6 / 12 / 78$ & 7.5 & 118 & 4 & 7.3 & 14.55 & $1.10 \mathrm{E}+05$ & 0 \\
\hline Miyagiken-Oki 2 & $6 / 12 / 78$ & 7.5 & 118 & 4.3 & 7.3 & 18.95 & $1.10 \mathrm{E}+05$ & 0 \\
\hline Miyagiken-Oki 2 & $6 / 12 / 78$ & 7.5 & 118 & 3.4 & 6.3 & 27.55 & $1.30 \mathrm{E}+05$ & 0 \\
\hline Miyagiken-Oki 2 & $6 / 12 / 78$ & 7.5 & 109 & 8 & 10 & 6.8 & $8.30 \mathrm{E}+04$ & 0 \\
\hline Miyagiken-Oki 2 & $6 / 12 / 78$ & 7.5 & 107 & 0.8 & 6.3 & 40.02 & $2.50 \mathrm{E}+05$ & 0 \\
\hline Miyagiken-Oki 2 & $6 / 12 / 78$ & 7.5 & 95 & 0 & 5 & 26.71 & $3.90 \mathrm{E}+05$ & 0 \\
\hline Miyagiken-Oki 2 & $6 / 12 / 78$ & 7.5 & 95 & 0 & 4 & 30.27 & $4.90 \mathrm{E}+05$ & 0 \\
\hline Miyagiken-Oki 2 & $6 / 12 / 78$ & 7.5 & 100 & 3.4 & 5.3 & 19.9 & $2.30 \mathrm{E}+05$ & 0 \\
\hline Guerrero & $6 / 20 / 78$ & 6.4 & 50 & 3.6 & 5.5 & 16.2 & $1.70 \mathrm{E}+04$ & 0 \\
\hline Montenegro & $4 / 15 / 79$ & 6.9 & 51 & 1 & 7 & 6.59 & $1.30 \mathrm{E}+05$ & 1 \\
\hline Imperial Valley & $10 / 16 / 79$ & 6.7 & 14 & 1.8 & 3.7 & 50.23 & $1.10 \mathrm{E}+06$ & 0 \\
\hline Imperial Valley & $10 / 16 / 79$ & 6.7 & 14 & 1.8 & 3.7 & 6.13 & $1.10 \mathrm{E}+06$ & 1 \\
\hline Imperial Valley & $10 / 16 / 79$ & 6.7 & 14 & 1.8 & 4.3 & 26.6 & $1.00 \mathrm{E}+06$ & 0 \\
\hline Imperial Valley & $10 / 16 / 79$ & 6.7 & 43 & 0.2 & 1.8 & 11.24 & $2.90 \mathrm{E}+05$ & 1 \\
\hline Imperial Valley & $10 / 16 / 79$ & 6.7 & 51 & 1.2 & 3.8 & 11.49 & $1.00 \mathrm{E}+05$ & 0 \\
\hline Imperial Valley & $10 / 16 / 79$ & 6.7 & 56 & 2.7 & 4 & 23.14 & $6.10 \mathrm{E}+04$ & 0 \\
\hline
\end{tabular}

B-6 


\begin{tabular}{|c|c|c|c|c|c|c|c|c|}
\hline Earthquake & Date & $\mathbf{M}$ & $\mathbf{R}$ & $\begin{array}{c}\text { Dw } \\
\text { Dept } \\
h \text { of } \\
\text { Wate } \\
r \\
\text { Tabl } \\
e \\
\end{array}$ & $\begin{array}{c}\text { D } \\
\text { Dept } \\
h \text { of } \\
\text { Sand }\end{array}$ & $\left(N_{1}\right)_{60}$ & $\begin{array}{c}\text { S } \\
\text { Seismic } \\
\text { Energy }\end{array}$ & $\begin{array}{c}\text { Liq. } \\
? ?\end{array}$ \\
\hline Imperial Valley & $10 / 16 / 79$ & 6.7 & 61 & 2.5 & 4 & 9.8 & $5.40 \mathrm{E}+04$ & 0 \\
\hline Imperial Valley & $10 / 16 / 79$ & 6.7 & 61 & 2.5 & 4 & 19.04 & $5.10 \mathrm{E}+04$ & 0 \\
\hline Imperial Valley & $10 / 16 / 79$ & 6.7 & 47 & 2 & 3.5 & 8.6 & $1.00 \mathrm{E}+05$ & 1 \\
\hline Imperial Valley & $10 / 16 / 79$ & 6.7 & 47 & 2 & 2.3 & 18.16 & $1.30 \mathrm{E}+05$ & 0 \\
\hline Imperial Valley & $10 / 16 / 79$ & 6.7 & 28 & 1.5 & 2.3 & 14.81 & $4.30 \mathrm{E}+05$ & 1 \\
\hline Imperial Valley & $10 / 16 / 79$ & 6.7 & 28 & 1.5 & 2.3 & 19.88 & $4.30 \mathrm{E}+05$ & 0 \\
\hline Imperial Valley & $10 / 16 / 79$ & 6.7 & 54 & 4.1 & 5 & 26 & $4.80 \mathrm{E}+04$ & 0 \\
\hline Imperial Valley & $10 / 16 / 79$ & 6.7 & 61 & 2.7 & 4.3 & 19.4 & $4.90 \mathrm{E}+04$ & 0 \\
\hline Mexicali Valley & $10 / 16 / 79$ & 6.4 & 38 & 2 & 5 & 8.16 & $5.70 \mathrm{E}+04$ & 1 \\
\hline Westmoreland & $4 / 26 / 81$ & 6 & 50.5 & 1.8 & 3.7 & 50.23 & $7.70 \mathrm{E}+03$ & 0 \\
\hline Westmoreland & $4 / 26 / 81$ & 6 & 50.5 & 1.8 & 3.7 & 6.13 & $7.70 \mathrm{E}+03$ & 0 \\
\hline Westmoreland & $4 / 26 / 81$ & 6 & 50.5 & 1.8 & 4.3 & 26.6 & $6.90 \mathrm{E}+03$ & 0 \\
\hline Westmoreland & $4 / 26 / 81$ & 6 & 16.6 & 0.2 & 1.8 & 11.24 & $1.70 \mathrm{E}+05$ & 0 \\
\hline Westmoreland & $4 / 26 / 81$ & 6 & 16.6 & 0.2 & 5.8 & 18.48 & $6.00 \mathrm{E}+04$ & 0 \\
\hline Westmoreland & $4 / 26 / 81$ & 6 & 10.2 & 1.2 & 3.8 & 11.49 & $2.30 \mathrm{E}+05$ & 1 \\
\hline Westmoreland & $4 / 26 / 81$ & 6 & 7.6 & 2.5 & 4 & 9.8 & $3.10 \mathrm{E}+05$ & 1 \\
\hline Westmoreland & $4 / 26 / 81$ & 6 & 7.6 & 2.5 & 4 & 11.7 & $2.90 \mathrm{E}+05$ & 1 \\
\hline Westmoreland & $4 / 26 / 81$ & 6 & 15.7 & 2 & 3.5 & 8.6 & $8.10 \mathrm{E}+04$ & 1 \\
\hline Westmoreland & $4 / 26 / 81$ & 6 & 15.7 & 2 & 2.3 & 18.16 & $1.00 \mathrm{E}+05$ & 0 \\
\hline Westmoreland & $4 / 26 / 81$ & 6 & 29 & 1.5 & 2.3 & 14.81 & $3.60 \mathrm{E}+04$ & 0 \\
\hline Westmoreland & $4 / 26 / 81$ & 6 & 29 & 1.5 & 2.3 & 15.49 & $3.60 \mathrm{E}+04$ & 0 \\
\hline Westmoreland & $4 / 26 / 81$ & 6 & 14.4 & 4.1 & 5 & 20.84 & $6.00 \mathrm{E}+04$ & 0 \\
\hline Westmoreland & $4 / 26 / 81$ & 6 & 8 & 2.7 & 4.3 & 15.08 & $2.60 \mathrm{E}+05$ & 0 \\
\hline Loma Prieta & $10 / 17 / 89$ & 6.9 & 89.8 & 3.5 & 8 & 7.32 & $2.60 \mathrm{E}+04$ & 1 \\
\hline Loma Prieta & $10 / 17 / 89$ & 6.9 & 89.8 & 3.5 & 4 & 7.91 & $4.10 \mathrm{E}+04$ & 1 \\
\hline Loma Prieta & $10 / 17 / 89$ & 6.9 & 89.8 & 3.5 & 7 & 7.28 & $2.90 \mathrm{E}+04$ & 1 \\
\hline Loma Prieta & $10 / 17 / 89$ & 6.9 & 89.8 & 3.5 & 5 & 7.56 & $3.60 \mathrm{E}+04$ & 1 \\
\hline Loma Prieta & $10 / 17 / 89$ & 6.9 & 89.8 & 3.5 & 7 & 7.28 & $2.90 E+04$ & 1 \\
\hline Loma Prieta & $10 / 17 / 89$ & 6.9 & 89.8 & 3.5 & 5 & 7.56 & $3.60 \mathrm{E}+04$ & 1 \\
\hline Loma Prieta & $10 / 17 / 89$ & 6.9 & 74.1 & 3 & 7 & 9.6 & $4.40 \mathrm{E}+04$ & 1 \\
\hline Loma Prieta & $10 / 17 / 89$ & 6.9 & 74.1 & 3 & 5 & 11.29 & $5.50 \mathrm{E}+04$ & 1 \\
\hline Loma Prieta & $10 / 17 / 89$ & 6.9 & 74.1 & 3 & 13.9 & 12.66 & $2.60 \mathrm{E}+04$ & 0 \\
\hline Loma Prieta & $10 / 17 / 89$ & 6.9 & 74.1 & 3 & 9.3 & 15.85 & $3.50 \mathrm{E}+04$ & 0 \\
\hline Loma Prieta & $10 / 17 / 89$ & 6.9 & 74.1 & 3 & 8.4 & 18.31 & $3.80 \mathrm{E}+04$ & 0 \\
\hline Loma Prieta & $10 / 17 / 89$ & 6.9 & 74.1 & 3 & 13 & 21.17 & $2.70 \mathrm{E}+04$ & 0 \\
\hline Loma Prieta & $10 / 17 / 89$ & 6.9 & 74.1 & 3 & 10.7 & 24.69 & $3.20 E+04$ & 0 \\
\hline Loma Prieta & $10 / 17 / 89$ & 6.9 & 74.1 & 3 & 8.8 & 28.65 & $3.70 \mathrm{E}+04$ & 0 \\
\hline Loma Prieta & $10 / 17 / 89$ & 6.9 & 74.1 & 3 & 4.3 & 30.91 & $6.10 \mathrm{E}+04$ & 0 \\
\hline Loma Prieta & $10 / 17 / 89$ & 6.9 & 74.1 & 3 & 7.9 & 31.85 & $4.00 E+04$ & 0 \\
\hline Loma Prieta & $10 / 17 / 89$ & 6.9 & 74.1 & 3 & 11.6 & 34.99 & $3.00 E+04$ & 0 \\
\hline Loma Prieta & $10 / 17 / 89$ & 6.9 & 74.1 & 3 & 10.2 & 36.85 & $3.30 \mathrm{E}+04$ & 0 \\
\hline Loma Prieta & $10 / 17 / 89$ & 6.9 & 74.1 & 3 & 9.8 & 38.36 & $3.40 E+04$ & 0 \\
\hline Loma Prieta & $10 / 17 / 89$ & 6.9 & 74.1 & 3 & 11.1 & 50.39 & $3.10 E+04$ & 0 \\
\hline Loma Prieta & $10 / 17 / 89$ & 6.9 & 74.1 & 3 & 13.4 & 57.07 & $2.60 E+04$ & 0 \\
\hline
\end{tabular}

B-7 


\begin{tabular}{|c|c|c|c|c|c|c|c|c|}
\hline Earthquake & Date & $\mathbf{M}$ & $\mathbf{R}$ & $\begin{array}{c}\text { Dw } \\
\text { Dept } \\
\text { h of } \\
\text { Wate } \\
r \\
\text { Tabl } \\
e\end{array}$ & $\begin{array}{c}\text { D } \\
\text { Dept } \\
h \text { of } \\
\text { Sand }\end{array}$ & $\left(N_{1}\right)_{60}$ & $\begin{array}{c}\mathbf{S} \\
\text { Seismic } \\
\text { Energy }\end{array}$ & $\begin{array}{c}\text { Liq. } \\
?\end{array}$ \\
\hline Loma Prieta & $10 / 17 / 89$ & 6.9 & 74.1 & 3 & 3.8 & 61.08 & $6.60 E+04$ & 0 \\
\hline Loma Prieta & $10 / 17 / 89$ & 6.9 & 74.1 & 3 & 12.5 & 73.64 & $2.80 \mathrm{E}+04$ & 0 \\
\hline Loma Prieta & $10 / 17 / 89$ & 6.9 & 74.1 & 3 & 6 & 7.74 & $4.90 \mathrm{E}+04$ & 1 \\
\hline Loma Prieta & $10 / 17 / 89$ & 6.9 & 74.1 & 3 & 8.5 & 7.8 & $3.80 E+04$ & 1 \\
\hline Loma Prieta & $10 / 17 / 89$ & 6.9 & 74.1 & 3 & 11.1 & 15.27 & $3.10 E+04$ & 0 \\
\hline Loma Prieta & $10 / 17 / 89$ & 6.9 & 74.1 & 3 & 10.2 & 17.15 & $3.30 E+04$ & 0 \\
\hline Loma Prieta & $10 / 17 / 89$ & 6.9 & 74.1 & 3 & 5.6 & 21.55 & $5.10 E+04$ & 0 \\
\hline Loma Prieta & $10 / 17 / 89$ & 6.9 & 74.1 & 3 & 10.7 & 24.9 & $3.20 \mathrm{E}+04$ & 0 \\
\hline Loma Prieta & $10 / 17 / 89$ & 6.9 & 74.1 & 3 & 5.2 & 24.91 & $5.40 \mathrm{E}+04$ & 0 \\
\hline Loma Prieta & $10 / 17 / 89$ & 6.9 & 74.1 & 3 & 9.8 & 40.96 & $3 . \overline{40 E+04}$ & 0 \\
\hline Loma Prieta & $10 / 17 / 89$ & 6.9 & 74.1 & 3 & 4.3 & 46.11 & $6.10 \mathrm{E}+04$ & 0 \\
\hline Loma Prieta & $10 / 17 / 89$ & 6.9 & 74.1 & 3 & 4.7 & 62.99 & $5.80 \mathrm{E}+04$ & 0 \\
\hline Loma Prieta & $10 / 17 / 89$ & 6.9 & 74.1 & 3 & 3.8 & 72.3 & $6.60 \mathrm{E}+04$ & 0 \\
\hline Loma Prieta & $10 / 17 / 89$ & 6.9 & 74.1 & 3 & 3.4 & 74.56 & $7.00 \mathrm{E}+04$ & 0 \\
\hline Loma Prieta & $10 / 17 / 89$ & 6.9 & 71.2 & 3 & 7.5 & 10.18 & $4.50 E+04$ & 1 \\
\hline Loma Prieta & $10 / 17 / 89$ & 6.9 & 71.2 & 3 & 8.8 & 11.43 & $4.00 \mathrm{E}+04$ & 0 \\
\hline Loma Prieta & $10 / 17 / 89$ & 6.9 & 71.2 & 3 & 5 & 11.72 & $6.00 \mathrm{E}+04$ & 1 \\
\hline Loma Prieta & $10 / 17 / 89$ & 6.9 & 71.2 & 3 & 8.3 & 13.64 & $4.20 E+04$ & 0 \\
\hline Loma Prieta & $10 / 17 / 89$ & 6.9 & 71.2 & 3 & 3 & 14.4 & $8.20 E+04$ & 0 \\
\hline Loma Prieta & $10 / 17 / 89$ & 6.9 & 71.2 & 3 & 9.3 & 18.27 & $3.90 \mathrm{E}+04$ & 0 \\
\hline Loma Prieta & $10 / 17 / 89$ & 6.9 & 71.2 & 3 & 10.4 & 19.3 & $3.50 \mathrm{E}+04$ & 0 \\
\hline Loma Prieta & $10 / 17 / 89$ & 6.9 & 71.2 & 3 & 3.8 & 22.56 & $7.10 \mathrm{E}+04$ & 0 \\
\hline Loma Prieta & $10 / 17 / 89$ & 6.9 & 71.2 & 3 & 3.4 & 26.06 & $7.70 \mathrm{E}+04$ & 0 \\
\hline Loma Prieta & $10 / 17 / 89$ & 6.9 & 71.2 & 3 & 4.7 & 27.4 & $6.30 \mathrm{E}+04$ & 0 \\
\hline Loma Prieta & $10 / 17 / 89$ & 6.9 & 71.2 & 3 & 4.3 & 31.98 & $6.70 \mathrm{E}+04$ & 0 \\
\hline Loma Prieta & $10 / 17 / 89$ & 6.9 & 71.2 & 3 & 9.8 & 41.92 & $3.70 \mathrm{E}+04$ & 0 \\
\hline Loma Prieta & $10 / 17 / 89$ & 6.9 & 71.2 & 3 & 8 & 9.88 & $4.30 \mathrm{E}+04$ & 1 \\
\hline Loma Prieta & $10 / 17 / 89$ & 6.9 & 71.2 & 3 & 5.3 & 11.49 & $5.80 \mathrm{E}+04$ & 1 \\
\hline Loma Prieta & $10 / 17 / 89$ & 6.9 & 71.2 & 3 & 4.8 & 22.56 & $6.20 \mathrm{E}+04$ & 0 \\
\hline Loma Prieta & $10 / 17 / 89$ & 6.9 & 71.2 & 3 & 5.3 & 28.71 & $5.80 \mathrm{E}+04$ & 0 \\
\hline Loma Prieta & $10 / 17 / 89$ & 6.9 & 71.2 & 3 & 4.4 & 41.51 & $6.60 \mathrm{E}+04$ & 0 \\
\hline Loma Prieta & $10 / 17 / 89$ & 6.9 & 71.2 & 3 & 9.4 & 43.96 & $3.80 \mathrm{E}+04$ & 0 \\
\hline Loma Prieta & $10 / 17 / 89$ & 6.9 & 71.2 & 3 & 3.5 & 48.43 & $7.60 \mathrm{E}+04$ & 0 \\
\hline Loma Prieta & $10 / 17 / 89$ & 6.9 & 71.2 & 3 & 8.5 & 49.61 & $4.10 \mathrm{E}+04$ & 0 \\
\hline Loma Prieta & $10 / 17 / 89$ & 6.9 & 58.7 & 3.5 & 5 & 6.19 & $8.40 \mathrm{E}+04$ & 1 \\
\hline Loma Prieta & $10 / 17 / 89$ & 6.9 & 58.7 & 3.5 & 8 & 6.25 & $6.10 \mathrm{E}+04$ & 1 \\
\hline Loma Prieta & $10 / 17 / 89$ & 6.9 & 58.7 & 5.5 & 6.7 & 36.94 & $5.90 \mathrm{E}+04$ & 0 \\
\hline Loma Prieta & $10 / 17 / 89$ & 6.9 & 58.7 & 5.5 & 6.2 & 39.67 & $6.10 \mathrm{E}+04$ & 0 \\
\hline Loma Prieta & $10 / 17 / 89$ & 6.9 & 58.7 & 5.5 & 7.6 & 45.76 & $5.40 \mathrm{E}+04$ & 0 \\
\hline Loma Prieta & $10 / 17 / 89$ & 6.9 & 58.7 & 5.5 & 7.1 & 48.71 & $5.70 \mathrm{E}+04$ & 0 \\
\hline Loma Prieta & $10 / 17 / 89$ & 6.9 & 58.7 & 5.5 & 5.8 & 54.21 & $6.40 \mathrm{E}+04$ & 0 \\
\hline Kobe & $1 / 17 / 95$ & 6.9 & 24.6 & 3.9 & 6.2 & 11.44 & $4.00 \mathrm{E}+05$ & 1 \\
\hline Kobe & $1 / 17 / 95$ & 6.9 & 24.6 & 3.9 & 8.1 & 18.21 & $3.30 \mathrm{E}+05$ & 0 \\
\hline Kobe & $1 / 17 / 95$ & 6.9 & 24.6 & 3.9 & 9.3 & 21.04 & $3.00 \mathrm{E}+05$ & 0 \\
\hline
\end{tabular}




\begin{tabular}{|c|c|c|c|c|c|c|c|c|}
\hline Earthquake & Date & $\mathbf{M}$ & $\mathbf{R}$ & $\begin{array}{c}\text { Dw } \\
\text { Dept } \\
\text { h of } \\
\text { Wate } \\
\text { r } \\
\text { Tabl } \\
\text { e }\end{array}$ & $\begin{array}{c}\text { D } \\
\text { Dept } \\
h \text { of } \\
\text { Sand }\end{array}$ & $\left(N_{1}\right)_{60}$ & $\begin{array}{c}\mathbf{S} \\
\text { Seismic } \\
\text { Energy }\end{array}$ & $\begin{array}{c}\text { Liq. } \\
?\end{array}$ \\
\hline Kobe & $1 / 17 / 95$ & 6.9 & 24.6 & 3.9 & 10.3 & 21.55 & $2.80 \mathrm{E}+05$ & 0 \\
\hline Kobe & $1 / 17 / 95$ & $6 . \overline{9}$ & 24.6 & 3.9 & 8.1 & 8.83 & $3.30 \mathrm{E}+05$ & 1 \\
\hline Kobe & $1 / 17 / 95$ & 6.9 & 24.6 & 3.9 & 12 & 13.81 & $2.50 \mathrm{E}+05$ & 0 \\
\hline Kobe & $1 / 17 / 95$ & 6.9 & 28.8 & 4 & 10.6 & 10.78 & $2.00 \mathrm{E}+05$ & 1 \\
\hline Kobe & $1 / 17 / 95$ & 6.9 & 28.8 & 4 & 11.4 & 18.46 & $1.90 \mathrm{E}+05$ & 0 \\
\hline Kobe & $1 / 17 / 95$ & 6.9 & 28.8 & 4 & 12.3 & 19.17 & $1.80 \mathrm{E}+05$ & 0 \\
\hline Kobe & $1 / 17 / 95$ & 6.9 & 29.7 & 4 & 10.9 & 9.56 & $1.80 \mathrm{E}+05$ & 1 \\
\hline Kobe & $1 / 17 / 95$ & 6.9 & 29.7 & 4 & 14.4 & 15.24 & $1.50 \mathrm{E}+05$ & 0 \\
\hline Kobe & $1 / 17 / 95$ & 6.9 & 20.7 & 1.2 & 4.1 & 12.45 & $1.00 \mathrm{E}+06$ & 1 \\
\hline Chi-Chi & $9 / 21 / 99$ & 7.6 & 16.6 & 0.6 & 5.3 & 18.37 & $1.60 \mathrm{E}+07$ & 1 \\
\hline Chi-Chi & $9 / 21 / 99$ & 7.6 & 16.6 & 0.6 & 10.8 & 43.85 & $8.30 \mathrm{E}+06$ & 0 \\
\hline Chi-Chi & $9 / 21 / 99$ & 7.6 & 16.6 & 0.6 & 12.1 & 37.88 & $7.50 \mathrm{E}+06$ & 0 \\
\hline Chi-Chi & $9 / 21 / 99$ & 7.6 & 16.6 & 0.6 & 13.7 & 39.58 & $6.70 \mathrm{E}+06$ & 0 \\
\hline Chi-Chi & $9 / 21 / 99$ & 7.6 & 16.6 & 1.5 & 5.8 & 20.73 & $1.30 \mathrm{E}+07$ & 1 \\
\hline Chi-Chi & $9 / 21 / 99$ & 7.6 & 28.9 & 1 & 4.8 & 14.74 & $5.50 \mathrm{E}+06$ & 1 \\
\hline Chi-Chi & $9 / 21 / 99$ & 7.6 & 28.9 & 0.6 & 2.8 & 17.78 & $9.50 \mathrm{E}+06$ & 1 \\
\hline Chi-Chi & $9 / 21 / 99$ & 7.6 & 28.9 & 0.6 & 13.4 & 21.56 & $2.20 \mathrm{E}+06$ & 0 \\
\hline Chi-Chi & $9 / 21 / 99$ & 7.6 & 28.4 & 2.2 & 5.9 & 11.9 & $4.10 E+06$ & 1 \\
\hline Chi-Chi & 9/21/99 & 7.6 & 28.4 & 2 & 5.7 & 10.66 & $4.30 \mathrm{E}+06$ & 1 \\
\hline Chi-Chi & $9 / 21 / 99$ & 7.6 & 28.4 & 2 & 11.8 & 24.52 & $2.40 \mathrm{E}+06$ & 0 \\
\hline Chi-Chi & $9 / 21 / 99$ & 7.6 & 28.4 & 2 & 13.3 & 26.22 & $2.10 \mathrm{E}+06$ & 0 \\
\hline Chi-Chi & $9 / 21 / 99$ & 7.6 & 28.4 & 2 & 14.9 & 27.78 & $1.90 \mathrm{E}+06$ & 0 \\
\hline Chi-Chi & $9 / 21 / 99$ & 7.6 & 24 & 1.2 & 4.3 & 14.08 & $8.40 \mathrm{E}+06$ & 1 \\
\hline Chi-Chi & $9 / 21 / 99$ & 7.6 & 24 & 1.2 & 5.8 & 77.53 & $6.60 \mathrm{E}+06$ & 0 \\
\hline Chi-Chi & $9 / 21 / 99$ & 7.6 & 24 & 1.2 & 8.8 & 51.69 & $4.60 \mathrm{E}+06$ & 0 \\
\hline
\end{tabular}




\section{Appendix C}

\section{RELIABILITY INDICES AND PROBABILITY OF \\ LIQUEFACTION DATA}




\begin{tabular}{|c|c|c|c|c|c|c|c|}
\hline Earthquake & $\left(N_{1}\right)_{60}$ & $\mathbf{M}_{\mathbf{w}}$ & $\mathbf{R}$ & $\sigma_{0}^{\prime}[\mathrm{kPa}]$ & $\bar{\beta}$ & $\mathbf{P}_{\text {Lia }}$ & Liq.? \\
\hline Tangshan & 10.10 & 7.60 & 121.00 & 81.70 & -0.78 & 0.78 & 1 \\
\hline Tangshan & 10.14 & 7.60 & 49.00 & 47.55 & -1.39 & 0.92 & 1 \\
\hline Tokachioki & 10.15 & 8.20 & 162.20 & 47.40 & -1.28 & 0.90 & 1 \\
\hline Loma Prieta & 10.18 & 6.90 & 71.20 & 98.14 & -0.34 & 0.63 & 1 \\
\hline San Francisco & 10.66 & 7.60 & 28.40 & 72.43 & -1.47 & 0.93 & 0 \\
\hline San Francisco & 10.68 & 7.50 & 62.00 & 42.06 & -1.06 & 0.86 & 0 \\
\hline Niigata & 10.78 & 6.90 & 28.80 & 134.95 & -0.64 & 0.74 & 0 \\
\hline Tangshan & 10.80 & 7.60 & 45.20 & 102.46 & -1.13 & 0.87 & 0 \\
\hline Chi-Chi & 11.24 & 6.70 & 43.00 & 20.93 & -0.62 & 0.73 & 1 \\
\hline Niigata & 11.29 & 6.90 & 74.10 & 74.13 & -0.17 & 0.57 & 1 \\
\hline Kobe & 11.30 & 7.60 & 67.50 & 93.44 & -0.85 & 0.80 & 1 \\
\hline Tangshan & 11.34 & 8.20 & 74.70 & 38.45 & -1.53 & 0.94 & 1 \\
\hline Tangshan & 11.44 & 6.90 & 24.60 & 92.48 & -0.71 & 0.76 & 0 \\
\hline Imperial Valley & 11.49 & 6.00 & 10.20 & 41.79 & -0.52 & 0.70 & 1 \\
\hline Westmoreland & 11.49 & 6.90 & 71.20 & 76.14 & -0.13 & 0.55 & 0 \\
\hline Loma Prieta & 11.62 & 7.50 & 62.00 & 107.58 & -0.69 & 0.75 & 1 \\
\hline Tangshan & 11.70 & 6.00 & 7.60 & 59.70 & -0.54 & 0.71 & 1 \\
\hline Tokachioki & 11.72 & 6.90 & 71.20 & 73.60 & -0.10 & 0.54 & 1 \\
\hline Loma Prieta & 11.74 & 7.00 & 56.60 & 89.74 & -0.27 & 0.61 & 0 \\
\hline Kobe & 11.80 & 7.80 & 30.00 & 101.25 & -1.26 & 0.90 & 1 \\
\hline Imperial Valley & 11.90 & 7.60 & 28.40 & 75.96 & -1.20 & 0.88 & 0 \\
\hline Westmoreland & 11.96 & 7.80 & 51.40 & 94.85 & -1.02 & 0.85 & 1 \\
\hline Loma Prieta & 11.99 & 7.60 & 47.10 & 59.59 & -1.05 & 0.85 & 1 \\
\hline Niigata & 12.00 & 8.20 & 291.00 & 69.30 & -0.55 & 0.71 & 1 \\
\hline Westmoreland & 12.00 & 7.50 & 114.00 & 42.76 & -0.52 & 0.70 & 1 \\
\hline Loma Prieta & 12.14 & 7.50 & 62.00 & 75.84 & -0.67 & 0.75 & 1 \\
\hline Haicheng & 12.30 & 7.60 & 14.60 & 98.20 & -1.42 & 0.92 & 1 \\
\hline Mino-Owari & 12.32 & 7.60 & 80.00 & 67.67 & -0.65 & 0.74 & 1 \\
\hline Chi-Chi & 12.45 & 6.90 & 20.70 & 52.25 & -0.78 & 0.78 & 1 \\
\hline Mino-Owari & 12.50 & 7.50 & 62.00 & 64.25 & -0.66 & 0.74 & 1 \\
\hline Tangshan & 12.50 & 7.60 & 41.40 & 91.60 & -0.89 & 0.81 & 1 \\
\hline Tokachioki & 12.55 & 7.60 & 83.20 & 78.89 & -0.56 & 0.71 & 1 \\
\hline Miyagiken-Oki 1 & 12.60 & 8.00 & 200.00 & 86.21 & -0.39 & 0.65 & 0 \\
\hline Miyagiken-Oki 2 & 12.67 & 7.60 & 94.60 & 56.14 & -0.53 & 0.70 & 1 \\
\hline Miyagiken-Oki 1 & 13.19 & 7.60 & 86.10 & 61.61 & -0.46 & 0.68 & 0 \\
\hline Miyagiken-Oki 2 & 13.78 & 9.20 & 94.50 & 54.35 & -1.84 & 0.97 & 0 \\
\hline \begin{tabular}{|l|} 
Niigata \\
\end{tabular} & 13.90 & 7.50 & 62.00 & 74.61 & -0.38 & 0.65 & 1 \\
\hline Tangshan & 13.94 & 7.50 & 112.00 & 42.96 & -0.20 & 0.58 & 1 \\
\hline Tangshan & 14.08 & 7.60 & 24.00 & 51.92 & -1.08 & 0.86 & 1 \\
\hline Kobe & 14.20 & 7.60 & 34.90 & 98.20 & -0.70 & 0.76 & 1 \\
\hline Niigata & 14.20 & 7.50 & 114.00 & 40.24 & -0.17 & 0.57 & 1 \\
\hline Tangshan & 14.30 & 7.50 & 62.00 & 110.15 & -0.21 & 0.58 & 1 \\
\hline Tangshan & 14.40 & 6.60 & 19.00 & 37.29 & -0.30 & 0.62 & 1 \\
\hline Tonankai & 14.50 & 7.60 & 26.10 & 122.91 & -0.74 & 0.77 & 1 \\
\hline Loma Prieta & 14.74 & 7.60 & 28.90 & 54.68 & -0.88 & 0.81 & 0 \\
\hline
\end{tabular}




\begin{tabular}{|c|c|c|c|c|c|c|c|}
\hline Tangshan & 14.81 & 6.70 & 28.00 & 33.28 & -0.13 & 0.55 & 1 \\
\hline Tangshan & 14.90 & 7.60 & 47.10 & 145.17 & -0.31 & 0.62 & 0 \\
\hline Tangshan & 15.39 & 7.60 & 23.60 & 47.98 & -0.92 & 0.82 & 1 \\
\hline San Francisco & 15.60 & 7.60 & 45.20 & 94.58 & -0.35 & 0.64 & 0 \\
\hline San Francisco & 15.60 & 7.60 & 66.00 & 94.53 & -0.13 & 0.55 & 0 \\
\hline Santa Rosa & 15.93 & 7.60 & 68.00 & 57.79 & -0.20 & 0.58 & 0 \\
\hline Tangshan & 16.48 & 9.20 & 65.30 & 61.65 & -1.63 & 0.95 & 0 \\
\hline Miyagiken-Oki 1 & 16.54 & 9.20 & 93.00 & 72.95 & -1.40 & 0.92 & 0 \\
\hline Miyagiken-Oki 2 & 16.88 & 7.60 & 15.00 & 79.74 & -0.85 & 0.80 & 0 \\
\hline Loma Prieta & 17.30 & 7.90 & 72.00 & 56.90 & -0.28 & 0.61 & 0 \\
\hline Alaska & 17.78 & 7.60 & 28.90 & 31.66 & -0.62 & 0.73 & 1 \\
\hline Kobe & 17.83 & 7.80 & 51.70 & 125.01 & -0.08 & 0.53 & 0 \\
\hline Niigata & 18.00 & 7.80 & 30.00 & 72.32 & -0.53 & 0.70 & 1 \\
\hline Miyagiken-Oki 1 & 18.03 & 9.20 & 133.00 & 60.46 & -1.10 & 0.86 & 0 \\
\hline Miyagiken-Oki 2 & 18.37 & 7.60 & 18.80 & 54.67 & -0.63 & 0.74 & 1 \\
\hline Tokachioki & 18.37 & 7.60 & 16.60 & 56.97 & -0.70 & 0.76 & 0 \\
\hline Tangshan & 19.30 & 7.60 & 18.60 & 79.79 & -0.42 & 0.66 & 0 \\
\hline Chi-Chi & 19.40 & 7.80 & 30.00 & 129.51 & -0.19 & 0.58 & 1 \\
\hline Tangshan & 20.71 & 7.50 & 65.20 & 72.12 & 0.55 & 0.29 & 1 \\
\hline Miyagiken-Oki 1 & 20.73 & 7.60 & 16.60 & 70.12 & -0.36 & 0.64 & 0 \\
\hline Miyagiken-Oki 2 & 21.40 & 7.60 & 17.00 & 72.43 & -0.26 & 0.60 & 1 \\
\hline Niigata & 22.02 & 7.60 & 17.20 & 44.69 & -0.28 & 0.61 & 1 \\
\hline Niigata & 22.08 & 7.30 & 16.30 & 90.66 & 0.14 & 0.44 & 0 \\
\hline \begin{tabular}{|l|} 
Nishi-Saitama \\
\end{tabular} & 22.09 & 7.80 & 51.40 & 72.96 & 0.26 & 0.40 & 1 \\
\hline Loma Prieta & 10.20 & 7.90 & 54.00 & 105.56 & -1.39 & 0.92 & 0 \\
\hline Tangshan & 10.20 & 5.30 & 14.00 & 105.75 & 0.33 & 0.37 & 1 \\
\hline Miyagiken-Oki 1 & 10.36 & 7.50 & 62.00 & 210.28 & -0.75 & 0.77 & 0 \\
\hline Miyagiken-Oki 2 & 10.42 & 7.60 & 66.50 & 107.17 & -0.96 & 0.83 & 0 \\
\hline Tangshan & 10.90 & 7.60 & 59.70 & 70.48 & -1.05 & 0.85 & 0 \\
\hline Chi-Chi & 11.24 & 6.00 & 16.60 & 21.35 & -0.48 & 0.68 & 1 \\
\hline Imperial Valley & 11.43 & 6.90 & 71.20 & 110.40 & -0.03 & 0.51 & 1 \\
\hline Westmoreland & 11.49 & 6.70 & 51.00 & 43.14 & -0.28 & 0.61 & 0 \\
\hline Tangshan & 12.00 & 6.40 & 130.00 & 42.83 & 0.65 & 0.26 & 1 \\
\hline Niigata & 12.04 & 6.40 & 96.00 & 95.99 & 0.70 & 0.24 & 0 \\
\hline \begin{tabular}{|l|} 
Westmoreland \\
\end{tabular} & 12.04 & 7.50 & 85.00 & 94.66 & -0.48 & 0.68 & 0 \\
\hline Kobe & 12.66 & 6.90 & 74.10 & 156.82 & 0.33 & 0.37 & 0 \\
\hline Loma Prieta & 12.76 & 7.60 & 121.00 & 68.63 & -0.32 & 0.63 & 0 \\
\hline Tangshan & 13.20 & 7.90 & 54.00 & 62.25 & -1.00 & 0.84 & 1 \\
\hline Westmoreland & 13.20 & 5.30 & 18.00 & 62.52 & 0.91 & 0.18 & 0 \\
\hline Tangshan & 13.20 & 4.80 & 80.60 & 62.56 & 1.94 & 0.03 & 1 \\
\hline Tangshan & 13.20 & 7.60 & 92.10 & 56.95 & -0.43 & 0.67 & 1 \\
\hline Tangshan & 13.61 & 6.40 & 130.00 & 39.93 & 0.90 & 0.18 & 0 \\
\hline Haicheng & 13.61 & 7.50 & 114.00 & 40.24 & -0.26 & 0.60 & 0 \\
\hline Loma Prieta & 13.64 & 6.90 & 71.20 & 105.15 & 0.36 & 0.36 & 0 \\
\hline Tangshan & 13.81 & 6.90 & 24.60 & 147.98 & -0.14 & 0.56 & 1 \\
\hline Guerrero & 13.94 & 6.40 & 130.00 & 42.83 & 0.96 & 0.17 & 0 \\
\hline
\end{tabular}




\begin{tabular}{|c|c|c|c|c|c|c|c|}
\hline Tokachioki & 14.00 & 8.20 & 181.00 & 35.83 & -0.61 & 0.73 & 0 \\
\hline Alaska & 14.04 & 7.60 & 121.00 & 95.31 & 0.00 & 0.50 & 1 \\
\hline Alaska & 14.20 & 6.40 & 130.00 & 39.93 & 0.98 & 0.16 & 1 \\
\hline Tangshan & 14.34 & 7.50 & 62.00 & 94.41 & -0.26 & 0.60 & 1 \\
\hline Tangshan & 14.40 & 6.90 & 71.20 & 53.86 & 0.27 & 0.39 & 0 \\
\hline Loma Prieta & 14.55 & 6.40 & 131.00 & 110.47 & 1.30 & 0.10 & 0 \\
\hline Kwanto & 14.55 & 7.50 & 118.00 & 116.10 & 0.21 & 0.42 & 1 \\
\hline Fukui & 14.60 & 7.60 & 15.40 & 105.92 & -1.02 & 0.85 & 0 \\
\hline Tokyo & 14.81 & 6.00 & 29.00 & 33.03 & 0.57 & 0.29 & 0 \\
\hline Kwanto & 15.08 & 7.50 & 62.00 & 154.20 & 0.01 & 0.50 & 0 \\
\hline Tangshan & 15.08 & 6.00 & 8.00 & 60.10 & 0.04 & 0.48 & 0 \\
\hline Chi-Chi & 15.24 & 6.90 & 29.70 & 169.20 & 0.23 & 0.41 & 1 \\
\hline Mino-Owari & 15.27 & 6.90 & 74.10 & 131.52 & 0.69 & 0.24 & 1 \\
\hline Mino-Owari & 15.49 & 6.00 & 29.00 & 33.03 & 0.67 & 0.25 & 1 \\
\hline Alaska & 15.78 & 7.60 & 71.40 & 117.32 & 0.02 & 0.49 & 1 \\
\hline Imperial Valley & 15.80 & 7.00 & 92.00 & 93.40 & 0.71 & 0.24 & 0 \\
\hline Westmoreland & 15.85 & 6.90 & 74.10 & 116.49 & 0.75 & 0.23 & 0 \\
\hline Kobe & 16.20 & 6.40 & 50.00 & 93.67 & 0.99 & 0.16 & 0 \\
\hline Niigata & 16.40 & 8.20 & 181.00 & 30.45 & -0.34 & 0.63 & 0 \\
\hline Loma Prieta & 16.96 & 7.60 & 12.10 & 100.92 & -0.88 & 0.81 & 0 \\
\hline Loma Prieta & 17.15 & 6.90 & 74.10 & 123.55 & 0.93 & 0.18 & 0 \\
\hline Tangshan & 17.36 & 7.30 & 20.60 & 52.51 & -0.42 & 0.66 & 1 \\
\hline Chi-Chi & 17.59 & 7.60 & 65.00 & 37.16 & -0.12 & 0.55 & 1 \\
\hline Tokyo & 17.59 & 7.90 & 102.00 & 37.80 & -0.14 & 0.56 & 0 \\
\hline Kwanto & 17.59 & 7.60 & 87.10 & 38.95 & 0.07 & 0.47 & 0 \\
\hline Nishi-Saitama & 18.16 & 6.70 & 47.00 & 39.07 & 0.67 & 0.25 & 0 \\
\hline Kobe & 18.16 & 6.00 & 15.70 & 40.57 & 0.74 & 0.23 & 0 \\
\hline Westmoreland & 18.21 & 6.90 & 24.60 & 112.10 & 0.40 & 0.34 & 0 \\
\hline Niigata & 18.22 & 7.50 & 62.00 & 24.35 & -0.08 & 0.53 & 0 \\
\hline \begin{tabular}{|l|} 
San Francisco \\
\end{tabular} & 18.27 & 6.90 & 71.20 & 113.23 & 1.00 & 0.16 & 0 \\
\hline \begin{tabular}{|l|} 
San Francisco \\
\end{tabular} & 18.31 & 6.90 & 74.10 & 107.30 & 1.02 & 0.15 & 0 \\
\hline Miyagiken-Oki 1 & 18.43 & 7.60 & 58.00 & 32.47 & -0.13 & 0.55 & 0 \\
\hline Miyagiken-Oki 2 & 18.43 & 7.90 & 105.00 & 33.80 & -0.06 & 0.52 & 0 \\
\hline Tokachioki & 18.43 & 6.60 & 34.00 & 32.72 & 0.58 & 0.28 & 0 \\
\hline \begin{tabular}{|l|} 
Imperial Valley \\
\end{tabular} & 18.46 & 6.90 & 28.80 & 142.06 & 0.59 & 0.28 & 0 \\
\hline Kobe & 18.48 & 6.00 & 16.60 & 60.48 & 0.92 & 0.18 & 0 \\
\hline Tangshan & 18.52 & 7.50 & 65.20 & 57.30 & 0.23 & 0.41 & 1 \\
\hline Loma Prieta & 18.80 & 7.90 & 54.00 & 105.56 & -0.09 & 0.53 & 0 \\
\hline Chile & 18.80 & 5.30 & 18.00 & 105.80 & 1.68 & 0.05 & 0 \\
\hline Mino-Owari & 18.95 & 6.40 & 131.00 & 115.99 & 1.76 & 0.04 & 1 \\
\hline Imperial Valley & 18.95 & 7.50 & 118.00 & 116.10 & 0.81 & 0.21 & 0 \\
\hline Miyagiken-Oki 1 & 19.00 & 8.20 & 181.00 & 35.83 & 0.04 & 0.48 & 0 \\
\hline Tangshan & 19.04 & 6.70 & 61.00 & 59.12 & 1.04 & 0.15 & 0 \\
\hline Imperial Valley & 19.17 & 6.90 & 28.80 & 149.95 & 0.70 & 0.24 & 0 \\
\hline Miyagiken-Oki 1 & 19.30 & 6.90 & 71.20 & 126.17 & 1.16 & 0.12 & 0 \\
\hline Miyagiken-Oki 2 & 19.39 & 9.50 & 127.90 & 83.62 & -1.17 & 0.88 & 0 \\
\hline
\end{tabular}




\begin{tabular}{|c|c|c|c|c|c|c|c|}
\hline Miyagiken-Oki 1 & 19.40 & 6.70 & 61.00 & 61.54 & 1.08 & 0.14 & 0 \\
\hline Tangshan & 19.58 & 6.40 & 96.00 & 93.91 & 1.64 & 0.05 & 0 \\
\hline Miyagiken-Oki 1 & 19.60 & 7.60 & 63.60 & 51.75 & 0.21 & 0.42 & 0 \\
\hline Miyagiken-Oki 2 & 19.88 & 6.70 & 28.00 & 33.28 & 0.53 & 0.30 & 0 \\
\hline Tangshan & 19.90 & 6.40 & 98.00 & 76.76 & 1.64 & 0.05 & 0 \\
\hline Tokachioki & 19.90 & 7.50 & 100.00 & 77.32 & 0.73 & 0.23 & 0 \\
\hline Niigata & 20.00 & 6.40 & 131.00 & 30.13 & 1.59 & 0.06 & 0 \\
\hline Niigata & 20.19 & 7.60 & 26.50 & 155.52 & 0.08 & 0.47 & 1 \\
\hline Chi-Chi & 20.32 & 6.40 & 130.00 & 98.15 & 1.84 & 0.03 & 1 \\
\hline Niigata & 20.32 & 7.50 & 112.00 & 94.51 & 0.87 & 0.19 & 0 \\
\hline Tangshan & 20.34 & 7.60 & 84.50 & 61.72 & 0.50 & 0.31 & 0 \\
\hline Westmoreland & 20.50 & 8.20 & 181.00 & 30.45 & 0.17 & 0.43 & 0 \\
\hline Kobe & 20.63 & 7.50 & 62.00 & 107.58 & 0.62 & 0.27 & 0 \\
\hline Loma Prieta & 20.74 & 7.50 & 62.00 & 107.58 & 0.64 & 0.26 & 0 \\
\hline Tangshan & 20.84 & 7.60 & 11.20 & 69.05 & -0.59 & 0.72 & 0 \\
\hline Tangshan & 20.84 & 6.00 & 14.40 & 80.38 & 1.15 & 0.13 & 0 \\
\hline Tangshan & 21.04 & 6.90 & 24.60 & 123.31 & 0.76 & 0.22 & 1 \\
\hline Loma Prieta & 21.17 & 6.90 & 74.10 & 151.01 & 1.40 & 0.08 & 0 \\
\hline Kobe & 21.32 & 7.60 & 118.00 & 112.75 & 0.97 & 0.17 & 0 \\
\hline Chi-Chi & 21.36 & 7.60 & 49.00 & 117.55 & 0.49 & 0.31 & 0 \\
\hline Tangshan & 21.55 & 6.90 & 74.10 & 79.95 & 1.25 & 0.11 & 0 \\
\hline Tangshan & 21.55 & 6.90 & 24.60 & 132.12 & 0.82 & 0.21 & 0 \\
\hline Tangshan & 21.56 & 7.60 & 28.90 & 136.70 & 0.25 & 0.40 & 1 \\
\hline Fukui & 21.68 & 7.60 & 15.00 & 74.43 & -0.31 & 0.62 & 1 \\
\hline Mino-Owari & 21.68 & 7.60 & 49.00 & 117.55 & 0.53 & 0.30 & 1 \\
\hline Tangshan & 22.16 & 7.60 & 47.10 & 94.36 & 0.48 & 0.31 & 0 \\
\hline Loma Prieta & 22.56 & 6.90 & 71.20 & 62.20 & 1.27 & 0.10 & 0 \\
\hline Loma Prieta & 22.56 & 6.90 & 71.20 & 71.23 & 1.32 & 0.09 & 0 \\
\hline Imperial Valley & 23.14 & 6.70 & 56.00 & 58.65 & 1.36 & 0.09 & 0 \\
\hline Tangshan & 23.97 & 7.60 & 52.30 & 61.22 & 0.61 & 0.27 & 0 \\
\hline Tangshan & 24.25 & 7.60 & 78.70 & 10.76 & 0.41 & 0.34 & 0 \\
\hline Chi-Chi & 24.52 & 7.60 & 28.40 & 129.76 & 0.52 & 0.30 & 0 \\
\hline Tangshan & 24.53 & 7.60 & 39.60 & 64.07 & 0.51 & 0.30 & 0 \\
\hline Tangshan & 24.60 & 7.60 & 16.10 & 103.09 & 0.13 & 0.45 & 0 \\
\hline Mino-Owari & 24.64 & 7.80 & 51.40 & 82.48 & 0.53 & 0.30 & 0 \\
\hline Loma Prieta & 24.69 & 6.90 & 74.10 & 127.41 & 1.64 & 0.05 & 0 \\
\hline Loma Prieta & 24.90 & 6.90 & 74.10 & 127.41 & 1.64 & 0.05 & 0 \\
\hline Loma Prieta & 24.91 & 6.90 & 74.10 & 75.50 & 1.54 & 0.06 & 0 \\
\hline Alaska & 25.63 & 9.20 & 157.00 & 98.45 & -0.08 & 0.53 & 0 \\
\hline Alaska & 25.98 & 9.20 & 74.00 & 104.75 & -0.48 & 0.68 & 0 \\
\hline Imperial Valley & 26.00 & 6.70 & 54.00 & 80.16 & 1.64 & 0.05 & 0 \\
\hline Loma Prieta & 26.06 & 6.90 & 71.20 & 57.35 & 1.54 & 0.06 & 0 \\
\hline Chi-Chi & 26.22 & 7.60 & 28.40 & 148.30 & 0.71 & 0.24 & 0 \\
\hline Tangshan & 26.33 & 7.60 & 41.20 & 67.26 & 0.70 & 0.24 & 0 \\
\hline Tokachioki & 26.47 & 8.20 & 178.10 & 39.31 & 0.82 & 0.21 & 0 \\
\hline Imperial Valley & 26.60 & 6.70 & 14.00 & 57.25 & 0.90 & 0.18 & 0 \\
\hline
\end{tabular}




\begin{tabular}{|c|c|c|c|c|c|c|c|}
\hline Westmoreland & 26.60 & 6.00 & 50.50 & 56.83 & 2.01 & 0.02 & 0 \\
\hline Miyagiken-Oki 1 & 26.71 & 6.40 & 98.00 & 49.94 & 2.01 & 0.02 & 0 \\
\hline Miyagiken-Oki 2 & 26.71 & 7.50 & 95.00 & 50.52 & 1.21 & 0.11 & 0 \\
\hline Miyagiken-Oki 1 & 27.00 & 6.40 & 130.00 & 71.38 & 2.19 & 0.01 & 0 \\
\hline Miyagiken-Oki 2 & 27.00 & 7.50 & 113.00 & 73.30 & 1.39 & 0.08 & 0 \\
\hline Loma Prieta & 27.40 & 6.90 & 71.20 & 70.10 & 1.62 & 0.05 & 0 \\
\hline Miyagiken-Oki 1 & 27.55 & 6.40 & 131.00 & 96.66 & 2.25 & 0.01 & 0 \\
\hline Miyagiken-Oki 2 & 27.55 & 7.50 & 118.00 & 98.24 & 1.52 & 0.06 & 0 \\
\hline Chi-Chi & 27.78 & 7.60 & 28.40 & 163.91 & 0.85 & 0.20 & 0 \\
\hline Tokachioki & 28.36 & 8.20 & 178.10 & 39.31 & 0.96 & 0.17 & 0 \\
\hline Loma Prieta & 28.65 & 6.90 & 74.10 & 110.20 & 1.83 & 0.03 & 0 \\
\hline Loma Prieta & 28.71 & 6.90 & 71.20 & 76.14 & 1.74 & 0.04 & 0 \\
\hline Tangshan & 28.91 & 6.70 & 22.50 & 2.55 & 0.71 & 0.24 & 0 \\
\hline San Francisco & 29.00 & 7.90 & 54.00 & 41.15 & 0.67 & 0.25 & 0 \\
\hline San Francisco & 29.00 & 5.30 & 16.00 & 40.96 & 2.10 & 0.02 & 0 \\
\hline Miyagiken-Oki 1 & 30.27 & 6.40 & 98.00 & 41.45 & 2.15 & 0.02 & 0 \\
\hline Miyagiken-Oki 2 & 30.27 & 7.50 & 95.00 & 40.21 & 1.39 & 0.08 & 0 \\
\hline
\end{tabular}

C-6 


\section{Appendix D}

\section{LOGISTIC REGRESSION ANALYSIS}

\section{D-1 Introduction}

Regression analysis focuses on describing the relationship between a response variable (dependent) and one or more explanatory (independent) variables. When the response variable is discrete, taking on two or more possible values, the regression is called logistic regression. A special case of logistic regression is the binary regression analysis where the response variable is binary, taking on only two values, i.e., zero or one.

An example of the above would be the liquefaction data complied in this study where the dependent variable is the liquefaction index which has only two possibilities, liquefaction or non-liquefaction. The independent variables are the measurements taken in conjunction with the response variable such as, earthquake magnitude, hypocenter distance, standard penetration resistance, and effective overburden stress.

The binary response variable can be represented by any numbers (Pampel 2000). However, using $(0,1)$ to code the liquefaction index has many advantages, chief among them is that the response variable can be interpreted as a probability. 


\section{D-2 The Bernoulli and the Binomial Distributions}

If we code the probability that the liquefaction index $(Y)$ takes the value of one as the probability of liquefaction $P(Y=1)=\pi(x)$, then the corresponding probability of nonliquefaction would be $P(Y=0)=1-\pi(x)$. It is useful, as we shall see in the following sections, to express these two probabilities in a single expression and so if $y$ is the observed value of the random (response) variable $Y$, where y is either 0 or 1 , we can write:

$$
P(Y=y)=\pi(x)^{y}(1-\pi(x))^{1-y}, \quad y=0,1
$$

This expression defines how the probabilities of the two events, $Y=0$ and $Y=1$, are distributed, and so it expresses the conditional portability distribution of $Y$. This particular probability distribution is known as the Bernoulli distribution. The mean, or expected value, of the random variable $Y$ is, by definition, given as (Collett 1991):

$$
E(Y)=0 \times P(Y=0)+1 \times P(Y=1)=\pi(x)
$$

The variance of $Y$, a measure of the dispersion of the random variable, can be found as:

$$
\operatorname{Var}(Y)=E\left(Y^{2}\right)-[E(Y)]^{2}
$$

then:

$$
E\left(Y^{2}\right)=0^{2} \times P(Y=0)+1^{2} \times P(Y=1)=\pi(x)
$$

hence: 


$$
\operatorname{Var}(Y)=\pi(x)-[\pi(x)]^{2}=\pi(x)[1-\pi(x)]
$$

Now let $y$ be the total number of liquefied cases in the total number $n$ of the compiled data. If we also assume that the data are independent from one another, the total number of ways in which a sequence of $y$ ones and $n-y$ zeros can occur is given by:

$$
\left(\begin{array}{l}
n \\
y
\end{array}\right)=\frac{n !}{y !(n-y) !}
$$

Therefore, the total probability of obtaining a sequence of $y$ ones and $n-y$ zeros, independent of the ordering of the binary observations, will be $\left(\begin{array}{l}n \\ y\end{array}\right)$ multiplied by the probability of any particular arrangement of the $y$ ones and $n-y$ zeros. The probability of $y$ successes in $n$ observation is therefore given by:

$$
P(Y=y)=\left(\begin{array}{l}
n \\
y
\end{array}\right) \pi(x)^{y}[1-\pi(x)]^{n-y}, \quad \text { for } y=0,1 \ldots, n
$$

That is, the conditional distribution of the outcome variable $Y$ follows a Binomial distribution, which is a special case of the Bernoulli distribution. It also follows that the expected value of $Y$ is:

$$
E(Y)=n \cdot \pi(x)
$$

Eq. D- 8

and the variance of $Y$ is: 


$$
\operatorname{Var}(Y)=n \cdot \pi(x)[1-\pi(x)]
$$

Eq. D- 9

\section{D-3 The Linear Model vs. the Linear Logistic Model:}

When a response variable is continuous, models for $n$ observations $y_{1}, y_{2}, \ldots, y_{n}$, are often of the form:

$$
y_{i}=\beta_{0}+\beta_{1} \chi_{1 i}+\beta_{2} \chi_{2 i}+\ldots+\beta_{n} \chi_{n i}+\varepsilon_{i}
$$

Eq. D- 10

which expresses the fact that the response for the $i^{\text {th }}$ observation, $y_{i}, i=1,2, \ldots, n$, depends linearly on the values of $k$ explanatory variables labeled $x_{1}, x_{2}, \ldots, x_{\mathrm{k}}$, through unknown parameters $\beta_{0}, \beta_{1}, \ldots, \beta_{k}$. The explanatory variables are assumed to be fixed and known without error. Since the response is linear in the unknown parameters, it is called a linear model. The term $\varepsilon_{i}$ is an unobservable random variable which represents the residual variation. It is usually assumed that $\varepsilon_{i}$ is normally distributed with a zero mean and a constant variance. It follows the expected value of the $i^{\text {th }}$ observation, $y_{i}$, (the conditional mean):

$$
E\left(y_{i} \backslash x_{i}\right)=\beta_{0}+\beta_{1} \chi_{1 i}+\beta_{2} \chi_{2 i}+\ldots+\beta_{n} \chi_{n i}
$$

and the conditional distribution of the outcome variable given $x$ will be also normal with mean $E(Y l x)$. This expression implies that it is possible for $E(Y l x)$ to take on any value as $x$ ranges from $-\infty$ and $+\infty$. However, the above is not applicable to the present compiled liquefaction data as the response variable is binary, taking only two possible values, 0 or 1. A plot of the response variable against any of the explanatory variables would look like 
Figure D- 1 . Therefore, trying to model the response variable based on conventional regression analysis (minimize the sum of squared deviations) yields a linear equation of the form:

$$
E\left(y_{i} \backslash M_{i}\right)=\beta_{0}+\beta_{1} M_{i}
$$

Eq. D- 12

However, a conceptual problem arises from this type of regression. The response variable in the above equation can take on any value, exceeding one or less than zero, which is illogical as probability cannot exceed one or take on negative values.

Therefore, a more logical, non-linear function that describes the relationship between the dependent and independent variables can be represented by an S-shaped curve such that shown in Figure D- 2. This S-shaped curve guarantees that the response variable does not exceed one or dips below zero.

The S-shaped curve (Figure D- 2) resembles many plots of cumulative distribution functions. The most commonly used is the logistic function as it is extremely flexible and easily used function and moreover, results obtained through this function are easily interpreted. 


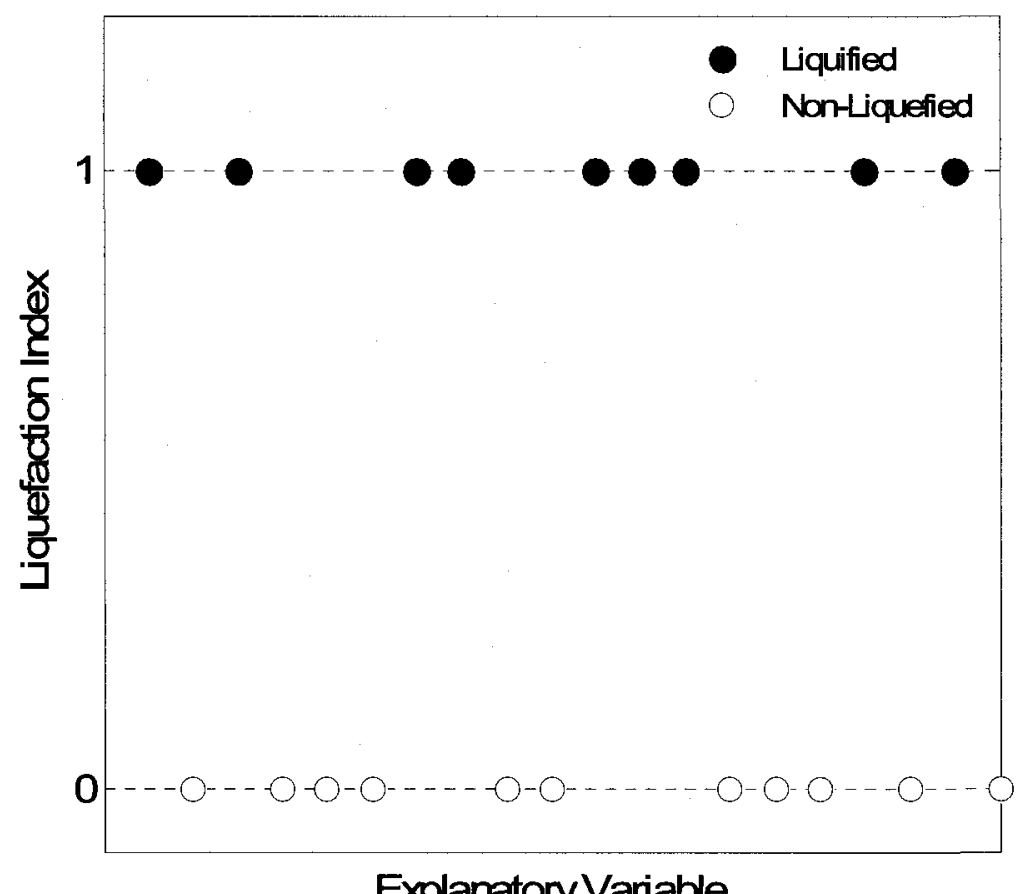

Figure D- 1: Scatter plot of liquefaction index against standard penetration resistance

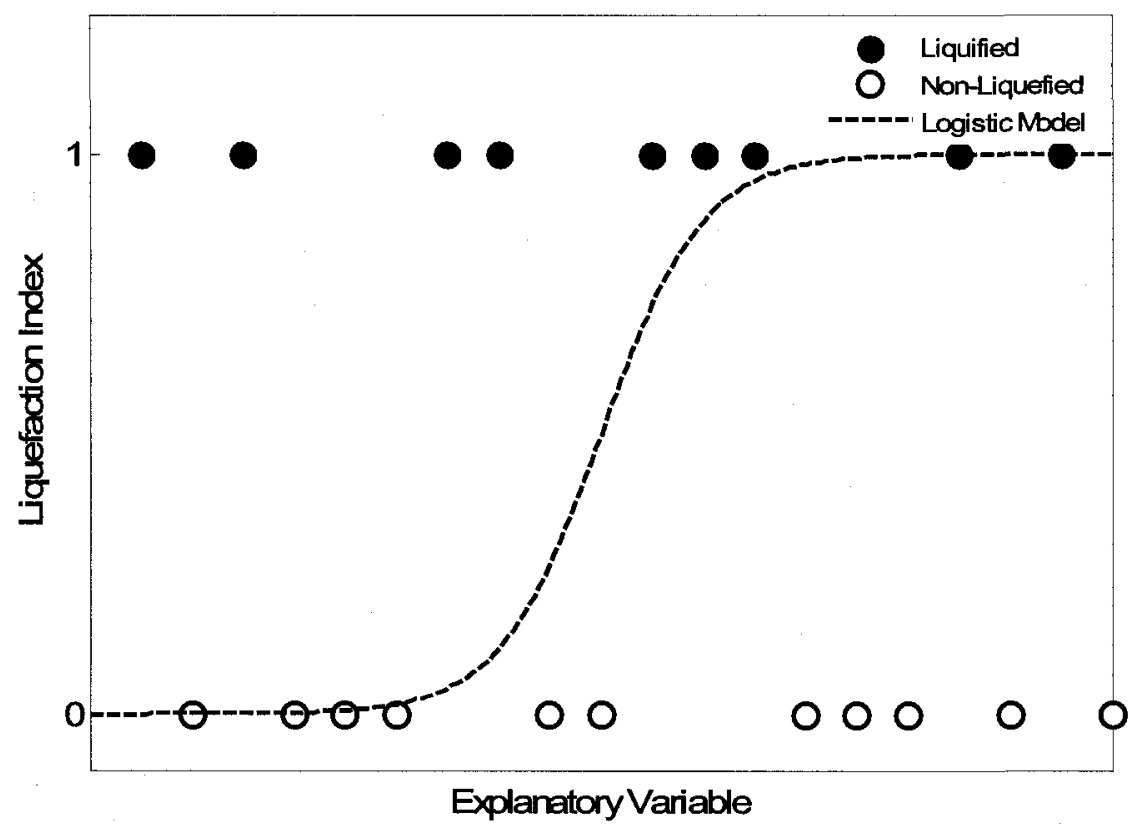

Figure D- 2: Plot of the proportion of liquefied cases in each earthquake magnitude group 
The logistic model can be expressed as:

$$
\pi(x)=\frac{e^{\left(\beta_{0}+\beta_{1} X_{1}+\ldots \beta_{k} X_{k}\right)}}{1+e^{\left(\beta_{0}+\beta_{1} X_{1}+\ldots \beta_{k} X_{k}\right)}}
$$

where $\pi(x)$ represents the conditional mean or probability of $Y$ given $x$ when the distribution is logistic.

\section{D-4 The Transformation (Link) Function:}

As the probability $\pi(x)$ ranges from zero to one, the probability scale is first has to be transformed to $(-\infty$ to $+\infty)$ prior to adopting a linear model for the dependence of the success probability on explanatory variables. This can be done through many transformation functions such as the logistic, the probit and the complementary log-log transformation.

\section{D-5 The Logistic Transformation:}

The logistic transformation is given as:

$$
\operatorname{logit}[\pi(x)]=\ln \left(\frac{\pi(x)}{1-\pi(x)}\right)
$$

Eq. D- 14

which implies that for any given value of $\pi(x)$ that ranges from 0 to 1 , the corresponding logit ranges from $-\infty$ to $+\infty$. The logit function is shown in Figure D- 3 which reveals that it is a sigmoid curve and it is symmetric about $\pi(x)=0$. The logistic function is also linear between $\pi(x)=0.2$ and $\pi(x)=0.8$, however, it becomes highly non-linear outside this range. 


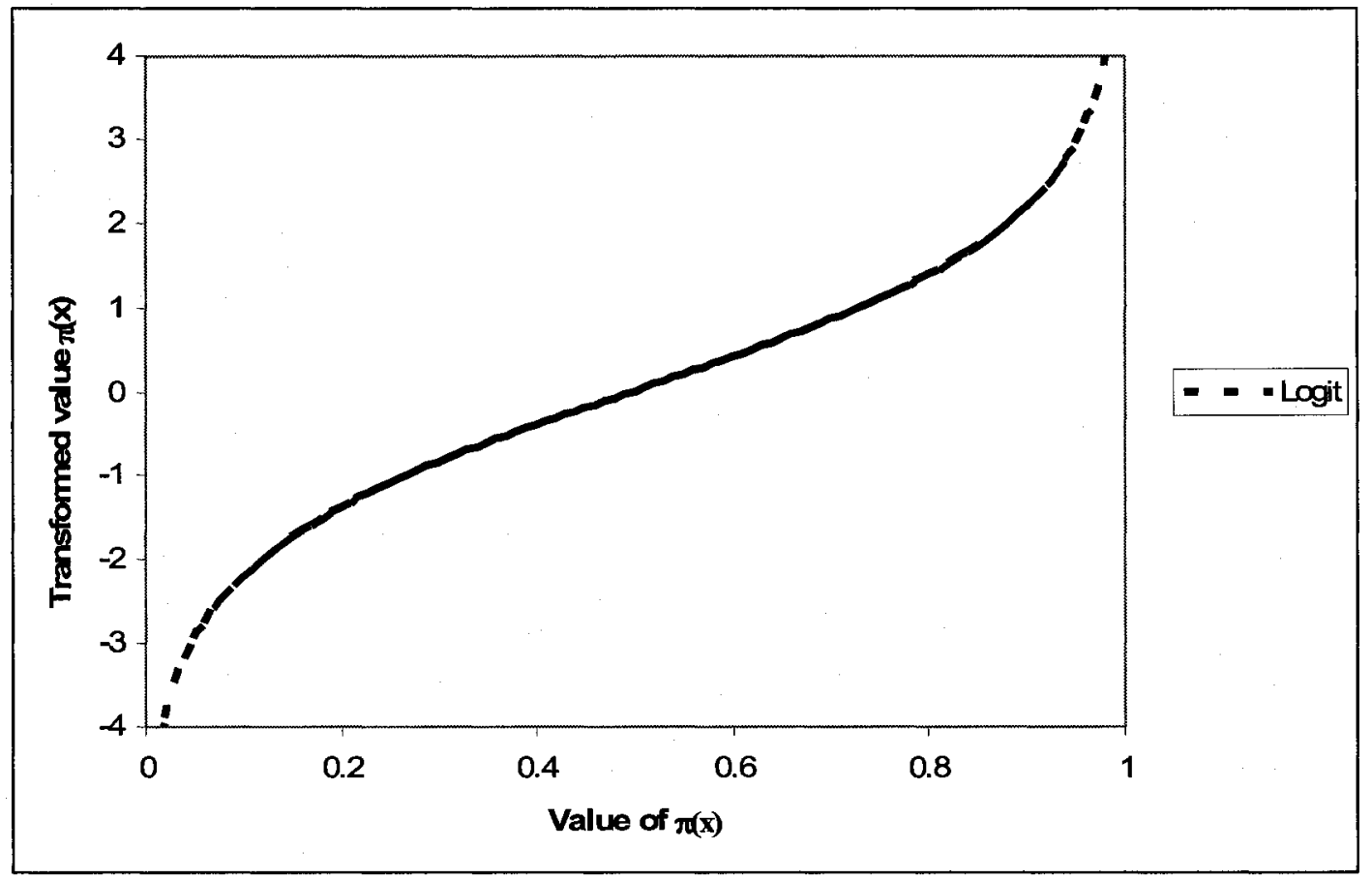

Figure D- 3: The Logit transformation of $\pi(x)$ as a function of $\pi(x)$

\section{D-6 The Probit Transformation:}

The probit of a probability $\pi(x)$ is the value $\zeta$ where:

$$
\zeta=\Phi^{-1}[\pi(x)]
$$

Eq. D- 15

where $\Phi^{-1}$ is the inverse standard normal distribution. The probit function is also symmetric in $\pi(x)$ and ranges from $-\infty$ to $+\infty$ for $\pi(x)$ that goes form 0 to 1 . 


\section{D-7 The Complementary log-log Transformation:}

The complementary $\log$ - $\log$ transformation of a probability $\pi(x)$ is given as:

$$
\text { comp } \log \log =\log [-\log (1-\pi(x))]
$$

This function again transforms a probability in the range $(0,1)$ to a value in $(-\infty,+\infty)$, but unlike the logistic and probit transformations, this function is not symmetric about $\pi(x)=0.5$. The use of the complementary log-log transformation is limited to those situations where it is appropriate to deal with success probabilities in an asymmetric manner (Collett 1991 and 1999).

The logistic and probit transformations are quite similar to each other, but from the computational viewpoint, the logistic transformation is more convenient. Also, it has a direct interpretation in terms of the logarithm of the odds in favor of a success. The odds of a success is given as:

$$
\frac{\pi(x)}{1-\pi(x)}
$$

The relationship between $\pi(x)$ and $x$ is sigmoidal, whereas, logit $[\pi(x)]$ is linearly related to $x$. When a linear logistic model is fitted to explore the relationship between a binary response variable and one or more explanatory variables, the model is also referred to as a logistic regression model. 
Noting that:

$$
g(x)=\beta_{0}+\beta_{1} X_{1}+\ldots .+\beta_{k} X_{k}
$$

Eq. D- 18

rearranging of the above we get:

$$
\operatorname{logit}[\pi(x)]=g(x)=\beta_{0}+\beta_{1} X_{1}+\ldots .+\beta_{k} X_{k}
$$

Eq. D- 19

\section{D-8 Fitting the Logistic Regression Model to the Binary Data:}

In order to fit the linear logistic model, given above, to the binary data (or generally any binomial data) the $k+1$ unknown parameters $\left(\beta_{0}, \beta_{1} \ldots\right.$ and $\left.\beta_{k}\right)$ have first to be estimated. A likelihood function has to be constructed for this estimation. The likelihood function is the joint probability or probability density of the observed data, interpreted as a function of the unknown parameters $\left(\beta_{0}, \beta_{1} \ldots\right.$ and $\left.\beta_{k}\right)$ in the model, rather than as a function of the data.

Generally, in order to specify the likelihood function, a particular distributional form for the data must be assumed. For our case, as we have seen earlier that our response variable (Y) can reasonably be assumed to follow a Binomial distribution, conditional on the given data, the probability density function for one observation $y$ with mean $\pi(x)$ is:

$$
\pi(x)^{y}[1-\pi(x)]^{1-y}, \text { where } \mathrm{y}=0,1
$$

Eq. D- 20 
and the joint probability density of the $n$ observations $y_{1}, y_{2}, \ldots, y_{n}$, is the product of $n$ such density functions. The likelihood function is then expressed, assuming the observations are independent, as:

$$
l(\beta)=\prod_{i=1}^{n} \pi\left(x_{i}\right)^{y_{i}}\left[1-\pi\left(x_{i}\right)\right]^{1-y_{i}}
$$

The likelihood depends on the unknown probability $\pi(x)$, which in turn depend on $\beta_{0}$, $\beta_{1} \ldots$ and $\beta_{k}$ through the equation:

$$
\pi(x)=\frac{e^{\left(\beta_{0}+\beta_{1} X_{1}+\ldots+\beta_{k} X_{k}\right)}}{1+e^{\left(\beta_{0}+\beta_{1} X_{1}+\ldots+\beta_{k} X_{k}\right)}}
$$

so the likelihood function can be regarded as a function of $\beta$.

The next step is to obtain those values $\hat{\beta}_{0}, \hat{\beta}_{1}, \ldots, \hat{\beta}_{k}$ which maximize $l(\beta)$, or equivalently $\log [l(\beta)]$. This is called the maximum likelihood estimation which aims to find those coefficients that have the greatest likelihood of producing the observed data.

The logarithm of the likelihood function is:

$$
L(\beta)=\ln [l(\beta)]=\sum_{i=1}^{n}\left\{y_{i} \ln \left[\pi\left(x_{i}\right)\right]+\left(1-y_{i}\right) \ln \left[1-\pi\left(x_{i}\right)\right]\right\}
$$


To find the value of $\beta$ that maximizes $L(\beta)$ we differentiate $L(\beta)$ with respect to $\beta_{0}, \beta_{1}, \ldots$, and $\beta_{k}$ and set the resulting expressions equal to zero. These equations, known as the likelihood equations, are:

$$
\sum_{i=1}^{n}\left[y_{i}-\pi\left(x_{i}\right)\right]=0
$$

Eq. D- 24

and:

$$
\sum_{i=1}^{n} x_{i}\left[y_{i}-\pi\left(x_{i}\right)\right]=0
$$

Eq. D- 25

An interesting sequence of the first equation (Hosmer and Lemeshow 2003) is that:

$$
\sum_{i=1}^{n} y_{i}=\sum_{i=1}^{n} \hat{\pi}\left(x_{i}\right)
$$

Eq. D- 26

That is, the sum of the observed values of $y$ is equal to the sum of the predicted (expected) values, in other words, the sum of probabilities is equal to the number of observations.

The expressions in the above equations are nonlinear in $\beta_{0,} \beta_{l}, \ldots, \beta_{k}$ and therefore, finding solutions that satisfy them is based on iterative procedures.

\section{D-9 Testing the overall goodness of fit of the model: the Likelihood Ratio Test}

After the model has been fitted to the data, evaluation of the overall goodness of fit of the model is warranted. The basis of the goodness of fit test, in logistic regression, is to compare the developed model with the "ideal" model or a saturated model. A saturated 
model is a model that contains as many parameters as there are data points. The comparison is done through calculating a statistic called deviance, which is expressed as:

$$
D=-2 \ln \left[\frac{\text { likelihood of the fitted } \bmod e l}{\text { likelihood of the saturated } \bmod e l}\right]
$$

Eq. D- 27

The deviance follows the chi-squared distribution $\left(\chi^{2}\right)$ with $(n-k)$ degrees of freedom, where $n$ is the number of binomial data and $k$ is the number of the unknown parameters in the linear logistic model. Therefore, the deviance can be used for hypothesis testing purposes (Pampel 2000, Collett 1999 and, Hosmer and Lemeshow 2003).

Using Eq. D- 23, the above equation becomes (Hosmer and Lemeshow 2003):

$$
D=-2 \sum_{i=1}^{n}\left[y_{i} \ln \left(\frac{\hat{\pi}\left(x_{i}\right)}{y_{i}}\right)+\left(1-y_{i}\right) \ln \left(\frac{1-\hat{\pi}\left(x_{i}\right)}{1-y_{i}}\right)\right]
$$

However, if the data being modeled is binary, the likelihood of the saturated model is 1 . Specifically, it follows from the definition of a saturated model that $\hat{\pi}_{i}=y_{i}$ and the likelihood is:

$$
l(\text { saturated model })=\prod_{i=1}^{n} y_{i}^{y_{i}} \times\left(1-y_{i}\right)^{\left(1-y_{i}\right)}=1
$$

Thus, it follows that the deviance is:

$$
D=-2 \ln (\text { likelihood of the fitted model })
$$

Eq. D- 30 
and therefore, Eq. D- 28 becomes (Collett 1991):

$$
D=-2 \sum_{i=1}^{n}\left[\hat{\pi}\left(x_{i}\right) \cdot \operatorname{logit}\left[\hat{\pi}\left(x_{i}\right)\right]+\ln \left[1-\hat{\pi}\left(x_{i}\right)\right]\right]
$$

Eq. D- 31

This deviance depends on the binary observations $y_{i}$ only through the fitted probabilities $\pi\left(x_{i}\right)$ and so it can tell us nothing about the agreement between the observations and their corresponding fitted probabilities. Moreover, the deviance in this particular case no longer follows the chi-squared distribution (Collett 1991). Therefore, the deviance on fitting a model to binary response data cannot be used as a summary measure of the goodness of fit of a model.

However, when comparing two deviances, of two binary models, the term involving the saturated model in Eq. D- 27 disappears, hence:

$$
D_{1}-D_{2}=-2\left[\ln \hat{L}_{1}-\ln \hat{L}_{2}\right]
$$

As a result, the Chi-Squared approximation to the difference between two deviances can be used to compare nested models for binary as well as binomial data. When one model contains terms that are additional to those in another, the two models are said to be nested. This will be further discussed when constructing the model in subsequent sections. 


\section{D-10 Testing the significance of the model parameters: The Wald Test}

The Wald test is commonly used to test the significance of individual logistic regression coefficients for each independent variable (that is, to test the null hypothesis in logistic regression that a particular logit (effect) coefficient is zero). The Wald test statistic is expressed as:

$$
W_{i}=\frac{\hat{\beta}_{i}}{\hat{S E}\left(\hat{\beta}_{i}\right)}
$$

where $S E$ is the standard error of the estimated coefficient $\hat{\beta}$.

\section{D-11 Variance, Covariance, and Standard Error:}

The variance of vector is a measure of spread or dispersion of sample variable, the covariance of matrix is a measure of strength of linear relationships between variables, and the standard error is the square root of the variance.

The method of estimating the variances and covariances of the estimated coefficients are based on the theory of maximum likelihood estimation (Hosmer and Lemeshoe 2003). This theory states that the estimators are obtained from the matrix of second partial derivatives of the $\log$ likelihood function. These partial derivatives have the following general form: 


$$
\begin{gathered}
\frac{\partial^{2} L(\beta)}{\partial \beta_{j}^{2}}=-\sum_{i=1}^{n} x_{i j}^{2} \cdot \pi_{i}\left(1-\pi_{i}\right) \\
\frac{\partial^{2} L(\beta)}{\partial \beta_{j} \partial \beta_{l}}=-\sum_{i=1}^{n} x_{i j} x_{i l} \cdot \pi_{i}\left(1-\pi_{i}\right)
\end{gathered}
$$

for $j, l=0,1,2, \ldots, k$, where $k$ is the number of explanatory variables.

The variances and covariances of the estimated coefficients are obtained from the inverse of the observed information matrix $I(\beta)$, which is a $(1+k) \times(1+k)$ matrix containing the negative of the terms given in Eq. D- 34 and Eq. D- 35. The observed information matrix $I(\beta)$ can be constructed such as:

$$
\hat{\mathrm{I}}(\hat{\beta})=\mathrm{X}^{\prime} \mathrm{WX}
$$

where $X$ is an $n \times k+1$ matrix containing the data for each variable, and $W$ is an $\mathrm{n} \times \mathrm{n}$ diagonal matrix with general element $\hat{\pi}_{i}\left(1-\hat{\pi}_{i}\right)$. That is, the matrix $X$ is:

$$
\mathrm{X}=\left[\begin{array}{ccccccc}
1 & x_{11} & x_{12} & x_{13} & \cdot & \cdot & x_{1 k} \\
1 & x_{21} & x_{22} & x_{23} & . & \cdot & x_{2 k} \\
\cdot & \cdot & \cdot & \cdot & \cdot & \cdot & \cdot \\
\cdot & \cdot & \cdot & \cdot & \cdot & \cdot & \cdot \\
\cdot & \cdot & \cdot & \cdot & \cdot & \cdot & \cdot \\
1 & x_{n 1} & x_{n 2} & x_{n 3} & \cdot & \cdot & x_{n k}
\end{array}\right]
$$

and the diagonal matrix $W$ (the weight matrix) is: 


$$
\mathrm{W}=\left[\begin{array}{cccccc}
\hat{\pi_{1}}\left(1-\hat{\pi}_{1}\right) & 0 & 0 & . & . & 0 \\
0 & \hat{\pi}_{2}\left(1-\hat{\pi}_{2}\right) & 0 & . & . & 0 \\
0 & 0 & \hat{\pi}_{3}\left(1-\hat{\pi}_{3}\right) & \cdot & . & \cdot \\
\cdot & \cdot & \cdot & \cdot & \cdot & \cdot \\
\cdot & . & . & . & \cdot & 0 \\
0 & 0 & . & . & 0 & \hat{\pi}_{n}\left(1-\hat{\pi}_{n}\right)
\end{array}\right]
$$

So, we can write:

$$
\operatorname{Var}(\beta)=\mathrm{I}^{-1}(\beta)
$$

Eq. D- 37

The diagonal elements of the $\operatorname{Var}(\beta)$ matrix are the variances of $\beta_{j}, \operatorname{Var}\left(\beta_{j}\right)$, and the offdiagonal elements are the covariances of the coefficients $\beta_{j}$ and $\beta_{l}, \operatorname{Cov}\left(\beta_{j}, \beta_{l}\right)$. The standard error is given as:

$$
\hat{S E}\left(\hat{\beta}_{j}\right)=\left[\hat{\operatorname{Var}}\left(\hat{\beta}_{j}\right)\right]^{1 / 2}
$$

Eq. D- 38

\section{D-12 Correlation Coefficients:}

Correlation coefficient is a normalized measure of linear relationship strength between variables. The matrix of correlation coefficients can be calculated from the variance matrix $\operatorname{Var}\left(\beta_{j}\right)$, where:

$$
\rho_{j l}=\frac{\operatorname{Cov}\left(\beta_{j}, \beta_{l}\right)}{\sqrt{\operatorname{Var}\left(\beta_{j}\right) \cdot \operatorname{Var}\left(\beta_{l}\right)}}
$$




\section{D-13 Confidence Interval Estimation}

The confidence interval is an informative summary which gives an estimated range of values which is likely to include the estimated coefficients (means). The confidence interval usually has a prescribed probability, conventionally taken as $95 \%$, of including the estimated coefficient. The endpoints of a $100(1-\alpha) \%$ confidence interval for a coefficient are given as:

$$
\hat{\beta}_{j} \pm z_{1-\alpha / 2} \hat{S E}\left(\hat{\beta}_{j}\right)
$$

where $z_{1-\alpha / 2}$ is the area under the standard normal curve that equals $100(1-\alpha / 2) \%$ or $95 \%$ when $\alpha$ is equal to 0.05 .

\section{D-14 Definition of Residuals:}

Residuals are the differences between the observed and predicted data. They are measures of the goodness of fit. Different types of residuals can be introduced which will help assess the goodness of fit of the models.

\section{D-15 Pearson Residuals:}

The Pearson residual is defined as: 


$$
X_{i}=\frac{y_{i}-\hat{\pi}_{i}}{\sqrt{\left\{\hat{\pi}_{i}\left(1-\hat{\pi}_{i}\right)\right\}}}
$$

where:

$y_{i}$ is the observed response variable, and $\pi_{i}$ is the predicted response variable. The nominator of the above equation is called the raw residuals.

The standardized Pearson residual is calculated by dividing the Pearson residual by its standard error. The standard error of the residuals is expressed as:

$$
\text { s.e. }\left(y_{i}-\hat{\pi}_{i}\right)=\sqrt{\left\{\hat{v}_{i}\left(1-h_{i}\right)\right\}}
$$

where $\hat{v}_{i}=\hat{\pi}_{i}\left(1-\hat{\pi}_{i}\right)$ and $h_{i}$ is the $i^{\text {th }}$ diagonal element of the $n \times n \mathbf{H}$ matrix where, $\mathbf{H}$ is called the hat matrix (also defined above):

$$
\mathrm{H}=W^{1 / 2} X\left(X^{\prime} W X\right)^{-1} X^{\prime} W^{1 / 2}
$$

where $\mathbf{W}$ (the weight matrix) and $\mathbf{X}$ (the expanded observation matrix) matrices were also introduced above.

The standardized Pearson residuals are then given as: 


$$
r_{p_{i}}=\frac{y_{i}-\hat{\pi}_{i}}{\sqrt{\left\{v_{i}\left(1-h_{i}\right)\right\}}}
$$

\section{D-16 Deviance Residuals:}

Another type of residual can be constructed from the deviance that is obtained after fitting a linear logistic model to the binary data, expressed as:

$$
d_{i}=\operatorname{sgn}\left(y_{i}-\hat{\pi}_{i}\right) \cdot \sqrt{\left\{-2\left[y_{i} \cdot \ln \hat{\pi}_{i}+\left(1-y_{i}\right) \ln \left(1-\hat{\pi}_{i}\right)\right]\right\}}
$$

where $\operatorname{sgm}\left(y_{i}-\hat{\pi}_{i}\right)$ is the Signum function that makes $d_{i}$ positive when $y_{i} \geq \pi_{i}$, negative when $y_{i}<\pi_{i}$, and zero otherwise. It should be noted that the deviance $D=\Sigma d_{i}$. The deviance residual can also be standardized to have approximate unit variance by dividing by $\operatorname{sqrt}\left(1-h_{i}\right)$ :

$$
r_{D i}=\frac{d_{i}}{\sqrt{\left(1-h_{i}\right)}}
$$

Eq. D- 46

\section{Model Diagnostics}

\section{D-17 The Constructed Variable Plot:}

The constructed variable plot is a visual presentation of the data, where the form of the explanatory variable included in the model is examined. In other words, if $x$ is an explanatory variable included in the model, it is desired to investigate whether $x$ should 
be replaced by some power of $x$. Box and Cox (1964) suggested a power transformation as follows:

$$
x^{\lambda}= \begin{cases}\frac{x^{\lambda}-1}{\lambda}, & \lambda \neq 0 \\ \ln (x), & \lambda=0\end{cases}
$$

when $\lambda=1, x(1)=x-1$, and this corresponds to no transformation of $x$. Also, $\lambda=0.5$ corresponds to the square-root transformation, $\lambda=-1$ to the reciprocal transformation, and as $\lambda \rightarrow 0, x(\lambda) \rightarrow \ln (x)$, so $x(\lambda)$ is a continuous function of $\lambda$. Therefore, to identify whether $\lambda$ is different from unity for an explanatory variable $x_{j}$, the constructed variable $z_{j}$ is first evaluated as:

$$
z_{j}=\hat{\beta}_{j} \cdot x_{j} \cdot \ln \left(x_{j}\right)
$$

where $\hat{\beta}_{j}$ is the coefficient of $x_{j}$ in the fitted model.

Then, the Pearson residuals are plotted against the elements of $(I-\mathbf{H}) \mathbf{W}^{1 / 2} z_{j}$, where $z_{j}$ is the vector of values of the constructed variable $z_{\mathrm{j}}$ for the $n$ observations, and $\mathbf{I}$ is the $n \times n$ identity matrix.

If a linear trend in the constructed variable plot exists, a non-linear term in $x$ is needed. Since the estimated slope is equal to $\lambda-1$, the slope of the line in the plot can be used to indicate the value of the transformation parameter $\lambda$. In practice, the resulting estimate will usually be rounded off to the nearest half (Collett 1991). 


\section{D-18 The Added Variable Plot:}

The added variable plot provides a graphical means of identifying whether or not a particular explanatory variable should be included in a linear logistic model, in the presence of other explanatory variables. The variable that is the candidate for inclusion in the model may be a new explanatory variable, or it may simply be a higher power of one that is currently included in the model. If $u$ is a further explanatory variable measured on each observation, and it is desired to explore whether $u$ should be added to the original model. The added variable plot for the new variable $u$ is a plot of Pearson residuals against the $t^{t h}$ element of the vector $(I-H) \cdot W^{1 / 2} u$, where $I$ is the $n \times n$ identity matrix and $u$ is the vector of values of $u$ for the $n$ observations. If there is no particular pattern in the added variable plot, then $u$ is not an important variable. On the other hand, if the plot has a linear trend, one would conclude that the variable $u$ is needed in the presence of the other variables.

\section{D-19 Checking the adequacy of the link function:}

In developing the model, the logit function was adopted for the transformation. However, as stated earlier, other types of link function, such as the complementary log-log, do exist and could be used as well for the transformation. Therefore, rather than just adopting the logit function in our model, we can verify whether other link functions would be better for our model. A general form of the link functions that are usually used when modeling binary and binomial data is proposed by Aranda-Qrdaz (1981), where:

$$
g\left(\pi_{i} ; \alpha\right)=\log \left\{\frac{\left(1-\pi_{i}\right)^{-\alpha}-1}{\alpha}\right\}
$$


when $\alpha=1$, the above equation yields the logistic transformation:

$$
g\left(\pi_{i} ; \alpha\right)=\log \left\{\frac{\pi_{i}}{\left(1-\pi_{i}\right)}\right\}
$$

Eq. D- 50

As $\alpha \rightarrow 0$, the above equation yields the complementary log-log link function:

$$
g\left(\pi_{i} ; a\right)=\log \left[-\log \left(1-\pi_{i}\right)\right]
$$

Eq. D- 51

In testing the adequacy of the logit link function, a constructed variable, $z_{i}$, is added to the model, where:

$$
Z_{i}=-\left[1+\hat{\pi}_{i}^{-1} \log \left(1-\hat{\pi}_{i}\right)\right]
$$

where $\hat{\pi}_{i}$ is the fitted response probability for the $i^{\text {th }}$ observation, obtained from fitting the model where the initial choice of the link function is the logit. The constructed $z$ variable is added to the logistic regression model as an additional explanatory variable, then the reduction in the deviance is tested to check whether it is a significant reduction or not. If the reduction in deviance was significant, then we conclude that the logistic transformation we used was not a good choice and therefore, other link function should be considered. 


\section{D-20 Checking the form of the linear predictor:}

\section{Half normal plots of residuals}

When the fitted model is correct, the deviance residuals or the standardized deviance residuals can be approximated by the standard normal distribution. Therefore, the half normal plot of residuals offers the means with which one can assess the normality of the standardized deviance residuals and consequently the appropriateness of the fitted model. The half normal plot of residuals is constructed by plotting the absolute values of the standardized deviance residuals (arranged in ascending order) against their expected values derived under the assumption that they are normally distributed, $\Phi^{-1}\{(i+n$ $1 / 8) /(2 n+1 / 2)\}$, where $\Phi$ is the standard normal distribution and $n$ is the total number of observations. A straight line indicates that the residuals can be assumed to have a normal distribution. Outliers will appear at the top right of the plot as points that are separated from the others.

\section{Simulated Envelope}

The interpretation of a half-normal plot of residuals is much easier when it is viewed within the context of a simulated envelope proposed by Atkinson (1981). If the fitted model is correct, the plotted points are all likely to fall within the boundaries of the envelope.

A simulated envelope for a half-normal plot of the standardized deviance residuals is constructed in the following way. For each of the $n$ observations, nineteen additional observations are simulated from a binomial distribution with parameters $n_{i}$ and $\pi_{i}$, where 
$n_{i}$ is the binomial denominator and $\pi_{i}$ is the estimated response probability for the $i^{\text {th }}$ observation in the original data set, $i=1,2, . ., n$. The model fitted to the original data is then fitted to each of these nineteen sets of simulated values of the binomial response variable, where the explanatory variables in the model keep their original values. From each of these fits, the absolute values of the standardized deviance residuals are obtained. The values are then ordered in an ascending order. Then, the mean, minimum and maximum of the values of $|r D|(i)$ over the nineteen simulated data sets, for $i=1,2, \ldots n$, are then computed and plotted on the half-normal plot of the standardized deviance residuals from the original data set. A MATLAB program for the constructing of the half-normal plot and its simulated envelope is presented in the Appendix A.

By using nineteen simulations, there is a chance of 1 in 20 , or $5 \%$, that the largest absolute residual from the original data set lies outside the simulated envelope, when the fitted model is correct. This result can be used to assess whether the observation that yields the largest residual can be regarded as an outlier. However, the main advantage of the simulation envelope is that the half-normal plot can be interpreted without having to make assumptions about the distribution the residuals. In particular, deviation of the points from the mean of the simulated values, or the occurrence of points outside the simulated envelope, indicates that the fitted model is not appropriate. 
Appendix E

CONTOURS OF LIQUEFACTION

PROBABILITY

E-1 

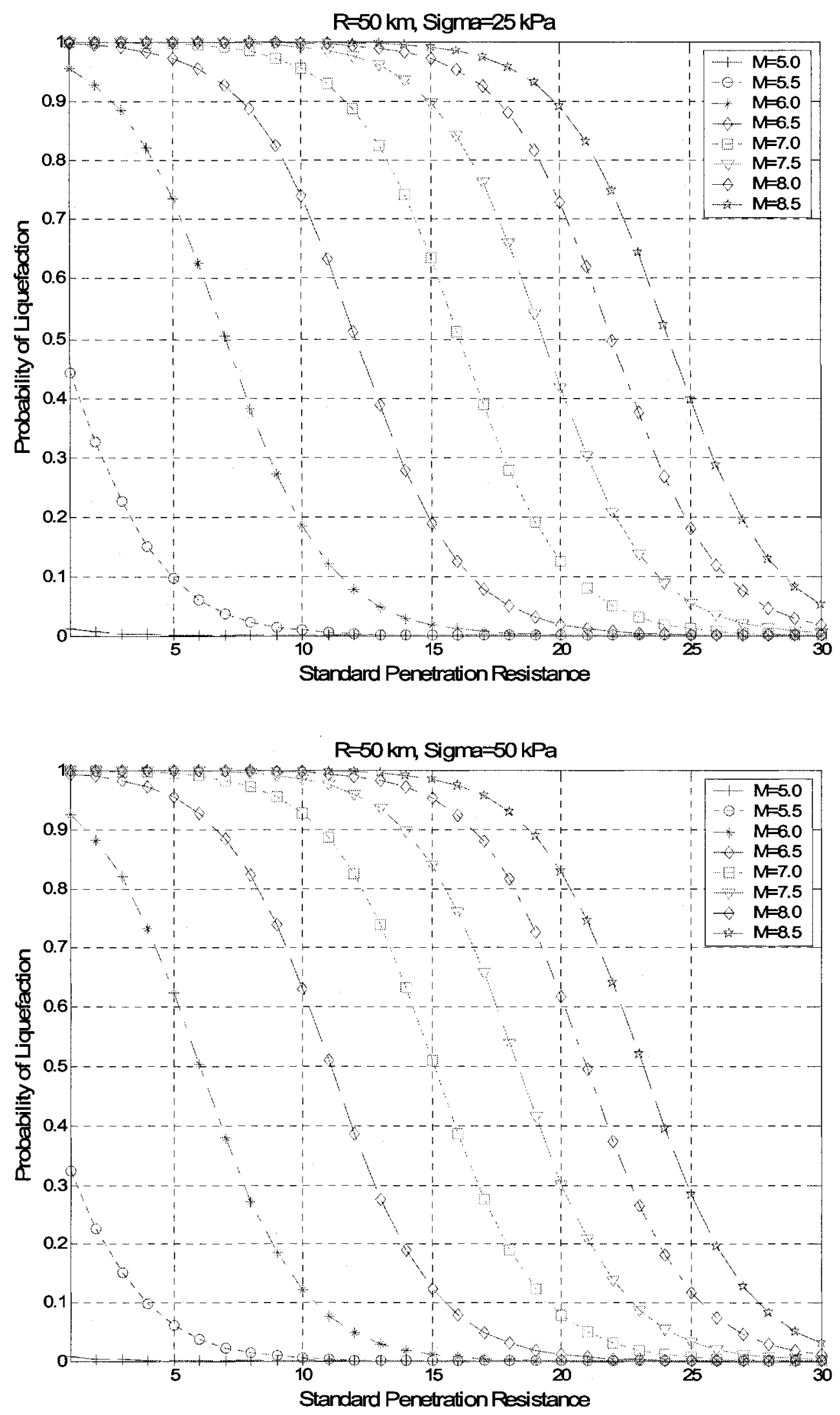

E-2 

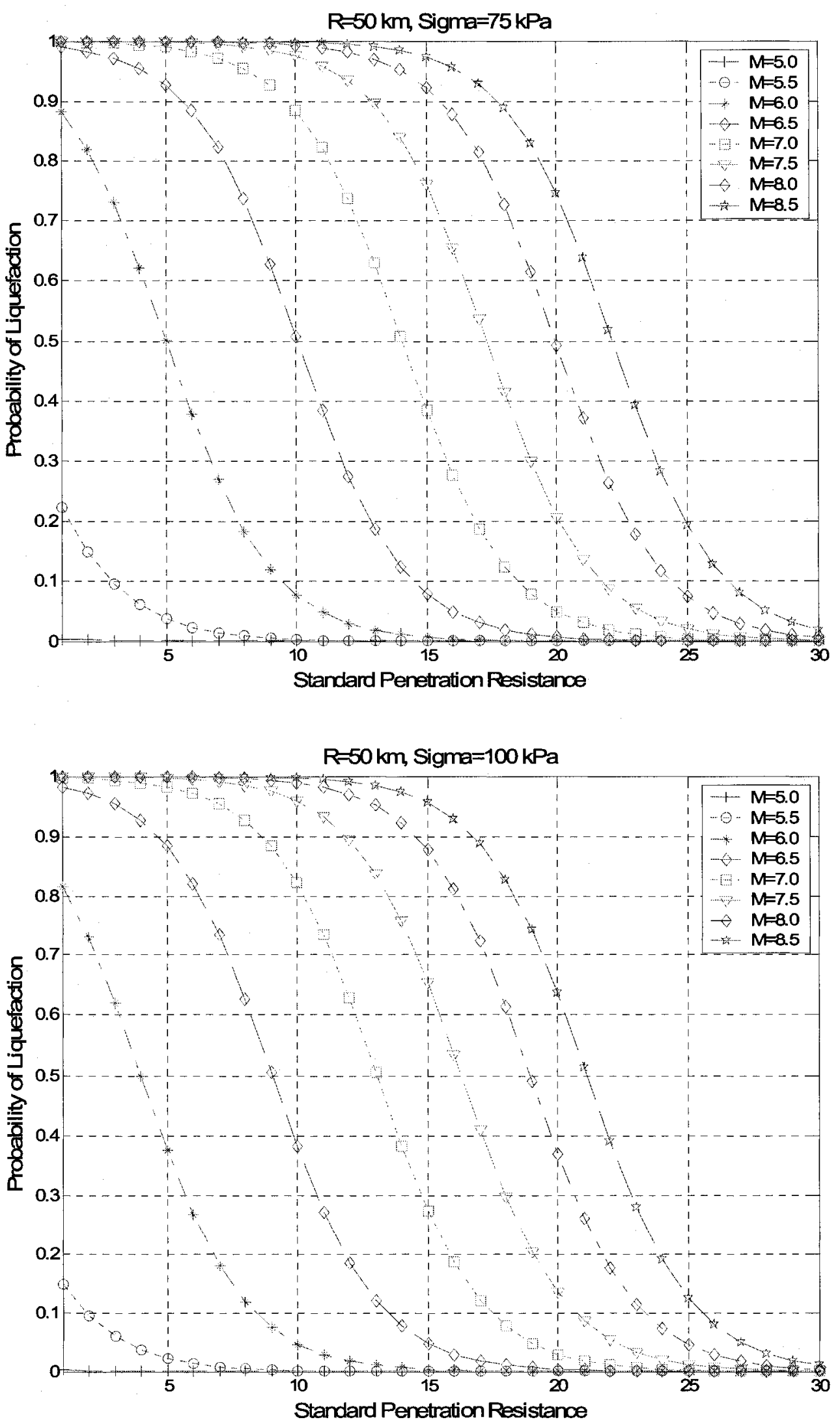

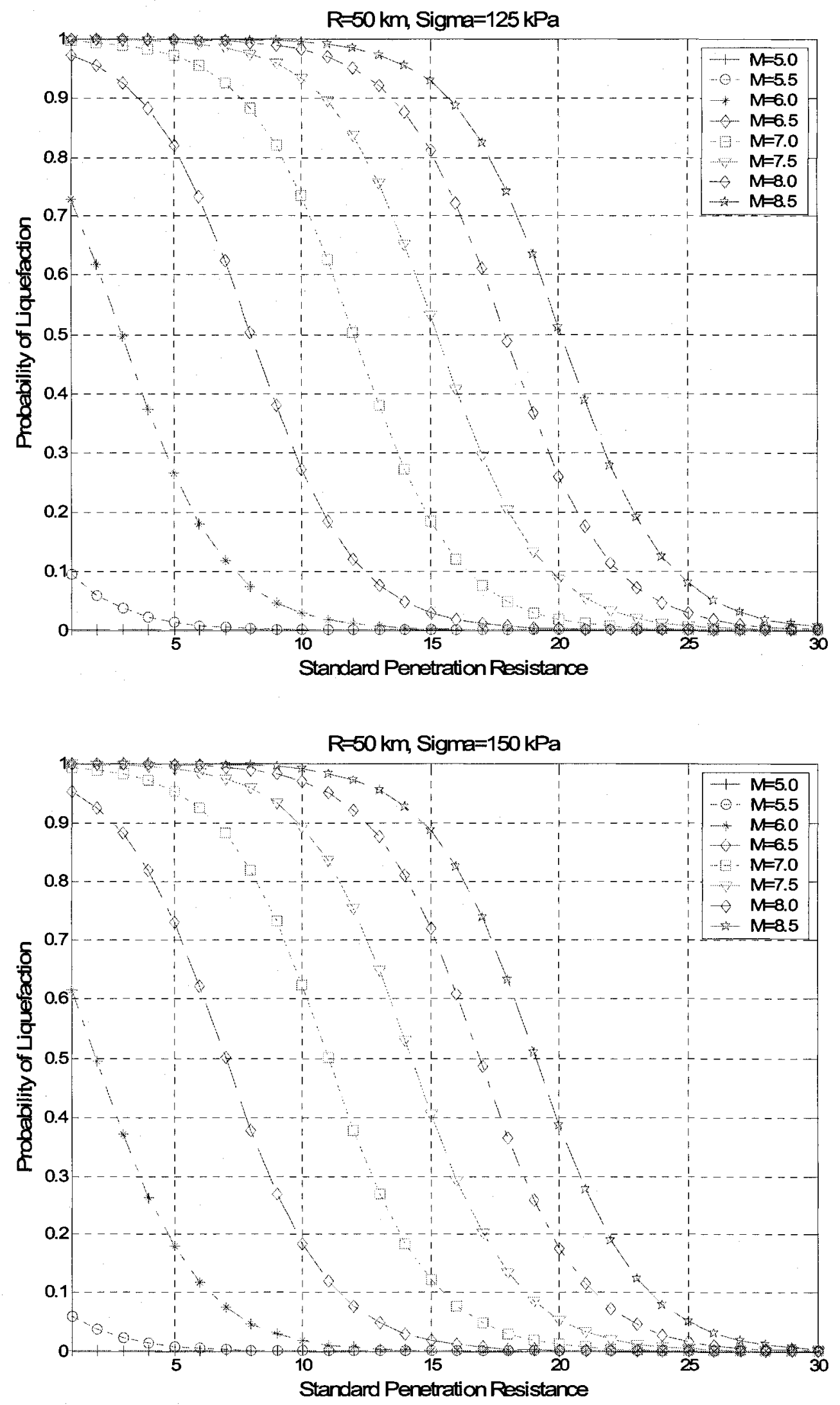

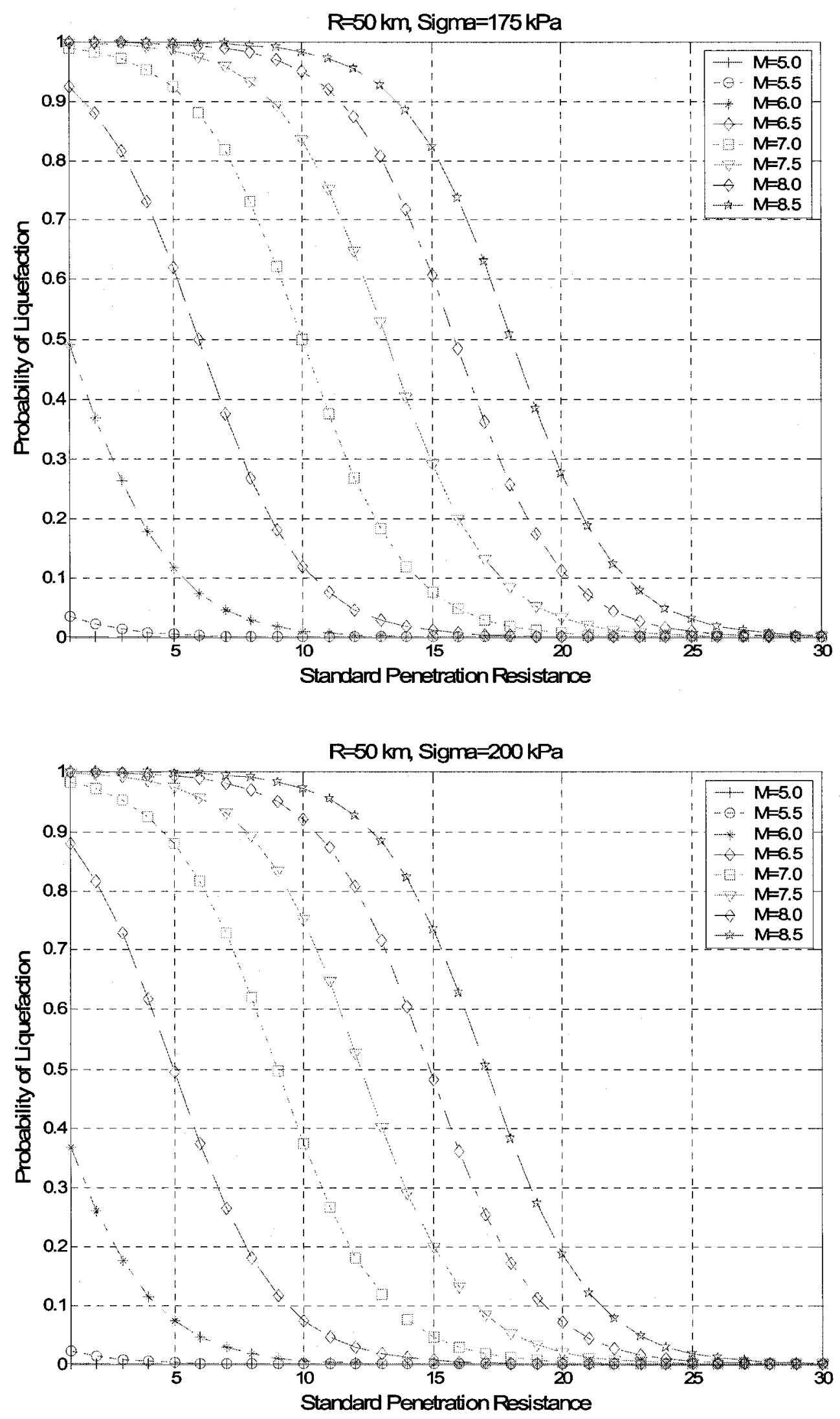

E-5 

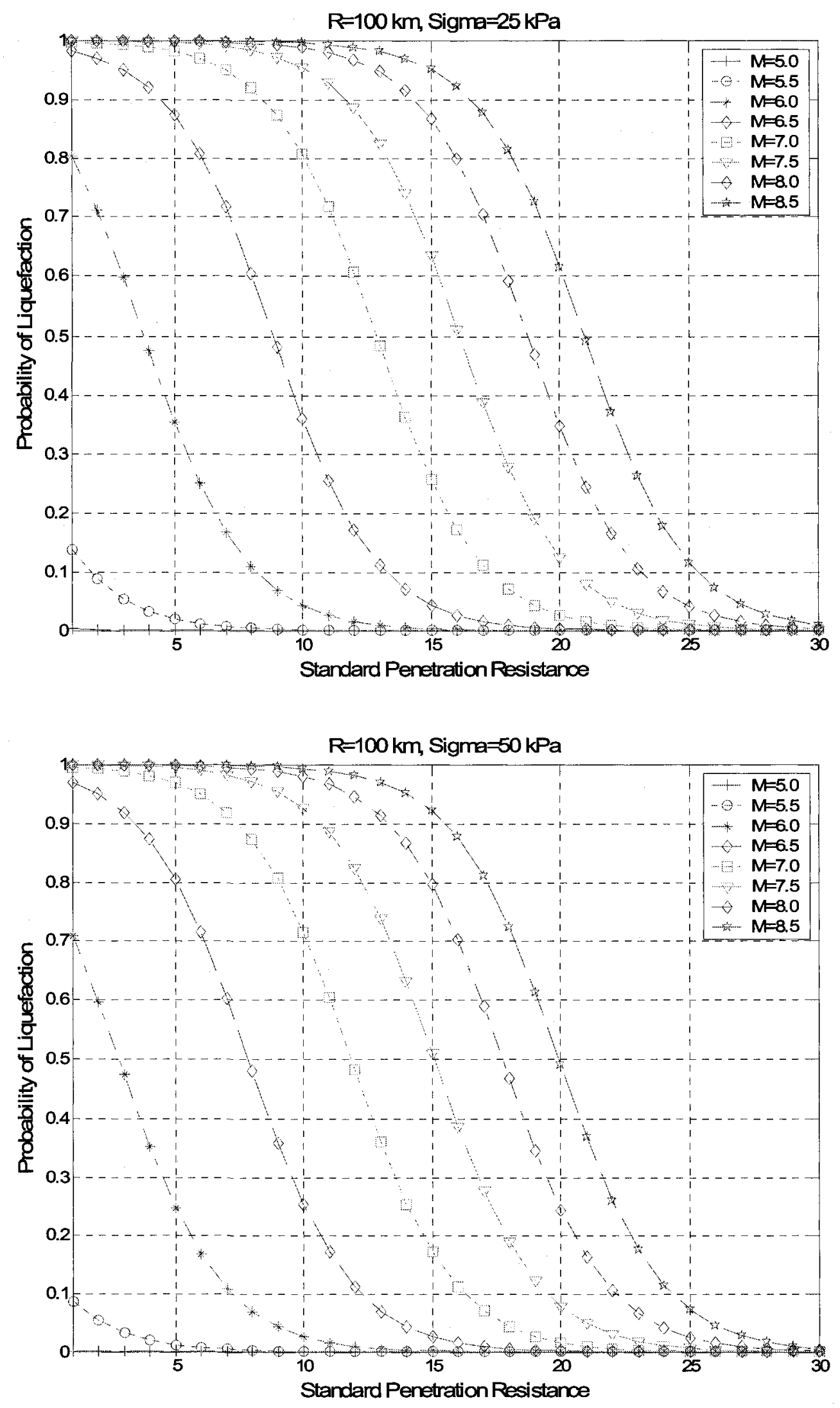

E-6 

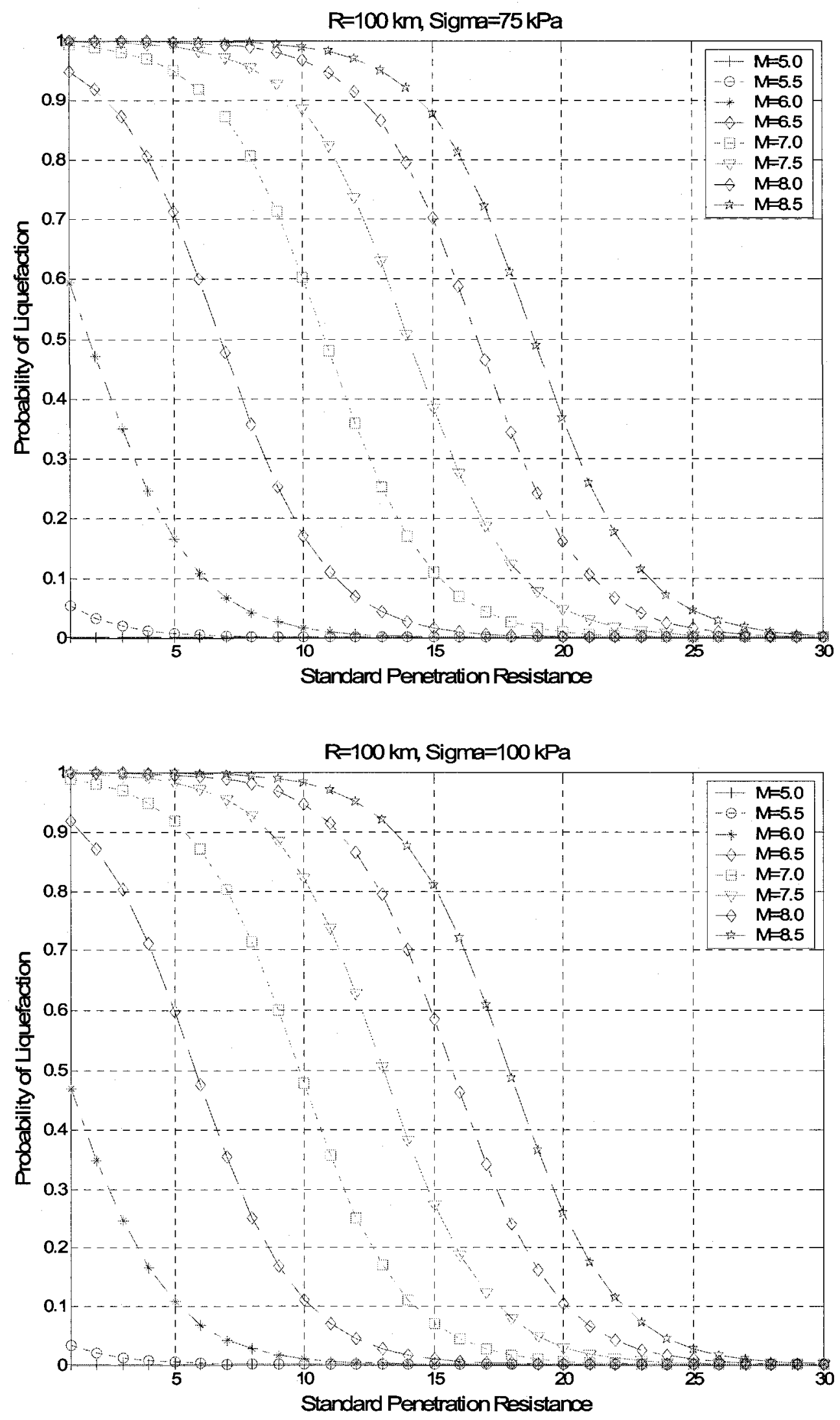

E-7 

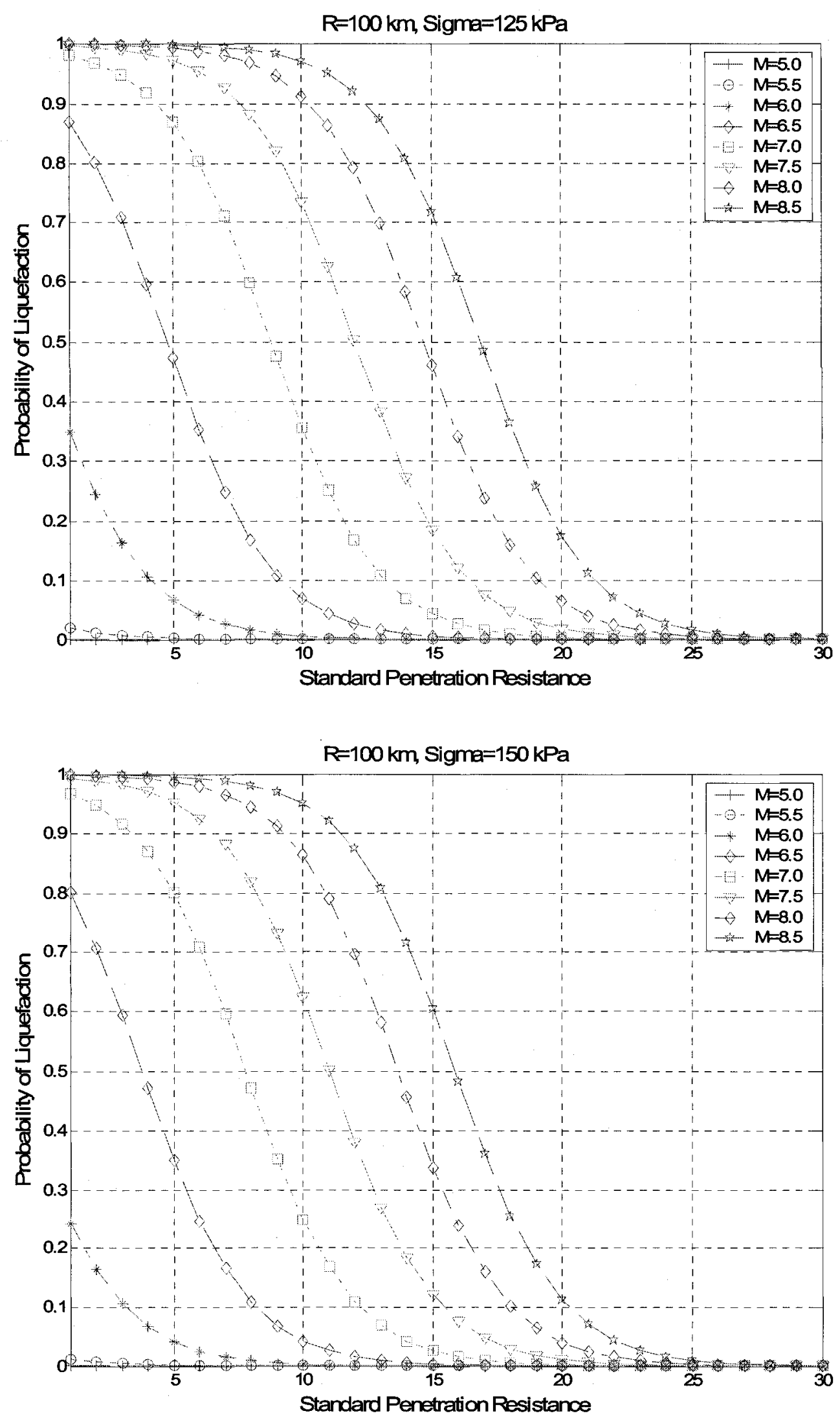

E-8 

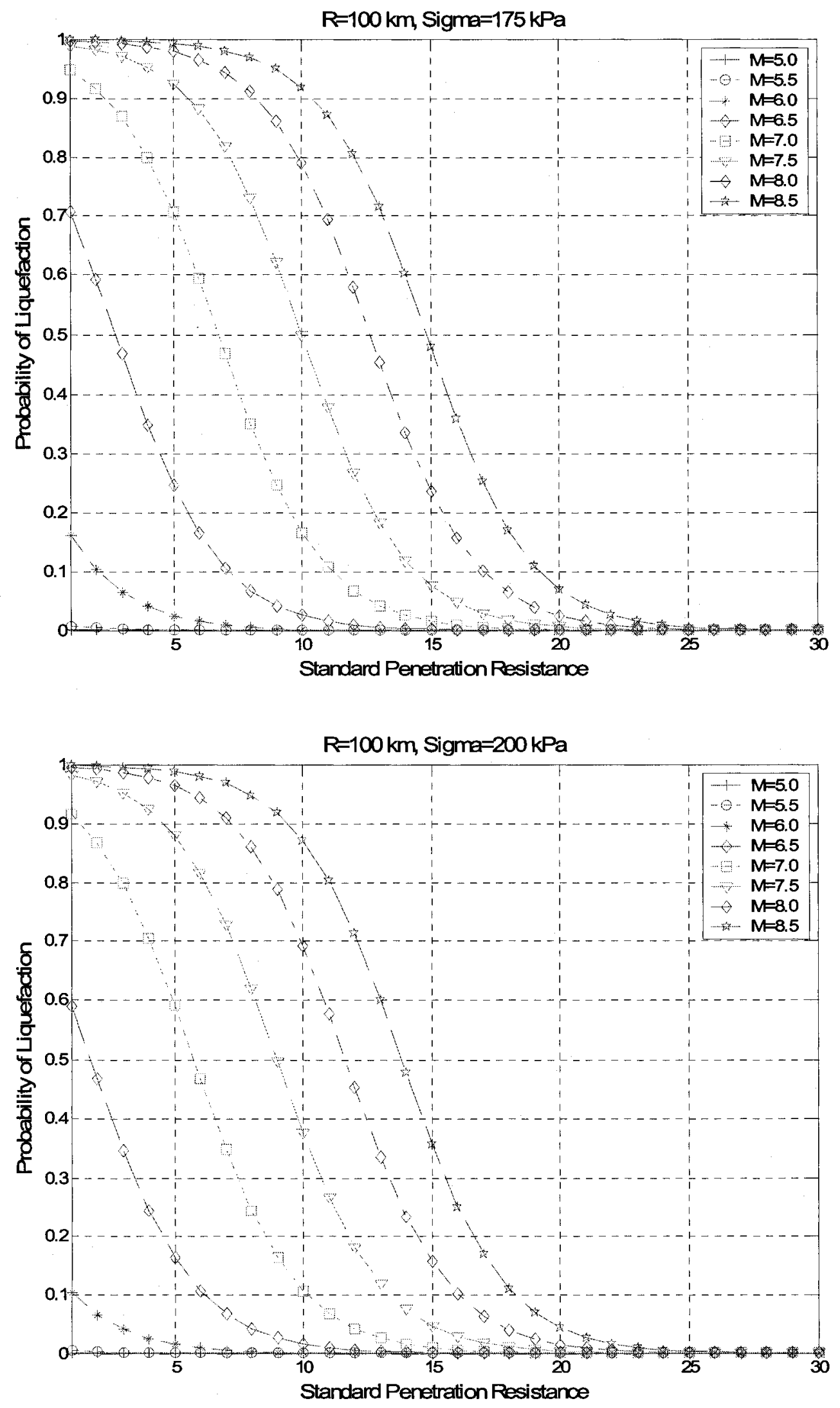

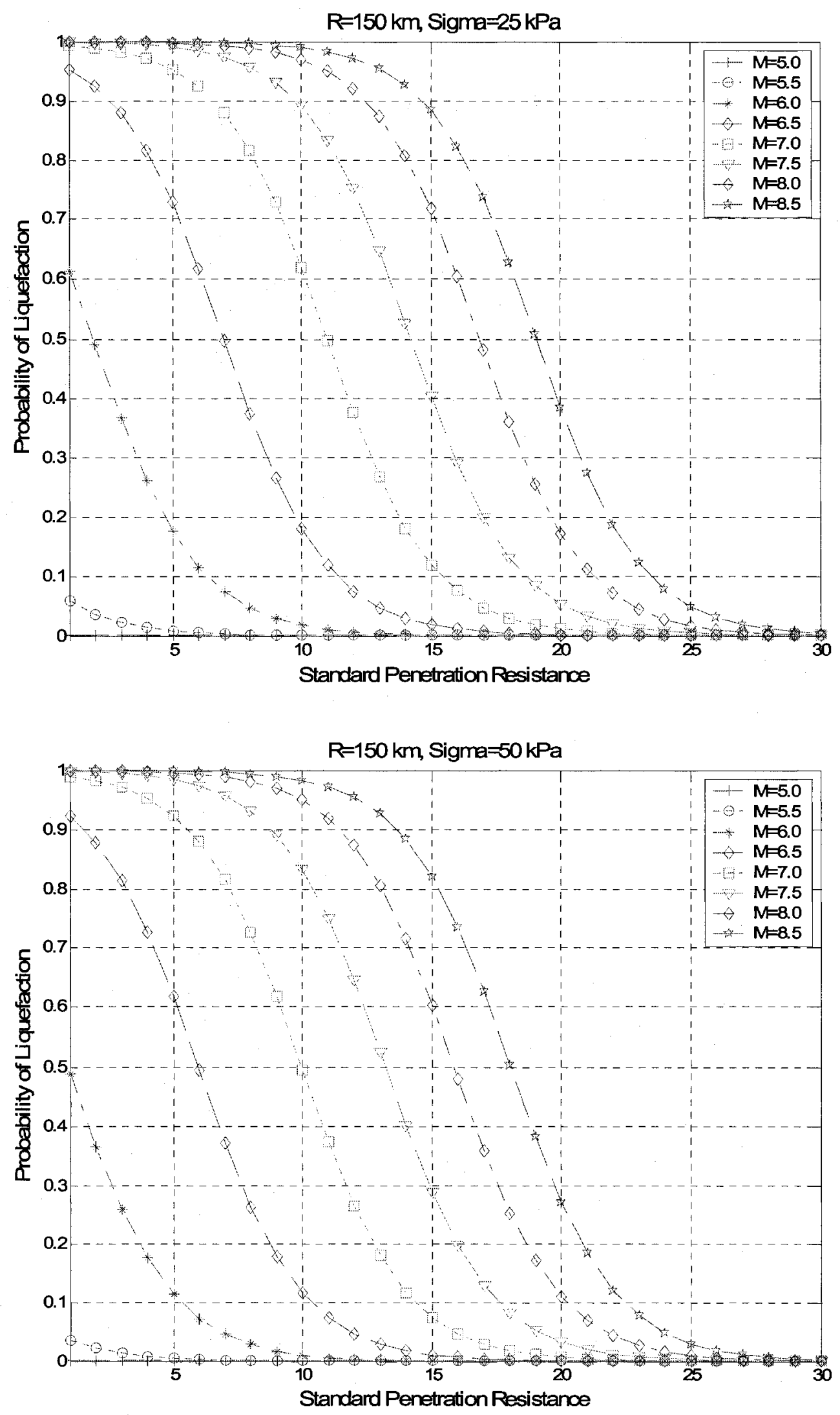

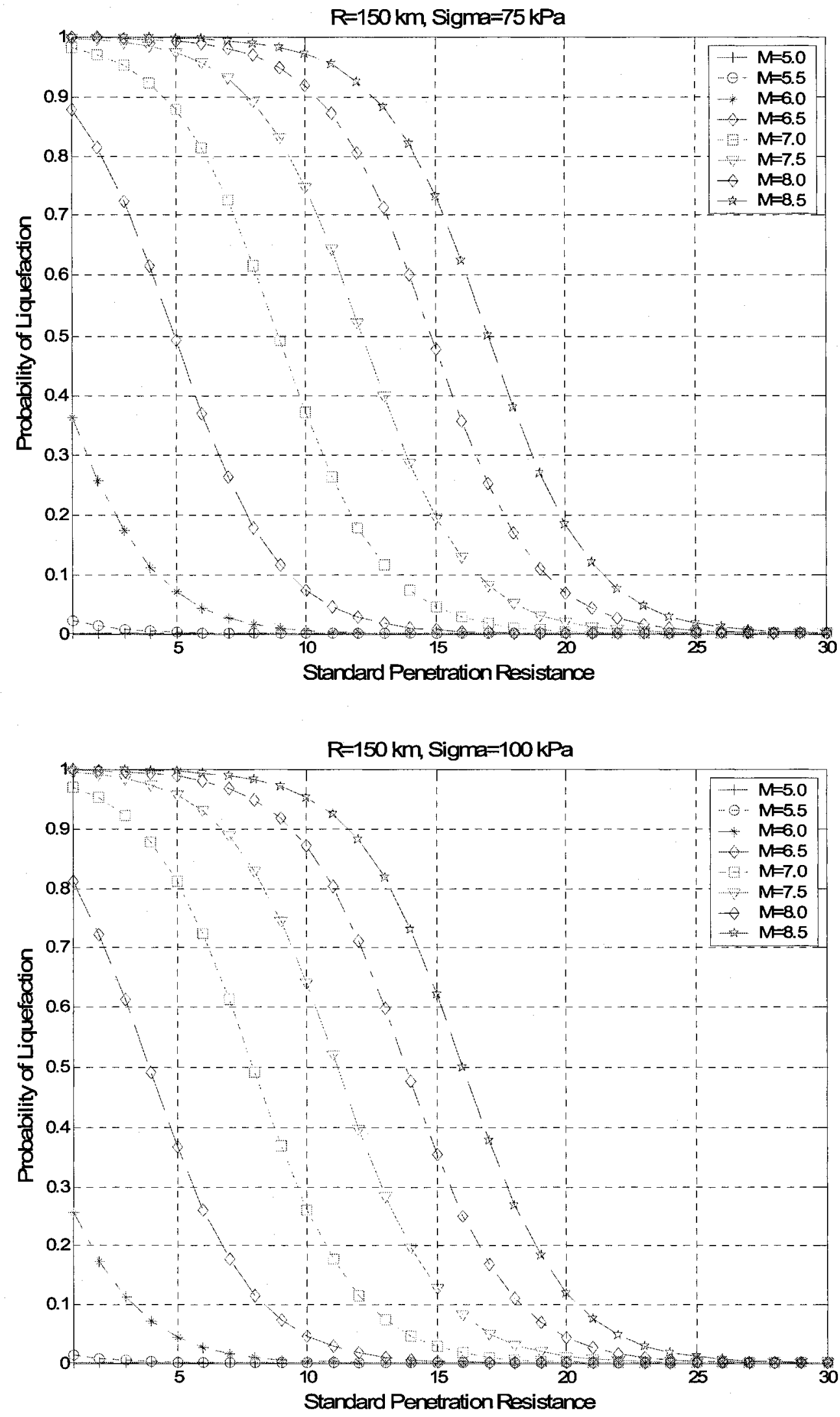

E-11 

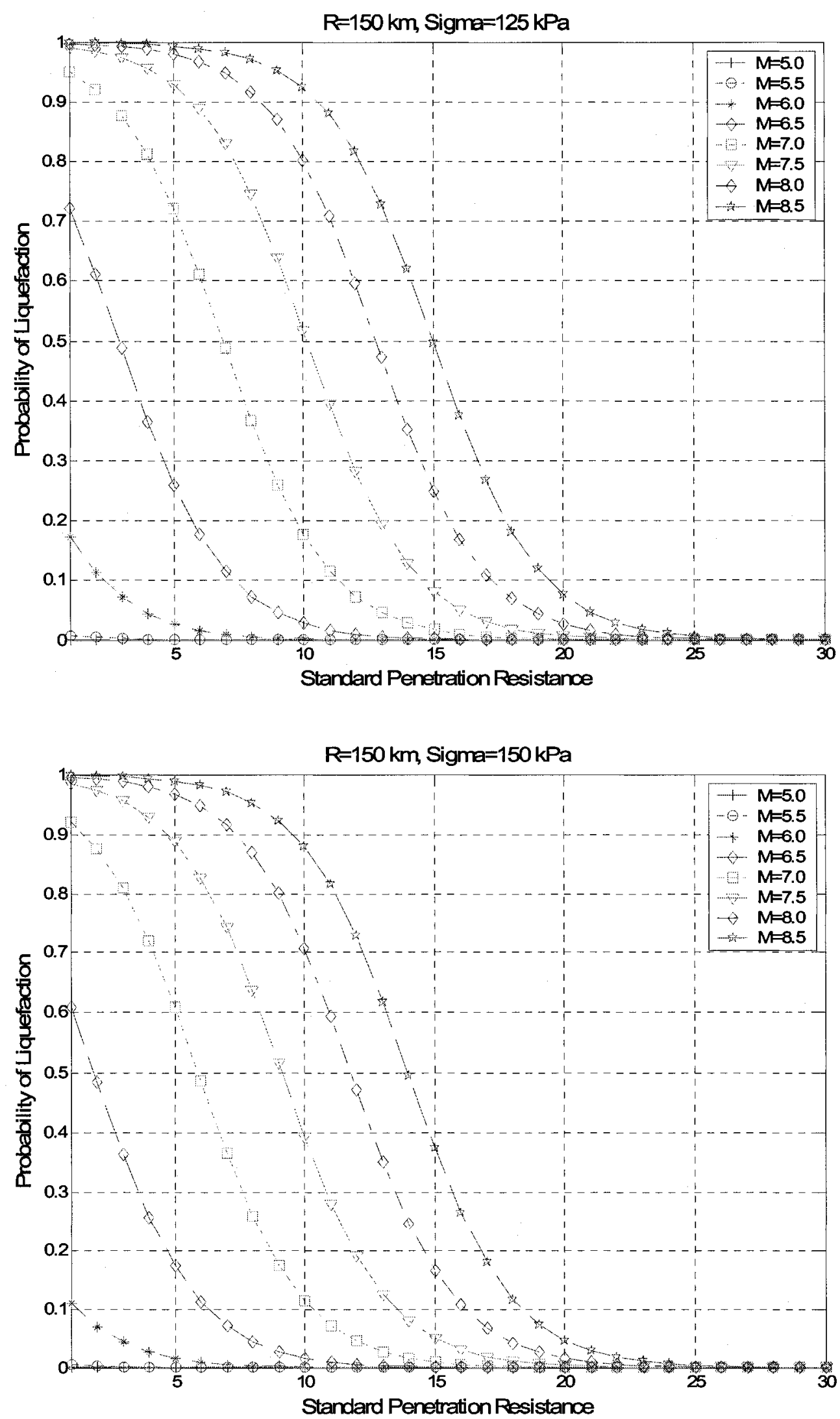

E-12 

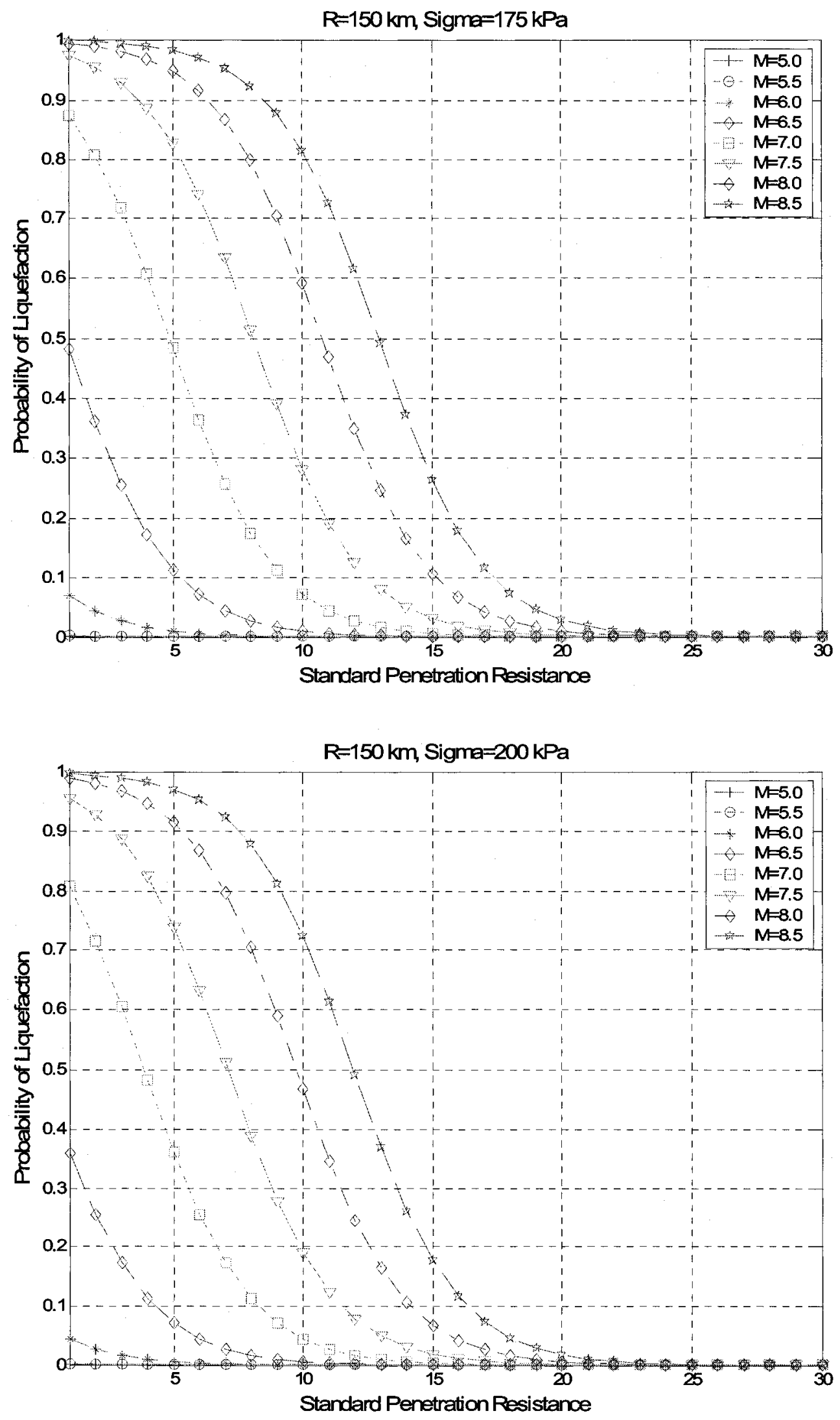

E-13 

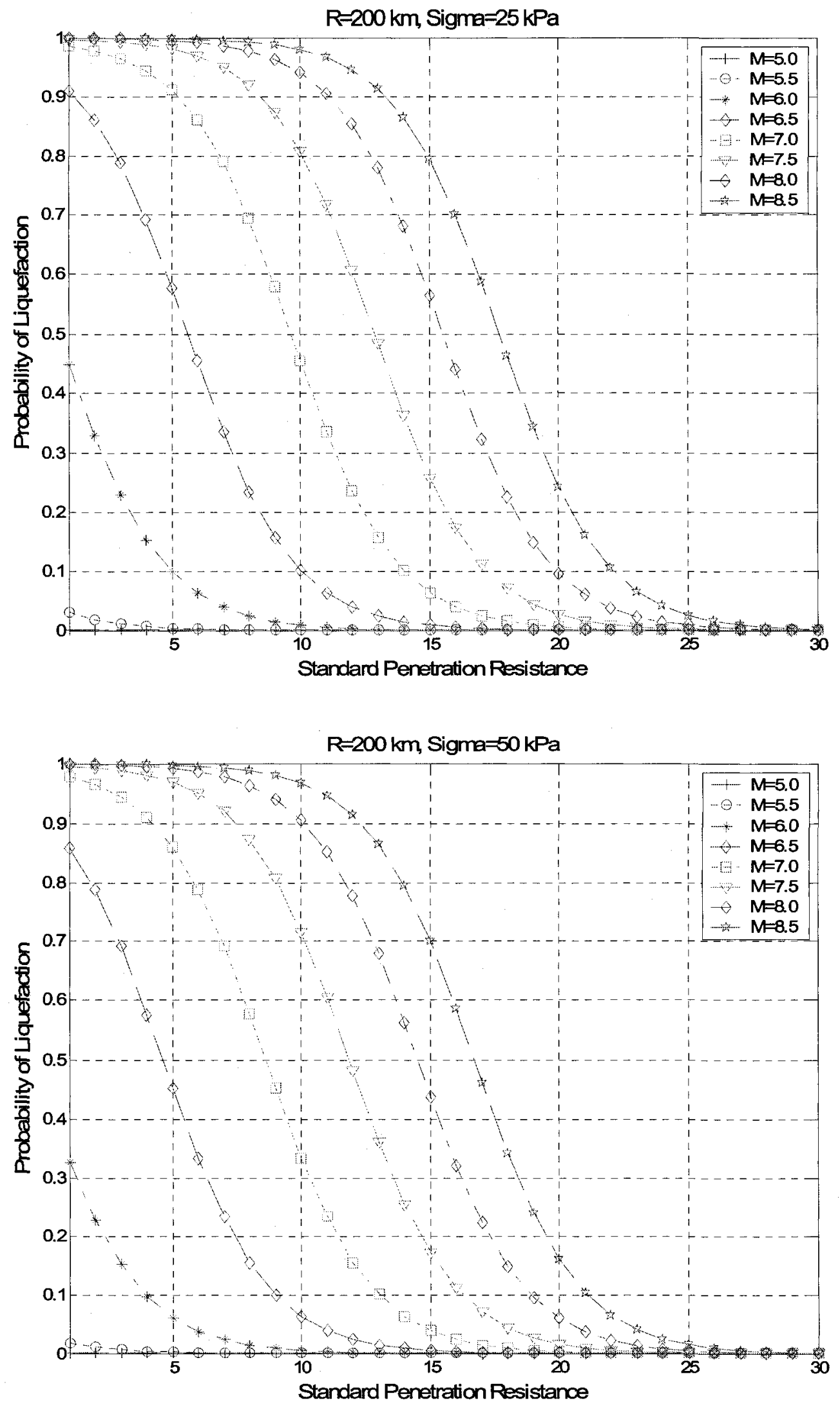

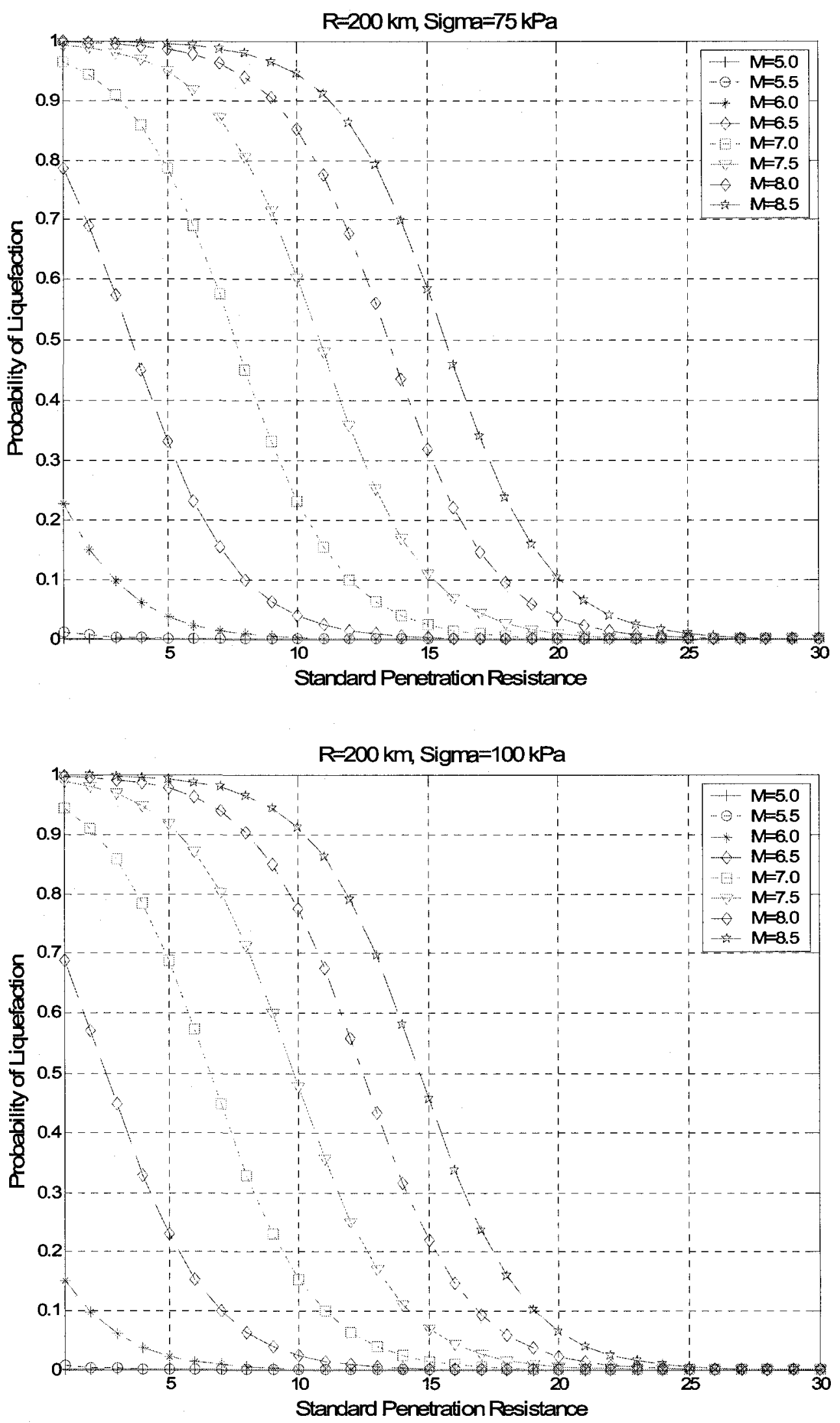

E-15 

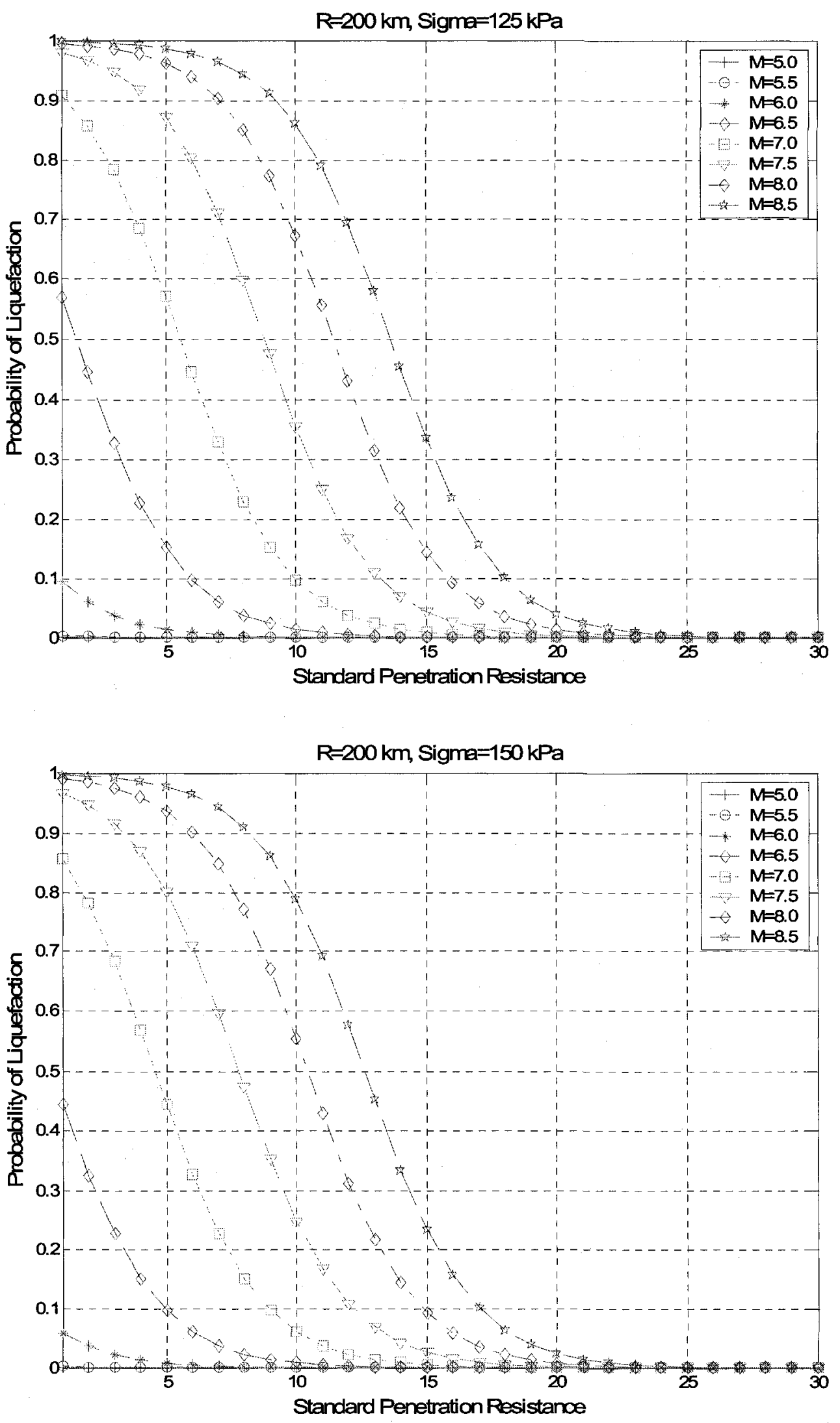

E-16 

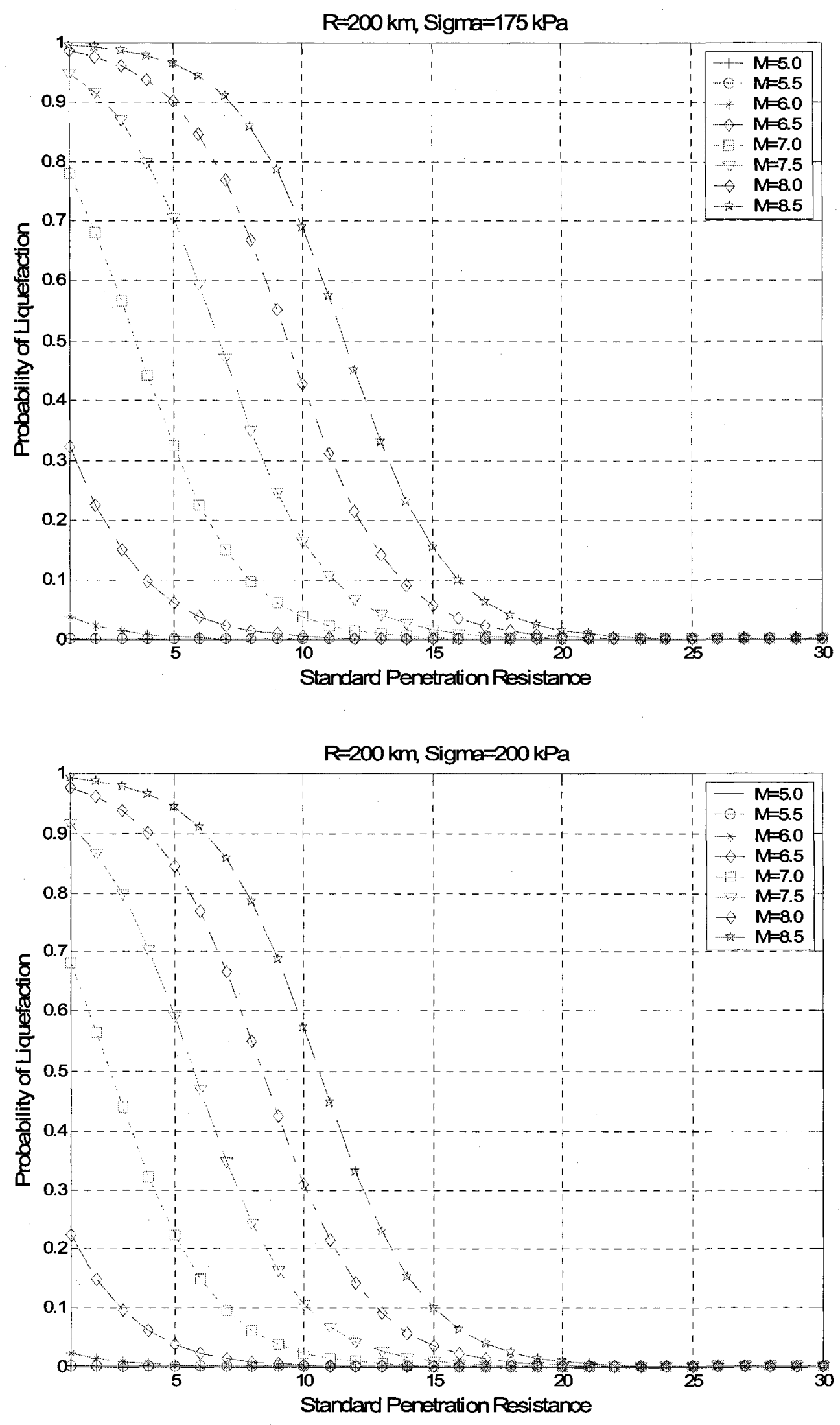

E-17 